- Centre of Biodiversity and Sustainable Land Use -

Section: Biodiversity, Ecology and Nature Conservation

\title{
DIVERSE FORESTS FOR CLIMATE CHANGE: \\ DROUGHT STRESS TOLERANCE OF SECONDARY \\ TIMBER SPECIES
}

\author{
Dissertation \\ zur Erlangung des mathematisch-naturwissenschaftlichen Doktorgrades \\ "Doctor rerum naturalium" \\ der Georg-August-Universität Göttingen \\ im Promotionsprogramm \\ Biodiversity and Ecology \\ der Georg-August-University School of Science (GAUSS) \\ vorgelegt von \\ Sebastian Mario Fuchs \\ aus \\ Schwalmstadt
}

Göttingen, Dezember 2020

- Version zur Veröffentlichung, Juli 2021 - 



\section{Thesis committee:}

- Prof. Dr. Christoph Leuschner, Abteilung Pflanzenökologie und Ökosystemforschung, Universität Göttingen

- Prof. Dr. Dirk Hölscher, Abteilung Waldbau und Waldökologie der Tropen, Universität Göttingen

- Prof. Dr. Bernhard Schuldt, Lehrstuhl für Ökophysiologie und Vegetationsökologie, Universität Würzburg

\section{Examination board:}

- Prof. Dr. Christoph Leuschner, Abteilung Pflanzenökologie und Ökosystemforschung, Universität Göttingen

- Prof. Dr. Dirk Hölscher, Abteilung Waldbau und Waldökologie der Tropen, Universität Göttingen

- Prof. Dr. Bernhard Schuldt, Lehrstuhl für Ökophysiologie und Vegetationsökologie, Universität Würzburg

- Prof. Dr. Holger Kreft, Abteilung Biodiversität, Makroökologie und Biogeographie, Universität Göttingen

- Prof. Dr. Hermann Behling, Abteilung Palynologie und Paläoökologie, Universität Göttingen

- Prof. Dr. Erwin Bergmeier, Abteilung Vegetationsanalyse und Phytodiversität, Universität Göttingen

Date of the oral examination: 12.01 .2021 



\section{SUMMARY}

Accelerated climate warming in the past decades and a recent increase in the frequency and severity of summer heat-waves in combination with more irregular summer precipitation challenge silvicultural concepts in Europe's temperate forest region, as some of the main timber species seem to be relatively susceptible to drought and possibly also heat. Notably, Norway spruce (Picea abies (L.) H. Karst.) and European beech (Fagus sylvatica L.) showed drought-related dieback and vitality losses. For that reason, concepts to admix and promote native, putatively drought-tolerant, minor timber species are gaining growing interest in Central Europe. Norway maple (Acer platanoides L.), common hornbeam (Carpinus betulus L.), European ash (Fraxinus excelsior L.), and small-leaved lime (Tilia cordata Mill.) are promising candidates due to their occurrence in the more continental climate of Eastern Europe and scattered knowledge from ecophysiological studies.

The present thesis assessed the drought tolerance of the four aforementioned species in comparison to sessile oak (Quercus petraea Matt. Liebl), a well-studied, droughttolerant, and major timber in Central Europe. A combination of three methodological packages was applied to quantify drought tolerance, namely plant hydraulic traits, fine root inventories and dendroecology. To allow for quantification of the species' plasticity, the assessment was accomplished in a field study along a precipitation transect from putatively optimal to relatively dry conditions (mean annual precipitation range from ca. 900 to $500 \mathrm{~mm}$ ) around the Harz mountain range in Central Eastern Germany.

Hydraulic efficiency- (xylem conductivity and Huber value) and safety-related traits (xylem embolism resistance, leaf turgor loss point, hydraulic safety margins) were quantified from sun-exposed branches from the uppermost canopy. Although a certain intra-specific trait variability in safety-related traits was observed, the magnitude was small compared to interspecific variability. In contrast, efficiency-related traits showed a high intra-specific trait variability both within populations and within the crowns of single trees. Surprisingly, the observed ITV of all traits was neither driven by climatic or soil water availability, nor by tree height, indicating a complex control of adult trees' hydraulic traits by the environment. A. platanoides and $C$. betulus showed very wide safety margins, a highly resistant xylem and higher trait plasticity, whereas $T$. cordata was vulnerable to embolism and operated with consistently narrow margins. 
Fine root inventories in the uppermost mineral soil were carried out in spring under ample water supply and after extreme summer drought in 2018, assessing fine root biomass, necromass and morphology. The extent of the root necromass/biomass ratio (N/B) increase and reductions in root tip frequency were used as a measure of the species' belowground sensitivity to water deficits. $Q$. petraea showed the smallest fine root density and was the only species not increasing N/B towards drier sites and without losses of root tips after summer drought, indicating the most conservative and resistant fine root system. The other species showed a more susceptible fine root system with distinctly increased N/B towards drier sites, mostly elevated N/B after summer drought (especially on moister sites), and throughout reduced root tip frequencies in response to drought.

For the dendroecological assessment, climate-growth relationships, their temporal variation, and the resistance and resilience to climatic droughts was analyzed from increment cores for the past 50 years. While growth responded in all four species positively to summer precipitation and negatively to higher summer temperature and climatic aridity, climate sensitivity of growth decreased in the period of 1967-2016. None of the species showed negative growth trends with recent climate warming and drought sensitivity was not higher at drier sites, indicating a considerable acclimation and adaptation potential. The resistance of radial growth to drought was higher in ring-porous species (F.excelsior, Q. petraea) in comparison to diffuse-porous species (A. platanoides, T. cordata), but resilience was high in all species.

The findings of the present work and knowledge from literature were combined to a synoptic evaluation of the species' abilities to withstand drought and an integration of the drought response strategies into the isohydry-anisohydry syndrome. $Q$. petraea and $F$. excelsior are strictly anisohydric and highly drought-tolerant, keeping up high productivity under unfavorable water supply. However, F. excelsior is severely threatened by the fungus Hymenoscyphus fraxineus, causing a pan-European ash dieback and rendering any recommendations for silvicultural planning impossible in the near future. A. platanoides is strictly isohydric with high hydraulic safety, accepting temporary reductions of productivity for the sake of a low drought-related mortality risk. $T$. cordata did not prove to be highly drought-resistant overall, but pursues a unique semi-isohydric strategy with high stem and leaf water capacitance, buffering well against mediocre droughts. C. betulus showed no drought-resistant fine root system, but fairly droughtresistant hydraulic properties. Early leaf shedding and radial growth stagnation seem to 
be safety mechanisms of $C$. betulus in order to provide a certain tenacity in coping with unfavorable conditions.

In comparison to $F$. sylvatica and $P$. abies, all five species seem to be more droughtresistant, and especially $A$. platanoides (in addition to $Q$. petraea) deserves a broader consideration in silvicultural concepts targeted at adapting production forests to climate warming. 


\section{Contents}

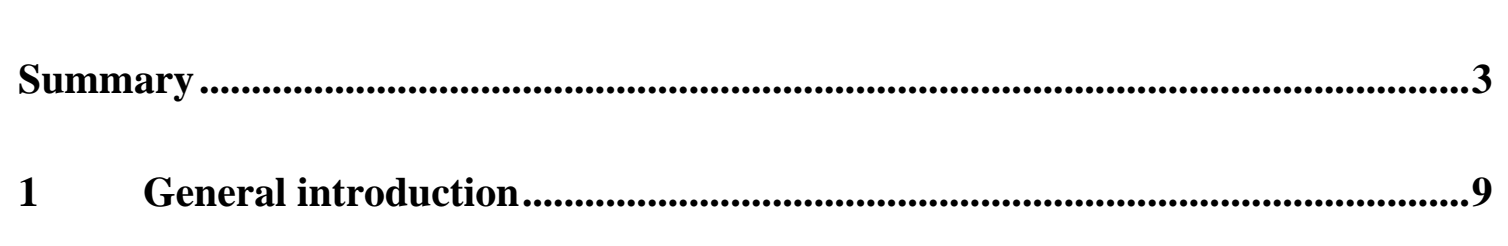

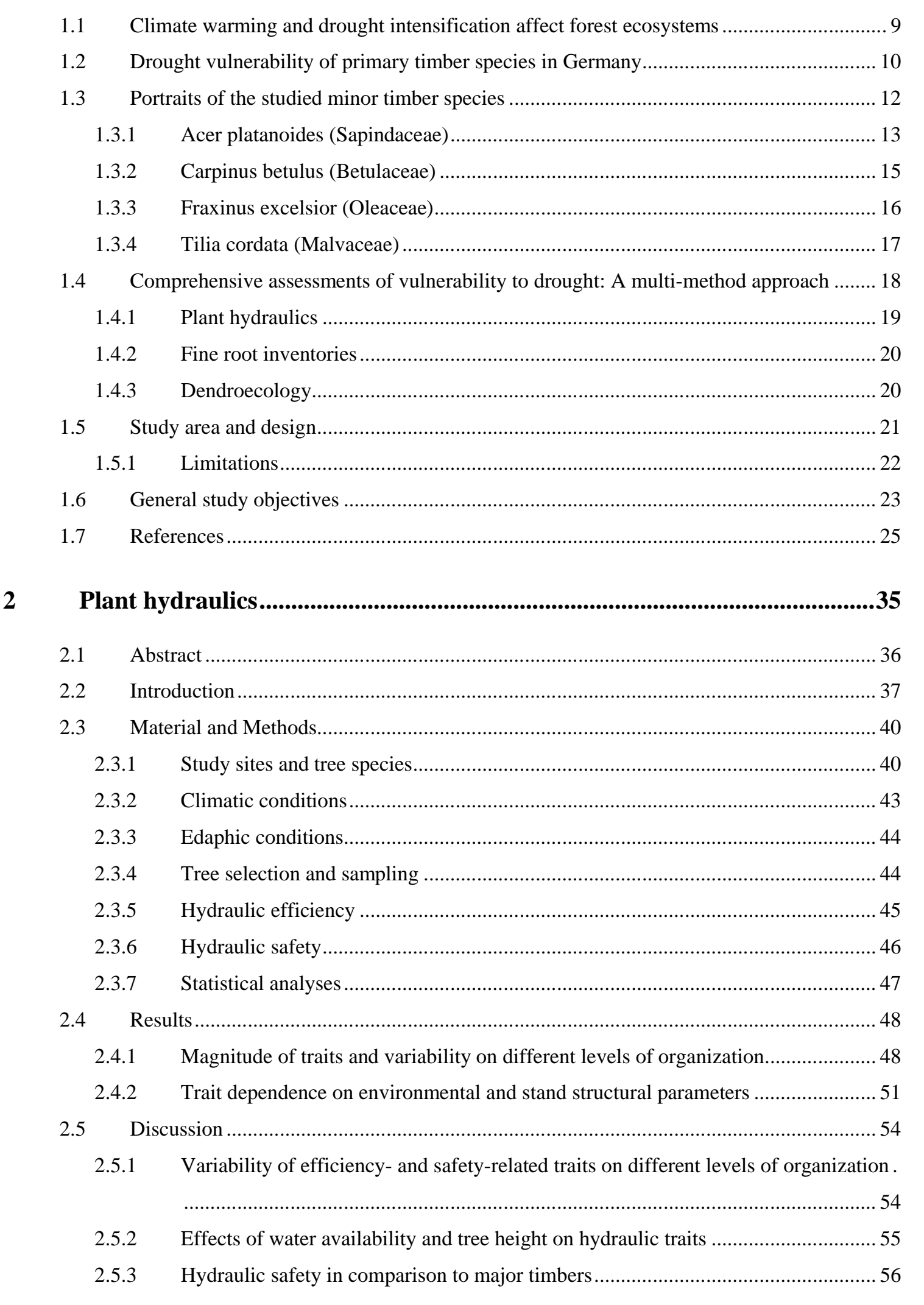




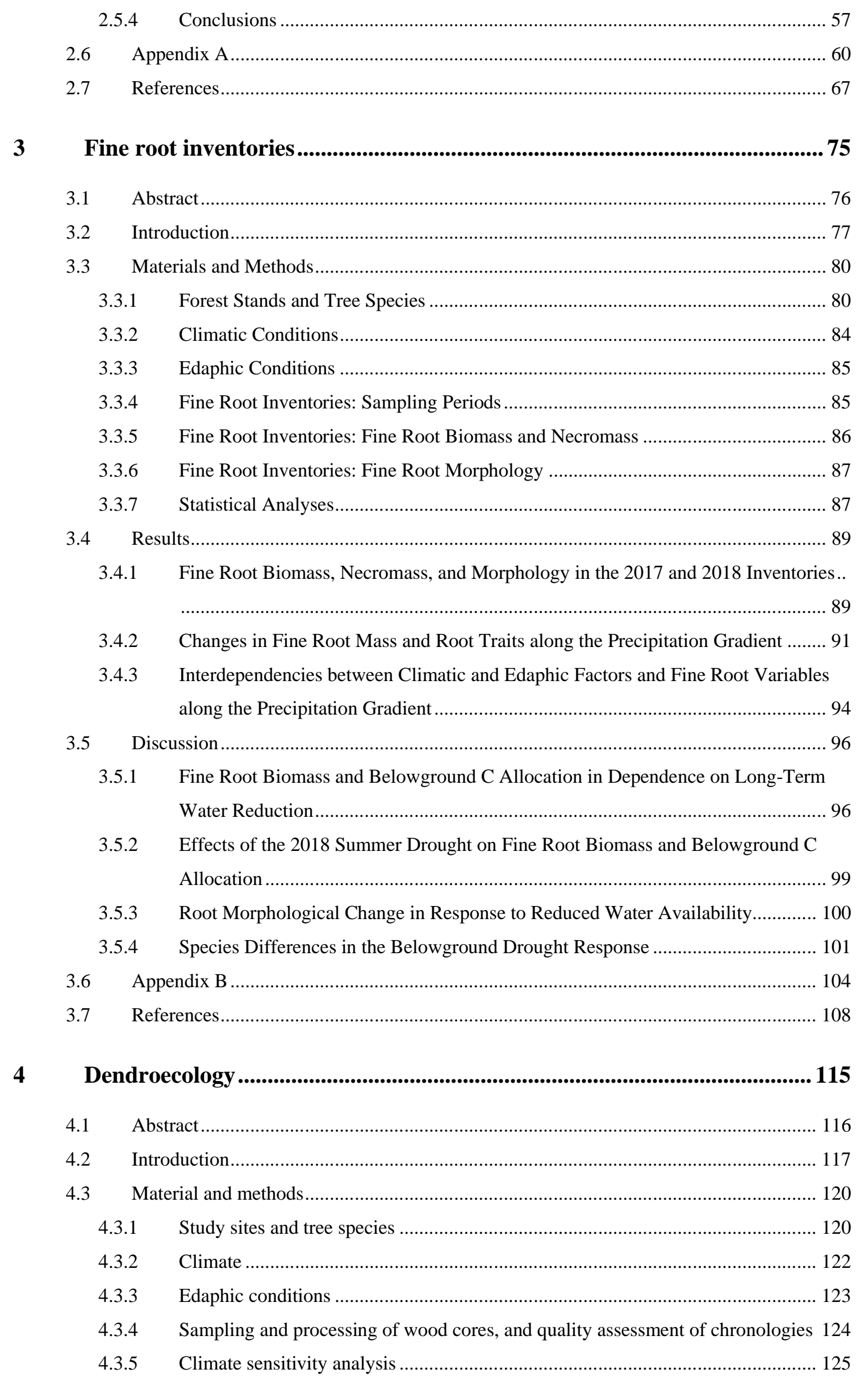




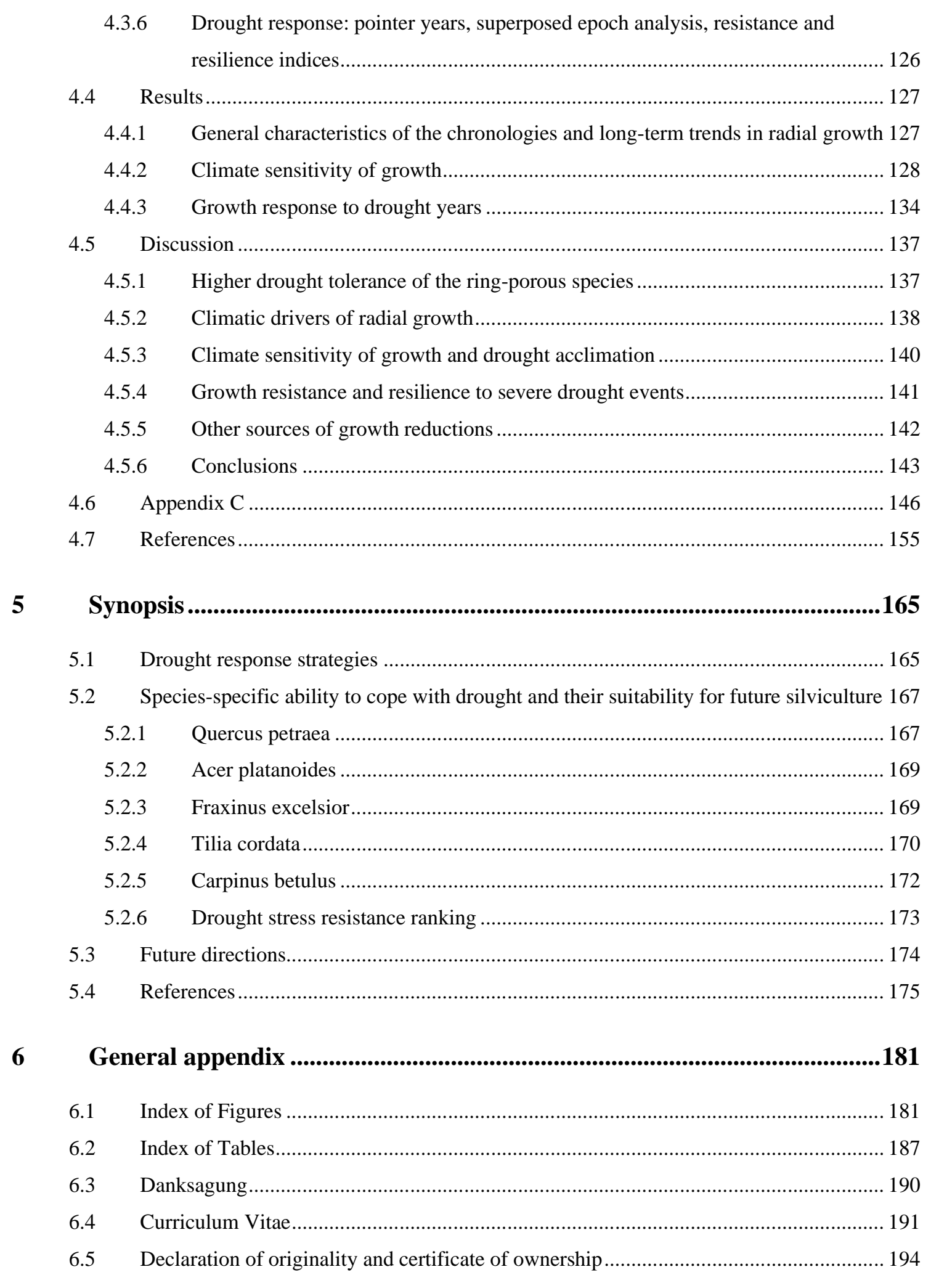




\section{General inTRODUCTION}

\subsection{Climate warming and drought intensification affect forest ecosystems}

Anthropogenic global warming already reached about $1{ }^{\circ} \mathrm{C}$ above preindustrial levels and is estimated to continue to increase to more than $1.5^{\circ} \mathrm{C}$ until 2050 under constant rates of greenhouse gas emissions (IPCC, 2014). The continuously rising temperatures since the 1980s affect ecosystems directly, but also via increasing vapor pressure deficits of the atmosphere (Held and Soden, 2006; Schuldt et al., 2020) leading to a higher likelihood and severity of drought conditions (Trenberth et al., 2014). Under ongoing drought, this is a self-enhancing process due to positive feedbacks of reduced evaporative cooling on surface temperatures (Breshears et al., 2013; Maness et al., 2013). The predicted increase in intensity and frequency of severe heat waves in Central Europe (Schär et al., 2004) is already reality (Christidis et al., 2015; Ionita et al., 2017). Additionally, summer precipitation rates are expected to decrease and become more irregular in many areas in Central Europe (IPCC, 2014; Fischer et al., 2014; Rowell and Jones, 2006), and the increase of precipitation deficits may even accelerate quicker than predicted (Orth et al., 2016).

Around the globe, forests are important sources of a wide range of economic and ecological services, ranging from their prominent role in primary production, $\mathrm{CO}_{2}$ fixation and climate regulation, over pedogenesis and groundwater replenishment, to timber and food production (Bonan, 2008). Additionally, forest ecosystems are home to the biggest fraction of global biodiversity and provide a variety of socio-cultural benefits like recreational space and spiritual value (Hassan et al., 2005). Forests worldwide, however, are affected by climate change (Bonan, 2008). Possible effects include positive feedbacks (e.g. $\mathrm{CO}_{2}$ fertilization, reduced frost impacts, longer growing seasons) as well as negative impacts (e.g. reduced productivity due to stomatal limitations, heat- and drought stress induced vulnerability to pests and pathogens and drought-induced hydraulic failure and mortality; Allen et al., 2010; Ayres and Lombardero, 2000; McDowell et al., 2011). In the past decade, though, the number of reviews and studies reporting negative impacts of climate warming on forests, increased steeply. This includes drought-induced mortality rates (e.g. Allen et al., 2010; Anderegg et al., 2013; Breshears et al., 2018; Schuldt et al., 2020; Senf et al., 2018; Senf et al., 2020) and reduced 
growth and vitality (e.g. Sanginés de Cárcer et al., 2018; Yuan et al., 2019), covering a wide range of different forest types and climates. Accordingly, within all climatic extremes, drought was evaluated as the biggest global constraint on forest productivity (Choat et al., 2018; Reichstein et al., 2013).

A change in the drought characteristics over the past decades is a very plausible explanation for the former underestimation of global forest vulnerability to droughtrelated mortality due to global warming. This phenomenon is usually referred to as "global-change-type droughts" (Breshears et al., 2013) or "hotter droughts" (Allen et al., 2015), where water supply deficits are combined with extraordinarily high temperatures. Besides the above-mentioned additional effects of temperature on evaporative demand, higher temperatures lead to steeply increasing residual water losses in trees due to a nonlinear change of cuticular permeability above $40^{\circ} \mathrm{C}$ (Riederer and Schreiber, 2001; Schuster et al., 2016). The role of residual water loss that cannot be mitigated by stomatal control was highlighted in recent literature and should be considered in ecosystem models (Cochard, 2019; Duursma et al., 2019).

Particularly in the context of rapidly accelerating climate change, understanding and predicting possible future forest declines in order to mitigate negative impacts on the global biosphere remain one of biggest challenges for ecologists (Boisvenue and Running, 2006; Bonan, 2008)

\subsection{Drought vulnerability of primary timber species in Germany}

In Central Europe, water availability is a key determinant of forest species composition and productivity (Bréda et al., 2006; Leuschner and Ellenberg, 2017) and changes in species composition under a drier climate in the future can be expected (Buras and Menzel, 2019). The latest increase in frequency of severe drought and heatwaves (Christidis et al., 2015; Schuldt et al., 2020) in combination with a sharp increase of observed tree mortality (Braun et al., 2020; Schuldt et al., 2020; Senf et al., 2020) and overall loss of forest vitality (Waldzustandserhebung Deutschland, 2019) highlight the fact, that forest transitions with a change of species composition imply broad-scale mortality events. This fundamentally affects a wide range of environmental processes and ecosystem services (Allen et al., 2015; Anderegg et al., 2013; Breshears et al., 2011). Thus, smoothing this process by anticipatory and sustainable silvicultural planning and management is of major importance. 
Norway spruce (Picea abies [L.] H. Karst) is the most abundant tree species in Germany and its area has expanded far beyond the limits of its natural range in the $20^{\text {th }}$ century (Spiecker, 2000). There is broad consensus on its sensitivity to drought and its ongoing decline due to climate change (Hanewinkel et al., 2013; Mäkinen et al., 2002; Pretzsch et al., 2013; Spiecker, 2000; Vitasse et al., 2019; Zang et al., 2014). Large-scale dieback in the past few years due to drought-related predisposition and bark beetle infestation has confirmed the concerns (Waldzustandserhebung Deutschland, 2019; Rigling et al., 2019).

Three other major timber species in Germany, European beech (Fagus sylvatica L.), Scots pine (Pinus sylvestris L.), and sessile oak (Quercus petraea (Matt.) Liebl.) have been regarded as relatively drought tolerant for decades (Roloff and Grundmann, 2008), but especially in case of $F$. sylvatica, this has become a matter of intense debates in the post-millennial decade (Ammer et al., 2005; Bolte, 2005; Leuschner, 2009; Rennenberg et al., 2004). Meanwhile, despite its high adaptability and plasticity (Roloff and Grundmann, 2008; Schuldt et al., 2016), reports on high climate sensitivity of radial growth (Cavin and Jump, 2017; Michelot et al., 2012; Scharnweber et al., 2011; Walentowski et al., 2017; Weber et al., 2013), long-term growth declines due to climate change (Latte et al., 2016; Scharnweber et al., 2011; Zimmermann et al., 2015), potential loss of dominance in mixed stands (Cavin et al., 2013; Mette et al., 2013), increased mortality after the drought year of 2018 (Waldzustandserhebung Deutschland, 2019; Schuldt et al., 2020), and legacy effects on crown vitality in years after drought (Bréda et al., 2006; Schuldt et al., 2020) emerged.

P. sylvestris is one of the most common species on drier sites in Germany, especially on nutrient-poor, sandy soils in the eastern federal states (Roloff et al., 2010), but is also increasingly affected by drought (Buras et al., 2018; Dobbertin et al., 2005; Rigling et al., 2013; Walentowski et al., 2007). Additionally, P. sylvestris is known to be a very weak competitor in mixed stands under ample nutrient availability and may therefore only be an option on sandy soils - even more in the light of increasing nutrient leaching from agriculture (Roloff and Grundmann, 2008).

$Q$. petraea, on the other hand, has proven its high growth resistance to drought events in many dendroecological studies (e.g. Mette et al., 2013; Scharnweber et al., 2011; Zang, 2011), is known to be a deep-rooting species with a drought-resistant fine root system (Leuschner et al., 2001; Roloff and Grundmann, 2008), and has a remarkably resistant hydraulic system in comparison to co-occurring species (based on xylem resistance to 
embolism and hydraulic safety margins; Dietrich et al., 2019; Lobo et al., 2018; Schuldt et al., 2020). On the other hand, the genus Quercus is susceptible to infestations with pests, insects, and fungi as well as partly inexplicable vitality losses in Central Europe over the past decades (Donaubaur, 1998; Gibbs and Greig, 1997; Roloff et al., 2010). Still, $Q$. petraea is one of the major timber species in Germany that is better suited for climate change, also because of its thermophilic characteristics (Roloff and Grundmann, 2008).

Considering the above, in the sub-continental central-eastern part of Germany with mean annual precipitation sums of $500 \mathrm{~mm}$ and below, some of the primary timber species are already operating close to or even beyond the drought limitations of their bioclimatic envelopes (Kölling, 2007). In the context of climate change, forests in such drought-prone areas might approach the point for a substantial ecological transition in near future, which highlights the urgent need to identify timber species suited to cope with these climatic changes.

The promotion and establishment of alternative, more drought-tolerant species is broad consensus in silviculture, but the criteria for the choice of these species are heavily debated. One popular perspective is the introduction and promotion of species that are already established major timbers in other regions and known to be productive on relatively arid sites, such as Douglas fir (Pseudotsuga menziesii [Mirbel] Franco; Eilmann and Rigling, 2012; Isaac-Renton et al., 2014) and European black pine (Pinus nigra J.F. Arnold; Eilmann and Rigling, 2012). However, this approach raises concerns regarding unknown effects on native biodiversity (Felton et al., 2016) and unpredictable risks regarding future susceptibility to pests (Roques et al., 2019). For that reason, there is growing interest in concepts of admixture and promotion of native and putatively drought-tolerant species that are naturally widespread, but only minor timbers (Brang et al., 2008; Grundmann and Roloff, 2009; Kunz et al., 2018; Kunz and Bauhus, 2015).

\subsection{Portraits of the studied minor timber species}

The tree flora of Central Europe contains several tree species of the genera Acer, Carpinus, Fraxinus, Quercus, Sorbus and Tilia, which occur also in the more continental climate of eastern Central and Eastern Europe, indicating that they might be more drought tolerant than the major timbers. According to general assessments of the drought tolerance of native minor timbers in Germany, several species might be suitable for promotion and establishment in forests in Central Europe in a future drier climate. 
Norway maple (Acer platanoides L.), field maple (Acer campestre L.), small-leaved and large-leaved lime (Tilia cordata Mill. and Tilia platyphyllos Scop.), European hornbeam (Carpinus betulus L.), European ash (Fraxinus excelsior L.), the wild service tree (Sorbus torminalis (L.) Crantz), and the service tree (Sorbus domestica L.) are expected to be relatively drought tolerant based on their distribution ranges towards continental parts of eastern Europe (Figure 1.1), their occurrence on edaphically dry sites or their ecophysiological traits (Hemery et al., 2010; Köcher et al., 2009; Leuschner et al., 2019; Leuschner and Meier, 2018; Roloff and Grundmann, 2008). Sorbus species, A. campestre and T. platyphyllos were already subject of recent studies comparing their drought tolerance to major timbers (Kunz et al., 2018; Walentowski et al., 2017). Thus, we focus here on A. platanoides, $C$. betulus, F. excelsior, and T. cordata and compare them to the well-studied and drought-tolerant major timber $Q$. petraea.

These species are widespread in Central and East Europe (Figure 1.1) with natural occurrences in various types of broadleaf mixed forest communities of the phytosociological alliances Carpinion betuli (oak-hornbeam forests) and Tilio-Acerion (mixed maple slope forests), in which European beech (Fagus sylvatica), the dominant species of Central Europe's natural forest vegetation, is rare or absent (Leuschner and Ellenberg, 2017). The four minor timbers are less competitive than $F$. sylvatica and more demanding in terms of soil base saturation than F. sylvatica, but their competitive ability increases on dry, shallow, and rocky soils (Roloff et al., 2010).

\subsubsection{Acer platanoides (Sapindaceae)}

A. platanoides grows mainly on nutrient-rich sites with medium to high base saturation and is intolerant to highly acidic soils (Caudullo and de Rigo, 2016). It often occurs widely scattered in low frequencies in mixed forests due to its low competitive potential in comparison to most other broadleaves. Only the seedlings are shade-tolerant, adult trees need increasingly more light (Roloff et al., 2010). In Central Germany, it gains competitive advantages over F. sylvatica, F. excelsior and Acer pseudoplatanus on shallow, calcareous soils, upper slopes, and in open stands because of its thermophilic and heliophilic characteristics (Roloff et al., 2010). Due to massive seed production and drought and shade tolerant saplings (Kunz et al., 2016; Roloff et al., 2010), A. platanoides has a very high natural regeneration potential which is mostly inhibited by browsing damage (Roloff et al., 2010). The wood is diffuse-porous, well-suited for woodworking and therefore often utilized for furniture production. Additionally, special fields of 
application include the construction of bows and music instruments due to its elasticity and attractive grain figures (Caudullo and de Rigo, 2016; Schütt and Aas, 1992).

Several general assessments attribute $A$. platanoides a good aptitude to play a bigger role in drought-tolerant mixed broadleaf forests in the future (Hemery et al., 2010; Leuschner and Meier, 2018; Roloff and Grundmann, 2008). Its distribution range reaches relatively continental climates in the Ukraine and towards the southern Ural and it serves as ornamental tree in many cities where summer microclimate is often much drier and warmer compared to forest sites. A. platanoides has been compared in dendroecological studies to Q. petraea and F. sylvatica in a set of minor broadleaves by Kunz et al. (2018) in south-west Germany and by Zimmermann et al. (2015) in central Germany, attesting relatively strong growths depressions in drought years, but also a high resilience due to quick and full growth recovery afterwards. This behavior is most probably due to the strictly isohydric and drought-avoiding strategy of A. platanoides, conservatively sacrificing carbon assimilation for the sake of a safe and intact hydraulic system: Low xylem water potentials and xylem embolism are avoided by rigid stomatal control (Leuschner et al., 2019) and wide hydraulic safety margins (Messinger, 2017, unpublished). Summarizing the above, A. platanoides might be well suited to grow in a warmer and drier climate in the future in Germany and serve as a surrogate timber in regions where $F$. sylvatica is declining. 


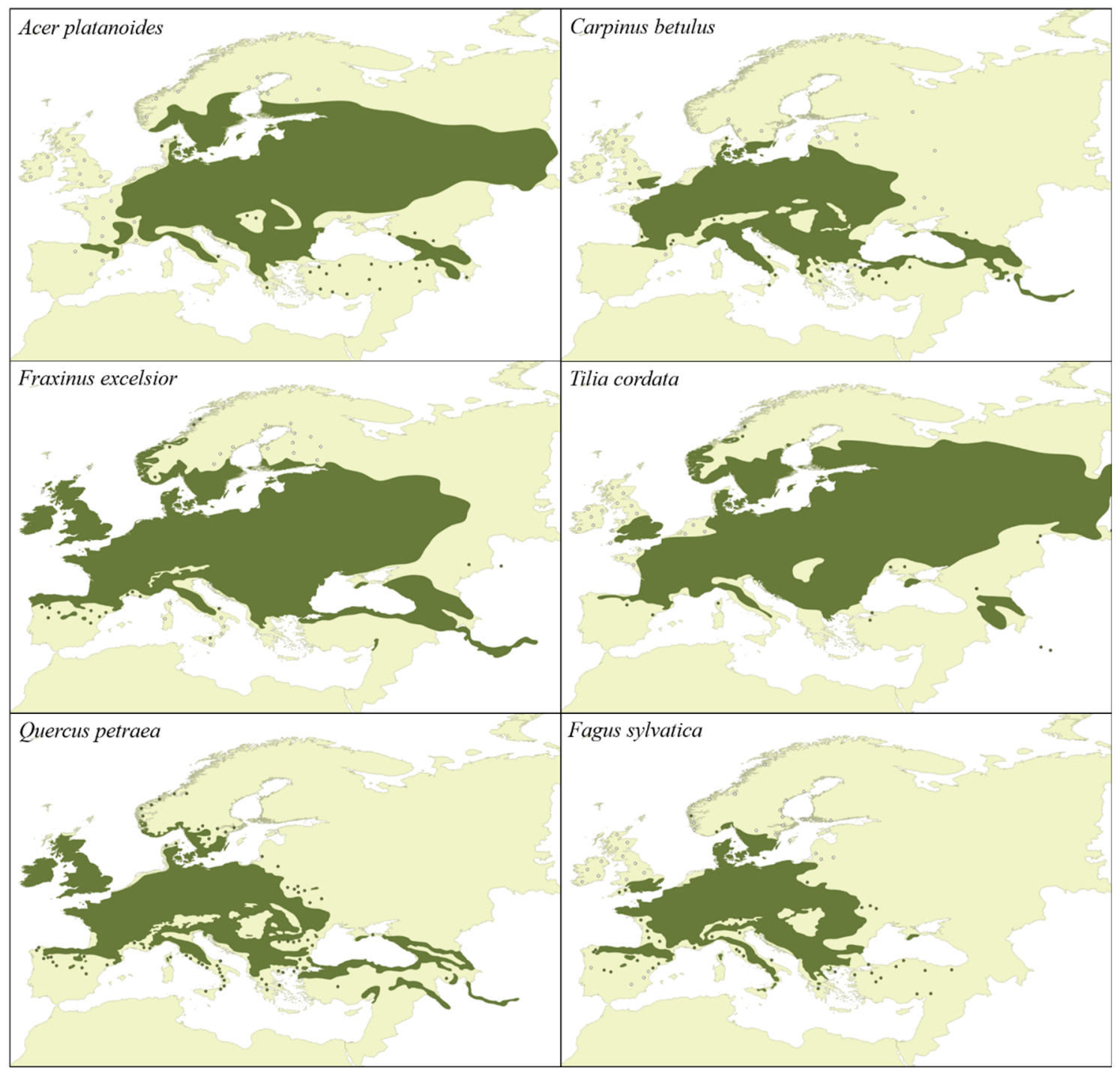

Figure 1.1: Distribution ranges of the four minor timber species (A. platanoides, C. betulus, F. excelsior, and $T$. cordata) and two major timbers ( $Q$. petraea and $F$. sylvatica) based on the synthetic chorology database of Caudullo (2017).

\subsubsection{Carpinus betulus (Betulaceae)}

Generally, C. betulus is widespread and very common in most parts of Europe (except for northern and southern margins), but because of its irregular stem shape, spiral growth and mediocre qualities for woodworking (strong shrinkage and poor elasticity), economic interest in this species is low and scientific literature is scarce (Praciak, 2013; Sikkema et al., 2016). However, it occurs in admixture in many varieties of oak- and beechdominated forests because of its exceptional shade tolerance (Leuschner and Ellenberg, 2017) and has a high ecologic value due to its ability to improve soil quality in mixed stands (enhances litter decomposition and mineralization; Dziadowiec, 2014; Roloff et al., 2010). Except for highly acidic sites, C. betulus tolerates a very wide range of edaphic conditions from sub-acidic to calcareous soils and from nutrient-poor sand to heavy clay (Praciak, 2013; Roloff et al., 2010). It also occurs on very shallow and rocky soils as well 
as on heavily disturbed sites due to its resilience to mechanical disturbance and high vegetative regeneration potential (Sikkema et al., 2016).

Its drought tolerance has barely been evaluated and dendro-ecological studies are missing completely. Also, its southern and eastern distribution margins (slightly more continental compared to $F$. sylvatica, Figure 1.1) are not particularly insightful. Nevertheless, from the perspective of plant-water relations, $C$. betulus shows surprisingly drought tolerant properties including a high embolism resistance and wide safety margins (Schuldt et al., 2020). Additionally, Köcher et al. (2009) judged this species as fairly drought tolerant in comparison to other Central European broadleaves based on leaf water status and sap flux measurements in response to dry soils.

Hence, $C$. betulus can be expected to play an ecologically important part in mixed forests on drier sites in the context of climate change.

\subsubsection{Fraxinus excelsior (Oleaceae)}

This species occurs on a wide range of nutrient-rich, basic soil types and is most productive on moist and deep soils. It has, however, a very broad amplitude regarding water availability, as it becomes a dominant component in forests on either dry calcareous slopes or deep, nutrient-rich alluvial soils, both unfavorable conditions for otherwise dominant F. sylvatica (Dobrowolska et al., 2011; Leuschner and Ellenberg, 2017). This fragmentation of the realized niche to the extremes of the physiological amplitude gave birth to the differentiation in two ecotypes (so-called "water-ash" on wet and "chalk-ash" on dry sites), but this theory has been proven wrong (Roloff et al., 2010; Weiser, 1995). In juvenile stages, $F$. excelsior is very shade tolerant, but light demand increases sharply with age, resulting in high mortality among middle aged ashes in dense stands (Dobrowolska et al., 2011). The wood is ring-porous and valuable for tool production, furniture and interior construction due to its high tensile and flexural strength (Kollmann, 1941; Roloff et al., 2010).

Based on preferred habitats and indicator values (Ellenberg et al., 1991; Leuschner and Ellenberg, 2017), F. excelsior has often been judged as adapted to ample water supply (Roloff and Grundmann, 2008). Studies on its drought resistance are rare, Zimmermann et al. (2015) attested F. excelsior a high resistance to drought (comparable to Q. petraea) based on long-term trends and climate sensitivity of radial growth. A few other dendroecological studies were either conducted on moist study sites (Weemstra et al., 2013) or only assessed very general climate-growth relationships (Koval and Maksymenko, 2020; Roibu et al., 2020) and are not suited to evaluate the ability to grow 
on arid sites with respect to its remarkable physiological plasticity. This plasticity also finds expression in a highly adaptive xylem embolism resistance in dependence of the site water availability (Lemoine et al., 2001). Additionally, F. excelsior is exceptionally anisohydric with a drought tolerance strategy (rather than drought avoidance; Carlier et al., 1992; Leuschner et al., 2019), keeping stomata open even at predawn water potentials near -5 MPa (Carlier et al., 1992). In combination with its distribution range across the Balkans, the Ukraine and the southern Caucasus region, F. excelsior is a promising candidate for a warmer and drier climate in the future.

However, F. excelsior is existentially threatened by the pan-European ash dieback due to the fungus Hymenoscyphus fraxineus (Enderle, 2019; Erfmeier et al., 2019; Pautasso et al., 2013). Dependent on the further progress of this disease and its possible mitigation due to climate change (Goberville et al., 2016; Grosdidier et al., 2018), F. excelsior might still be an option for future silviculture.

\subsubsection{Tilia cordata (Malvaceae)}

T. cordata has the widest natural distribution range within the set of the abovementioned species (Figure 1.1), with common occurrences from West Europe to Central Siberia in the steppe-forest ecotone (Roloff et al., 2010; Schütt and Aas, 1992). In western parts of Europe, its silvicultural role is rather minor, but in Central Eastern Europe its abundance, silvicultural appreciation and competitive strength rises with increasing continentality (Jaegere et al., 2016). Historically, T. cordata has even been a semidominant major species in temperate primeval woodlands in Eastern Europe (Jaegere et al., 2016) because of its high shade tolerance and its mid- to late-successional character in forest dynamics (Leuschner and Ellenberg, 2017). Additionally, its growth rates are relatively high under favorable water and nutrient conditions (Jaegere et al., 2016). Its wood is diffuse-porous, semi-soft, bright and evenly colored, and has a very balanced shrinkage-behavior in axial and radial directions. Therefore, it is very well-suited for turnery and small applications and veneers in furniture production, but never used in construction (Roloff et al., 2010).

In comparison to co-occurring species in Central Europe, $T$. cordata is thermophilic (Hemery et al., 2010) but still highly frost-tolerant (Till, 1956). It is tolerant to a wide range of soil fertilities, fairly insensitive to soil acidity and grows on semi-moist to very dry and shallow sites. However, waterlogged conditions are avoided (Jaegere et al., 2016; Roloff et al., 2010). 
T. cordata tolerates drought with a fairly unique strategy, not easily assessable within the isohydric-anisohydric spectrum. Literature is inconsistent on this matter (Köcher et al., 2009; Leuschner et al., 2019; Moser et al., 2016) because of a semi-isohydric stomatal control and a tight safety margin due to its vulnerable xylem (Messinger, 2017, unpublished; Schuldt et al., 2020). This "risky" strategy is only possible because of its extraordinary water capacitance on stem- (Köcher et al., 2013) and leaf-level (Leuschner et al., 2019), buffering over periods of water shortage. Thus, T. cordata can tolerate short to medium periods of drought easily (Hemery et al., 2010; Köcher et al., 2009; Köcher et al., 2012), but its radial growth is strongly affected by prolonged periods of drought (Kulagin and Shayakhmetov, 2007). Still, its ability to recover from drought and its longterm resilience to frequent droughts is higher in comparison to F. sylvatica (Latte et al., 2020).

According to Jaegere et al. (2016), almost all known aspects about its biology are indicative that $T$. cordata is a well-suited and underused timber species for admixture in Central European forests in the face of climate change, and that studies and field observations are urgently needed for further determination of its potential.

\subsection{Comprehensive assessments of vulnerability to drought: A multi- method approach}

Conventional and general assessments of the suitability of tree species in a warmer and drier climate are often based on climate envelopes (e.g. Kölling, 2007) or species distribution models (e.g. Falk and Hempelmann, 2013). These correlative approaches are a valuable instrument for a first estimate but lack ecophysiological explanations (Walentowski et al., 2017). Criticism further includes the over-simplistic nature of climate parameters and exclusion of extreme events, the omission of edaphic factors, and, most importantly, the missing consideration of plasticity and adaptability of the species to temporal climate variations (Bolte et al., 2008). Available assessments based on the reaction of potted plants or saplings to artificial drought conditions can hardly be extrapolated to mature stands (Cavender-Bares and Bazzaz, 2000; Cornelissen et al., 2003).

To comprehensively address the drought tolerance of the species and to enable a comparison between them, a combination of three methodological packages was chosen:

- plant hydraulic properties (xylem vulnerability to embolism, leaf turgor loss point, hydraulic safety margins, xylem efficiency), 
- fine root inventories (biomass, necromass and morphology after moist and dry periods), and

- dendroecology (climate-growth relations, drought induced increment reductions and recovery)

To allow for a quantification of the species' plasticity, the assessment was accomplished in a field gradient study along a precipitation transect from putatively optimal to relatively dry conditions (mean annual precipitation range from ca. 900 to $500 \mathrm{~mm}$ ). This allows for the deduction of precipitation limits of changes in increment, physiological parameters, and stress indicators (e.g. fine root mortality) and is a "space-for-time substitution" (Pickett, 2012) to project responses to spatially increasing drought exposure towards prospective climate change.

\subsubsection{Plant hydraulics}

Survival and productivity of trees under drought are intimately associated with their ability to supply water to their leaves by avoiding excessive formation of embolism in their hydraulic system (Maherali et al., 2004). Under drought, stomatal control over transpiration (and simultaneously $\mathrm{CO}_{2}$ uptake) is an important mechanism to keep the xylem tension below a critical value and hence control the risk of embolism formation. This balancing act mediates between two interconnected physiological mechanisms (i.e. carbon starvation and hydraulic failure) that explain reduced tree productivity and increased mortality following severe drought exposure (McDowell et al., 2008; McDowell et al., 2011). Xylem vulnerability to embolism and the leaf turgor loss point (the capacity of a leaf to maintain its turgor during dehydration) are important hydraulic traits to describe the ability of a given species to withstand drought. The hydraulic safety margin is usually defined as the width of the water potential safety-buffer between stomatal closure and excessive embolism formation in the xylem (Meinzer et al., 2009). It is a measure of the conservatism of a plant's stomatal control strategy (Choat et al., 2012). Trees with smaller safety margins operate closer to the threshold of runaway embolism formation and are therefore more prone to hydraulic failure (Choat et al. 2012).

For the four minor timbers, comparative assessments of leaf-water-relations, stomatal control strategies, stem sap flow, and stem water storage are available (Köcher et al., 2009; Köcher et al., 2013; Leuschner et al., 2019). However, magnitude of the mentioned hydraulic traits and particularly their plasticity in dependence of environmental conditions have rarely or never been assessed on mature trees. Here, a set of hydraulic traits was quantified from sun-exposed branches and leaves from the upper canopy of 
mature trees across the climatic gradient in order to compare the species' embolism resistance, their drought-tolerance/-avoidance strategies, and their ability to adapt to drier conditions.

\subsubsection{Fine root inventories}

Information on the below-ground drought responses of all four species are completely missing yet. How tree roots and the root system respond to drought is increasingly a matter of debate, but the empirical data basis is quite limited, especially for mature trees. Optimal partitioning theory predicts that trees tend to increase their root-to-shoot ratio under conditions of limited water availability to increase their absorptive capacity in relation to the transpiring surface (Brunner et al., 2015; Reich, 2002), but evidence from field studies is scarce. In contrast, literature is consistent on increased fine root mortality as a consequence of drought exposure, reflected by elevated necromass/biomass ratios. Fine root may just die due to dehydration, but active root shedding was also proposed as physiological explanation, where fine roots act as hydraulic fuses, uncoupling the rest of the hydraulic system from low water potentials in the dry soil to avoid embolism formation in more expensive plant organs (Alder et al., 1996; Jackson et al., 2000). The necromass/biomass ratio can be seen as an integral over the processes of root mortality and the production of new fine roots during the observation period, thus reflecting both, the root system's resistance to drought and its resilience after drought. The ratio has therefore been used in several studies and reviews as an inverse indicator of tree and root system vitality under exposure to drought or chemical stress (Persson and Stadenberg, 2010; Puhe, 2003; Wang et al., 2018).

Two fine root inventories were carried out across the climatic gradient, addressing biomass, necromass and morphology. The first inventory assessed the parameters under ample water supply after average spring conditions in April, and the second inventory was conducted after the exceptionally dry summer in 2018 with extended rainless periods on all study sites.

\subsubsection{Dendroecology}

The analysis of annual radial increment over many decades with respect to climatic drivers and the impact of exceptional drought events is a powerful tool to gain information about the climate sensitivity of trees. Arguably, temporal increment reductions are not unambiguously representing a species' vulnerability to drought (Lloret et al., 2011; McDowell et al., 2008; Walentowski et al., 2017), but also indicating an adaptive 
mechanism to cope with drought (e.g. by adjusting xylem anatomy or by increasing carbon allocation to roots). However, the reduction of radial increment is, besides mortality, one of the most important economic aspects of drought impacts.

Most of the existing dendroecological studies on minor timbers either did not allow for a comparison between species or did not take the spatial or temporal plasticity of the species into account. The few studies that partially did so (Kunz et al., 2018; Walentowski et al., 2017) were addressing mainly other species and were conducted in the South German Uplands and not on Pleistocene grounds.

Here, classical dendroecological methods were applied, including climate sensitivity analyses (annual climate-growth relationships) and superposed epoch analyses of the growth response to drought years. Since climate-growth relationships are usually nonstationary (Wilmking et al., 2020), temporal dynamics with respect to recent climate warming were additionally tracked in a moving window analysis (Biondi, 1997). Drought tolerance indices (resistance and resilience) according to Lloret et al. (2011) were calculated, compared between species and regressed against climatic and edaphic gradients of water availability.

\subsection{Study area and design}

The study was conducted in Central Germany in the transition zone between a suboceanic and a sub-continental climate in the rain shadow of the Harz Mountains (Figure 1.2). The study area is situated in the planar to colline zone (110-440 m a.s.l.) between the northern parts of the Central Uplands and its foothills towards the North German Plain which is characterized by a small-scale heterogeneity in geology. The study sites are located on leptic/vertic cambisols over Triassic limestone or on Pleistocene loose sediments over Triassic sandstone. 


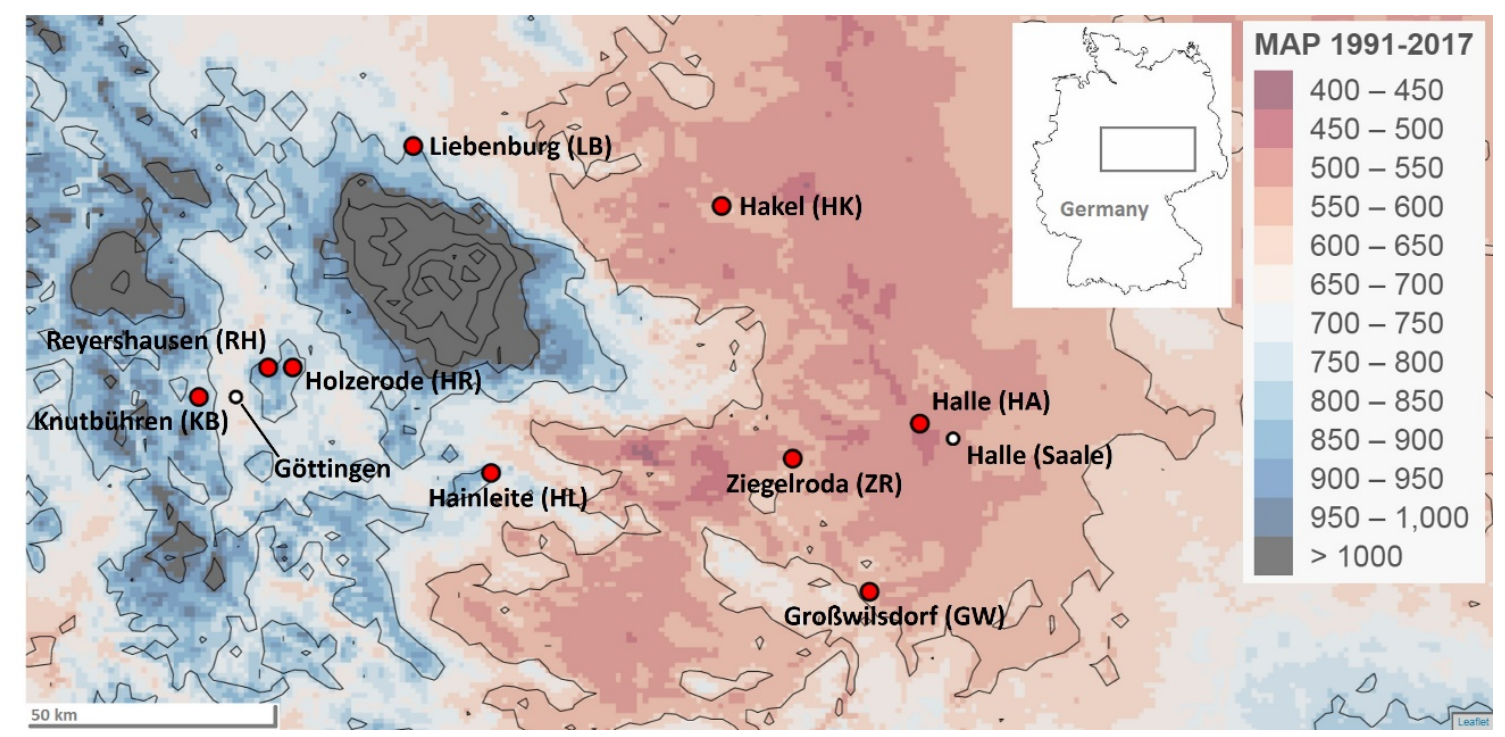

Figure 1.2: Map of the study area between Göttingen and Halle/S. in central Germany with the precipitation gradient from the west to the east. The nine study sites are marked with red dots. The background colors and isohyets indicate the mean annual precipitation (MAP 1991-2017). The area with MAP over $1000 \mathrm{~mm}$ north-east of Göttingen is the Harz mountain range. For further information on the study sites, refer to the detailed tables $2.1,3.1$, and 4.1 in the following chapters.

For minor timber species, mixed stands of comparable stand structure and tree age with presence of all five species under identical edaphic conditions are uncommon. As a consequence, not all species are present at all nine study sites, but every species occurs at least at five sites along the precipitation transect. Every site consists of several mixed forests of variable species composition in a maximum distance of several hundred meter to a few kilometers to each other. All investigated stands are of mature age (range: 69139 years), with the exception of two older oak stands (170 years). To ensure that climate and weather are the predominant factors for water availability, steep slopes (inclination > $5^{\circ}$ ), groundwater influence, stagnant moisture and very shallow soils were avoided. To address the differences in soil types, chemical and physical soil properties were recorded for each species on each site separately, including modelled plant available water storage capacity based on soil texture classes, bulk density and soil depth.

\subsubsection{Limitations}

In case of $C$. betulus, dendrochronological analyses were not possible because of long sections of indistinguishable annual rings in almost all increment cores. Neither different planing, sanding or coloring techniques, nor the microscopic analysis of whole-core microsections solved this problem. Apparently, C. betulus shows longer periods of radial growth stagnation due to a relatively low tree height and competitive strength in mixed stands, especially in earlier stages of ontogeny. If partially suppressed, C. betulus allocates a bigger fraction of its carbon budget to the development of its crown, resulting 
in high branching and foliation density (Roloff et al., 2010). Thus, it was excluded from the dendroecological assessment.

The assessment of some important hydraulic traits (vulnerability to embolism, hydraulic conductivity, and hydraulic safety margins) were not possible for the ringporous species (F. excelsior, $Q$. petraea). The underlying reason is the distinctly different xylem anatomy. Ring-porous species feature long xylem vessels, that do not allow to use of the centrifugation method in combination with standard-sized rotors due to the socalled "open-vessel artifact" (e.g. Martin-StPaul et al., 2014). An alternative method suited for long-vesseled species (bench dehydration; Sperry and Tyree, 1988) was applied, but the comparison of results from two different methods is highly error-prone. Despite literature confirming the comparability of the two methods, the high variability and inconsistency of our bench dehydration results suggested to refrain from doing so. Therefore, the chapter on plant hydraulic properties only include the diffuse-porous species (A. platanoides, C. betulus, T. cordata).

\subsection{General study objectives}

The present study is a comprehensive assessment of the drought resistance of four minor timber species (A. platanoides, C. betulus, F. excelsior, and T. cordata) in comparison to $Q$. petraea to identify species that are suitable for silviculture in the subcontinental climate of central and eastern Germany under warmer and drier conditions. The project's aims were

- to compare the species' resistance to embolism, hydraulic safety margins, and hydraulic efficiency of sun crown branches,

- to quantify the plasticity of hydraulic traits within species and populations and in dependence on edaphic and climatic water availability,

- to study adaptations of the fine root system of the five species to soil water deficits,

- to compare fine root mortality in reaction to extreme summer drought,

- to identify the most important climatic drivers of radial growth and compare them between the species, across the precipitation gradient, and over the past 50 years,

- to quantify the species' drought-year induced growth reductions ('resistance' index) and the ability to reach pre-drought growth levels afterwards ('resilience' index), and

- to test how resistance and resilience change across the gradients of edaphic and climatic water availability. 
The overarching goal of the study is the deduction of a drought resistance ranking of the five species. Drought resistance will be evaluated based on a synthetic discussion of the sections on plant-water-relations, drought sensitivity of the fine root system, dendroecology, and knowledge from literature. Drought resistance is defined here as a broader term to describe a species ability to withstand water stress, either by tolerance or by avoidance mechanisms (Levitt, 1980; Basu et al., 2016). 


\subsection{References}

Alder, N.N., Sperry, J.S., Pockman, W.T., 1996. Root and stem xylem embolism, stomatal conductance, and leaf turgor in Acer grandidentatum populations along a soil moisture gradient. Oecologia 105, 293-301. https://doi.org/10.1007/BF00328731.

Allen, C.D., Breshears, D.D., McDowell, N.G., 2015. On underestimation of global vulnerability to tree mortality and forest die-off from hotter drought in the Anthropocene. Ecosphere 6, art129. https://doi.org/10.1890/ES15-00203.1.

Allen, C.D., Macalady, A.K., Chenchouni, H., Bachelet, D., McDowell, N., Vennetier, M. et al, 2010. A global overview of drought and heat-induced tree mortality reveals emerging climate change risks for forests. For. Ecol. Manage. 259, 660-684. https://doi.org/10.1016/j.foreco.2009.09.001.

Ammer, C., Albrecht, H., Borchert, H., Brosinger, F., Dittmar, C., Elling, W. et al, 2005. Zur Zukunft der Buche (Fagus sylvatica L.) in Mitteleuropa. Allg. Forst- u. J.Ztg. 176, S-60.

Anderegg, W.R.L., Kane, J.M., Anderegg, L.D.L., 2013. Consequences of widespread tree mortality triggered by drought and temperature stress. Nat. Clim. Change 3, 3036. https://doi.org/10.1038/nclimate1635.

Ayres, M.P., Lombardero, M.J., 2000. Assessing the consequences of global change for forest disturbance from herbivores and pathogens. Sci. Total Environ. 262, 263-286. https://doi.org/10.1016/S0048-9697(00)00528-3.

Basu, S., Ramegowda, V., Kumar, A., Pereira, A., 2016. Plant adaptation to drought stress. F1000Research 5. https://doi.org/10.12688/f1000research.7678.1.

Biondi, F., 1997. Evolutionary and moving response functions in dendroclimatology. Dendrochronologia 15, 139-150.

Boisvenue, C., Running, S.W., 2006. Impacts of climate change on natural forest productivity - evidence since the middle of the 20th century. Global Change Biol. 12, 862-882. https://doi.org/10.1111/j.1365-2486.2006.01134.x.

Bolte, A., 2005. Zur Zukunft der Buche in Mitteleuropa. AFZ - Der Wald 20, 10771078.

Bolte, A., Ibisch, P., Menzel, A., Rothe, A., 2008. Was Klimahüllen uns verschweigen. AFZ - Der Wald 63, 800-803.

Bonan, G.B., 2008. Forests and climate change: forcings, feedbacks, and the climate benefits of forests. Science 320, 1444-1449.

https://doi.org/10.1126/science.1155121.

Brang, P., Bugmann, H., Bürgi, A., Mühlethaler, U., Rigling, A., Schwitter, R., 2008. Klimawandel als waldbauliche Herausforderung | Climate change as a challenge for silviculture. Schweiz. Z. Forstwes. 159, 362-373. https://doi.org/10.3188/szf.2008.0362.

Braun, S., Witte, L.C. de, Hopf, S.E., 2020. Auswirkungen des Trockensommers 2018 auf Flächen der Interkantonalen Walddauerbeobachtung. Schweiz. Z. Forstwes. 171, 270-280. https://doi.org/10.3188/szf.2020.0270. 
Bréda, N., Huc, R., Granier, A., Dreyer, E., 2006. Temperate forest trees and stands under severe drought: a review of ecophysiological responses, adaptation processes and long-term consequences. Ann. For. Sci. 63, 625-644. https://doi.org/10.1051/forest:2006042.

Breshears, D.D., Adams, H.D., Eamus, D., McDowell, N.G., Law, D.J., Will, R.E. et al, 2013. The critical amplifying role of increasing atmospheric moisture demand on tree mortality and associated regional die-off. Front. Plant Sci. 4, 266. https://doi.org/10.3389/fpls.2013.00266.

Breshears, D.D., Carroll, C.J.W., Redmond, M.D., Wion, A.P., Allen, C.D., Cobb, N.S. et al, 2018. A Dirty Dozen Ways to Die: Metrics and Modifiers of Mortality Driven by Drought and Warming for a Tree Species. Front. For. Global Change 1, 115014. https://doi.org/10.3389/ffgc.2018.00004.

Breshears, D.D., López-Hoffman, L., Graumlich, L.J., 2011. When ecosystem services crash: preparing for big, fast, patchy climate change. Ambio 40, 256-263. https://doi.org/10.1007/s13280-010-0106-4.

Brunner, I., Herzog, C., Dawes, M.A., Arend, M., Sperisen, C., 2015. How tree roots respond to drought. Front. Plant Sci. 6, 547. https://doi.org/10.3389/fpls.2015.00547.

Buras, A., Menzel, A., 2019. Projecting Tree Species Composition Changes of European Forests for 2061-2090 Under RCP 4.5 and RCP 8.5 Scenarios. Front. Plant Sci. 9. https://doi.org/10.3389/fpls.2018.01986.

Buras, A., Schunk, C., Zeiträg, C., Herrmann, C., Kaiser, L., Lemme, H. et al, 2018. Are Scots pine forest edges particularly prone to drought-induced mortality? Environ. Res. Lett. 13, 25001. https://doi.org/10.1088/1748-9326/aaa0b4.

Carlier, G., Peltier, J.P., Gielly, L., 1992. Comportement hydrique du frêne (Fraxinus excelsior L) dans une formation montagnarde mésoxérophile. Ann. For. Sci. 49, 207-223. https://doi.org/10.1051/forest:19920301.

Caudullo, G., Welk, E., San-Miguel-Ayanz, J., 2017. Chorological maps for the main European woody species. Data in brief 12, 662-666. https://doi.org/10.1016/j.dib.2017.05.007.

Caudullo, G., de Rigo, D., 2016. Acer platanoides in Europe: distribution, habitat, usage and threats, in: San-Miguel-Ayanz, J., Rigo, D. de, Caudullo, G., Durrant, T.H., Mauri, A. (Eds.), European atlas of forest tree species, 2016th ed. Publication Office of the European Union, Luxembourg.

Cavender-Bares, J., Bazzaz, F.A., 2000. Changes in drought response strategies with ontogeny in Quercus rubra: implications for scaling from seedlings to mature trees. Oecologia 124, 8-18.

Cavin, L., Jump, A.S., 2017. Highest drought sensitivity and lowest resistance to growth suppression are found in the range core of the tree Fagus sylvatica L. not the equatorial range edge. Global Change Biol. 23, 362-379.

https://doi.org/10.1111/gcb.13366.

Cavin, L., Mountford, E.P., Peterken, G.F., Jump, A.S., 2013. Extreme drought alters competitive dominance within and between tree species in a mixed forest stand. Funct. Ecol. 27, 1424-1435. https://doi.org/10.1111/1365-2435.12126. 
Choat, B., Brodribb, T.J., Brodersen, C.R., Duursma, R.A., López, R., Medlyn, B.E., 2018. Triggers of tree mortality under drought. Nature 558, 531-539. https://doi.org/10.1038/s41586-018-0240-X.

Choat, B., Jansen, S., Brodribb, T.J., Cochard, H., Delzon, S., Bhaskar, R. et al, 2012. Global convergence in the vulnerability of forests to drought. Nature 491, 752-755. https://doi.org/10.1038/nature11688.

Christidis, N., Jones, G.S., Stott, P.A., 2015. Dramatically increasing chance of extremely hot summers since the 2003 European heatwave. Nat. Clim. Change 5, 46-50. https://doi.org/10.1038/nclimate2468.

Cochard, H., 2019. A new mechanism for tree mortality due to drought and heatwaves. BioRxiv preprints. https://doi.org/10.1101/531632

Cornelissen, J.H.C., Cerabolini, B., Castro-Díez, P., Villar-Salvador, P., MontserratMartí, G., Puyravaud, J.P. et al, 2003. Functional traits of woody plants: correspondence of species rankings between field adults and laboratory-grown seedlings? Journal of Vegetation Science 14, 311-322. https://doi.org/10.1111/j.1654-1103.2003.tb02157.x.

Dietrich, L., Delzon, S., Hoch, G., Kahmen, A., 2019. No role for xylem embolism or carbohydrate shortage in temperate trees during the severe 2015 drought. J. Ecol. 107, 334-349. https://doi.org/10.1111/1365-2745.13051.

Dobbertin, M., Mayer, P., Wohlgemuth, T., Feldmeyer-Christe, E., Graf, U., Zimmermann, N. et al, 2005. The decline of Pinus sylvestris L. Forests in the Swiss Rhone Valley - a Result of Drought Stress? Phyton 45, 153-156.

Dobrowolska, D., Hein, S., Oosterbaan, A., Wagner, S., Clark, J., Skovsgaard, J.P., 2011. A review of European ash (Fraxinus excelsior L.): implications for silviculture. Forestry 84, 133-148. https://doi.org/10.1093/forestry/cpr001.

Donaubaur, E., 1998. Die Bedeutung von Krankheitserregern beim gegenwärtigen Eichensterben in Europa - eine Literaturübersicht. Eur. J. For. Pathol. 28, 91-98. https://doi.org/10.1111/j.1439-0329.1998.tb01170.x.

Duursma, R.A., Blackman, C.J., Lopéz, R., Martin-Stpaul, N.K., Cochard, H., Medlyn, B.E., 2019. On the minimum leaf conductance: its role in models of plant water use, and ecological and environmental controls. New Phytol. 221, 693-705. https://doi.org/10.1111/nph.15395.

Dziadowiec, H., 2014. The decomposition of plant litter fall in an oak-linden-hornbeam forest and an oak-pine mixed forest of the Białowieża National Park. Acta Soc. Bot. Pol. 56, 169-185. https://doi.org/10.5586/asbp.1987.019.

Eilmann, B., Rigling, A., 2012. Tree-growth analyses to estimate tree species' drought tolerance. Tree Physiol. 32, 178-187. https://doi.org/10.1093/treephys/tps004.

Ellenberg, H., Weber, H., Düll, R., Wirth, V., Werner, W., Paulissen, D., 1991. Zeigwerte von Pflanzen in Mitteleuropa. Scr. Geobot. 18, 248.

Enderle, R., 2019. An overview of ash (iFraxinus/i spp.) and the ash dieback disease in Europe. CAB Reviews 14. https://doi.org/10.1079/PAVSNNR201914025.

Erfmeier, A., Haldan, K.L., Beckmann, L.-M., Behrens, M., Rotert, J., Schrautzer, J., 2019. Ash Dieback and Its Impact in Near-Natural Forest Remnants - A Plant Community-Based Inventory. Front. Plant Sci. 10, 658. https://doi.org/10.3389/fpls.2019.00658. 
Falk, W., Hempelmann, N., 2013. Species Favourability Shift in Europe due to Climate Change: A Case Study for Fagus sylvatica L. and Picea abies (L.) Karst. Based on an Ensemble of Climate Models. J. Climatol. 2013, 1-18. https://doi.org/10.1155/2013/787250.

Felton, A., Gustafsson, L., Roberge, J.-M., Ranius, T., Hjältén, J., Rudolphi, J. et al, 2016. How climate change adaptation and mitigation strategies can threaten or enhance the biodiversity of production forests: Insights from Sweden. Biol. Conserv. 194, 11-20. https://doi.org/10.1016/J.BIOCON.2015.11.030.

Fischer, E.M., Sedláček, J., Hawkins, E., Knutti, R., 2014. Models agree on forced response pattern of precipitation and temperature extremes. Geophys. Res. Lett. 41, 8554-8562. https://doi.org/10.1002/2014GL062018.

Gibbs, J., Greig, B., 1997. Biotic and abiotic factors affecting the dying back of pedunculate oak Quercus robur L. Forestry 70, 399-406.

Goberville, E., Hautekèete, N.-C., Kirby, R.R., Piquot, Y., Luczak, C., Beaugrand, G., 2016. Climate change and the ash dieback crisis. Sci. Rep. 6, 35303. https://doi.org/10.1038/srep35303.

Grosdidier, M., Ioos, R., Marçais, B., 2018. Do higher summer temperatures restrict the dissemination of Hymenoscyphus fraxineus in France? Forest Pathology, 48(4), e12426. For. Path. 48, e12426. https://doi.org/10.1111/EFP.12426.

Grundmann, B.M., Roloff, A., 2009. Use of Forest Tree Species Under Climate Change, in: Feldmann, F. (Ed.), Crop plant resistance to biotic and abiotic factors. Current potential and future demands; DPG, Braunschweig. Spectrum Phytomedizin.

Hanewinkel, M., Cullmann, D.A., Schelhaas, M.-J., Nabuurs, G.-J., Zimmermann, N.E., 2013. Climate change may cause severe loss in the economic value of European forest land. Nat. Clim. Change 3, 203-207. https://doi.org/10.1038/nclimate1687.

Hassan, R.M., 2005. Ecosystems and human well-being: Current State and Trends. Island Press, Washington, DC. Millennium ecosystem assessment series.

Held, I.M., Soden, B.J., 2006. Robust Responses of the Hydrological Cycle to Global Warming. J. Clim. 19, 5686-5699. https://doi.org/10.1175/JCLI3990.1.

Hemery, G.E., Clark, J.R., Aldinger, E., Claessens, H., Malvolti, M.E., O'connor, E. et al, 2010. Growing scattered broadleaved tree species in Europe in a changing climate: a review of risks and opportunities. Forestry 83, 65-81. https://doi.org/10.1093/FORESTRY/CPP034.

Ionita, M., Tallaksen, L.M., Kingston, D.G., Stagge, J.H., Laaha, G., van Lanen, H.A.J. et al, 2017. The European 2015 drought from a climatological perspective. Hydrol. Earth Syst. Sci. 21, 1397-1419. https://doi.org/10.5194/hess-21-1397-2017.

IPCC, 2014. Climate Change 2014: Impacts, Adaptation, and Vulnerability. Part A: Global and Sectoral Aspects, in: Field, C.B., Barros, V.R., Dokken, D.J., Mach, K.J., Mastrandrea, M.D. (Eds.), Contribution of Working Group II to the Fifth Assessment Report of the Intergovernmental Panel on Climate Change. Cambridge University Press, Cambridge.

Isaac-Renton, M.G., Roberts, D.R., Hamann, A., Spiecker, H., 2014. Douglas-fir plantations in Europe: a retrospective test of assisted migration to address climate change. Global Change Biol. 20, 2607-2617. https://doi.org/10.1111/gcb.12604. 
Jackson, R.B., Sperry, J.S., Dawson, T.E., 2000. Root water uptake and transport: using physiological processes in global predictions. Trends Plant Sci. 5, 482-488. https://doi.org/10.1016/S1360-1385(00)01766-0.

Jaegere, T. de, Hein, S., Claessens, H., 2016. A Review of the Characteristics of SmallLeaved Lime (Tilia cordata Mill.) and Their Implications for Silviculture in a Changing Climate. Forests 7, 56. https://doi.org/10.3390/f7030056.

Köcher, P., Gebauer, T., Horna, V., Leuschner, C., 2009. Leaf water status and stem xylem flux in relation to soil drought in five temperate broad-leaved tree species with contrasting water use strategies. Ann. For. Sci. 66, 101. https://doi.org/10.1051/forest/2008076.

Köcher, P., Horna, V., Beckmeyer, I., Leuschner, C., 2012. Hydraulic properties and embolism in small-diameter roots of five temperate broad-leaved tree species with contrasting drought tolerance. Ann. For. Sci. 69, 693-703. https://doi.org/10.1007/s13595-012-0189-0.

Köcher, P., Horna, V., Leuschner, C., 2013. Stem water storage in five coexisting temperate broad-leaved tree species: significance, temporal dynamics and dependence on tree functional traits. Tree Physiol. 33, 817-832. https://doi.org/10.1093/treephys/tpt055.

Kölling, C., 2007. Klimahüllen für 27 Waldbaumarten. AFZ - Der Wald 23, 1242-1245.

Kollmann, F., 1941. Die Esche und ihr Holz. Springer, Berlin, Heidelberg. Schriftenreihe Eigenschaften und Verwertung der deutschen Nutzhölzer 1.

Koval, I., Maksymenko, N., 2020. The radial increment of European ash (Fraxinus excelsior L.) under climate change, Ukraine. J. For. Sci. 66, 288-298. https://doi.org/10.17221/37/2020-JFS.

Kulagin, A.Y., Shayakhmetov, I.F., 2007. Natural under-canopy regeneration and height-age structure of small-leaved linden (Tilia cordata Mill.) undergrowth in water-conservation forests around Pavlovskoe Reservoir, Ufa River. Russ. J. Ecol. 38, 247-252. https://doi.org/10.1134/S1067413607040054.

Kunz, J., Bauhus, J., 2015. Das Potenzial seltener und trockentoleranter Laubbaumarten zur Aufforstung von aufgelassenen Weinbergen, in: Korn, H., Böckmühl, K., Schliep, R. (Eds.), Biodiversität und Klima. Bundesamt für Naturschutz, Bonn-Bad Godesberg. BfN-Skripten 389, pp. 63-69.

Kunz, J., Löffler, G., Bauhus, J., 2018. Minor European broadleaved tree species are more drought-tolerant than Fagus sylvatica but not more tolerant than Quercus petraea. For. Ecol. Manage. 414, 15-27. https://doi.org/10.1016/j.foreco.2018.02.016.

Kunz, J., Räder, A., Bauhus, J., 2016. Effects of Drought and Rewetting on Growth and Gas Exchange of Minor European Broadleaved Tree Species. Forests, 7(12), 239. Forests 7, 239. https://doi.org/10.3390/F7100239.

Latte, N., Perin, J., Kint, V., Lebourgeois, F., Claessens, H., 2016. Major Changes in Growth Rate and Growth Variability of Beech (Fagus sylvatica L.) Related to Soil Alteration and Climate Change in Belgium. Forests 7, 174. https://doi.org/10.3390/f7080174. 
Latte, N., Taverniers, P., Jaegere, T. de, Claessens, H., 2020. Dendroecological assessment of climate resilience of the rare and scattered forest tree species Tilia cordata Mill. in northwestern Europe. Forestry 93, 675-684.

https://doi.org/10.1093/forestry/cpaa011.

Lemoine, D., Peltier, J.-P., Marigo, G., 2001. Comparative studies of the water relations and the hydraulic characteristics in Fraxinus excelsior, Acer pseudoplatanus and A. opalus trees under soil water contrasted conditions. Ann. For. Sci. 58, 723-731. https://doi.org/10.1051/forest:2001159.

Leuschner, C., 2009. Die Trockenheitsempfindlichkeit der Rotbuche vor dem Hintergrund des prognostizierten Klimawandels, Jahrbuch Der Gottinger Akademie Der Wissenschaften. 2008. Walter De Gruyter Inc.

Leuschner, C., Backes, K., Hertel, D., Schipka, F., Schmitt, U., Terborg, O. et al, 2001. Drought responses at leaf, stem and fine root levels of competitive Fagus sylvatica L. and Quercus petraea (Matt.) Liebl. trees in dry and wet years. For. Ecol. Manage. 149, 33-46. https://doi.org/10.1016/S0378-1127(00)00543-0.

Leuschner, C., Ellenberg, H., 2017. Ecology of Central European Forests. Springer International Publishing, Cham.

Leuschner, C., Meier, I.C., 2018. The ecology of Central European tree species: Trait spectra, functional trade-offs, and ecological classification of adult trees. Perspect. Plant Ecol. Evol. Syst. 33, 89-103. https://doi.org/10.1016/j.ppees.2018.05.003.

Leuschner, C., Wedde, P., Lübbe, T., 2019. The relation between pressure-volume curve traits and stomatal regulation of water potential in five temperate broadleaf tree species. Ann. For. Sci. 76, 93. https://doi.org/10.1007/s13595-019-0838-7.

Levitt, J., 1980. Responses of plants to environmental stresses: Volume II. Water, radiation, salt, and other stresses, 2. ed. Academic Press, New York, NY. Physiological ecology.

Lloret, F., Keeling, E.G., Sala, A., 2011. Components of tree resilience: effects of successive low-growth episodes in old ponderosa pine forests. Oikos 120, 19091920. https://doi.org/10.1111/J.1600-0706.2011.19372.X.

Lobo, A., Torres-Ruiz, J.M., Burlett, R., Lemaire, C., Parise, C., Francioni, C. et al, 2018. Assessing inter- and intraspecific variability of xylem vulnerability to embolism in oaks. For. Ecol. Manage. 424, 53-61. https://doi.org/10.1016/j.foreco.2018.04.031.

Maherali, H., Pockman, W.T., Jackson, R.B., 2004. Adaptive Variation in the Vulnerability of Woody Plants to Xylem Cavitation. Ecology 85, 2184-2199. https://doi.org/10.1890/02-0538.

Mäkinen, H., Nöjd, P., Kahle, H.-P., Neumann, U., Tveite, B., Mielikäinen, K. et al, 2002. Radial growth variation of Norway spruce (Picea abies (L.) Karst.) across latitudinal and altitudinal gradients in central and northern Europe. For. Ecol. Manage. 171, 243-259. https://doi.org/10.1016/S0378-1127(01)00786-1.

Maness, H., Kushner, P.J., Fung, I., 2013. Summertime climate response to mountain pine beetle disturbance in British Columbia. Nat. Geosci. 6, 65-70. https://doi.org/10.1038/ngeo1642. 
Martin-StPaul, N.K., Longepierre, D., Huc, R., Delzon, S., Burlett, R., Joffre, R. et al, 2014. How reliable are methods to assess xylem vulnerability to cavitation? The issue of 'open vessel' artifact in oaks. Tree Physiol. 34, 894-905. https://doi.org/10.1093/treephys/tpu059.

McDowell, N., Pockman, W.T., Allen, C.D., Breshears, D.D., Cobb, N., Kolb, T. et al, 2008. Mechanisms of plant survival and mortality during drought: why do some plants survive while others succumb to drought? New Phytol. 178, 719-739. https://doi.org/10.1111/j.1469-8137.2008.02436.x.

McDowell, N.G., Beerling, D.J., Breshears, D.D., Fisher, R.A., Raffa, K.F., Stitt, M., 2011. The interdependence of mechanisms underlying climate-driven vegetation mortality. Trends Ecol. Evol. 26, 523-532. https://doi.org/10.1016/j.tree.2011.06.003.

Meinzer, F.C., Johnson, D.M., Lachenbruch, B., McCulloh, K.A., Woodruff, D.R., 2009. Xylem hydraulic safety margins in woody plants: coordination of stomatal control of xylem tension with hydraulic capacitance. Funct. Ecol. 23, 922-930. https://doi.org/10.1111/j.1365-2435.2009.01577.x.

Messinger, E., 2017. Hydraulic safety margins and stomatal control strategies of five ring- and diffuse-porous temperate tree species. Masters thesis, Georg-August University Göttingen, Germany.

Mette, T., Dolos, K., Meinardus, C., Bräuning, A., Reineking, B., Blaschke, M. et al, 2013. Climatic turning point for beech and oak under climate change in Central Europe. Ecosphere 4, art145. https://doi.org/10.1890/ES13-00115.1.

Michelot, A., Bréda, N., Damesin, C., Dufrêne, E., 2012. Differing growth responses to climatic variations and soil water deficits of Fagus sylvatica, Quercus petraea and Pinus sylvestris in a temperate forest. For. Ecol. Manage. 265, 161-171. https://doi.org/10.1016/J.FORECO.2011.10.024.

Moser, A., Rötzer, T., Pauleit, S., Pretzsch, H., 2016. The Urban Environment Can Modify Drought Stress of Small-Leaved Lime (Tilia cordata Mill.) and Black Locust (Robinia pseudoacacia L.). Forests 7, 71. https://doi.org/10.3390/f7030071.

Orth, R., Zscheischler, J., Seneviratne, S.I., 2016. Record dry summer in 2015 challenges precipitation projections in Central Europe. Sci. Rep. 6, 28334. https://doi.org/10.1038/srep28334.

Pautasso, M., Aas, G., Queloz, V., Holdenrieder, O., 2013. European ash (Fraxinus excelsior) dieback - A conservation biology challenge. Biol. Conserv. 158, 37-49. https://doi.org/10.1016/j.biocon.2012.08.026.

Persson, H.Å., Stadenberg, I., 2010. Fine root dynamics in a Norway spruce forest (Picea abies (L.) Karst) in eastern Sweden. Plant Soil 330, 329-344. https://doi.org/10.1007/s11104-009-0206-8.

Pickett, S.T.A., 2012. Space-for-Time Substitution as an Alternative to Long-Term Studies, in: Likens, G.E. (Ed.), Long-Term Studies in Ecology. Springer-Verlag New York Inc, New York, NY, pp. 110-135.

Praciak, A., 2013. The CABI encyclopedia of forest trees. CABI, Wallingford, UK. 
Pretzsch, H., Schütze, G., Uhl, E., 2013. Resistance of European tree species to drought stress in mixed versus pure forests: evidence of stress release by inter-specific facilitation. Plant. Biol. 15, 483-495. https://doi.org/10.1111/j.14388677.2012.00670.x.

Puhe, J., 2003. Growth and development of the root system of Norway spruce (Picea abies) in forest stands-a review. For. Ecol. Manage. 175, 253-273. https://doi.org/10.1016/S0378-1127(02)00134-2.

Reich, P., 2002. Root-Shoot Relations, in: Kafkafi, U., Waisel, Y., Eshel, A. (Eds.), Plant Roots. CRC Press, Boca Raton, Florida, USA, pp. 205-220.

Reichstein, M., Bahn, M., Ciais, P., Frank, D., Mahecha, M.D., Seneviratne, S.I. et al, 2013. Climate extremes and the carbon cycle. Nature 500, 287-295. https://doi.org/10.1038/nature12350.

Rennenberg, H., Seiler, W., Matyssek, R., Gessler, A., Kreuzwieser, J., 2004. Die Buche (Fagus sylvatica L.) - ein Waldbaum ohne Zukunft im südlichen Mitteleuropa. Allg. Forst- u. J.-Ztg. 175, 210-224.

Riederer, M., Schreiber, L., 2001. Protecting against water loss: analysis of the barrier properties of plant cuticles. J. Exp. Bot. 52, 2023-2032. https://doi.org/10.1093/jexbot/52.363.2023.

Rigling, A., Bigler, C., Eilmann, B., Feldmeyer-Christe, E., Gimmi, U., Ginzler, C. et al, 2013. Driving factors of a vegetation shift from Scots pine to pubescent oak in dry Alpine forests. Global Change Biol. 19, 229-240. https://doi.org/10.1111/gcb.12038.

Rigling, A., Etzold, S., Bebi, P., Brang, P., Ferretti, M., Forrester, D. et al, 2019. Wie viel Trockenheit ertragen unsere Wälder? Lehren aus extremen Trockenjahren, in: Bründl, M., Schweizer, J. (Eds.), Forum für Wissen. Lernen aus Extremereignissen, Davos, pp. 39-51.

Roibu, C.-C., Sfeclă, V., Mursa, A., Ionita, M., Nagavciuc, V., Chiriloaei, F. et al, 2020. The Climatic Response of Tree Ring Width Components of Ash (Fraxinus excelsior L.) and Common Oak (Quercus robur L.) from Eastern Europe. Forests, 11(5), 600. Forests 11, 600. https://doi.org/10.3390/F11050600.

Roloff, A., Grundmann, B., 2008. Waldbaumarten und ihre Verwendung im Klimawandel. Arch. Forstwes. Landschaftsökol. 42, 97-109.

Roloff, A., Weisgerber, H., Lang, U.M., Stimm, B. (Eds.), 2010. Bäume Mitteleuropas: Von Aspe bis Zirbel-Kiefer, 1. Aufl. Wiley-VCH, Weinheim. Sachbuch.

Roques, A., Auger-Rozenberg, M.-A., Capretti, P., Sauvard, D., La Porta, N., Santini, A., 2019. Pests and diseases in the native and European range of Douglas-fir. 3.5, in: Spiecker, H., Lindner, M., Schuler, J.K. (Eds.), Douglas-fir. An option for Europe. European Forest Institute, Joensuu.

Rowell, D.P., Jones, R.G., 2006. Causes and uncertainty of future summer drying over Europe. Clim. Dyn. 27, 281-299. https://doi.org/10.1007/s00382-006-0125-9.

Sanginés de Cárcer, P., Vitasse, Y., Peñuelas, J., Jassey, V.E.J., Buttler, A., Signarbieux, C., 2018. Vapor-pressure deficit and extreme climatic variables limit tree growth. Global Change Biol. 24, 1108-1122. https://doi.org/10.1111/gcb.13973.

Schär, C., Vidale, P.L., Lüthi, D., Frei, C., Häberli, C., Liniger, M.A. et al, 2004. The role of increasing temperature variability in European summer heatwaves. Nature 427, 332-336. https://doi.org/10.1038/nature02300. 
Scharnweber, T., Manthey, M., Criegee, C., Bauwe, A., Schröder, C., Wilmking, M., 2011. Drought matters - Declining precipitation influences growth of Fagus sylvatica L. and Quercus robur L. in north-eastern Germany. For. Ecol. Manage. 262, 947-961. https://doi.org/10.1016/j.foreco.2011.05.026.

Schuldt, B., Buras, A., Arend, M., Vitasse, Y., Beierkuhnlein, C., Damm, A. et al, 2020. A first assessment of the impact of the extreme 2018 summer drought on Central European forests. Basic Appl. Ecol. https://doi.org/10.1016/j.baae.2020.04.003.

Schuldt, B., Knutzen, F., Delzon, S., Jansen, S., Müller-Haubold, H., Burlett, R. et al, 2016. How adaptable is the hydraulic system of European beech in the face of climate change-related precipitation reduction? New Phytol. 210, 443-458. https://doi.org/10.1111/nph.13798.

Schuster, A.-C., Burghardt, M., Alfarhan, A., Bueno, A., Hedrich, R., Leide, J. et al, 2016. Effectiveness of cuticular transpiration barriers in a desert plant at controlling water loss at high temperatures. AoB PLANTS 8. https://doi.org/10.1093/aobpla/plw027.

Schütt, P., Aas, G. (Eds.), 1992. Lexikon der Forstbotanik: Morphologie, Pathologie, Ökologie und Systematik wichtiger Baum- und Straucharten, 1. Aufl. Ecomed, Landsberg/Lech. Ecomed-Umweltinformation.

Senf, C., Pflugmacher, D., Zhiqiang, Y., Sebald, J., Knorn, J., Neumann, M. et al, 2018. Canopy mortality has doubled in Europe's temperate forests over the last three decades. Nat. Commun. 9, 4978. https://doi.org/10.1038/s41467-018-07539-6\#.

Senf, C., Sebald, J., Seidl, R., 2020. Increases in canopy mortality and their impact on the demographic structure of Europe's forests.

Sikkema, R., Caudullo, G., de Rigo, D., 2016. Carpinus betulus in Europe: distribution, habitat, usage and threats, in: San-Miguel-Ayanz, J., Rigo, D. de, Caudullo, G., Durrant, T.H., Mauri, A. (Eds.), European atlas of forest tree species, 2016th ed. Publication Office of the European Union, Luxembourg.

Sperry, J.S., Tyree, M.T., 1988. Mechanism of water stress-induced xylem embolism. Plant Physiol. 88, 581-587. https://doi.org/10.1104/pp.88.3.581.

Spiecker, H., 2000. Growth of Norway spruce (Picea abies [L.] Karst.) under changing environmental conditions in Europe, in: Klimo, E., Hager, H., Kulhavy, J. (Eds.), EFI Proceedings. Spruce Monocultures in Central Europe - Problems and Prospects 33, pp. 11-26.

Till, O., 1956. Über die Frosthärte von Pflanzen sommergrüner Laubwälder. Flora 143, 499-542.

Trenberth, K.E., Dai, A., van der Schrier, G., Jones, P.D., Barichivich, J., Briffa, K.R. et al, 2014. Global warming and changes in drought. Nat. Clim. Change 4, 17-22. https://doi.org/10.1038/nclimate2067.

Vitasse, Y., Bottero, A., Cailleret, M., Bigler, C., Fonti, P., Gessler, A. et al, 2019. Contrasting resistance and resilience to extreme drought and late spring frost in five major European tree species. Global Change Biol. 25, 3781-3792. https://doi.org/10.1111/gcb.14803.

Waldzustandserhebung Deutschland, 2019, Bundesministerium für Ernährung und Landwirtschaft (BMEL), Referat für nachhaltige Waldbewirtschaftung und Holzmarkt, Bonn, Germany. 
Walentowski, H., Falk, W., Mette, T., Kunz, J., Bräuning, A., Meinardus, C. et al, 2017. Assessing future suitability of tree species under climate change by multiple methods: a case study in southern Germany. Ann. For. Res. 60. https://doi.org/10.15287/afr.2016.789.

Walentowski, H., Kölling, C., Ewald, J., 2007. Die Waldkiefer - bereit für den Klimawandel? LWF Wissen 57, 37-46.

Wang, C., Chen, Z., Yin, H., Guo, W., Cao, Y., Wang, G. et al, 2018. The Responses of Forest Fine Root Biomass/Necromass Ratio to Environmental Factors Depend on Mycorrhizal Type and Latitudinal Region. J. Geophys. Res. Biogeosci. 123, 17691788. https://doi.org/10.1029/2017JG004308.

Weber, P., Bugmann, H., Pluess, A.R., Walthert, L., Rigling, A., 2013. Drought response and changing mean sensitivity of European beech close to the dry distribution limit. Trees 27, 171-181. https://doi.org/10.1007/s00468-012-0786-4.

Weemstra, M., Eilmann, B., Sass-Klaassen, U.G.W., Sterck, F.J., 2013. Summer droughts limit tree growth across 10 temperate species on a productive forest site. For. Ecol. Manage. 306, 142-149. https://doi.org/10.1016/J.FORECO.2013.06.007.

Weiser, F., 1995. Beitrag zur Existenz von Ökotypen bei gemeiner Esche (Fraxinus excelsior L.). Forstarchiv 66, 251-257.

Wilmking, M., van der Maaten-Theunissen, M., van der Maaten, E., Scharnweber, T., Buras, A., Biermann, C. et al, 2020. Global assessment of relationships between climate and tree growth. Global Change Biol. 26, 3212-3220. https://doi.org/10.1111/gcb.15057.

Yuan, W., Zheng, Y., Piao, S., Ciais, P., Lombardozzi, D., Wang, Y. et al, 2019. Increased atmospheric vapor pressure deficit reduces global vegetation growth. Sci. Adv. 5. https://doi.org/10.1126/sciadv.aax1396.

Zang, C.S., 2011. Growth reaction of temperate forest trees to summer drought. Dissertation, Technische Universität München, Germany.

Zang, C.S., Hartl-Meier, C., Dittmar, C., Rothe, A., Menzel, A., 2014. Patterns of drought tolerance in major European temperate forest trees: climatic drivers and levels of variability. Global Change Biol. 20, 3767-3779.

https://doi.org/10.1111/gcb.12637.

Zimmermann, J., Hauck, M., Dulamsuren, C., Leuschner, C., 2015. Climate WarmingRelated Growth Decline Affects Fagus sylvatica, But Not Other Broad-Leaved Tree Species in Central European Mixed Forests. Ecosystems 18, 560-572. https://doi.org/10.1007/s10021-015-9849-x. 


\section{Plant hydraulics}

\section{HydRAUlic VARIABILITy OF THREE TEMPERATE BROADLEAF TREE SPECIES ALONG A WATER AVAILABILITY GRADIENT IN CENTRAL EUROPE}

Published in New Phytologist:

Fuchs, S., Leuschner, C., Link, R.M. and Schuldt, B., 2021. Hydraulic variability of three temperate broadleaf tree species along a water availability gradient in central Europe. New Phytologist. https://doi.org/10.1111/nph.17448

Sebastian Fuchs ${ }^{1}$, Christoph Leuschner ${ }^{1,2}$, Roman Mathias Link ${ }^{1,3}$, Bernhard Schuldt ${ }^{1,3}$

1 Plant Ecology, Albrecht von Haller Institute for Plant Sciences, University of Goettingen, Untere Karspüle 2, 37073 Goettingen, Germany

2 Centre for Biodiversity and Sustainable Land Use (CBL), University of Goettingen, 37075 Goettingen, Germany

3 Present address: Ecophysiology and Vegetation Ecology, Julius-von-Sachs-Institute of Biological Sciences, University of Würzburg, Julius-von-Sachs-Platz, 97082 Würzburg, Germany 


\subsection{Abstract}

Plant hydraulic traits are key for understanding and predicting tree drought responses. Information about the degree of the traits' intra-specific variability may guide the selection of drought-resistant genotypes and is crucial for trait-based modelling approaches.

For the three temperate minor broadleaf tree species Acer platanoides, Carpinus betulus and Tilia cordata, we measured xylem embolism resistance $\left(P_{50}\right)$, leaf turgor loss point $\left(P_{\mathrm{TLP}}\right)$, specific hydraulic conductivity $\left(K_{\mathrm{S}}\right)$, Huber values $(\mathrm{HV})$, and hydraulic safety margins in adult trees across a precipitation gradient. We further quantified trait variability on different organizational levels (inter-specific to within-canopy variation), and analyzed its relationship to climatic and soil water availability.

Although we observed a certain intra-specific trait variability (ITV) in safety-related traits $\left(P_{50}, P_{\mathrm{TLP}}\right)$ with higher within-tree and between-tree than between populations variability, the magnitude was small compared to inter-specific differences, which explained $78.4 \%$ and $58.3 \%$ of the variance in $P_{50}$ and $P_{\mathrm{TLP}}$, respectively. In contrast, efficiency-related traits $\left(K_{\mathrm{s}}, \mathrm{HV}\right)$ showed a high ITV both within populations and within the crowns of single trees. Surprisingly, the observed ITV of all traits was neither driven by climatic nor soil water availability.

In conclusion, the high degree of conservatism in safety-related traits highlights their potential for trait-based modelling approaches.

Keywords: embolism resistance, Huber value, hydraulic conductivity, hydraulic plasticity, hydraulic safety margin, leaf turgor loss point, precipitation gradient, xylem safety. 


\subsection{Introduction}

In many regions of central Europe, important primary timber species such as European beech (Fagus sylvatica L.) and Norway spruce (Picea abies [L.] H. Karst.) are approaching their drought limit (van der Maaten-Theunissen et al., 2013; Lévesque et al., 2014; Leuschner, 2020). Since 1980, this region has experienced a continuous increase in temperature and concomitantly in atmospheric vapour pressure deficit (Schuldt et al., 2020), which culminated in a massive tree dieback of these two primary timber species in many central European forests during the exceptional 2018/2019 drought (Braun et al., 2020; Schuldt et al., 2020; Senf et al., 2020). At least in the drier regions of central Europe, there is an urgent need to identify native timber species suited for production forests that better withstand drought and heat.

The survival and therefore overall fitness of trees under drought are intimately linked to their ability to supply water to the canopy by avoiding excessive formation of embolism in their hydraulic system in order to maintain a sufficiently high carbon gain (McDowell, 2011; Sapes et al., 2019). Two interconnected physiological mechanisms that explain reduced tree productivity and increased mortality following severe drought exposure, namely carbon starvation and hydraulic failure, have widely been discussed in the past since their introduction by McDowell et al. (2008). Recent results, however, indicate that hydraulic failure is the proximate cause of drought-induced tree mortality in various biomes (Rowland et al., 2015; Anderegg et al., 2016; Adams et al., 2017; Correia et al., 2019; Hajek et al., 2020; Powers et al., 2020; Arend et al., 2021; Nolan et al., 2021).

Hydraulic traits have widely been used to characterize plants in their disposition to suffer from hydraulic failure (Choat, 2013; Skelton et al., 2015; Choat et al., 2018), and to predict the effects of increased drought exposure on the productivity and mortality of woody plants (Choat et al., 2012; Anderegg, 2015; Anderegg et al., 2016). The link between productivity and mortality under drought is mirrored by the proposed trade-off between hydraulic efficiency and safety (Tyree et al., 1994; Sperry et al., 2008). According to said trade-off, plants are not able to simultaneously maximize the conductivity of their water transport system and minimize the risk of embolism formation. Studies across species and biomes provide moderate support for this hypothesis (Maherali et al., 2004; Lens et al., 2011; Gleason et al., 2016; Schumann et al., 2019), although opposite results exist (Torres-Ruiz et al., 2017). Within species, evidence for this tradeoff seems to be even weaker (Burgess et al., 2006; Schuldt et al., 2016; but see Liang et al., 2019). 
Two traits commonly used to describe a plant's hydraulic safety are the xylem water potential at $50 \%$ loss of hydraulic conductance $\left(P_{50}\right.$; Sperry \& Tyree, 1988) and the water potential at the leaf turgor loss point ( $P_{\mathrm{TLP}}$; Oppenheimer, 1963). Furthermore, $P_{50}$ is directly related to the resistance of the xylem against embolism formation, while the $P_{\text {TLP }}$ describes the capacity of a leaf to maintain its turgor during dehydration. Hydraulic efficiency, however, has often been associated with the xylem area-specific conductivity (Ks; Farmer, 1918) or the Huber value (HV; Huber, 1928), i.e. the sapwood-to-leaf area ratio. Both parameters are major determinants of the ratio of a tree's assimilation rate to its xylem construction costs. These four traits are crucial for understanding the hydraulic variability of tree species and their potential to cope with drought. Adaptive modifications in these traits to different levels of water availability have been demonstrated across various species and biomes. Several studies observed higher hydraulic safety (Maherali et al., 2004; Schuldt et al., 2016; Larter et al., 2017; Zhu et al., 2018; Rosas et al., 2019) and lower hydraulic efficiency in drier environments (Maherali et al., 2004; Rosas et al., 2019). Intra-specific variability of $P_{50}$ and $P_{\text {TLP }}$, however, has been much less studied in the past (Anderegg \& Meinzer, 2015), and the few available studies on the response of hydraulic traits to water availability in mature trees of the same species produced contradictory results. For example, while some intra-specific studies indeed observed an increase in embolism resistance with declining water availability (Schuldt et al., 2016; Stojnic et al., 2018), others observed either the opposite (Herbette et al., 2010) or no relationship across climatic gradients (Martínez-Vilalta et al., 2009; Martin-StPaul et al., 2013; González-Muñoz et al., 2018; Rosas et al., 2019). In contrast, $P_{\text {TLP }}$ has been found to decrease rather consistently with increasing aridity across (Lenz et al., 2006; Bartlett et al., 2012b; Mitchell \& O'Grady, 2015; Zhu et al., 2018) and within species (Liang et al., 2019; Rosas et al., 2019; Pritzkow et al., 2020). One reason for the difference is that $P_{50}$ depends on wood properties that are strongly conserved, while $P_{\mathrm{TLP}}$ is not static and can be adjusted actively by the plant to match the current environmental conditions.

Another explanation for the often missing relationship between xylem safety and climatic variables might be that most field studies on plant hydraulics neglect the role of soil hydrology, and only use climatic drought indices like the climatic aridity index. In order to characterize the aridity of a stand, however, variation in soil texture and soil hydraulic properties should likewise be acknowledged, as both properties can strongly affect tree hydraulics (Sperry \& Hacke, 2002; Hultine et al., 2006; Waite et al., 2019). Congruently, several recent studies observed a close relationship between soil hydraulic 
properties (as the soil capacity for plant-available water, AWC) and drought-induced tree mortality (Peterman et al., 2013; Hember et al., 2017; Rehschuh et al., 2017; Breshears et al., 2018).

The vulnerability of the hydraulic system to drought does not solely depend on the xylem resistance to embolism, but on the interaction of several physiological processes which includes the stomatal control strategy (e.g. Mencuccini, 2003; Choat et al., 2018). Hydraulic safety margins (HSMs) relate resistance on the xylem level to stomatal control (Meinzer et al., 2009), and trees with small safety margins operate closer to the threshold of runaway embolism formation and are therefore more prone to hydraulic failure (Choat et al., 2012). HSMs are usually defined as the difference between minimum leaf water potential $\left(P_{\min }\right)$ and a measure of xylem embolism resistance (e.g. $\left.P_{50}\right)$, representing a measure of the conservatism in a tree's hydraulic strategy (Choat et al., 2012). Recently, the point of stomatal closure $\left(P_{\mathrm{gs} 90,}, 90 \%\right.$ reduction of stomatal conductance) or $P_{\mathrm{TLP}}$ have been used instead of $P_{\min }$ (Martin-StPaul et al., 2017; Ziegler et al., 2019; Powers et al., 2020), as measurements of the latter are labour-intense and often unreliable.

While most central European studies investigating plant hydraulic traits and their variability under altered water availability focused on the four economically most important tree genera, Picea, Pinus, Fagus, and Quercus, only little is known about minor timber species. Yet, small-leaved lime (Tilia cordata Mill., Malvaceae), Norway maple (Acer platanoides L., Sapindaceae) and European hornbeam (Carpinus betulus L., Betulaceae) may be more drought-resistant than European beech and Norway spruce, the most important broadleaf and coniferous timber species in Germany. Under the prospect of climate warming, the importance of minor tree species might increase if they prove to be better adapted to a future warmer and drier climate and their wood is suited for the timber industry. In the absence of physiological data, the drought tolerance assessment of minor timber trees is mainly based on analyses of the climate envelope of the distribution ranges and comparative expert assessment based on habitat preferences in natural forests (Ellenberg et al., 2001; Niinemets \& Valladares, 2006; Leuschner \& Meier, 2018). Hence, there is an urgent need for more precise empirical data on the drought response of these minor timber species. In particular, information on traits associated with hydraulic safety and efficiency and their variability in response to shifts in water availability is largely missing.

To close this knowledge gap, we examined the variability of the four major hydraulic traits related to hydraulic efficiency and safety at the wood and leaf level $\left(P_{50}, P_{\text {TLP }}, \mathrm{HV}\right.$ 
and $K_{\mathrm{s}}$, respectively) in three broadleaf, diffuse-porous tree species along a precipitation gradient in central Germany, and compared the species' drought tolerance in terms of their hydraulic safety margins. For doing so, we partitioned the variance in the four studied traits into the relative contributions of different hierarchical levels of variability, and computed the fraction of variance explained by species differences, by differences between populations, by individual differences within populations, and by random within-individual variability. Subsequently, we tested the hypothesis that within each species, the differences in hydraulic traits between populations are driven by climatic and edaphic water availability. We hereby assumed that traits related to hydraulic efficiency are more closely associated to water availability than traits related to hydraulic safety.

\subsection{Material and Methods}

\subsubsection{Study sites and tree species}

The nine study sites are situated along a precipitation gradient in west-east orientation in central Germany between Göttingen and Halle/S. at planar to colline elevation (110$440 \mathrm{~m}$ above sea level (asl)). The climate is cool temperate with mean annual temperatures (MATs) of 7.9 to $9.9^{\circ} \mathrm{C}$. Mean annual precipitation (MAP) ranges between 528 and $918 \mathrm{~mm}$ and mean growing season precipitation (MGSP, April-September) between 291 and $412 \mathrm{~mm}$, with a general decrease from west to east (Fig. 2.1). This represents a gradient from hydrologically optimal conditions to values close to the assumed drought limit of the species (Leuschner \& Ellenberg, 2017). 


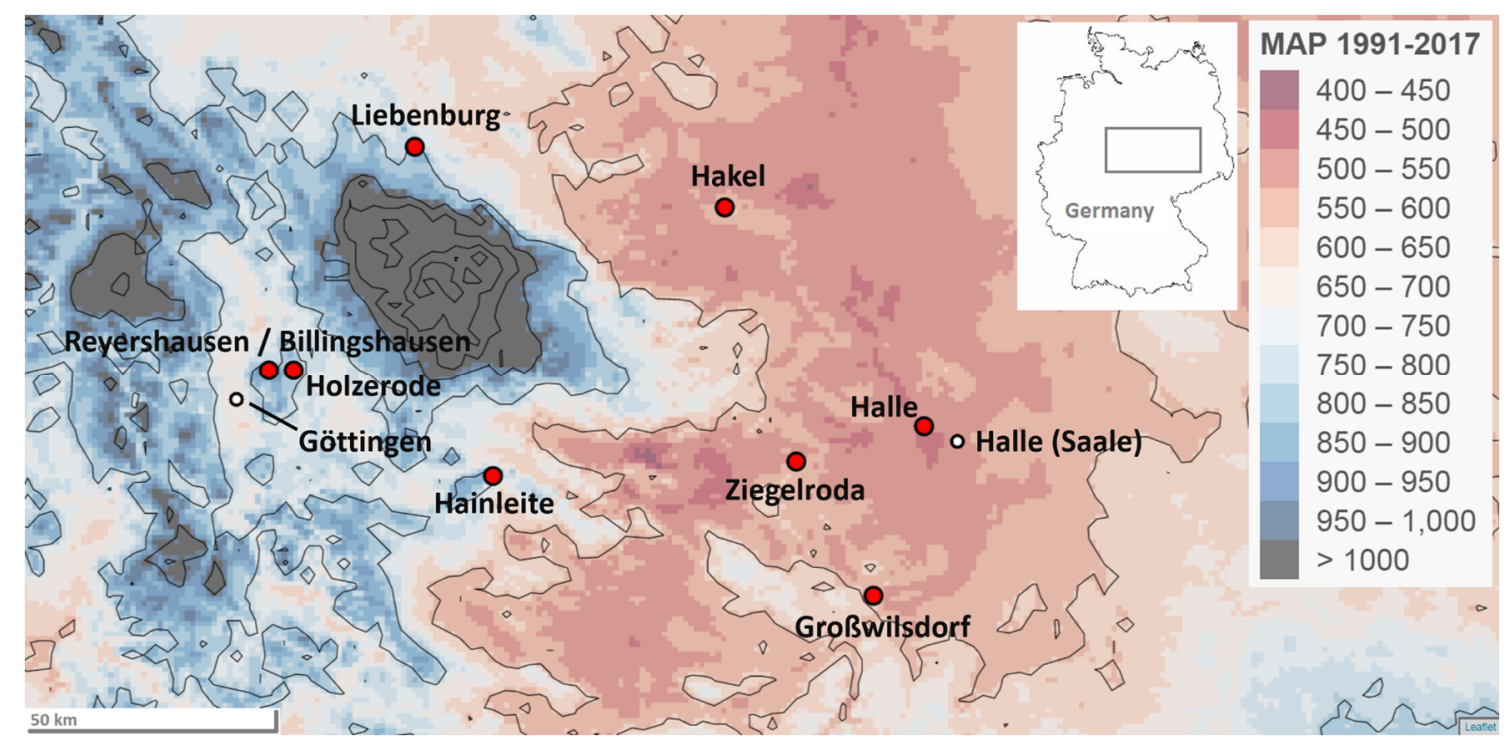

Figure 2.1: Map of the study area between Göttingen and Halle/S. in central Germany with the precipitation gradient from west to east. The study sites are marked with red dots, the background colours indicate the mean annual precipitation (MAP 1991-2017). The area with MAP over $1000 \mathrm{~mm}$ northeast of Göttingen is the Harz mountain range. 


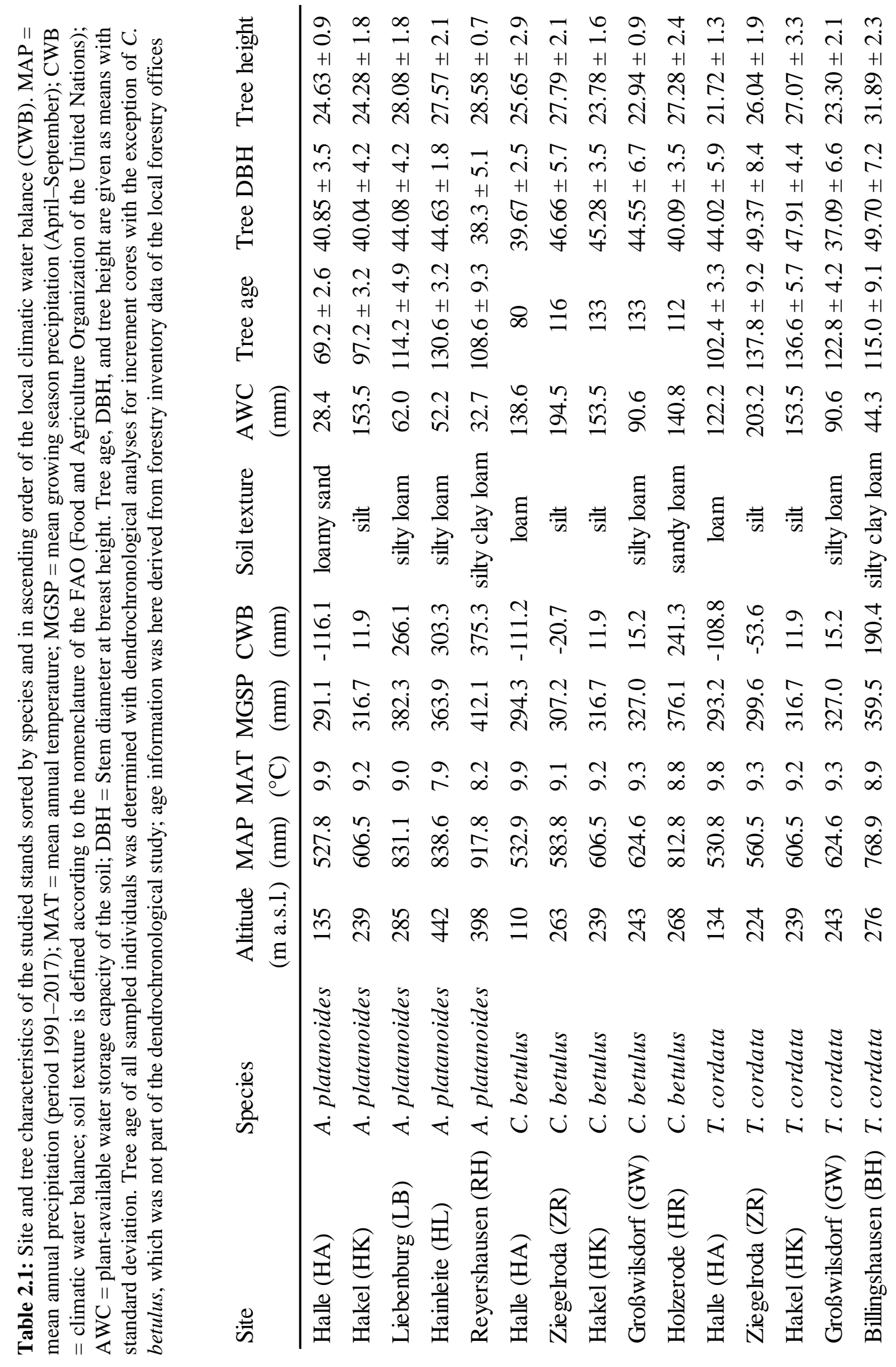


The three investigated tree species (A. platanoides, T. cordata, C. betulus) are naturally widespread in various types of central European broadleaf mixed forest communities of the phytosociological alliances Carpinion betuli (oak-hornbeam forests) and TilioAcerion (mixed maple slope forests, for species distributions see Appendix A, Fig. 2.5), where the dominant species of central Europe's natural forest vegetation (F. sylvatica L.) is rare or absent (Leuschner \& Ellenberg, 2017). The three species are more demanding in terms of soil base saturation than F. sylvatica, but they also occur in more continental climates in eastern Europe and thus are thought to be more drought tolerant (Roloff \& Grundmann, 2008; Roloff et al., 2010). While F. sylvatica is the most important broadleaf timber species in central European forestry, the three investigated species are only minor timbers. Therefore, mixed stands of comparable age, soil, and structure with presences of all three species are uncommon. Consequently, not all species were present at all nine study sites, but every species occurred in five stands along the precipitation gradient. Each site was composed of several mixed forest stands of variable species composition. The target species grew at a given site in a maximum distance of several hundred metres to a few kilometres to each other under comparable edaphic and climatic conditions. To take small-scale variation within a site into account, the edaphic and climatic conditions in the different stands were recorded separately for each species. All stands were located on level terrain (maximum inclination $5^{\circ}$ ) without groundwater influence.

\subsubsection{Climatic conditions}

Precipitation, air temperature, and potential evapotranspiration (PET) data were calculated from gridded data of $1 \mathrm{~km}$ mesh width retrieved from the German Weather Service (Deutscher Wetterdienst (DWD), Offenbach, Germany) database. The PET data of the DWD were calculated with the Penman-Monteith equation (Penman, 1948; Monteith, 1965; Löpmeier, 1994), the climatic water balance (CWB) was computed for the whole year as the difference of precipitation and PET.

Long-term annual means of climatic variables were calculated for the period 19912017, because PET data are available from DWD only since 1991. We tested our models with a variety of climatic parameters including long-term (27 yr) and short-term (2-5 yr) data of precipitation and evapotranspiration of whole year-periods and growing seasonperiods only. Because the ratio of summer precipitation to annual precipitation is almost constant, temperature is inversely proportional to precipitation along the transect, and short-term and long-term climate data did not differ notably in the 27 -yr period, we 
obtained very similar results for precipitation and CWB data and decided to report results for CWB only.

\subsubsection{Edaphic conditions}

The capability of soils to store water, which is available for plant uptake, is characterized by the AWC. We employed pedo-transfer functions according to Schaap et al. (2001), using the module 'Rosetta' implemented in the software Retc (v.6.02; van Genuchten et al., 1991), to estimate soil hydraulic properties (the so-called van Genuchten (1980) parameters) from local data on soil texture class and bulk density. The modelled water retention curves were used to retrieve the soil water content (in vol.\%) at field capacity (soil matric potential of $-0.03 \mathrm{MPa}, \mathrm{pF} 2.5$ ) and at the conventional permanent wilting point (-1.5 MPa, $\mathrm{pF} 4.2)$. AWC was then calculated as the difference between these two water contents. Soil texture classes and soil bulk density were determined in samples taken in soil pits at $0-10 \mathrm{~cm}, 10-30 \mathrm{~cm}$ and $30-60 \mathrm{~cm}$ depth. Sand fractions were obtained by sieving, silt and clay fractions by gravitational sedimentation according to the international standard ISO 11277 with an integral suspension pressure method (Durner et al., 2017), using the Pario device (Metergroup, Munich, Germany). The profile total of AWC (in millimetres) of a given stand was obtained by adding the AWC values of the three measured layers for the 0-60 cm profile, and extrapolating AWC to $120 \mathrm{~cm}$ depth by assuming constant soil texture below $60 \mathrm{~cm}$ depth. The data of three pits per stand were averaged. In case of shallower soils, we used the measured average bedrock depth for AWC extrapolation.

\subsubsection{Tree selection and sampling}

Five mature trees of comparable size per species and site were selected. All trees belonged to the upper canopy (dominant or co-dominant individuals). Tree height $(H)$ was comparable across the gradient except for $T$. cordata, where $H$ decreased notably towards the drier sites (Table 2.1). In June and July 2017/2018, branches were collected from the uppermost sun-exposed canopy with tree-climbing equipment. Sampling took place in a rotating scheme so that sites and species were spread evenly across the sampled season and the studied years. Seasonal or year effects on the traits of interest were not detected. To decide for an appropriate sample length, we performed preliminary measurements with the air-injection method that suggested the maximum vessel length of all studied species was well below $20 \mathrm{~cm}$. Per tree, six branches of $100 \mathrm{~cm}$ length were air-cut, re-cut to $50 \mathrm{~cm}$ under water, immediately transferred to plastic tubes filled with 
de-ionized water, and stored at $4^{\circ} \mathrm{C}$. Within five days, three of these branches were used to construct xylem vulnerability curves, and the remaining three used for hydraulic conductivity measurements and quantification of the total leaf area distal to the reference measuring point (basipetal end of the sample, 50-100 cm from the apex). Additionally, three distal twigs per tree with $c$. 5-10 mature and fully intact leaves were harvested from the uppermost canopy to determine turgor loss point. Twigs were recut under water and transported to the laboratory with the cut surface submerged in water bottles to enable rehydration over-night at $10^{\circ} \mathrm{C}$ and $100 \%$ air humidity. For all four measured variables $\left(P_{50}, P_{\mathrm{TLP}}, K_{\mathrm{S}}, \mathrm{HV}\right)$, each 75 samples per species were investigated (three branches $\times$ five trees $\times$ five sites), yielding 225 in total.

\subsubsection{Hydraulic efficiency}

For calculating HV, i.e. the sapwood-to-leaf area ratio, all leaves distal to the reference measuring point of a branch were scanned (Expression 11000XL; Epson Deutschland GmbH, Meerbusch, Germany) and analysed with WinFolia 2014 software (Régent Instruments, Quebec City, QC, Canada). In order to estimate the cross-sectional xylem area $\left(A_{\text {xylem }}\right.$ in $\left.\mathrm{mm}^{2}\right)$ without pith and bark at the reference measuring point, a linear regression was carried out between total cross-sectional area ( $\left.A_{\text {cross}}\right)$ and $A_{\text {xylem }}$ (cf. Hajek et al., 2014; Schuldt et al., 2016). Per species, 75 digitalized semi-thin transverse sections, taken at $1-3 \mathrm{~cm}$ proximal from the reference measuring point, were used. The obtained equations are as follows (Eqs. 1-3):

$$
\begin{aligned}
& \text { Acer: } \quad A_{\text {xylem }}=-5.84755+0.70525 \cdot A_{\text {cross }}\left(R^{2}=0.98\right) \\
& \text { Carpinus: } \quad A_{\text {xylem }}=-2.02419+0.76517 \cdot A_{\text {cross }}\left(R^{2}=0.98\right) \\
& \text { Tilia: } \quad A_{\text {xylem }}=-4.86760+0.56120 \cdot A_{\text {cross }}\left(R^{2}=0.90\right)
\end{aligned}
$$

For measuring hydraulic conductivity $\left(K_{\mathrm{h}}\right.$; in $\mathrm{kg} \mathrm{m} \mathrm{MPa}^{-1} \mathrm{~s}^{-1}$ ), branches (mean reference point diameter \pm SE: $10.12 \pm 0.08 \mathrm{~mm}$; mean length \pm SE: $298.83 \pm 0.46 \mathrm{~mm}$; $n=225$ ) were recut under water with a razor blade, lateral branches cut off and glued with quick-drying superglue working on wet surfaces in combination with an activator (Loctite 431 and 7452; Henkel, Düsseldorf, Germany). The value of $K_{\mathrm{h}}$ was measured along a $6 \mathrm{kPa}$-pressure gradient with the Xyl'em apparatus (Bronkhorst, Montigny les Cormeilles, France) after flushing the segments three times at $120 \mathrm{kPa}$ with filtered, degassed, and demineralized water $(10 \mathrm{mM}$ potassium chloride and $1 \mathrm{mM}$ calcium chloride). The value of $K_{\mathrm{S}}$ (in $\mathrm{kg} \mathrm{m}^{-1} \mathrm{MPa}^{-1} \mathrm{~s}^{-1}$ ) was calculated by dividing $K_{\mathrm{h}}$ by $A_{\text {xylem. }}$. 


\subsubsection{Hydraulic safety}

Vulnerability curves were constructed with the flow-centrifuge method (Cochard et al., 2005 using a custom-made honeycomb rotor attached to a commercially available centrifuge (Sorvall RC-5C; Thermo Fisher Scientific, Waltham, MA, USA). Nonflushed branches (mean diameter at basipetal end \pm SE: $9.14 \pm 0.07 \mathrm{~mm} ; n=225$ ) were recut to $27.5 \mathrm{~cm}$ with a razor blade and exposed to increasingly negative water potentials starting at $-0.8 \mathrm{MPa}$. Xylem water potential was lowered stepwise until the percentage loss of conductivity (PLC) reached at least 90\% (Appendix A, Fig. 2.6). Nonlinear mixed-effects models (R package nlme; Pinheiro et al., 2020) were fitted for each species to estimate the xylem pressure at $50 \%$ loss of conductivity $\left(P_{50}\right)$ and the slope of the curve at the inflexion point $(s)$ according to the sigmoidal function given by Pammenter \& van der Willigen 1998 :

$$
P L C=100 /\left(1+\exp \left(\frac{s}{25}\left(\Psi-P_{50}\right)\right)\right)
$$

where $\Psi$ is the water potential and PLC the percentage loss of conductivity. Due to repeated measurements on the same sample and three investigated samples per tree, a hierarchical structure of random effects had to be considered in the statistical analysis. We allowed both $s$ and $P_{50}$ to vary with a site-specific fixed effect and random effects for trees and samples nested in tree. Further analyses were based on conditional predictions on the branch level. The values for $P_{12}$ and $P_{88}$ (xylem pressure at $12 \%$ and $88 \%$ loss of conductivity) were calculated from branch-level $P_{50}$ predictions by rearranging Eq. 4 (where $x$ is the desired percentile loss of conductivity):

$$
P_{x}=\frac{\ln \left(\frac{100}{x}-1\right) \cdot 25}{s}+P_{50}
$$

Leaf $P_{\text {TLP }}$ (in MPa) was determined within 48 hours after sampling by the osmometric method (Bartlett et al., 2012a). The leaf osmotic potential $\left(\Psi_{0}\right)$ of freeze-thawed (liquid nitrogen) leaf discs from fully expanded, sun-exposed, and rehydrated leaves was measured in a vapour pressure osmometer (VAPRO 5600, Wescor, Logan, UT, USA) following the protocol of Bartlett et al. (2012a) and used to predict $P_{\text {TLP as: }}$

$$
P_{T L P}=0.832 \Psi_{0}-0.631
$$

The HSM was subsequently calculated on the tree level as the difference between mean $P_{\text {TLP }}$ and mean $P_{50 \text {. }}$ 


\subsubsection{Statistical analyses}

The coefficient of quartile variation $(\mathrm{CQV}=(\mathrm{Q} 3-\mathrm{Q} 1) /(\mathrm{Q} 1+\mathrm{Q} 3))$ was used to assess trait variability, as it provides a more robust measure of dispersion than the coefficient of variation, when data are partly nonnormally distributed or log-transformed (Canchola et al., 2017; Altunkaynak \& Gamgam, 2019; Rosas et al., 2019). To decompose the variability of each trait for different levels of organization (species, populations (sites), individuals, within-tree (branches)), log-linear mixed-effects models were fitted for each trait separately using the R package lme4 (Bates et al., 2015. Each of the models contained fixed effects for species, and random tree effects as well as species-wise random site effects (i.e. random effects for each combination of site and species). The total variance in the traits was then decomposed into variance components for the fixed (between-species) and random effects (between-population and between-tree) as well as the residual (within-tree) standard deviation analogous to the definition of conditional and marginal $R^{2}$ (cf. Nakagawa \& Schielzeth, 2013). The same models were used to investigate pair-wise differences between species across all sites using Tukey-adjusted $P$ values with degrees of freedom based on Satterthwaite's approximation ( $R$ package emmeans; Lenth, 2020).

To assess the effect of water availability on intraspecific trait variation, sets of linear mixed-effects models were fit for each trait $\left(P_{50}, P_{\mathrm{TLP}}, K_{\mathrm{S}}, \mathrm{HV}\right)$ and species. Climatic (CWB) and edaphic (AWC) water availability were included as fixed effects (both centred and scaled to simplify the comparison of regression coefficients). As the low number of five sites per species precluded adding random site effects, in these models we could only introduce tree-wise random intercepts, which thus are assumed to account both for between-site and within-site intra-specific variability. The explained variance was calculated according to Nakagawa \& Schielzeth 2013. This set of models was not fitted for the HSMs, as this variable could only be calculated on the tree level. Likewise, trait interrelations could not be assessed on the branch level because traits were not measured on the same observational units (different branches, leaves, etc.). Therefore, simple linear regressions across species based on means per site and species are reported in order to illustrate tendencies in trait interrelations. We are aware that the small number of species is not sufficient to draw generalizable conclusions for a larger species number.

For all dependent variables, model residuals were checked for normality and natural log-transformed whenever required to meet the assumption of normality. All analyses were carried out with the statistical software R (v.3.6.3; R Core Team, Vienna, Austria). 


\subsection{Results}

\subsubsection{Magnitude of traits and variability on different levels of organization}

According to their average $P_{50}$-values, the xylem embolism resistance of the three species could be ranked in the sequence A. platanoides $>C$. betulus $>$ T. cordata (Table 2.2). Both $A$. platanoides and $C$. betulus showed a fairly resistant xylem with the vast majority of $P_{50}$-values in the range of -5 to $-4 \mathrm{MPa}$, but $C$. betulus was markedly less resistant at the driest site with a median $P_{50}$ of $-3.8 \mathrm{MPa}$ (Fig. 2.2a). By contrast, the estimated $P_{50}$ of $T$. cordata was generally much less negative (mean of $-3.06 \mathrm{MPa}$; Table 2.2). This species ranking was, however, not mirrored in the $P_{\text {TLP-Values. The highest }}$ P TLP was found in A. platanoides and the lowest in C. betulus (Table 2.2; Fig. 2.2c). Consequently, the three species showed pronounced differences in HSMs with $A$. platanoides having the largest safety margin (2.59 MPa; Table 2.2), C. betulus showing intermediate values (1.6 MPa), and T. cordata operating with a narrow margin of 0.84 MPa.

The species rankings in terms of $P_{12}$ and $P_{88}$ were the same as in case of $P_{50}$, but the vulnerability curves of $C$. betulus showed less steep slopes (Appendix A, Fig. 2.6) and thus relatively low $P_{88}$ values that were very close to the values of $A$. platanoides (Table 2.2; Fig. 2.2b).

The values of $K_{\mathrm{S}}$ and $\mathrm{HV}$ barely differed between A. platanoides and C. betulus, but HV was significantly higher in $T$. cordata and $K_{\mathrm{S}}$ was at least tendentially higher and more variable in T. cordata (Table 2.2; Fig. 2.3).

Table 2.2: Means \pm SE of measured traits per species pooled over all study sites. Different letters denote significantly different means based on Tukey-adjusted p-values from linear mixed effects models with posthoc tests for pairwise species differences with degrees of freedom based on Satterthwaite's approximation. $P_{50 / 12 / 88}=$ xylem water potential at 50/12/88 \% loss of conductivity; $P_{\mathrm{TLP}}=$ leaf water potential at turgor loss point; $\mathrm{HSM}=$ hydraulic safety margin; Huber value $(\mathrm{HV})=A_{\text {xylem }} / A_{\text {Leaves }}$-ratio of branches; $K_{\mathrm{S}}=$ xylem area specific hydraulic conductivity of branches.

\begin{tabular}{|c|c|c|c|c|c|c|c|}
\hline Species & $\begin{array}{c}P_{50} \\
(\mathrm{MPa})\end{array}$ & $\begin{array}{c}P_{12} \\
(\mathrm{MPa})\end{array}$ & $\begin{array}{c}P_{88} \\
(\mathrm{MPa})\end{array}$ & $\begin{array}{c}P_{\mathrm{TLP}} \\
(\mathrm{MPa})\end{array}$ & $\begin{array}{l}\text { HSM } \\
\text { (Mpa) }\end{array}$ & $\begin{array}{c}\mathrm{HV} \\
\left(\mathrm{A}_{\text {xylem }} / \mathrm{A}_{\text {leaf }}\right)\end{array}$ & $\begin{array}{c}K_{\mathrm{S}} \\
\left(\mathrm{Kg} \mathrm{m}^{-1} \mathrm{~s}^{-1} \mathrm{Mpa}^{-1}\right)\end{array}$ \\
\hline A. platanoides & $-4.62 \pm 0.03$ (a) & $-3.97 \pm 0.04$ (a) & $-5.27 \pm 0.04$ (a) & $-2.02 \pm 0.02(\mathrm{a})$ & $2.59 \pm 0.07$ (a) & $0.0159 \pm 0.0007$ (a) & $1.73 \pm 0.07$ (a) \\
\hline C. betulus & $-4.25 \pm 0.05(b)$ & $-3.31 \pm 0.06(b)$ & $-5.19 \pm 0.06(a)$ & $-2.66 \pm 0.02(b)$ & $1.60 \pm 0.10(b)$ & $0.0165 \pm 0.0006(\mathrm{a})$ & $1.75 \pm 0.05$ (a) \\
\hline T. cordata & $-3.06 \pm 0.03(\mathrm{c})$ & $-2.44 \pm 0.03(\mathrm{c})$ & $-3.69 \pm 0.04(b)$ & $-2.23 \pm 0.03(\mathrm{c})$ & $0.84 \pm 0.05(\mathrm{c})$ & $0.0195 \pm 0.0011(b)$ & $2.28 \pm 0.12(\mathrm{a})$ \\
\hline
\end{tabular}



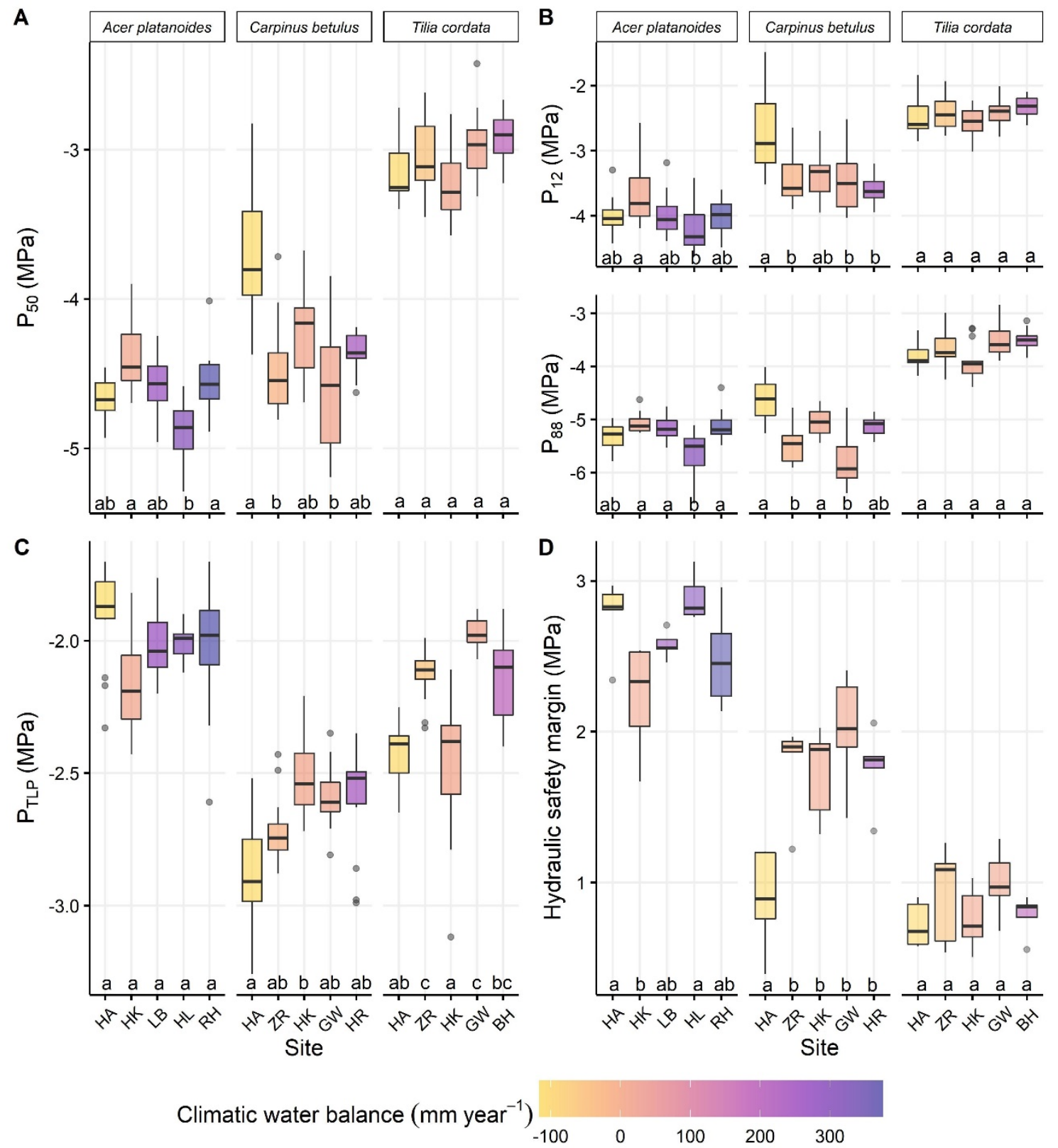

Figure 2.2: Hydraulic safety-related traits: (A) Xylem water potential at $50 \%$ loss of conductivity $\left(P_{50}\right)$, (B) xylem water potential at $12 / 88 \%$ loss of conductivity $\left(P_{12 / 88}\right),(\mathrm{C})$ leaf water potential at turgor loss point $\left(P_{\mathrm{TLP}}\right)$, and $(\mathrm{D})$ hydraulic safety margins of the three tree species at all study sites. Sites are sorted in ascending order according to the climatic water balance. Box-whisker plots include median and interquartile ranges (Q1-Q3); whiskers extend to max. 1.5 times the interquartile range. Different letters denote significantly different means between sites within a species based on Tukey-adjusted p-values with degrees of freedom based on Satterthwaite's approximation from linear mixed effects models with posthoc tests for pairwise differences. 

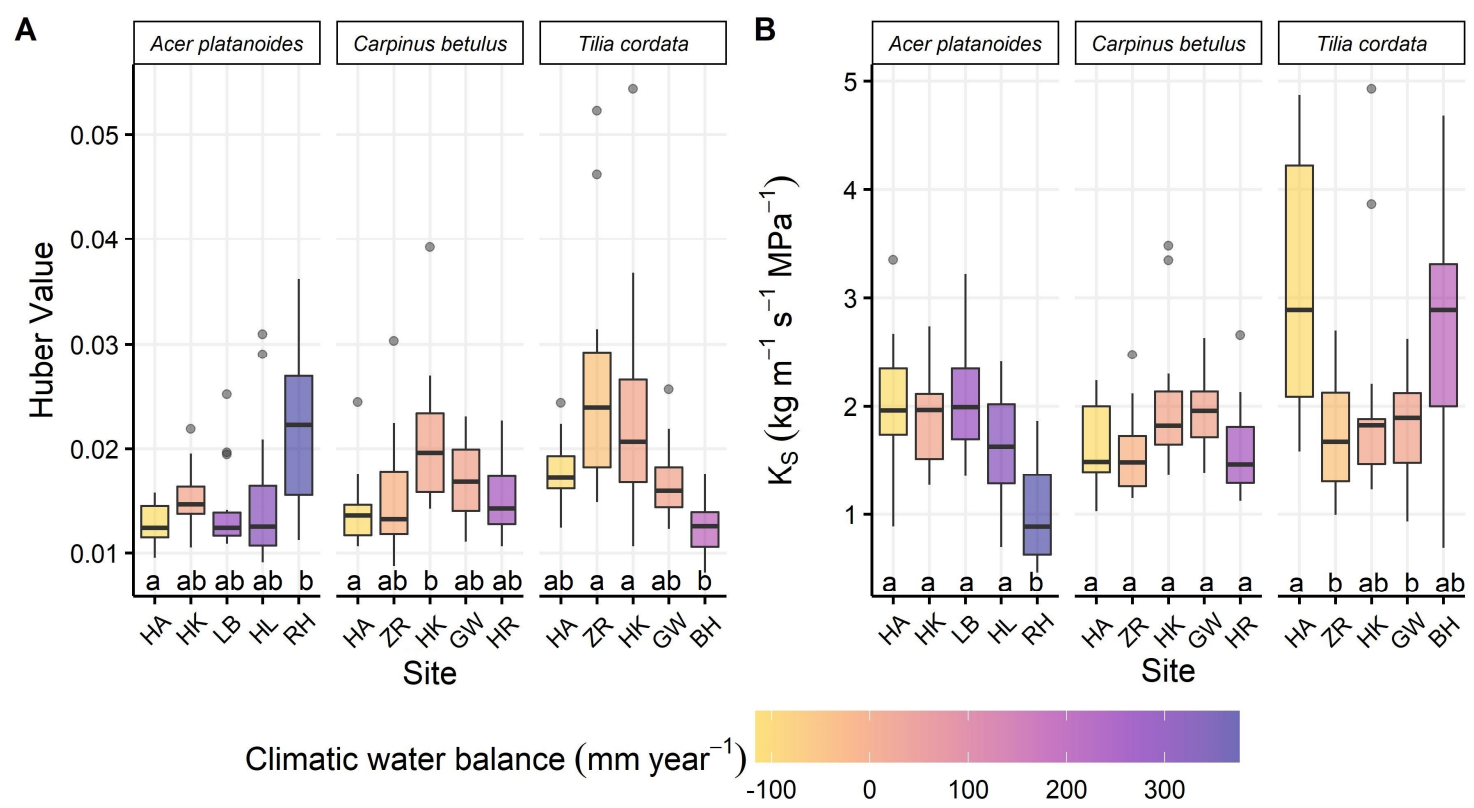

Figure 2.3: Hydraulic efficiency-related traits: (A) $A_{\text {Xylem }} / A_{\text {Leaves }}$-ratio of branches (Huber value), and (B) xylem area-specific hydraulic conductivity of branches $\left(K_{\mathrm{S}}\right)$ of the three tree species at all study sites. Sites are sorted in ascending order according to the climatic water balance. Box-whisker plots include median and interquartile ranges $(\mathrm{Q} 1-\mathrm{Q} 3)$; whiskers extend to max. 1.5 times the interquartile range. Different letters denote significantly different means between sites within a species based on Tukey-adjusted p-values with degrees of freedom based on Satterthwaite's approximation from linear mixed effects models with post-hoc tests for pairwise differences.

Generally, $K$ s and HV were the most variable traits, whereas $P_{\text {TLP }}$ showed the lowest variation (Fig. 2.4a). For the two hydraulic safety-related traits ( $P_{50}$ and $\left.P_{\text {TLP }}\right)$, the by far largest fraction of variance was explained by species differences. The intra-specific trait variability (ITV) between and within populations was small compared to the ITV in efficiency-related traits, especially in case of $P_{50}(22 \%$ or $42 \%$ of total trait variance for $P_{50}$ and $P_{\text {TLP, }}$ respectively; Fig. 2.4b). For $P_{50}$, we estimated a between-population standard deviation of $0.20 \mathrm{MPa}$ and between- and within-tree standard deviations of 0.23 $\mathrm{MPa}$ and 0.16 MPa, respectively (Fig. 2.4b; Appendix A, Table 2.4), while $P_{\text {TLP varied }}$ by $\pm 0.14 \mathrm{MPa}$ between populations, by $\pm 0.14 \mathrm{MPa}$ between trees within populations and by $\pm 0.10 \mathrm{MPa}$ within trees (Fig. 2.4b; Appendix A, Table 2.4). Hereby, the range of site averages of $P_{50}$ spanned $0.84 \mathrm{MPa}, 0.52 \mathrm{MPa}$ and $0.31 \mathrm{MPa}$ in case of C. betulus, $A$. platanoides and T. cordata, respectively (Fig. 2.2a). The range in site averages of $P_{\text {TLP }}$ was comparable (T. cordata: $0.50 \mathrm{MPa}, C$. betulus: $0.36 \mathrm{MPa}$, A. platanoides: $0.26 \mathrm{MPa}$; Fig. 2.2c).

In contrast to hydraulic safety, average efficiency-related traits ( $K_{\mathrm{S}}$ and $\mathrm{HV}$ ) nearly did not differ between species, but varied substantially between populations as well as between and within individuals (Fig. 2.4b). Particularly the residual variability within 
individuals was high (44\% of total variance in case of $\mathrm{HV}$ and $50 \%$ of total variance in case of $K \mathrm{~s})$.

For all four traits, the variability within populations (intra- and inter-individual) was larger than the variability between populations (Fig. 2.4b).

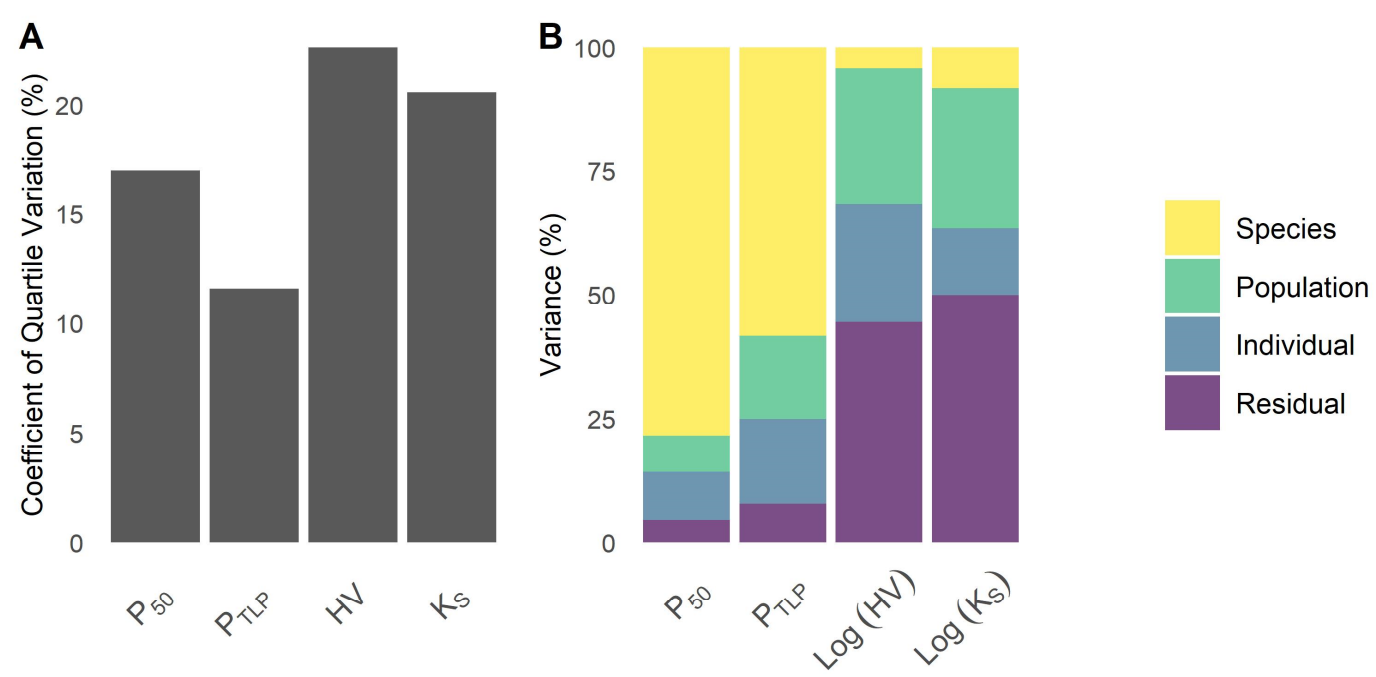

Figure 2.4: (A) Coefficient of quartile variation of the studied traits across all species and measurements; (B) variance decomposition between different levels of organization (between species, between populations, and between individuals; see Appendix A, Table 2.4 for full model output). Given are the xylem water potential at $50 \%$ loss of conductivity $\left(P_{50}\right)$, the leaf water potential at turgor loss point $\left(P_{\mathrm{TLP}}\right), A_{\text {xylem }} / A_{\text {leaf }}-$ ratio of branches (Huber value, $\mathrm{HV}$ ) and xylem area-specific hydraulic conductivity $\left(K_{\mathrm{S}}\right)$. 'Residual' denotes the unexplained variance of the models (i.e. variability between branches + estimation and measurement uncertainty).

\subsubsection{Trait dependence on environmental and stand structural parameters}

For most studied traits, significant differences between the study sites were observed for at least one species (Figs 2.2, 2.3). However, water availability (as expressed by the combined effect of CWB and AWC) explained only a small fraction of variance in the analysed traits (marginal $R^{2}$ 0.04-0.19 in nearly all cases; Table 2.3). The only exception was T. cordata, where $37 \%$ of the variance in HV was explained by water availability. Conditional $R^{2}$ were much larger $(0.28-0.88$, Table 2.3$)$, indicating that most of the variance in the data resulted from unexplained differences between sites and individual trees.

In general, the observed associations between the studied traits and climatic and soil water availability were weak, the only exceptions being a positive effect of AWC on HV 
in $T$. cordata (higher xylem area-to-leaf area ratio on sites with higher soil water storage capacity), a negative effect of AWC on P TLP in A. platanoides (lower turgor loss point on sites with better soil water storage capacity; Table 2.3; Appendix A, Fig. 2.7), and a reduction in $K_{\mathrm{S}}$ with $\mathrm{AWC}$ in $T$. cordata and with $\mathrm{CWB}$ in A. platanoides. Water availability had no significant influence on $P_{50}$, except for a marginally positive effect of AWC on $P_{50}$ in A. platanoides $\left(P<0.1\right.$; Table 2.3). The value of $P_{\text {TLP }}$ of $C$. betulus and $T$. cordata was not influenced by AWC, although the leaves of $C$. betulus showed a tendency of a turgor loss point reduction with increasing climatic aridity (positive effects of CWB on $P_{\text {TLP }}$ at $P<0.1$; Table 2.3; Fig. 2.2c). Although not part of the regression models, HSMs did not change systematically along the climatic gradient within species, as evident from Fig. 2.2d.

Further relationships between site variables and interrelations between traits are presented in the correlation matrix in Fig. 2.8 (Appendix A). 
Table 2.3: Results of the linear mixed effects models examining the relationships between environmental variables and functional traits. $P_{50}=$ xylem water potential at $50 \%$ loss of conductivity; $P_{\mathrm{TLP}}=$ leaf water potential at turgor loss point; HSM = hydraulic safety margin; Huber value $(\mathrm{HV})=A_{\mathrm{xylem}} / A_{\text {leaf }}-$ ratio of branches; $K_{\mathrm{S}}=$ xylem area specific hydraulic conductivity of branches. Given are the scaled estimates for CWB (climatic water balance) and AWC (plant-available water storage capacity of the soil), as well as the standard deviation for the tree-wise random intercept (Tree SD), the residual standard deviation (Res. SD), and marginal and conditional $R^{2}$ of the models (Marg. $R^{2}$ and Cond. $R^{2}$ ). Bold estimates represent significant effects $(*, P<0.05$; ** $P<0.01)$, (a) denotes marginally significant effects $(P<0.1)$. The full output of the models is given in Appendix A, Table 2.5.

\begin{tabular}{c|lcccc} 
Species & Term & $\mathrm{P}_{50}$ & $\mathrm{P}_{\mathrm{TLP}}$ & $\mathrm{HV}$ & $\mathrm{K}_{\mathrm{S}}$ \\
\hline A. platanoides & CWB & -0.054 & -0.214 & 0.343. & $\mathbf{- 0 . 4 0 2 *}$ \\
& AWC & 0.374. & $\mathbf{- 0 . 4 6 0 *}$ & 0.049 & 0.103 \\
& Tree SD & 0.81 & 0.724 & 0.708 & 0.685 \\
& Res. SD & 0.529 & 0.584 & 0.674 & 0.629 \\
C. betulus & Marg. $\mathrm{R}^{2}$ & 0.141 & 0.189 & 0.103 & 0.184 \\
& Cond. $\mathrm{R}^{2}$ & 0.743 & 0.68 & 0.574 & 0.627 \\
\hline TWB & -0.278 & 0.347. & 0.054 & -0.072 \\
& CWWC & 0.035 & -0.074 & -0.078 & -0.241 \\
& AWC & 0.854 & 0.87 & 0.565 & 0.548 \\
& Tree SD & 0.396 & 0.445 & 0.853 & 0.836 \\
& Res. SD & 0.083 & 0.121 & 0.009 & 0.057 \\
& Marg. $\mathrm{R}^{2}$ & 0.837 & 0.818 & 0.312 & 0.341 \\
\hline Cond. R & & 0.837 & & & \\
& CWB & 0.165 & 0.237 & -0.027 & -0.315 \\
& AWC & -0.144 & -0.04 & $\mathbf{0 . 6 0 4 * *}$ & $\mathbf{- 0 . 4 3 7 *}$ \\
& Tree SD & 0.822 & 0.963 & 0.511 & 0.437 \\
& Res. SD & 0.559 & 0.365 & 0.631 & 0.867 \\
& Marg. $\mathrm{R}^{2}$ & 0.076 & 0.064 & 0.371 & 0.094 \\
& Cond. R & 0.708 & 0.883 & 0.62 & 0.277
\end{tabular}




\subsection{Discussion}

2.5.1 Variability of efficiency- and safety-related traits on different levels of organization

In our field study on mature trees, the HV, i.e. the sapwood-to-leaf-area ratio, and $K_{\mathrm{S}}$ showed the highest, and the $P_{\mathrm{TLP}}$ the lowest variability across the three diffuse-porous species. This is in line with recent findings by Rosas et al. (2019). The high variability of the efficiency-related hydraulic traits $K_{\mathrm{S}}$ and HV was driven by large intra- and interindividual differences. Most likely, this can be attributed to small-scale variability in microclimatic conditions within the canopy of single trees and corresponding morphological and anatomical adjustments (e.g. Lemoine et al., 2002; Sellin \& Kupper, 2004; Schuldt et al., 2011; Sellin et al., 2011). In agreement hereon, both branch age and branch growth rate were found to vary considerably within the crown, and both are closely related to hydraulic efficiency (Schuldt et al., 2016). In dependence on the position in the canopy and associated differences in flow-path length, light exposure and evaporative demand, the xylem architecture is adjusted in order to meet the water demand of the supported leaf area. Still, the covered range in both efficiency-related variables was relatively low compared to other studies (cf. Rosas et al., 2019). We focused on cooccurring diffuse-porous angiosperms only, and did not include conifers or ring-porous angiosperms. This might explain why the efficiency-related traits were more or less comparable across species despite pronounced differences in xylem safety. All three species have co-evolved and are widespread in central and eastern Europe in various types of broadleaved mixed forest communities in which European beech ( F. sylvatica), the dominant species of central Europe's natural forest vegetation, is rare or absent (Leuschner \& Ellenberg, 2017).

The low variability in $P_{\text {TLP }}$ compared to other hydraulic traits has likewise been observed in other studies (Mencuccini et al., 2015; Bartlett et al., 2016; Farrell et al., 2017; Zhu et al., 2018). When excluding plants with sclerophyllous leaves or from perhumid ecosystems, the range of $P_{\mathrm{TLP}}$-variation based on differences in osmolality seems to be restricted to $2 \mathrm{MPa}$ (Bartlett et al., 2012b). In our study, most of the variability in $P_{\text {TLP }}$ could be attributed to species differences, although there still was a considerable amount of ITV between populations and individuals.

In contrast to the two efficiency-related traits, the xylem pressure at $P_{50}$ differed distinctly between species. Although ITV in xylem safety was not completely negligible 
as we observed intra-specific ranges of 0.3 to $0.8 \mathrm{MPa}$ across sites, $78 \%$ of the total variance in $P_{50}$ could be attributed to species differences. The highest ITV was observed between trees at given sites, which explained $14 \%$ of the total variance in $P_{50}$. This pattern of higher variability within than between populations has been confirmed for $P_{50}$ (Herbette et al., 2010; Wortemann et al., 2011; Hajek et al., 2016; Schuldt et al., 2016) and a wide range of other anatomical, foliar and hydraulic traits (Hajek et al., 2016; Rosas et al., 2019).

The low ITV in $P_{50}$ reinforces the assessment of xylem embolism resistance as an evolutionarily canalized trait (cf. Flatt, 2005; Lamy et al., 2014; Rosas et al., 2019; Sanchez-Martinez et al., 2020). Accordingly, neither environment nor genotype seems to have strong control over the phenotypic expression of $P_{50}$. For trait-based models of tree mortality (cf. Adams et al., 2013; Choat et al., 2018), this is an important finding as these models implicitly rely on trait conservation within species and do not account for ITV.

\subsubsection{Effects of water availability and tree height on hydraulic traits}

Given the relatively small intra-specific variation in hydraulic safety-related traits, we expected to trace this ITV back to local climatic or edaphic conditions that define the water availability of the stands. However, none of the two measures of water availability had a consistent influence on $P_{50}, P_{\mathrm{TLP}}$, or HSMs. For $P_{50}$, a majority of intra-specific studies on a wide range of tree species failed to identify environmental variables that drive ITV (Van der Willigen \& Pammenter, 1998; Cornwell et al., 2007; Martínez-Vilalta et al., 2009; Herbette et al., 2010; Wortemann et al., 2011; Martin-StPaul et al., 2013; González-Muñoz et al., 2018; Li et al., 2019; Rosas et al., 2019; but see Schuldt et al., 2016; Stojnic et al., 2018). It is therefore reasonable to conclude that the limited environmental control over $P_{50}$ is relatively complex, as assumed by Wortemann et al. (2011). In our study, only less than $10 \%$ of total variability occurred between populations, indicating that the effects of different drivers may often be difficult to disentangle in field studies on mature trees. For example, most of the aforementioned studies disregarded that various site-specific factors might, in addition to atmospheric climatic aridity, affect embolism resistance. To our knowledge, only Rosas et al. (2019) also included a wide range of stand, soil, and climatic factors as potential drivers of $P_{50}$, but the authors were likewise not able to identify the sources of the ITV in $P_{50}$ in adult field-grown trees.

In contrast to $P_{50}$, reports on an intra-specific decline in $P_{\text {TLP }}$ with increasing aridity are rather consistent (e.g. Liang et al., 2019; Rosas et al., 2019; Pritzkow et al., 2020). In our study, $C$. betulus indeed showed a marginally significant negative relationship between 
$P_{\text {TLP }}$ and aridity. Leaf traits might thus be under a stronger environmental control than wood traits, and one of the main acclimative responses of the broadleaf tree species of our sample to local climatic gradients might be osmotic adjustment (cf. Hartmann et al., 2021).

We did not find the expected increase in HV on drier sites, even though a high variability of HV across climatic gradients has been reported both within (MartínezVilalta et al., 2009; Rosas et al., 2019; Pritzkow et al., 2020) and across species (Gleason et al., 2013; Mencuccini et al., 2019). However, intra-specific variability in HV in response to climatic aridity has mainly been observed in different ecosystems or in conifers that showed limited variability in xylem traits (Martínez-Vilalta et al., 2009; Lamy et al., 2014).

While intra-specific adaptation of hydraulic efficiency in terms of xylem anatomical adjustments has been demonstrated (e.g. Schreiber et al., 2015; Liang et al., 2019), studies quantifying actual conductivities often failed to report such adaptive modifications (Martínez-Vilalta et al., 2009; Schuldt et al., 2016; Rosas et al., 2019). This is in line with our findings that $K_{\mathrm{s}}$ was not under environmental control, despite its very high ITV. One explanation for the missing relationship might be that empirically measured conductivity, in contrast to theoretical values, additionally includes the flow resistance of inter-vessel pits and conduit irregularities along the flow path, which are estimated to account for $50 \%$ of the total xylem resistance (Sperry et al., 2005).

We found a general inter-specific safety-efficiency trade-off as observed by others (Maherali et al., 2004; Gleason et al., 2016; Schumann et al., 2019). Across the three species of our sample, $P_{50}$ and $K_{\mathrm{S}}$ were correlated $\left(P<0.05, R^{2}=0.23\right.$; Appendix A, Fig. $2.9)$, but this observed safety-efficiency relationship did not hold within any of the species. We are aware that this finding may not be transferable to more general betweenspecies pattern due to the small number of species in our sample.

\subsubsection{Hydraulic safety in comparison to major timbers}

In our study, A. platanoides and C. betulus showed both an embolism resistant xylem $\left(P_{50}:-4.62 \mathrm{MPa}\right.$ and -4.25 MPa, respectively) and large HSMs (2.59 MPa and 1.6 MPa, respectively). In contrast to these two species that have been of minor silvicultural interest so far, the major broadleaf timber species in the study region, $F$. sylvatica, is less droughtresistant in terms of hydraulic safety $\left(P_{50}:-3.8 \mathrm{MPa}\right.$ to $-3.5 \mathrm{MPa}$; HSM: $0.2 \mathrm{MPa}$ to 1.5 $\mathrm{MPa} ; P_{50}$ and $P_{\min }$ data obtained from Schuldt et al., 2016; Dietrich et al., 2018; Schuldt et al., 2020). These two species even turned out to be a match-in terms of hydraulic 
safety-for another major timber species of the region, namely sessile oak (Quercus petraea), which is known to be more drought-resistant than European beech $\left(P_{50}:-5.0\right.$ MPa to -4.6 MPa, HSM: 1.8 MPa to $2.3 \mathrm{MPa}$; based on $P_{50}$ and $P_{\min }$ data from Dietrich et al., 2018; Lobo et al., 2018). Especially F. sylvatica is currently widely affected by drought-induced defoliation and tree mortality following the extreme 2018/2019 drought (Braun et al., 2020; Schuldt et al., 2020). According to dendroecological analyses, this species is more drought-sensitive than A. platanoides even in the core area of its distribution range (Zimmermann et al., 2015; Leuschner, 2020). Thus, A. platanoides and, from a plant hydraulic perspective, also $C$. betulus seem to be better suited than $F$. sylvatica for a future drier climate.

However, HSMs alone are not sufficient to capture drought tolerance on the wholetree level, because stem and leaf water capacitance act as additional buffers against desiccation (Choat et al., 2018). Tilia cordata has a relatively high stem water storage due to its low wood density (Köcher et al., 2013) and a high leaf water capacitance linked to a highly elastic leaf tissue (Leuschner et al., 2019), which might partly compensate for the species' relatively high xylem vulnerability and small HSM. Consequently, more holistic and integrated studies on whole-tree drought responses are needed to fully understand tolerance strategies and compare different species.

\subsubsection{Conclusions}

The three investigated minor timber species showed a considerable amount of intraspecific variability in efficiency-related traits, which were highly variable between and within individuals. In contrast, ITV was low in xylem safety-related traits despite pronounced differences between species. This implies that xylem safety-related traits at the wood $\left(P_{50}\right)$ and leaf $\left(P_{\mathrm{TLP}}\right)$ levels are more strongly conserved traits, which-given their high mechanistic importance for plant drought responses - underlines their value for trait-based modelling approaches in dynamic vegetation and land surface models.

Environmental control over hydraulic traits in mature stands seems to involve complex interactions with abiotic drivers. In our study, it was not possible to clearly disentangle their influence from other factors, even though both climate and soil water capacity were taken into account. Most likely, local properties of the stand and soil, including smallscale variability in moisture availability, belowground and aboveground competition with direct neighbours, as well as a high within-crown variability in branch hydraulic properties hamper the identification of the environmental drivers of xylem safety and efficiency for given species. 
Despite these uncertainties, our study provides valuable information on hydraulic traits and their variability for three promising minor timber species that may help to assess their suitability for broader inclusion in silvicultural concepts in central Europe in a future warmer and drier climate. In the light of large-scale vitality losses and dieback in some of the primary timber species in central Europe, minor timber species such as $A$. platanoides or $T$. cordata emerge as well-suited potential components of future more drought-tolerant production forests. 
Acknowledgements: We gratefully acknowledge the financial support granted by the Bundesministerium für Ernährung und Landwirtschaft (Germany), Bundesministerium für Umwelt, Naturschutz und nukleare Sicherheit (Germany) and the Fachagentur Nachwachsende Rohstoffe e. V. (Germany) within the frame of the "Waldklimafonds" (project DIVforCLIM). Additionally, we thank the local forestry authorities of Lower Saxony and Saxony-Anhalt and the DBU-Naturerbe $\mathrm{GmbH}$ for permissions to conduct the study, and the Nordwestdeutsche Forstliche Versuchsanstalt for kindly providing forest inventory data for the identification of suitable study sites. Special thanks go to Hannah Korp, Ana Sapoznikowa, Greta Weithmann and Leonhard Klinck for their skillful support in lab and field work. 


\subsection{Appendix A}

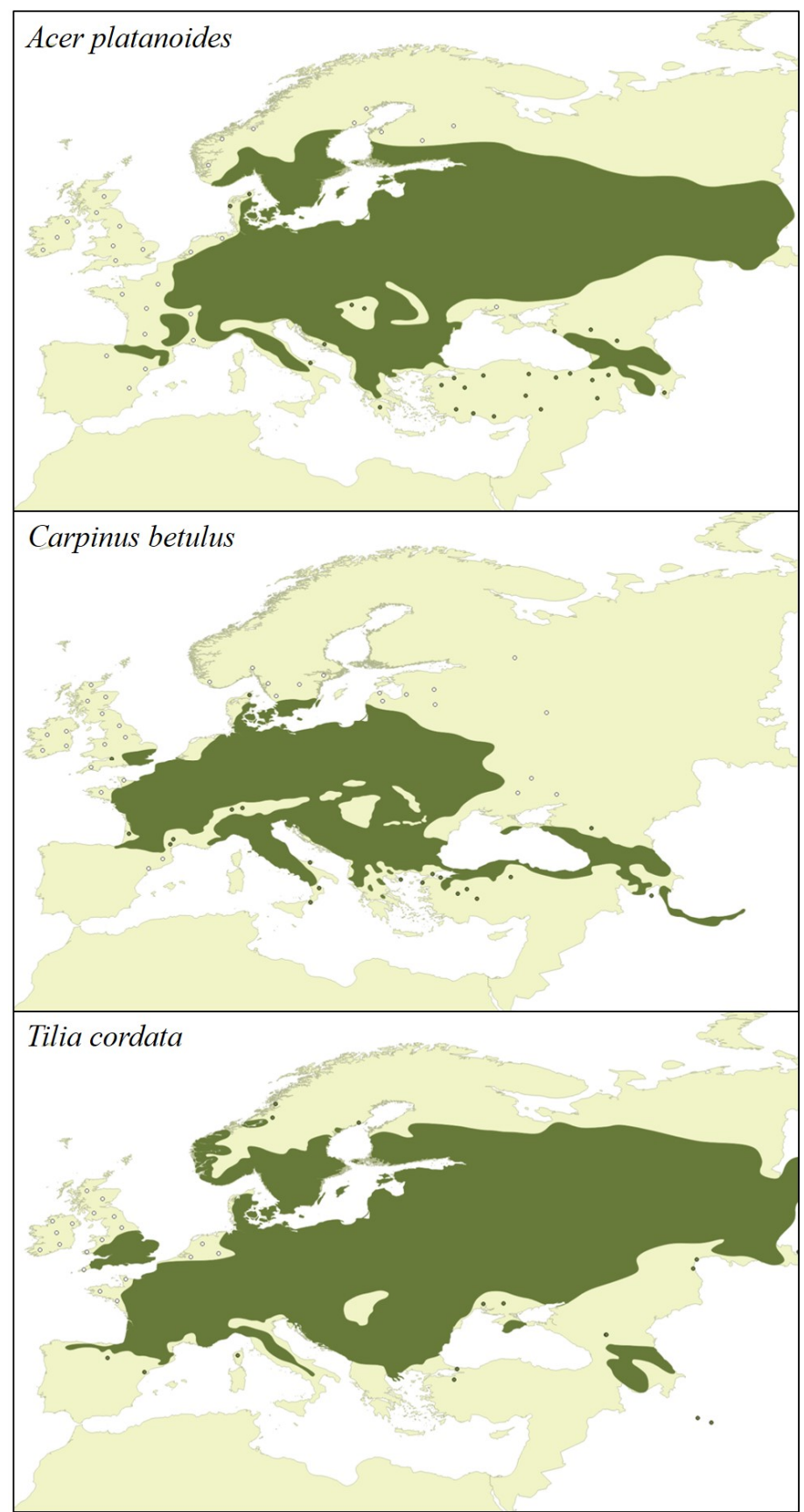

Figure 2.5: Distribution ranges of the three minor timber species (Acer platanoides, Carpinus betulus, and Tilia cordata) based on the synthetic chorology database of Caudullo et al. (2017). 


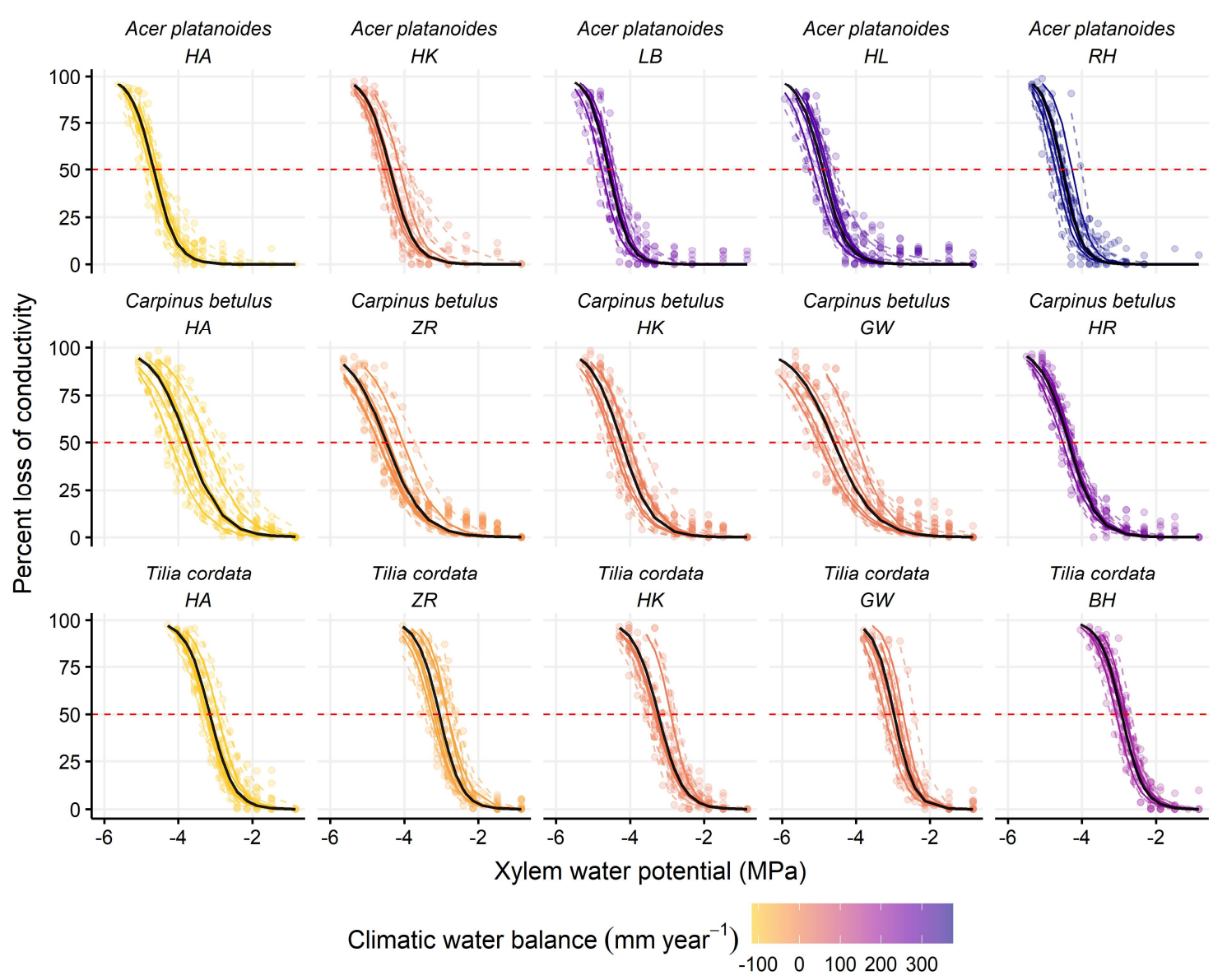

Figure 2.6: Xylem vulnerability curves illustrating percent loss of conductivity vs. xylem water potential. Plotted lines represent conditional predictions for single branches (colored, dotted), single trees (colored), and sites (black) based on species-wise non-linear mixed-effects models (pointsymmetrically, sigmoidal). 

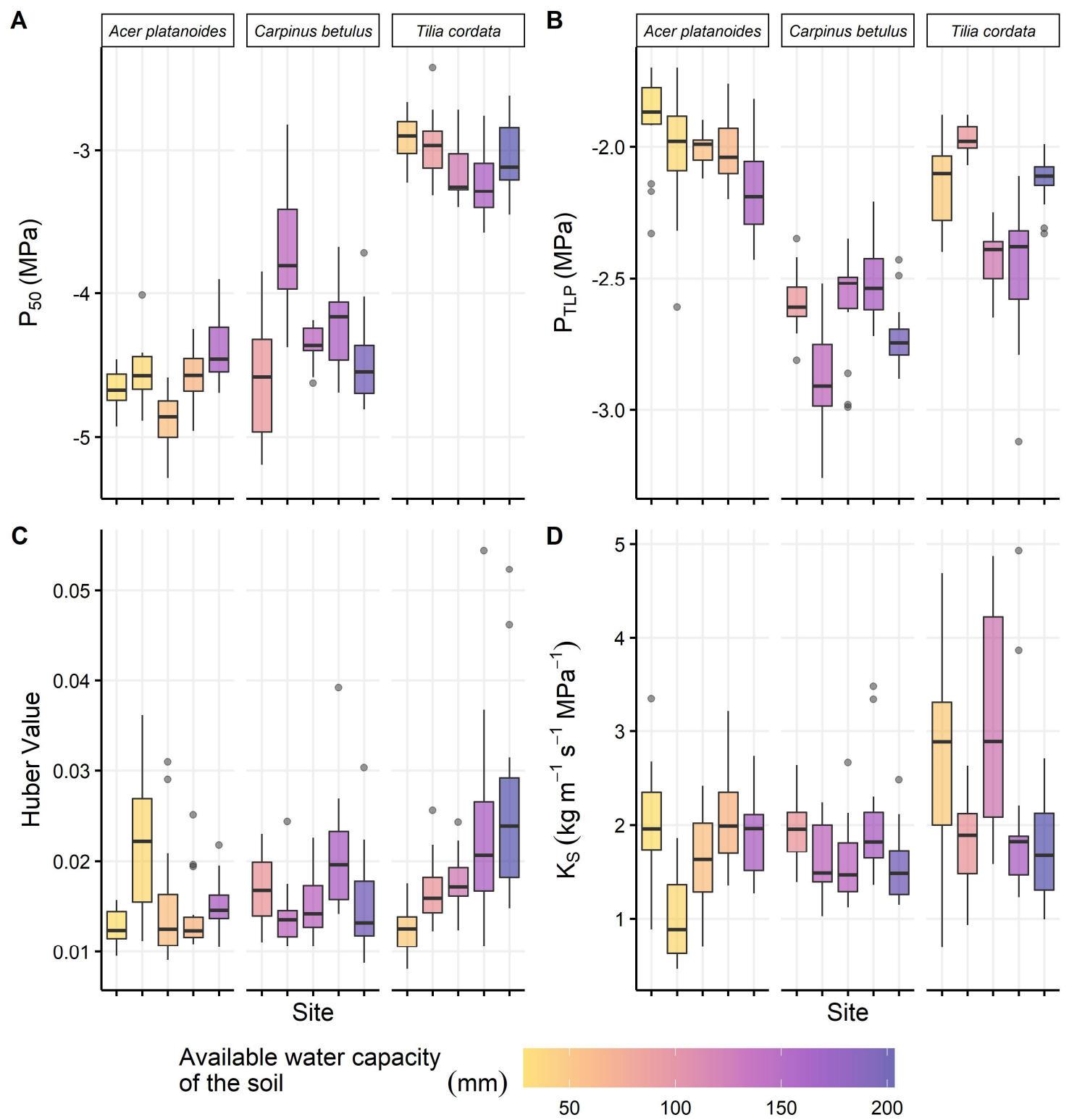

Figure 2.7: (A) Xylem water potential at $50 \%$ loss of conductivity $\left(P_{50}\right),(\mathrm{B})$ leaf water potential at turgor loss point ( $\left.P_{\mathrm{TLP}}\right),(\mathrm{C}) A_{\mathrm{Xylem}} / A_{\text {Leaves }}$-ratio of branches (Huber value), and (D) xylem area-specific hydraulic conductivity of branches $\left(K_{\mathrm{S}}\right)$ of the three tree species on all study sites. Sites are given in ascending order of plant-available water capacity of the soil. Box-whisker plots include median and interquartile ranges (Q1-Q3); whiskers extend to 1.5 times the interquartile range. 


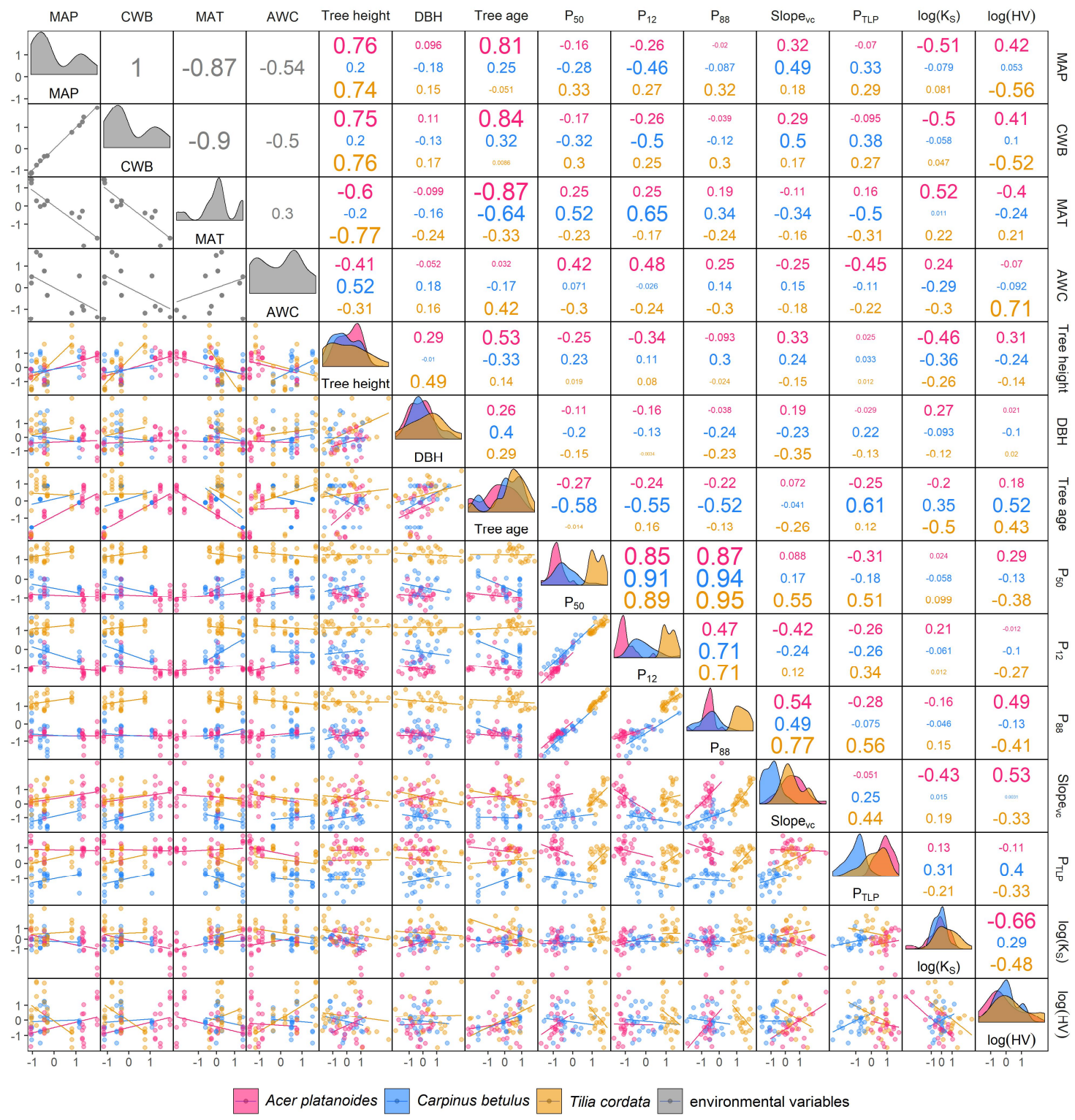

Figure 2.8: Pearson correlation matrix of environmental and tree-specific predictors and functional traits. Given are Pearson correlation coefficients per species in the top right triangle and the corresponding data in the lower left triangle. MAP = mean annual precipitation (period 1991-2017); CWB = climatic water balance; $\mathrm{MAT}=$ mean annual temperature; $\mathrm{AWC}=$ plant-available water storage capacity of the soil; $\mathrm{DBH}$ $=$ Stem diameter at breast height; $P_{50} / P_{12} / P_{88}=$ xylem water potential at $50 / 12 / 88 \%$ loss of conductivity; Slope $_{\mathrm{vc}}=$ slope of the vulnerability curve at the inflexion point; $P_{\mathrm{TLP}}=$ leaf water potential at turgor loss point; $K_{\mathrm{S}}=$ xylem area specific hydraulic conductivity of branches; $\mathrm{HV}=$ Huber value $\left(\mathrm{A}_{\text {xylem }} / \mathrm{A}_{\text {Leaves }}\right.$-ratio of branches). $K_{\mathrm{S}}$ and $\mathrm{HV}$ are natural log-transformed, traits measured on branch/leaf-level are means per tree. All variables are scaled by their standard deviation and centered around zero. 


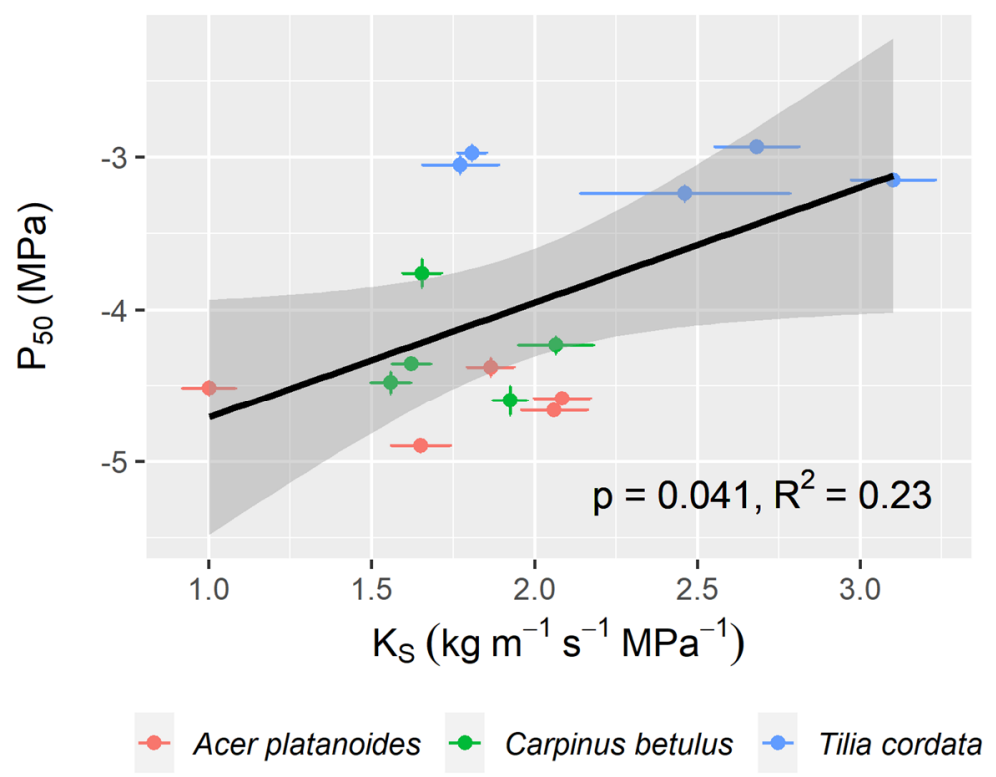

Figure 2.9: Tendency of a hydraulic safety-efficiency trade-off across species between $K_{\mathrm{S}}$ (xylem areaspecific hydraulic conductivity) and $P_{50}$ (xylem water potential at $50 \%$ loss of conductivity). Shown are mean values per site and species with standard errors and $\mathrm{p}$-value and $R^{2}$ of a linear regression across all species and sites. 
Table 2.4: Full output table of the linear mixed effects models for the variance decomposition (Fig. 4b). Given are the fixed effect estimates for the intercept (i.e. the Carpinus average), the differences of Acer and Tilia to Carpinus, with their standard errors, estimated degrees of freedom (edf) based on Sattherthwaite's approximation and $P$-values, as well as the estimates of the three variance components (tree level, population level and residual SD).

\begin{tabular}{|c|c|c|c|c|c|}
\hline Variable & Term & Es timate & Std.error & edf & $p$-value \\
\hline \multirow[t]{6}{*}{$\mathrm{P}_{50}$} & Carpinus (Intercept) & -4.284 & 0.103 & 12.0 & $<0.001$ \\
\hline & $\Delta$ Acer & -0.325 & 0.146 & 12.1 & 0.046 \\
\hline & $\Delta$ Tilia & 1.216 & 0.146 & 12.0 & $<0.001$ \\
\hline & Tree SD & 0.232 & & & \\
\hline & Population SD & 0.203 & & & \\
\hline & Residual SD & 0.158 & & & \\
\hline \multirow[t]{6}{*}{$\mathrm{P}_{\mathrm{TLP}}$} & Carpinus (Intercept) & -2.655 & 0.070 & 12.0 & $<0.001$ \\
\hline & $\Delta$ Acer & 0.634 & 0.099 & 12.0 & $<0.001$ \\
\hline & $\Delta$ Tilia & 0.423 & 0.099 & 12.0 & 0.001 \\
\hline & Tree SD & 0.144 & & & \\
\hline & Population SD & 0.141 & & & \\
\hline & Residual SD & 0.096 & & & \\
\hline \multirow[t]{6}{*}{ HV } & Carpinus (Intercept) & -4.143 & 0.094 & 11.9 & $<0.001$ \\
\hline & $\Delta$ Acer & -0.058 & 0.132 & 11.9 & 0.669 \\
\hline & $\Delta$ Tilia & 0.116 & 0.133 & 12.0 & 0.397 \\
\hline & Tree SD & 0.172 & & & \\
\hline & Population SD & 0.185 & & & \\
\hline & Residual SD & 0.235 & & & \\
\hline \multirow[t]{6}{*}{$\mathrm{K}_{\mathrm{S}}$} & Carpinus (Intercept) & 0.532 & 0.108 & 12.0 & $<0.001$ \\
\hline & $\Delta$ Acer & -0.065 & 0.153 & 12.0 & 0.679 \\
\hline & $\Delta$ Tilia & 0.212 & 0.153 & 12.1 & 0.191 \\
\hline & Tree SD & 0.150 & & & \\
\hline & Population SD & 0.219 & & & \\
\hline & Residual SD & 0.290 & & & \\
\hline
\end{tabular}

Table 2.5 (next page): Full output table of the linear mixed effects models examining the relationships between environmental variables and functional traits (corresponds to Table 2.3). Given are the scaled estimates for CWB (climatic water balance) and AWC (plant-available water storage capacity of the soil), the standard errors of the estimates (SE), the estimated degrees of freedom (DF) based on Sattherthwaite's approximation, $P$-values, and lower and upper border of likelihood-profile-based confidence intervals (CI low and CI high). 


\begin{tabular}{|c|c|c|c|c|c|c|c|c|c|}
\hline Spe cies & Variable & Effect & Term & Estimate & SE & DF & P-value & CI low & CI high \\
\hline \multirow{20}{*}{ 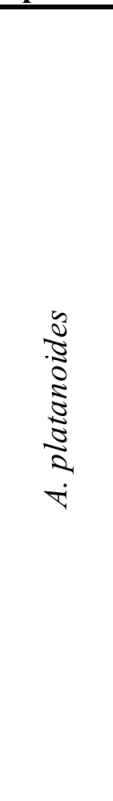 } & $\mathrm{P}_{50}$ & fixed & (Intercept) & 0.029 & 0.173 & 21.60 & 0.870 & -0.30 & 0.36 \\
\hline & $\mathrm{P}_{50}$ & fixed & CWB & -0.054 & 0.182 & 21.58 & 0.768 & -0.40 & 0.29 \\
\hline & $\mathrm{P}_{50}$ & fixed & $\mathrm{AWC}$ & 0.374 & 0.182 & 21.46 & 0.053 & 0.03 & 0.72 \\
\hline & $\mathrm{P}_{50}$ & random (tree) & SD_intercept & 0.810 & & & & 0.54 & 1.06 \\
\hline & $\mathrm{P}_{50}$ & random (residual) & SD_observation & 0.529 & & & & 0.44 & 0.66 \\
\hline & $\mathrm{P}_{\mathrm{TLP}}$ & fixed & (Intercept) & 0.000 & 0.160 & 22.00 & 1.000 & -0.31 & 0.31 \\
\hline & $\mathrm{P}_{\mathrm{TLP}}$ & fixed & CWB & -0.214 & 0.168 & 22.00 & 0.215 & -0.53 & 0.11 \\
\hline & $\mathrm{P}_{\mathrm{TLP}}$ & fixed & $\mathrm{AWC}$ & -0.460 & 0.168 & 22.00 & 0.012 & -0.78 & -0.14 \\
\hline & $\mathrm{P}_{\mathrm{TLP}}$ & random (tree) & SD_intercept & 0.724 & & & & 0.47 & 0.96 \\
\hline & $\mathrm{P}_{\mathrm{TLP}}$ & random (residual) & SD_observation & 0.584 & & & & 0.49 & 0.72 \\
\hline & $\mathrm{HV}$ & fixed & (Intercept) & 0.000 & 0.162 & 22.00 & 1.000 & -0.31 & 0.31 \\
\hline & $\mathrm{HV}$ & fixed & CWB & 0.343 & 0.170 & 22.00 & 0.056 & 0.02 & 0.67 \\
\hline & HV & fixed & AWC & 0.049 & 0.170 & 22.00 & 0.773 & -0.27 & 0.37 \\
\hline & $\mathrm{HV}$ & random (tree) & SD_intercept & 0.708 & & & & 0.43 & 0.95 \\
\hline & $\mathrm{HV}$ & random (residual) & SD_observation & 0.674 & & & & 0.56 & 0.83 \\
\hline & $\mathrm{K}_{\mathrm{S}}$ & fixed & (Intercept) & 0.000 & 0.155 & 22.00 & 1.000 & -0.30 & 0.30 \\
\hline & $\mathrm{K}_{\mathrm{S}}$ & fixed & CWB & -0.402 & 0.163 & 22.00 & 0.022 & -0.71 & -0.09 \\
\hline & $\mathrm{K}_{\mathrm{S}}$ & fixed & AWC & 0.103 & 0.163 & 22.00 & 0.536 & -0.21 & 0.41 \\
\hline & $\mathrm{K}_{\mathrm{S}}$ & random (tree) & SD_intercept & 0.685 & & & & 0.42 & 0.92 \\
\hline & $\mathrm{K}_{\mathrm{S}}$ & random (residual) & SD_observation & 0.629 & & & & 0.52 & 0.78 \\
\hline \multirow{20}{*}{ 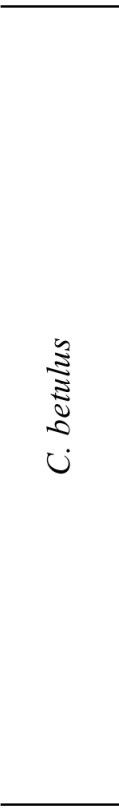 } & $\mathrm{P}_{50}$ & fixed & (Intercept) & -0.061 & 0.177 & 22.22 & 0.734 & -0.40 & 0.28 \\
\hline & $\mathrm{P}_{50}$ & fixed & CWB & -0.278 & 0.179 & 22.22 & 0.135 & -0.62 & 0.06 \\
\hline & $\mathrm{P}_{50}$ & fixed & AWC & 0.035 & 0.176 & 22.29 & 0.843 & -0.30 & 0.37 \\
\hline & $\mathrm{P}_{50}$ & random (tree) & SD_intercept & 0.854 & & & & 0.60 & 1.10 \\
\hline & $\mathrm{P}_{50}$ & random (residual) & SD_observation & 0.396 & & & & 0.33 & 0.48 \\
\hline & $\mathrm{P}_{\mathrm{TLP}}$ & fixed & (Intercept) & 0.011 & 0.182 & 21.94 & 0.953 & -0.34 & 0.36 \\
\hline & $\mathrm{P}_{\mathrm{TLP}}$ & fixed & CWB & 0.347 & 0.184 & 21.88 & 0.072 & 0.00 & 0.70 \\
\hline & $\mathrm{P}_{\mathrm{TLP}}$ & fixed & AWC & -0.074 & 0.184 & 22.02 & 0.692 & -0.43 & 0.28 \\
\hline & $\mathrm{P}_{\mathrm{TLP}}$ & random (tree) & SD_intercept & 0.870 & & & & 0.61 & 1.13 \\
\hline & $P_{\mathrm{TLP}}$ & random (residual) & SD_observation & 0.445 & & & & 0.37 & 0.55 \\
\hline & $\mathrm{HV}$ & fixed & (Intercept) & 0.007 & 0.150 & 21.59 & 0.962 & -0.28 & 0.29 \\
\hline & HV & fixed & CWB & 0.054 & 0.152 & 21.34 & 0.727 & -0.24 & 0.34 \\
\hline & HV & fixed & AWC & -0.078 & 0.152 & 21.35 & 0.611 & -0.37 & 0.21 \\
\hline & $\mathrm{HV}$ & random (tree) & SD_intercept & 0.565 & & & & 0.09 & 0.82 \\
\hline & HV & random (residual) & SD_observation & 0.853 & & & & 0.71 & 1.06 \\
\hline & $\mathrm{K}_{\mathrm{S}}$ & fixed & (Intercept) & 0.011 & 0.147 & 20.42 & 0.939 & -0.27 & 0.29 \\
\hline & $\mathrm{K}_{\mathrm{S}}$ & fixed & CWB & -0.072 & 0.148 & 20.17 & 0.633 & -0.35 & 0.21 \\
\hline & $\mathrm{K}_{\mathrm{S}}$ & fixed & $\mathrm{AWC}$ & -0.241 & 0.148 & 20.19 & 0.118 & -0.52 & 0.04 \\
\hline & $\mathrm{K}_{\mathrm{S}}$ & random (tree) & SD_intercept & 0.548 & & & & 0.00 & 0.81 \\
\hline & $\mathrm{K}_{\mathrm{S}}$ & random (residual) & SD_observation & 0.836 & & & & 0.69 & 1.04 \\
\hline \multirow{20}{*}{ 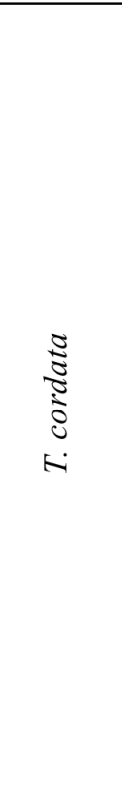 } & $\mathrm{P}_{50}$ & fixed & (Intercept) & -0.026 & 0.177 & 22.10 & 0.887 & -0.36 & 0.31 \\
\hline & $\mathrm{P}_{50}$ & fixed & CWB & 0.165 & 0.248 & 22.18 & 0.513 & -0.31 & 0.64 \\
\hline & $\mathrm{P}_{50}$ & fixed & AWC & -0.144 & 0.252 & 21.95 & 0.574 & -0.63 & 0.34 \\
\hline & $\mathrm{P}_{50}$ & random (tree) & SD_intercept & 0.822 & & & & 0.55 & 1.08 \\
\hline & $\mathrm{P}_{50}$ & random (residual) & SD_observation & 0.559 & & & & 0.46 & 0.69 \\
\hline & $\mathrm{P}_{\mathrm{TLP}}$ & fixed & (Intercept) & -0.023 & 0.197 & 21.90 & 0.909 & -0.40 & 0.35 \\
\hline & $\mathrm{P}_{\mathrm{TLP}}$ & fixed & CWB & 0.237 & 0.282 & 21.87 & 0.409 & -0.30 & 0.78 \\
\hline & $\mathrm{P}_{\mathrm{TLP}}$ & fixed & AWC & -0.040 & 0.282 & 21.89 & 0.887 & -0.58 & 0.50 \\
\hline & $\mathrm{P}_{\mathrm{TLP}}$ & random (tree) & SD_intercept & 0.963 & & & & 0.68 & 1.24 \\
\hline & $\mathrm{P}_{\mathrm{TLP}}$ & random (residual) & SD_observation & 0.365 & & & & 0.30 & 0.45 \\
\hline & $\mathrm{HV}$ & fixed & (Intercept) & -0.034 & 0.128 & 22.27 & 0.793 & -0.28 & 0.21 \\
\hline & HV & fixed & CWB & -0.027 & 0.183 & 22.48 & 0.884 & -0.38 & 0.32 \\
\hline & HV & fixed & AWC & 0.604 & 0.181 & 21.78 & 0.003 & 0.26 & 0.95 \\
\hline & $\mathrm{HV}$ & random (tree) & SD_intercept & 0.511 & & & & 0.23 & 0.72 \\
\hline & $\mathrm{HV}$ & random (residual) & SD_observation & 0.631 & & & & 0.52 & 0.79 \\
\hline & $\mathrm{K}_{\mathrm{S}}$ & fixed & (Intercept) & 0.015 & 0.136 & 19.89 & 0.915 & -0.24 & 0.28 \\
\hline & $\mathrm{K}_{\mathrm{S}}$ & fixed & CWB & -0.315 & 0.195 & 20.29 & 0.122 & -0.69 & 0.06 \\
\hline & $\mathrm{K}_{\mathrm{S}}$ & fixed & AWC & -0.437 & 0.193 & 19.27 & 0.035 & -0.80 & -0.07 \\
\hline & $\mathrm{K}_{\mathrm{S}}$ & random (tree) & SD_intercept & 0.437 & & & & 0.00 & 0.71 \\
\hline & $\mathrm{K}_{\mathrm{S}}$ & random (residual) & SD_observation & 0.867 & & & & 0.71 & 1.09 \\
\hline
\end{tabular}




\subsection{References}

Adams, H.D., Williams, A.P., Xu, C., Rauscher, S.A., Jiang, X., McDowell, N.G., 2013. Empirical and process-based approaches to climate-induced forest mortality models. Front. Plant Sci. 4, 438. https://doi.org/10.3389/fpls.2013.00438.

Adams, H.D., Zeppel, M.J.B., Anderegg, W.R.L., Hartmann, H., Landhäusser, S.M., Tissue, D.T. et al, 2017. A multi-species synthesis of physiological mechanisms in drought-induced tree mortality. Nat. Ecol. Evol. 1, 1285-1291. https://doi.org/10.1038/s41559-017-0248-x.

Altunkaynak, B., Gamgam, H., 2019. Bootstrap confidence intervals for the coefficient of quartile variation. Commun. Stat. - Simul. Comput. 48, 2138-2146. https://doi.org/10.1080/03610918.2018.1435800.

Ambrose, A.R., Sillett, S.C., Dawson, T.E., 2009. Effects of tree height on branch hydraulics, leaf structure and gas exchange in California redwoods. Plant Cell Environ. 32, 743-757. https://doi.org/10.1111/j.1365-3040.2009.01950.x.

Anderegg, W.R.L., 2015. Spatial and temporal variation in plant hydraulic traits and their relevance for climate change impacts on vegetation. New Phytol. 205, 10081014. https://doi.org/10.1111/nph.12907.

Anderegg, W.R.L., Klein, T., Bartlett, M., Sack, L., Pellegrini, A.F.A., Choat, B. et al, 2016. Meta-analysis reveals that hydraulic traits explain cross-species patterns of drought-induced tree mortality across the globe. PNAS 113, 5024-5029. https://doi.org/10.1073/pnas.1525678113.

Anderegg, W.R.L., Meinzer, F.C., 2015. Wood Anatomy and Plant Hydraulics in a Changing Climate, in: Hacke, U.G. (Ed.), Functional and Ecological Xylem Anatomy. Springer International Publishing, Cham, pp. 235-253.

Arend, M., Link, R.M., Patthey, R., Hoch, G., Schuldt, B., Kahmen, A., 2021. Rapid hydraulic collapse as cause of drought-induced mortality in conifers. PNAS 118. https://doi.org/10.1073/pnas.2025251118.

Bartlett, M.K., Klein, T., Jansen, S., Choat, B., Sack, L., 2016. The correlations and sequence of plant stomatal, hydraulic, and wilting responses to drought. PNAS 113, 13098-13103. https://doi.org/10.1073/pnas.1604088113.

Bartlett, M.K., Scoffoni, C., Ardy, R., Zhang, Y., Sun, S., Cao, K. et al, 2012a. Rapid determination of comparative drought tolerance traits: using an osmometer to predict turgor loss point. Methods Ecol. Evol. 3, 880-888. https://doi.org/10.1111/j.2041210X.2012.00230.x.

Bartlett, M.K., Scoffoni, C., Sack, L., 2012b. The determinants of leaf turgor loss point and prediction of drought tolerance of species and biomes: a global meta-analysis. Ecol. Lett. 15, 393-405. https://doi.org/10.1111/j.1461-0248.2012.01751.x.

Bates, D., Mächler, M., Bolker, B., Walker, S., 2015. Fitting Linear Mixed-Effects Models Using lme4. J. Stat. Soft. 67. https://doi.org/10.18637/jss.v067.i01.

Braun, S., Witte, L.C. de, Hopf, S.E., 2020. Auswirkungen des Trockensommers 2018 auf Flächen der Interkantonalen Walddauerbeobachtung. Schweiz. Z. Forstwes. 171, 270-280. https://doi.org/10.3188/szf.2020.0270. 
Breshears, D.D., Carroll, C.J.W., Redmond, M.D., Wion, A.P., Allen, C.D., Cobb, N.S. et al, 2018. A Dirty Dozen Ways to Die: Metrics and Modifiers of Mortality Driven by Drought and Warming for a Tree Species. Front. For. Global Change 1, 115014. https://doi.org/10.3389/ffgc.2018.00004.

Burgess, S.S.O., Pittermann, J., Dawson, T.E., 2006. Hydraulic efficiency and safety of branch xylem increases with height in Sequoia sempervirens (D. Don) crowns. Plant Cell Environ. 29, 229-239. https://doi.org/10.1111/j.1365-3040.2005.01415.x.

Canchola, J.A., Tang, S., Hemyari, P., Paxinos, E., Marins, E., 2017. Correct Use of Percent Coefficient of Variation (\%CV) Formula for Log-Transformed Data. MOJPB 6. https://doi.org/10.15406/mojpb.2017.06.00200.

Choat, B., 2013. Predicting thresholds of drought-induced mortality in woody plant species. Tree Physiol. 33, 669-671. https://doi.org/10.1093/treephys/tpt046.

Choat, B., Brodribb, T.J., Brodersen, C.R., Duursma, R.A., López, R., Medlyn, B.E., 2018. Triggers of tree mortality under drought. Nature 558, 531-539. https://doi.org/10.1038/s41586-018-0240-X.

Choat, B., Jansen, S., Brodribb, T.J., Cochard, H., Delzon, S., Bhaskar, R. et al, 2012. Global convergence in the vulnerability of forests to drought. Nature 491, 752-755. https://doi.org/10.1038/nature11688.

Cochard, H., Damour, G., Bodet, C., Tharwat, I., Poirier, M., Améglio, T., 2005. Evaluation of a new centrifuge technique for rapid generation of xylem vulnerability curves. Physiol. Plant. 124, 410-418. https://doi.org/10.1111/j.13993054.2005.00526.x.

Cornwell, W.K., Bhaskar, R., Sack, L., Cordell, S., Lunch, C.K., 2007. Adjustment of structure and function of Hawaiian Metrosideros polymorpha at high vs. low precipitation. Funct. Ecol. 21, 1063-1071. https://doi.org/10.1111/j.13652435.2007.01323.x.

Correia, D.L.P., Bouchard, M., Filotas, É., Raulier, F., 2019. Disentangling the effect of drought on stand mortality and productivity in northern temperate and boreal forests. J. Appl. Ecol. 56, 758-768. https://doi.org/10.1111/1365-2664.13305.

Dietrich, L., Delzon, S., Hoch, G., Kahmen, A., 2018. No role for xylem embolism or carbohydrate shortage in temperate trees during the severe 2015 drought. J. Ecol. 107, 334-349. https://doi.org/10.1111/1365-2745.13051.

Durner, W., Iden, S.C., Unold, G. von, 2017. The integral suspension pressure method (ISP) for precise particle-size analysis by gravitational sedimentation. Water Resour. Res. 53, 33-48. https://doi.org/10.1002/2016WR019830.

Ellenberg, H., Weber, H.E., Düll, R., Wirth, V., Werner, W., 2001. Zeigerwerte von Pflanzen in Mitteleuropa, 3rd edition. Erich Goltze GmbH \& Co KG, Göttingen. Scripta geobotanica Volume 18.

Farmer, J.B., 1918. On the quantitative differences in the water-conductivity of the wood in trees and shrubs. Part I. -The evergreens. Proc. R. Soc. Lond. B. 90, 218 232. https://doi.org/10.1098/rspb.1918.0012.

Farrell, C., Szota, C., Arndt, S.K., 2017. Does the turgor loss point characterize drought response in dryland plants? Plant Cell Environ. 40, 1500-1511. https://doi.org/10.1111/pce.12948. 
Flatt, T., 2005. The evolutionary genetics of canalization. Q. Rev. Biol. 80, 287-316. https://doi.org/10.1086/432265.

Gleason, S.M., Butler, D.W., Waryszak, P., 2013. Shifts in Leaf and Stem Hydraulic Traits across Aridity Gradients in Eastern Australia. Int. J. Plant Sci. 174, 12921301. https://doi.org/10.1086/673239.

Gleason, S.M., Westoby, M., Jansen, S., Choat, B., Hacke, U.G., Pratt, R.B. et al, 2016. Weak tradeoff between xylem safety and xylem-specific hydraulic efficiency across the world's woody plant species. New Phytol. 209, 123-136. https://doi.org/10.1111/nph.13646.

González-Muñoz, N., Sterck, F., Torres-Ruiz, J.M., Petit, G., Cochard, H., Arx, G. von et al, 2018. Quantifying in situ phenotypic variability in the hydraulic properties of four tree species across their distribution range in Europe. PloS one 13, e0196075. https://doi.org/10.1371/journal.pone.0196075.

Hajek, P., Kurjak, D., Wühlisch, G. von, Delzon, S., Schuldt, B., 2016. Intraspecific Variation in Wood Anatomical, Hydraulic, and Foliar Traits in Ten European Beech Provenances Differing in Growth Yield. Front. Plant Sci. 7, 791. https://doi.org/10.3389/fpls.2016.00791.

Hajek, P., Leuschner, C., Hertel, D., Delzon, S., Schuldt, B., 2014. Trade-offs between xylem hydraulic properties, wood anatomy and yield in Populus. Tree Physiol. 34, 744-756. https://doi.org/10.1093/treephys/tpu048.

Hartmann, H., Link, R.M., Schuldt, B., 2021. A whole-plant perspective of isohydry: stem-level support for leaf-level plant water regulation. Tree Physiol. 41, 901-905. https://doi.org/10.1093/treephys/tpab011.

Hember, R.A., Kurz, W.A., Coops, N.C., 2017. Relationships between individual-tree mortality and water-balance variables indicate positive trends in water stress-induced tree mortality across North America. Global Change Biol. 23, 1691-1710. https://doi.org/10.1111/gcb.13428.

Herbette, S., Wortemann, R., Awad, H., Huc, R., Cochard, H., Barigah, T.S., 2010. Insights into xylem vulnerability to cavitation in Fagus sylvatica L.: phenotypic and environmental sources of variability. Tree Physiol. 30, 1448-1455. https://doi.org/10.1093/treephys/tpq079.

Huber, B., 1928. Weitere quantitative Untersuchungen über das Wasserleitungssystem der Pflanzen. Jahrbücher für wissenschaftliche Botanik 67, 877-959.

Hultine, K.R., Koepke, D.F., Pockman, W.T., Fravolini, A., Sperry, J.S., Williams, D.G., 2006. Influence of soil texture on hydraulic properties and water relations of a dominant warm-desert phreatophyte. Tree Physiol. 26, 313-323. https://doi.org/10.1093/treephys/26.3.313.

Köcher, P., Horna, V., Leuschner, C., 2013. Stem water storage in five coexisting temperate broad-leaved tree species: significance, temporal dynamics and dependence on tree functional traits. Tree Physiol. 33, 817-832. https://doi.org/10.1093/treephys/tpt055.

Lamy, J.-B., Delzon, S., Bouche, P.S., Alia, R., Vendramin, G.G., Cochard, H. et al, 2014. Limited genetic variability and phenotypic plasticity detected for cavitation resistance in a Mediterranean pine. New Phytol. 201, 874-886. https://doi.org/10.1111/nph.12556. 
Larter, M., Pfautsch, S., Domec, J.-C., Trueba, S., Nagalingum, N., Delzon, S., 2017. Aridity drove the evolution of extreme embolism resistance and the radiation of conifer genus Callitris. New Phytol. 215, 97-112. https://doi.org/10.1111/nph.14545.

Lemoine, D., Cochard, H., Granier, A., 2002. Within crown variation in hydraulic architecture in beech (Fagus sylvatica L): evidence for a stomatal control of xylem embolism. Ann. For. Sci. 59, 19-27. https://doi.org/10.1051/forest:2001002.

Lens, F., Sperry, J.S., Christman, M.A., Choat, B., Rabaey, D., Jansen, S., 2011. Testing hypotheses that link wood anatomy to cavitation resistance and hydraulic conductivity in the genus Acer. New Phytol. 190, 709-723. https://doi.org/10.1111/j.1469-8137.2010.03518.x.

Lenth R, 2020. emmeans: Estimated Marginal Means, aka Least-Squares Means. https://CRAN.R-project.org/package=emmeans (accessed 10 August 2020).

Lenz, T.I., Wright, I.J., Westoby, M., 2006. Interrelations among pressure-volume curve traits across species and water availability gradients. Physiol. Plant. 127, 423-433. https://doi.org/10.1111/j.1399-3054.2006.00680.x.

Leuschner, C., 2020, in press. Drought response of European beech (Fagus sylvatica L.) - a review. Perspect. Plant Ecol. Evol. Syst. 47, 125576. https://doi.org/10.1016/j.ppees.2020.125576.

Leuschner, C., Ellenberg, H., 2017. Ecology of Central European Forests. Springer Nature, Cham.

Leuschner, C., Meier, I.C., 2018. The ecology of Central European tree species: Trait spectra, functional trade-offs, and ecological classification of adult trees. Perspect. Plant Ecol. Evol. Syst. 33, 89-103. https://doi.org/10.1016/j.ppees.2018.05.003.

Leuschner, C., Wedde, P., Lübbe, T., 2019. The relation between pressure-volume curve traits and stomatal regulation of water potential in five temperate broadleaf tree species. Ann. For. Sci. 76, 93. https://doi.org/10.1007/s13595-019-0838-7.

Lévesque, M., Rigling, A., Bugmann, H., Weber, P., Brang, P., 2014. Growth response of five co-occurring conifers to drought across a wide climatic gradient in Central Europe. Agric. For. Meteorol. 197, 1-12. https://doi.org/10.1016/j.agrformet.2014.06.001.

Li, X., Blackman, C.J., Peters, J.M.R., Choat, B., Rymer, P.D., Medlyn, B.E. et al, 2019. More than iso/anisohydry: Hydroscapes integrate plant water use and drought tolerance traits in 10 eucalypt species from contrasting climates. Funct. Ecol. 33, 1035-1049. https://doi.org/10.1111/1365-2435.13320.

Liang, X., He, P., Liu, H., Zhu, S., Uyehara, I.K., Hou, H. et al, 2019. Precipitation has dominant influences on the variation of plant hydraulics of the native Castanopsis fargesii (Fagaceae) in subtropical China. Agric. For. Meteorol. 271, 83-91. https://doi.org/10.1016/j.agrformet.2019.02.043.

Lobo, A., Torres-Ruiz, J.M., Burlett, R., Lemaire, C., Parise, C., Francioni, C. et al, 2018 b. Assessing inter- and intraspecific variability of xylem vulnerability to embolism in oaks. For. Ecol. Manage. 424, 53-61. https://doi.org/10.1016/j.foreco.2018.04.031.

Löpmeier, F.J., 1994. Berechnung der Bodenfeuchte und Verdunstung mittels agrarmeteorologischer Modelle. Zeitschrift f. Bewässerungswirtschaft 29, 157-167. 
Maherali, H., Pockman, W.T., Jackson, R.B., 2004. Adaptive Variation in the Vulnerability of Woody Plants to Xylem Cavitation. Ecology 85, 2184-2199. https://doi.org/10.1890/02-0538.

Martínez-Vilalta, J., Cochard, H., Mencuccini, M., Sterck, F., Herrero, A., Korhonen, J.F.J. et al, 2009. Hydraulic adjustment of Scots pine across Europe. New Phytol. 184, 353-364. https://doi.org/10.1111/j.1469-8137.2009.02954.x.

Martin-Stpaul, N.K., Limousin, J.-M., Vogt-Schilb, H., Rodríguez-Calcerrada, J., Rambal, S., Longepierre, D. et al, 2013. The temporal response to drought in a Mediterranean evergreen tree: comparing a regional precipitation gradient and a throughfall exclusion experiment. Global Change Biol. 19, 2413-2426. https://doi.org/10.1111/gcb.12215.

Martin-StPaul, N.K., Delzon, S., Cochard, H., 2017. Plant resistance to drought depends on timely stomatal closure. Ecol. Lett. 20, 1437-1447. https://doi.org/10.1111/ele.12851.

McDowell, N., Pockman, W.T., Allen, C.D., Breshears, D.D., Cobb, N., Kolb, T. et al, 2008. Mechanisms of plant survival and mortality during drought: why do some plants survive while others succumb to drought? New Phytol. 178, 719-739. https://doi.org/10.1111/j.1469-8137.2008.02436.x.

McDowell, N.G., 2011. Mechanisms linking drought, hydraulics, carbon metabolism, and vegetation mortality. Plant Physiol. 155, 1051-1059. https://doi.org/10.1104/pp.110.170704.

Meinzer, F.C., Johnson, D.M., Lachenbruch, B., McCulloh, K.A., Woodruff, D.R., 2009. Xylem hydraulic safety margins in woody plants: coordination of stomatal control of xylem tension with hydraulic capacitance. Funct. Ecol. 23, 922-930. https://doi.org/10.1111/j.1365-2435.2009.01577.x.

Mencuccini, M., 2003. The ecological significance of long-distance water transport: short-term regulation, long-term acclimation and the hydraulic costs of stature across plant life forms. Plant Cell Environ. 26, 163-182. https://doi.org/10.1046/j.13653040.2003.00991.x.

Mencuccini, M., Minunno, F., Salmon, Y., Martínez-Vilalta, J., Hölttä, T., 2015. Coordination of physiological traits involved in drought-induced mortality of woody plants. New Phytol. 208, 396-409. https://doi.org/10.1111/nph.13461.

Mencuccini, M., Rosas, T., Rowland, L., Choat, B., Cornelissen, H., Jansen, S. et al, 2019. Leaf economics and plant hydraulics drive leaf:wood area ratios. New Phytol. 224, 1544-1556. https://doi.org/10.1111/nph.15998.

Mitchell, P., O'Grady, A., 2015. Adaptation of Leaf Water Relations to Climatic and Habitat Water Availability. Forests 6, 2281-2295. https://doi.org/10.3390/f6072281.

Monteith, J.L., 1965. Evaporation and environment. Symp. Soc. Exp. Biol. 19, 205234.

Nakagawa, S., Schielzeth, H., 2013. A general and simple method for obtaining R2 from generalized linear mixed-effects models. Methods Ecol. Evol. 4, 133-142. https://doi.org/10.1111/j.2041-210x.2012.00261.x.

Niinemets, Ü., Valladares, F., 2006. Tolerance to Shade, Drought, and Waterlogging of Temperate Northern Hemisphere Trees and Shrubs. Ecol. Monogr. 76, 521-547. https://doi.org/10.1890/0012-9615(2006)076[0521:TTSDAW]2.0.CO;2. 
Nolan, R.H., Gauthey, A., Losso, A., Medlyn, B.E., Smith, R., Chhajed, S.S. et al, 2021. Hydraulic failure and tree size linked with canopy die-back in eucalypt forest during extreme drought. New Phytol. 230, 1354-1365. https://doi.org/10.1111/nph.17298.

Oppenheimer, H.R., 1963. Zur Kenntnis kritischer Wasser-Sättigungsdefizite in Blättern und Ihrer Bestimmung. Planta 60, 51-69. https://doi.org/10.1007/BF01911232.

Pammenter, N.W., van der Willigen, C., 1998. A mathematical and statistical analysis of the curves illustrating vulnerability of xylem to cavitation. Tree Physiol. 18, 589593. https://doi.org/10.1093/treephys/18.8-9.589.

Penman, H.L., 1948. Natural evaporation from open water, hare soil and grass. Proc. R. Soc. Lond. A Math. Phys. Sci. 193, 120-145. https://doi.org/10.1098/rspa.1948.0037.

Peterman, W., Waring, R.H., Seager, T., Pollock, W.L., 2013. Soil properties affect pinyon pine - juniper response to drought. Ecohydrol. 6, 455-463. https://doi.org/10.1002/eco.1284.

Pinheiro J, Bates D, DebRoy S, Sarkar D, Team RC, 2020. nlme: Linear and Nonlinear Mixed Effects Models. https://CRAN.R-project.org/package=nlme (accessed 1 October 2020).

Powers, J.S., Vargas G, G., Brodribb, T.J., Schwartz, N.B., Pérez-Aviles, D., SmithMartin, C.M. et al, 2020. A catastrophic tropical drought kills hydraulically vulnerable tree species. Global Change Biol. 26, 3122-3133. https://doi.org/10.1111/gcb.15037.

Pritzkow, C., Williamson, V., Szota, C., Trouvé, R., Arndt, S.K., 2020. Phenotypic plasticity and genetic adaptation of functional traits influences intra-specific variation in hydraulic efficiency and safety. Tree Physiol. 40, 215-229. https://doi.org/10.1093/treephys/tpz121.

Rehschuh, R., Mette, T., Menzel, A., Buras, A., 2017. Soil properties affect the drought susceptibility of Norway spruce. Dendrochronologia 45, 81-89. https://doi.org/10.1016/j.dendro.2017.07.003.

Roloff, A., Grundmann, B.M., 2008. Waldbaumarten und ihre Verwendung im Klimawandel. Arch. Forstwes. Landschaftsökol. 42, 97-109.

Roloff, A., Weisgerber, H., Lang, U.M., Stimm, B. (Eds.), 2010. Bäume Mitteleuropas: Von Aspe bis Zirbel-Kiefer, 1. Aufl. Wiley-VCH, Weinheim. Sachbuch.

Rosas, T., Mencuccini, M., Barba, J., Cochard, H., Saura-Mas, S., Martínez-Vilalta, J., 2019. Adjustments and coordination of hydraulic, leaf and stem traits along a water availability gradient. New Phytol. 223, 632-646. https://doi.org/10.1111/nph.15684.

Rowland, L., da Costa, A.C.L., Galbraith, D.R., Oliveira, R.S., Binks, O.J., Oliveira, A.A.R. et al, 2015. Death from drought in tropical forests is triggered by hydraulics not carbon starvation. Nature 528, 119-122. https://doi.org/10.1038/nature15539.

Sanchez-Martinez, P., Martínez-Vilalta, J., Dexter, K.G., Segovia, R.A., Mencuccini, M., 2020. Adaptation and coordinated evolution of plant hydraulic traits. Ecol. Lett. 23, 1599-1610. https://doi.org/10.1111/ele.13584.

Sapes, G., Roskilly, B., Dobrowski, S., Maneta, M., Anderegg, W.R.L., MartinezVilalta, J. et al, 2019. Plant water content integrates hydraulics and carbon depletion to predict drought-induced seedling mortality. Tree Physiol. 39, 1300-1312. https://doi.org/10.1093/treephys/tpz062. 
Schaap, M.G., Leij, F.J., van Genuchten, M.T., 2001. Rosetta: a computer program for estimating soil hydraulic parameters with hierarchical pedotransfer functions. J. Hydrol. 251, 163-176. https://doi.org/10.1016/S0022-1694(01)00466-8.

Schreiber, S.G., Hacke, U.G., Hamann, A., 2015. Variation of xylem vessel diameters across a climate gradient: insight from a reciprocal transplant experiment with a widespread boreal tree. Funct. Ecol. 29, 1392-1401. https://doi.org/10.1111/13652435.12455.

Schuldt, B., Buras, A., Arend, M., Vitasse, Y., Beierkuhnlein, C., Damm, A. et al, 2020. A first assessment of the impact of the extreme 2018 summer drought on Central European forests. Basic Appl. Ecol. 45, 86-103. https://doi.org/10.1016/j.baae.2020.04.003.

Schuldt, B., Knutzen, F., Delzon, S., Jansen, S., Müller-Haubold, H., Burlett, R. et al, 2016. How adaptable is the hydraulic system of European beech in the face of climate change-related precipitation reduction? New Phytol. 210, 443-458. https://doi.org/10.1111/nph.13798.

Schuldt, B., Leuschner, C., Horna, V., Moser, G., Köhler, M., van Straaten, O. et al, 2011. Change in hydraulic properties and leaf traits in a tall rainforest tree species subjected to long-term throughfall exclusion in the perhumid tropics. Biogeosciences 8, 2179-2194. https://doi.org/10.5194/bg-8-2179-2011.

Schumann, K., Leuschner, C., Schuldt, B., 2019. Xylem hydraulic safety and efficiency in relation to leaf and wood traits in three temperate Acer species differing in habitat preferences. Trees 33, 1475-1490. https://doi.org/10.1007/s00468-019-01874-x.

Sellin, A., Kupper, P., 2004. Within-crown variation in leaf conductance of Norway spruce: effects of irradiance, vapour pressure deficit, leaf water status and plant hydraulic constraints. Ann. For. Sci. 61, 419-429. https://doi.org/10.1051/forest:2004035.

Sellin, A., Sack, L., Õunapuu, E., Karusion, A., 2011. Impact of light quality on leaf and shoot hydraulic properties: a case study in silver birch (Betula pendula). Plant Cell Environ. 34, 1079-1087. https://doi.org/10.1111/j.1365-3040.2011.02306.x.

Senf, C., Sebald, J., Seidl, R., 2020. Increases in canopy mortality and their impact on the demographic structure of Europe's forests. bioRxiv Preprints. https://doi.org/10.1101/2020.03.30.015818.

Skelton, R.P., West, A.G., Dawson, T.E., 2015. Predicting plant vulnerability to drought in biodiverse regions using functional traits. PNAS 112, 5744-5749. https://doi.org/10.1073/pnas.1503376112.

Sperry, J.S., Hacke, U.G., 2002. Desert shrub water relations with respect to soil characteristics and plant functional type. Funct. Ecol. 16, 367-378. https://doi.org/10.1046/j.1365-2435.2002.00628.x.

Sperry, J.S., Hacke, U.G., Wheeler, J.K., 2005. Comparative analysis of end wall resistivity in xylem conduits. Plant Cell Environ. 28, 456-465. https://doi.org/10.1111/j.1365-3040.2005.01287.x.

Sperry, J.S., Meinzer, F.C., McCulloh, K.A., 2008. Safety and efficiency conflicts in hydraulic architecture: scaling from tissues to trees. Plant Cell Environ. 31, 632-645. https://doi.org/10.1111/j.1365-3040.2007.01765.x. 
Sperry, J.S., Tyree, M.T., 1988. Mechanism of water stress-induced xylem embolism. Plant Physiol. 88, 581-587. https://doi.org/10.1104/pp.88.3.581.

Stojnic, S., Suchocka, M., Benito-Garzón, M., Torres-Ruiz, J.M., Cochard, H., Bolte, A. et al, 2018. Variation in xylem vulnerability to embolism in European beech from geographically marginal populations. Tree Physiol. 38, 173-185. https://doi.org/10.1093/treephys/tpx128.

Torres-Ruiz, J.M., Cochard, H., Fonseca, E., Badel, E., Gazarini, L., Vaz, M., 2017. Differences in functional and xylem anatomical features allow Cistus species to cooccur and cope differently with drought in the Mediterranean region. Tree Physiol. 37, 755-766. https://doi.org/10.1093/treephys/tpx013.

Tyree, M.T., Davis, S.D., Cochard, H., 1994. Biophysical Perspectives of Xylem Evolution: is there a Tradeoff of Hydraulic Efficiency for Vulnerability to Dysfunction? IAWA J. 15, 335-360. https://doi.org/10.1163/22941932-90001369.

van der Maaten-Theunissen, M., Kahle, H.-P., van der Maaten, E., 2013. Drought sensitivity of Norway spruce is higher than that of silver fir along an altitudinal gradient in southwestern Germany. Ann. For. Sci. 70, 185-193. https://doi.org/10.1007/s13595-012-0241-0.

van der Willigen, C., Pammenter, N.W., 1998. Relationship between growth and xylem hydraulic characteristics of clones of Eucalyptus spp. at contrasting sites. Tree Physiol. 18, 595-600. https://doi.org/10.1093/treephys/18.8-9.595.

van Genuchten, M.T., 1980. A Closed-form Equation for Predicting the Hydraulic Conductivity of Unsaturated Soils. Soil Sci. Soc. Am. J. 44, 892-898. https://doi.org/10.2136/sssaj1980.03615995004400050002x.

van Genuchten, M.T., Leij, F.J., Yates, S., Williams, J., 1991. The RETC Code for Quantifying Hydraulic Functions of Unsaturated Soils. Environmental Protection Agency EPA/600/2-91/065, Washington, D.C. 83.

Waite, P.-A., Schuldt, B., Mathias Link, R., Breidenbach, N., Triadiati, T., Hennings, N. et al, 2019. Soil moisture regime and palm height influence embolism resistance in oil palm. Tree Physiol. 39, 1696-1712. https://doi.org/10.1093/treephys/tpz061.

Wortemann, R., Herbette, S., Barigah, T.S., Fumanal, B., Alia, R., Ducousso, A. et al, 2011. Genotypic variability and phenotypic plasticity of cavitation resistance in Fagus sylvatica L. across Europe. Tree Physiol. 31, 1175-1182. https://doi.org/10.1093/treephys/tpr101.

Zhu, S.-D., Chen, Y.-J., Ye, Q., He, P.-C., Liu, H., Li, R.-H. et al, 2018. Leaf turgor loss point is correlated with drought tolerance and leaf carbon economics traits. Tree Physiol. 38, 658-663. https://doi.org/10.1093/treephys/tpy013.

Ziegler, C., Coste, S., Stahl, C., Delzon, S., Levionnois, S., Cazal, J. et al, 2019. Large hydraulic safety margins protect Neotropical canopy rainforest tree species against hydraulic failure during drought. Ann. For. Sci. 76, 1285.

https://doi.org/10.1007/s13595-019-0905-0.

Zimmermann, J., Hauck, M., Dulamsuren, C., Leuschner, C., 2015. Climate WarmingRelated Growth Decline Affects Fagus sylvatica, But Not Other Broad-Leaved Tree Species in Central European Mixed Forests. Ecosystems 18, 560-572. https://doi.org/10.1007/s10021-015-9849-x. 


\section{FINE ROOT INVENTORIES}

\section{EFFECTS OF SUMMER DROUGHT ON THE FINE ROOT SYSTEM OF FIVE BROADLEAF TREE SPECIES ALONG A PRECIPITATION GRADIENT}

Published in Forests:

Fuchs, S., Hertel, D., Schuldt, B., Leuschner, C., 2020. Effects of Summer Drought on the Fine Root System of Five Broadleaf Tree Species along a Precipitation Gradient. Forests, 11(3), 289. https://doi.org/10.3390/F11030289.

Sebastian Fuchs ${ }^{1}$, Dietrich Hertel ${ }^{1}$, Bernhard Schuldt ${ }^{1,3}$ and Christoph Leuschner ${ }^{1,2}$

1 Plant Ecology, Albrecht von Haller Institute for Plant Sciences, University of Goettingen, Untere Karspüle 2, 37073 Goettingen, Germany

2 Centre for Biodiversity and Sustainable Land Use (CBL), University of Goettingen, 37075 Goettingen, Germany

3 Present address: Ecophysiology and Vegetation Ecology, Julius-von-Sachs-Institute of Biological Sciences, University of Würzburg, Julius-von-Sachs-Platz, 97082 Würzburg, Germany 


\subsection{Abstract}

While much research has addressed the aboveground response of trees to climate warming and related water shortage, not much is known about the drought sensitivity of the fine root system, in particular of mature trees. This study investigates the response of topsoil $(0-10 \mathrm{~cm})$ fine root biomass (FRB), necromass (FRN), and fine root morphology of five temperate broadleaf tree species (Acer platanoides L., Carpinus betulus L., Fraxinus excelsior L., Quercus petraea (Matt.) Liebl., Tilia cordata Mill.) to a reduction in water availability, combining a precipitation gradient study (nine study sites; mean annual precipitation (MAP): 920-530 $\mathrm{mm} \mathrm{year}^{-1}$ ) with the comparison of a moist period (average spring conditions) and an exceptionally dry period in the summer of the subsequent year. The extent of the root necromass/biomass (N/B) ratio increase was used as a measure of the species' belowground sensitivity to water deficits. We hypothesized that the N/B ratio increases with long-term (precipitation gradient) and short-term reductions (moist vs. dry period) of water availability, while FRB changes only a little. In four of the five species (exception: A. platanoides), FRB did not change with a reduction in MAP, whereas FRN and N/B ratio increased toward the dry sites under ample water supply (exception: $Q$. petraea). Q. petraea was also the only species not to reduce root tip frequency after summer drought. Different slopes of the N/B ratio-MAP relation similarly point at a lower belowground drought sensitivity of $Q$. petraea than of the other species. After summer drought, all species lost the MAP dependence of the N/B ratio. Thus, fine root mortality increased more at the moister than the drier sites, suggesting a generally lower belowground drought sensitivity of the drier stands. We conclude that the five species differ in their belowground drought response. $Q$. petraea follows the most conservative soil exploration strategy with a generally smaller FRB and more droughttolerant fine roots, as it maintains relatively constant FRB, FRN, and morphology across spatial and temporal dimensions of soil water deficits.

Keywords: Acer platanoides; Carpinus betulus; fine root biomass; fine root necromass; Fraxinus excelsior; necromass/biomass ratio; Quercus petraea; root morphology; Tilia cordata; water availability 


\subsection{Introduction}

Tree fine roots (roots $<2 \mathrm{~mm}$ in diameter) play a crucial role in forest ecosystem functioning, even though they represent only a few percent of tree biomass (Jackson et al., 1997; Leuschner and Ellenberg, 2017; Nadelhoffer and Raich, 1992). Fine roots serve as the interface between soil and tree and thus control water and nutrient uptake, they closely interact with mycorrhizal fungi and rhizosphere microbiota, and represent a major source of soil organic carbon (C) (Eissenstat and Yanai, 2002; Rasse et al., 2005). Due to their rapid turnover, it has been estimated that up to a third of the global annual net primary production refers to fine root growth (Jackson et al., 1997). The size, morphology, and turnover rate of the fine root system of trees is dependent on many biotic and abiotic factors. Water availability is a key determinant among the soil factors besides nutrient availability, soil acidity, and temperature (Brunner et al., 2015; Leuschner et al., 2004; Leuschner and Hertel, 2003).

With climate change, forests are exposed to warmer summers and a higher evaporative demand, and, in various regions, reduced and more irregular summer precipitation (IPCC, 2014; Schär et al., 2004), likely exposing trees to increased drought and heat stress. Recent reviews of climate change-related decreases in tree vitality and increasing mortality in many forest regions of the earth have predominantly focused on aboveground tree parts (Allen et al., 2010; Anderegg et al., 2013; Ryan, 2011; Senf et al., 2018), ignoring root responses. This is primarily caused by the fact that the fine root system of mature forests is difficult to observe, and methods are labour-intensive and often quite imprecise (Brunner et al., 2015).

How tree roots and the root system respond to drought is increasingly a matter of debate, but the empirical data basis is quite limited, especially for mature trees. Optimal partitioning theory (OPT) predicts that trees tend to increase their root-to-shoot ratio (R/S) under conditions of limited water availability to increase their absorptive capacity in relation to the transpiring surface (Bloom et al., 1985; Brunner et al., 2015; Reich, 2002). Evidence in support of OPT has been obtained by comparing the R/S of different plant functional types from different biomes (Kozlowski and Pallardy, 2002; Mokany et al., 2006), by analysing the R/S of trees or forests along precipitation gradients (Coomes and Grubb, 2000; Hertel et al., 2008), and by manipulating soil moisture in experiments with tree saplings (Thomas and Gausling, 2000; Tomlinson and Anderson, 1998; van Hees, 1997). Most studies with increases in R/S found a reduction in aboveground biomass (leaf mass or shoot mass), while fine root biomass (FRB) changed only a little, suggesting that 
shoot growth may respond more sensitively to drought than root growth (Kuster et al., 2013). Yet, it is not well understood how the fine root system of trees responds to a decrease in soil water availability, and existing findings are partly contradictory (Brunner et al., 2015; Hertel et al., 2013; Meier and Leuschner, 2008a). Many sapling studies found a decrease in FRB with decreasing soil moisture (Aspelmeier and Leuschner, 2006; Bongarten and Teskey, 1987; Meier and Leuschner, 2008b; Zang et al., 2014), but these responses can hardly be extrapolated to mature trees, and limited rooting space may sometimes have influenced the results. For mature stands, Leuschner and Hertel (2003) found in a meta-analysis of studies from temperate broad-leaved forests no clear trend in FRB in dependence on precipitation. The results of multi-site field studies with a single tree species are inconsistent: Some authors reported a higher FRB at drier sites (Bakker et al., 2006; Hertel et al., 2008; Hertel et al., 2013; Parker and van Lear, 1996), others a higher biomass at moister sites (Chenlemuge et al., 2013; Leuschner et al., 2004; Meier and Leuschner, 2008a; Santantonio and Hermann, 1985). The controversial results are partly explained by differences in species, in the steepness of the precipitation gradient, or in the severity and timing of drought events at the study sites. Moreover, different combinations of growth-related reductions in overall productivity, of shifts in aboveground/belowground carbohydrate partitioning, and of altered root lifespan may lead to opposing root/shoot ratio responses (McCormack and Guo, 2014).

More consistent are the reports about a fine root necromass (FRN) increase or elevated necromass/biomass (N/B) ratios as a consequence of drought exposure (Brunner et al., 2015; Wang et al., 2018), indicating increased fine root mortality. In accordance, (Hertel and Leuschner, 2002) found a large FRN increase in a mature beech forest after a summer drought, while FRB remained constant over the study period. It appears that certain tree species are capable of compensating elevated drought-induced fine root losses through increased production of new fine roots, thereby avoiding reductions in standing FRB. It is not known which species are capable of this response and under which conditions it occurs.

Root mortality reduces the lifespan of fine roots and, when dying roots are replaced by new ones, a reduction in mean fine root age in the root population is the consequence (Eissenstat et al., 2000; McCormack and Guo, 2014). One possible physiological explanation of a shortened fine root lifespan in dry soil is active root shedding, in which fine roots act as 'hydraulic fuses' in the tree's xylem system, uncoupling the rest of the hydraulic system from low water potentials in the dry soil to avoid embolism formation 
in more expensive or irreplaceable plant organs (Alder et al., 1996; Jackson et al., 2000; Rewald, 2008). This could happen when fine roots are indeed more sensitive to cavitation in the xylem than the stem and branches in the canopy. An alternative explanation assumes that younger fine roots, that replace the shed ones, are physiologically more active and therefore can support the tree by extracting more water, which increases fitness (Brunner et al., 2015; Eissenstat et al., 2000). Such a response would also be in agreement with OPT, which predicts a higher investment in the root system. In any case, root mortality will increase the N/B ratio, which must be seen as an integral over the processes of root mortality and the production of new fine roots during the observation period, thus reflecting both the root system's resistance to drought and its resilience after drought. The ratio has therefore been used in several studies and reviews as an indicator of tree and root system vitality under exposure to drought and chemical stress (Leuschner et al., 2004; Persson and Stadenberg, 2010; Puhe, 2003; Wang et al., 2018).

Field studies on the drought response of tree fine root systems usually adopt one of two approaches, either investigating temporal (natural or experimental) variation in soil moisture (Gaul et al., 2008; Leuschner et al., 2001a; Mainiero and Kazda, 2006; Makkonen and Helmisaari, 1998; Teskey and Hinckley, 1981; Tierney et al., 2003), or examining spatial differences in water availability, often along precipitation or soil moisture gradients (Bakker et al., 2006; Hertel et al., 2013; Hertel and Leuschner, 2002; Leuschner et al., 2004; López et al., 1998; Meier and Leuschner, 2008a; Persson and Stadenberg, 2010; Santantonio and Hermann, 1985). In central Europe, such studies focused on the economically most important coniferous and broad-leaved tree genera, i.e., Picea, Pinus, Fagus, and Quercus.

Only little is known about the fine root system of other common tree species that are minor timber species or of no use in current forestry. Small-leaved lime (Tilia cordata Mill.), Norway maple (Acer platanoides L.), European hornbeam (Carpinus betulus L.), and European ash (Fraxinus excelsior L.) may be more drought resistant than European beech and Norway spruce according to their distribution ranges and knowledge of aboveground physiological traits (Hemery et al., 2010; Leuschner and Ellenberg, 2017; Leuschner and Meier, 2018). While these species can be of interest for forestry in a warmer and drier climate in the future, their belowground drought response is unknown. Recent root research in temperate mixed forests with lime, maple, hornbeam, oak, and ash species has focused on species interactions and diversity effects, but drought responses have not been examined (Jacob et al., 2014; Kubisch et al., 2015; Meinen et 
al., 2009). A better understanding of the belowground drought response of these minor timber species is fundamental for predicting the species' performance in a drier climate.

This study investigates the response of the fine root biomass and necromass, and fine root morphology of four secondary tree species (T. cordata, A. platanoides, C. betulus, and $F$. excelsior) to a reduction in water availability, combining a precipitation gradient study with the comparison of a moist and a dry season. The well-studied and relatively drought-resistant sessile oak (Quercus petraea (Matt.) Liebl.) was included in the study for comparison. The sample thus comprised three ECM (ectomycorrhizal; T. cordata, $C$. betulus, $Q$. petraea) and two AM tree species (arbuscular mycorrhizal; A. platanoides, $F$. excelsior), and two ring-porous ( $Q$. petraea, $F$. excelsior) and three diffuse-porous species ( $T$. cordata, C. betulus, A. platanoides), thereby covering a broad range of tree functional types of the European temperate tree flora. Fine root inventories were carried out in the topsoil of nine study sites along a precipitation gradient (mean annual precipitation (MAP): 918-528 $\mathrm{mm} \mathrm{year}^{-1}$ ), comparing data from a moist (spring 2017) and a subsequent dry period (summer 2018). The precipitation gradient covers most of the MAP range encountered by the species at their natural occurrences in northern central Europe.

We expected that the five species differ in their root system response to water deficits and that the sensitivity of belowground and aboveground organs are linked to each other in these species. The extent of the N/B ratio increase was used as a measure of the species' belowground sensitivity to water deficits. Based on the existing knowledge about the drought response of tree fine root systems (Brunner et al., 2015; Hertel et al., 2013; Meier and Leuschner, 2008a), we hypothesized that, in all species, (i), the fine root N/B ratio increases with decreasing mean annual precipitation due to higher root mortality and thus an increase in necromass, while biomass changes only little, (ii) a severe summer drought increases necromass and the N/B ratio, and (iii) the increase in the N/B ratio upon drought is more pronounced at the moister sites, where trees are assumed to be more sensitive to water shortage.

\subsection{Materials and Methods}

\subsubsection{Forest Stands and Tree Species}

Nine study sites were chosen along a transect in central Germany between Göttingen and Halle/S., which represents a steep precipitation gradient in west-east orientation. All sites are in the planar to colline zone (110-440 $\mathrm{m}$ a.s.l.) and have a cool-temperate climate 
with annual mean temperatures of 7.9 to $9.9^{\circ} \mathrm{C}$. Mean annual precipitation (MAP) ranges between 918 and $528 \mathrm{~mm}$ and mean growing season precipitation (MGSP, AprilSeptember) between 291 and $412 \mathrm{~mm}$, with a general decrease from west to east (Figure 3.1).

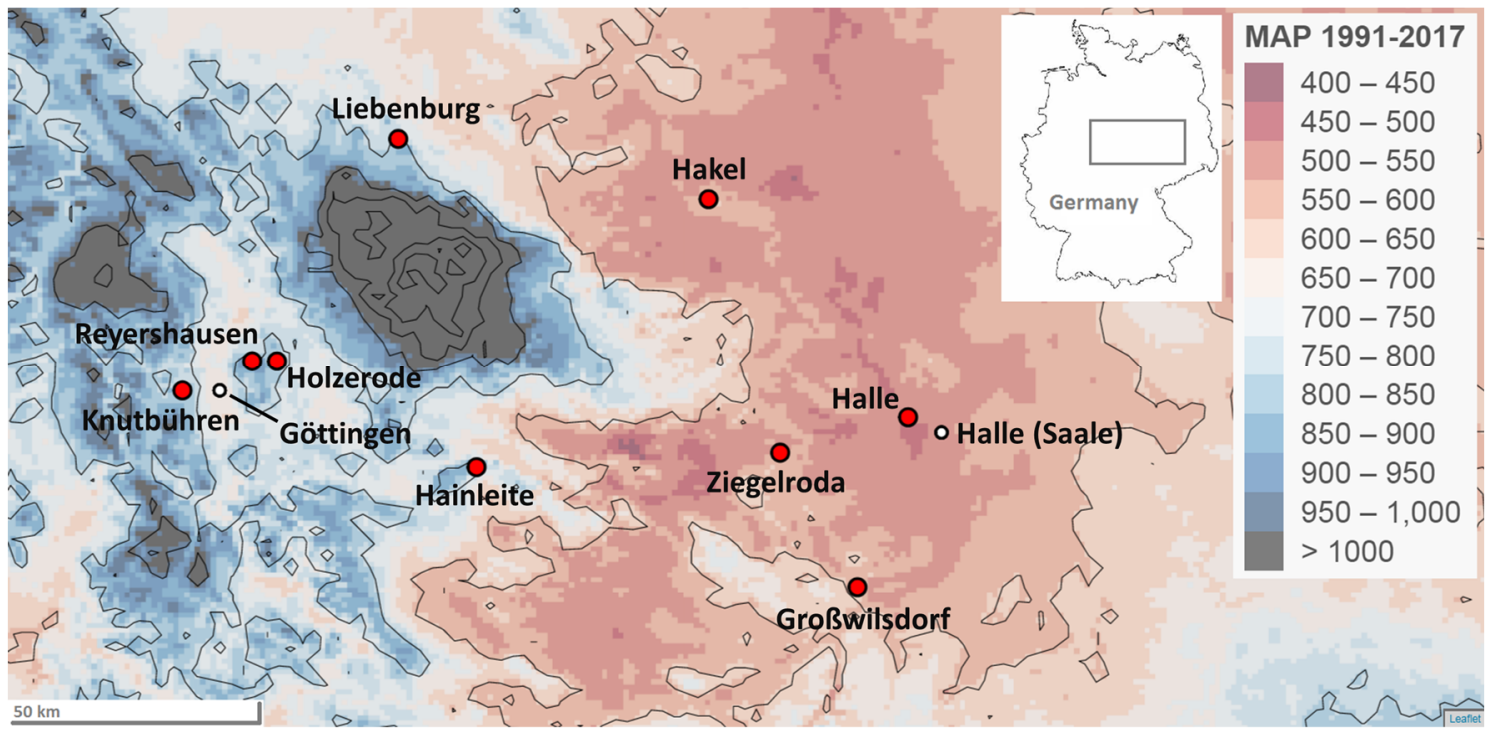

Figure 3.1: Map of the study area between Göttingen and Halle/S. in central Germany with the precipitation gradient from the west to the east. The nine study sites are marked with red dots. The colors indicate the mean annual precipitation (MAP 1991-2017). The area with MAP over $1000 \mathrm{~mm}$ NE of Göttingen is the Harz mountain range.

Four of the five investigated tree species (A. platanoides, T. cordata, C. betulus, and F. excelsior) are widespread in Central Europe with natural occurrences in various types of broadleaf mixed forest communities of the phytosociological alliances Carpinion betuli (oak-hornbeam forests) and Tilio-Acerion (mixed maple slope forests), in which European beech (Fagus sylvatica L.), the dominant species of Central Europe's natural forest vegetation, is rare or absent (Leuschner and Ellenberg, 2017). The four species are more demanding in terms of soil base saturation than beech and $Q$. petraea, the fifth species of this study, but they also occur in eastern Europe under a more continental climate and thus are thought to be relatively drought tolerant. While Q. petraea is one of the most important timber species of Central European forestry, the four other species are only secondary timber species in the study region. Therefore, mixed stands of comparable stand structure and tree age with presence of all five species are uncommon. As a consequence, not all species are present at all nine study sites, but every species occurs at least at five sites along the precipitation transect. Every site consisted of several mixed forests of variable species composition in a maximum distance of several hundred $\mathrm{m}$ to a few $\mathrm{km}$ to each other. The target species grew in these mixed stands of two to six species 
under comparable edaphic and climatic conditions. All stands were located on level terrain with an inclination of less than $5^{\circ}$ without groundwater influence.

The target trees in the stands were all of mature age (range: 69-139 years), with the exception of two older oak stands (170 years). The exact age of all individuals was determined from the investigation of increment cores and dendrochronological analysis, except for $C$. betulus, which was not included in the tree ring study, as the increment cores consist of long sections of indistinguishable annual rings. Age information for this species was taken from forest inventory data supplied by the local forestry offices. The investigated trees were selected for comparable height and $\mathrm{DBH}$ at the different sites (Table 3.1). From the moister western to the drier eastern sites, average tree height in the stands slightly decreased from 28.2 to $25.8 \mathrm{~m}$ (means of all species), while average DBH increased from 44.5 to $47.1 \mathrm{~cm}$. This indicates that aboveground biomass changes only little along the transect. Only in the case of $T$. cordata, tree height decreased notably towards the drier sites. In case of F. excelsior, we selected only trees that were not visibly affected by ash dieback, a recently spreading lethal infection caused by the fungus Hymenoscyphus fraxineus. 

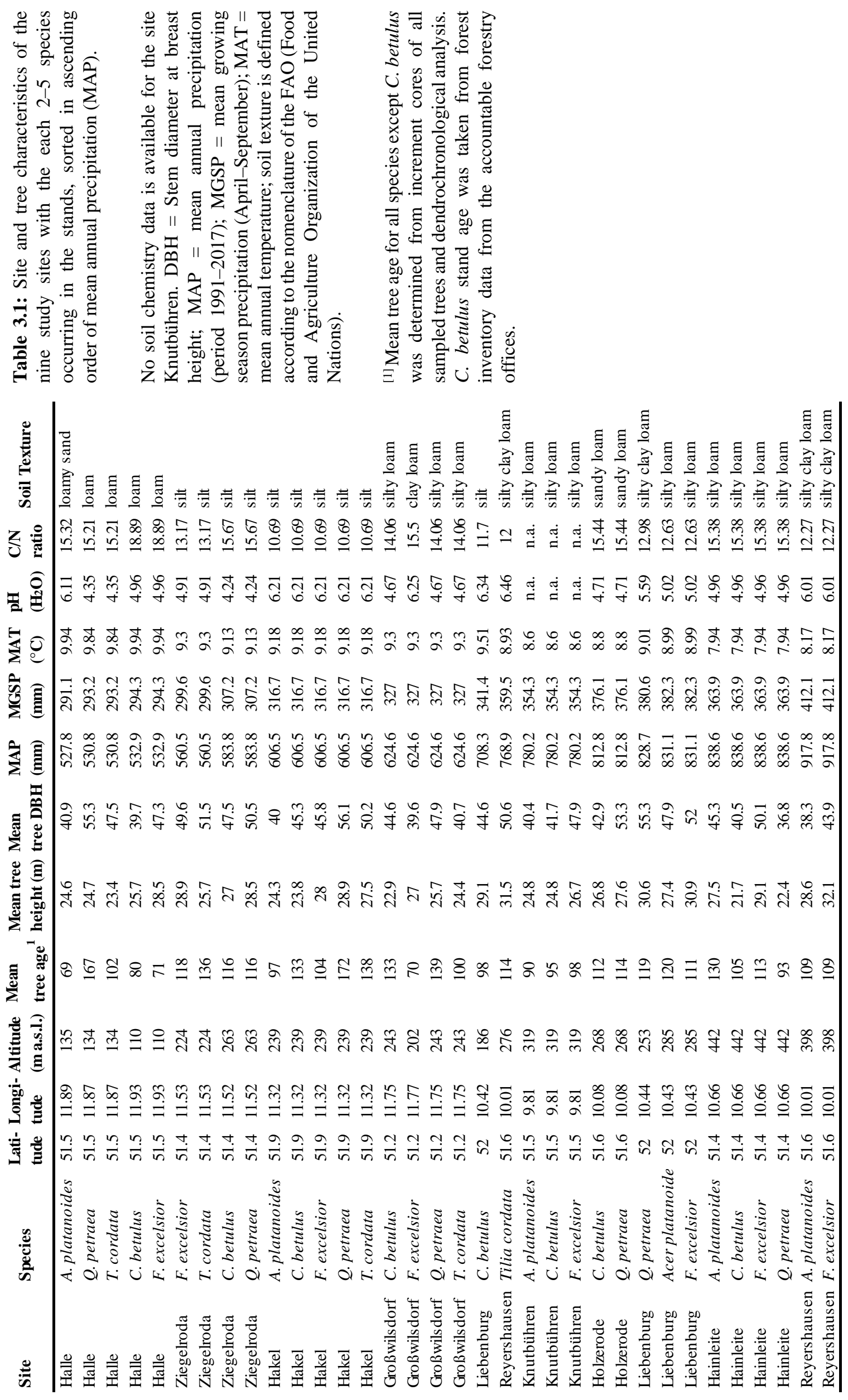


\subsubsection{Climatic Conditions}

Precipitation, air temperature, and potential evapotranspiration (PET) data were taken from the DWD (Deutscher Wetterdienst, Offenbach, Germany) database and the required local data were calculated from extrapolated $1 \mathrm{~km}$-gridded data. The gridding method of the DWD employs the reduction to a reference elevation level, the calculation of inverse squared-distance weights (horizontal interpolation), and finally the transformation to the actual elevation of the grid point using regression over elevation (Kaspar et al., 2013; Müller-Westermeier, 1995). This gridding method is relatively simple, but comparison and verification against other GIS-based interpolation methods (Maier and MüllerWestermeier, 2010) have confirmed its accuracy, which is partly a consequence of the relatively high weather station density in Germany. The largest distance between a study site and the closest weather station was ca. $7.1 \mathrm{~km}$.

PET was extrapolated from data derived from the agrometeorological model AMBAV (“Agrarmeteorologisches Modell zur Berechnung der aktuellen Verdunstung”, Löpmeier, 1994) that is based on the Penman-Monteith equation. Without doubt, these agrometeorological PET data do not characterize potential forest evapotranspiration exactly, but the values are used in the study only for characterizing the weather conditions prior to the two fine root inventory campaigns.

The mean de Martonne Index (DMI) for the respective three-month periods prior to each sampling date was calculated by dividing precipitation sums by the mean temperature + 10 (Martonne, 1926).

Long-term mean annual climate data were calculated for the period 1991-2017, because PET data generated with the AMBAV model are only available from DWD stations since 1991. Fine root data were modelled in dependence on a variety of parameters characterizing site water availability, notably mean annual precipitation (MAP), mean growing season precipitation (MGSP; April-September), and the climatic water balance (precipitation-PET, whole year and growing season). Because the ratio of summer precipitation to annual precipitation is constant and temperature is inversely proportional to precipitation along the transect, we obtained similar results for all tested variables in the correlation analyses and thus used in the analyses MAP as a proxy for climatic aridity along the transect. The actual precipitation in the 12 months prior to sampling was tested as well and resulted in the same patterns of correlation, as it was mostly proportional to MAP along the transect (see Appendix B, Table 3.6 and Figure $3.5)$. 


\subsubsection{Edaphic Conditions}

Various soil chemical and physical properties were analysed for the topsoil $(0-10 \mathrm{~cm}$ of mineral soil) of three soil pits per site, notably soil texture, organic matter content, soil $\mathrm{pH}$ (in $\mathrm{H}_{2} \mathrm{O}$ and in $\mathrm{KCl}$ ), and organic $\mathrm{C}$, organic $\mathrm{N}$, and resin-extractable $\mathrm{P}$ content. Organic carbon and nitrogen concentrations were determined by gas chromatography $(\mathrm{C} / \mathrm{N}$ elemental analysis) and the resin-extractable $\mathrm{P}$ concentration was determined with ICP-OES (inductively coupled plasma optical emission spectrometry) analysis, after $\mathrm{P}$ extraction with water using an anion-exchange resin and subsequent re-exchange of $\mathrm{P}$ with $\mathrm{NaCl}$ and $\mathrm{NaOH}$ solutions. The soil organic matter content was additionally determined through the dry ignition method at $600{ }^{\circ} \mathrm{C}$, the soil texture by sieving (sand fractions) and sedimentation (silt fractions) according to the international standard ISO 11277.

\subsubsection{Fine Root Inventories: Sampling Periods}

To examine the effect of seasonal drought on fine root mortality, two inventories with determination of fine root biomass and necromass were carried out at all sites in spring 2017 and summer 2018. The first inventory in April 2017 was conducted after a moderately moist spring period in order to examine fine root mass under ample soil moisture conditions along the precipitation gradient without the influence of unusual drought periods. On the other hand, no soil frost was influencing this inventory, as the winter was mild with no harsh frost periods. A second inventory was conducted in September 2018 after an exceptionally dry summer with an extended rainless period to investigate the effect of pronounced soil drought on the fine root system. The summer of 2018 with its extraordinary heatwave was on average $2.0-2.3{ }^{\circ} \mathrm{C}$ warmer and had $55-$ 74\% lower rainfall amounts than the average (1991-2017) in the study region. All study sites were exposed to very low rainfall between May and September prior to the inventory, with mostly $<30 \mathrm{~mm}$ of precipitation per month (Table 3.2). We decided to report the average weather in the 3 months prior to each sampling date and related it to the long-term means of the respective seasons. A period length of three months was chosen, because loamy soils in the study region are known to desiccate only with some delay after precipitation ceased in a dry period, and the peak of fine root mortality thus typically happens after an additional time lag of 1-2 months, according to a root study in central northern Germany (Hertel and Leuschner, 2002). 
Table 3.2: PET, precipitation, and temperature in the three months prior to the sampling dates in 2017 and 2018. Given are the totals of potential evapotranspiration (PET) and precipitation (P), the deviation of $\mathrm{P}$ from the long-term mean (1991-2017) in percent, and the absolute deviation of the average temperature of the three-month period from the long-term mean (1991-2017) in that period in ${ }^{\circ} \mathrm{C}$.

\begin{tabular}{|c|c|c|c|c|c|c|c|c|}
\hline \multirow[b]{2}{*}{ Site } & \multicolumn{4}{|l|}{2017} & \multicolumn{4}{|l|}{2018} \\
\hline & $\begin{array}{l}\text { PET } \\
(\mathbf{m m})\end{array}$ & $\begin{array}{l}\mathbf{P} \\
(\mathbf{m m})\end{array}$ & $\begin{array}{l}\mathbf{P} \\
\text { deviation } \\
(\%)\end{array}$ & $\begin{array}{l}\text { T } \\
\text { deviation } \\
\left({ }^{\circ} \mathrm{C}\right)\end{array}$ & $\begin{array}{l}\text { PET } \\
(\mathbf{m m})\end{array}$ & $\begin{array}{l}\mathbf{P} \\
(\mathbf{m m})\end{array}$ & $\begin{array}{l}P \\
\text { deviation } \\
(\%)\end{array}$ & $\begin{array}{l}\text { T } \\
\text { deviation } \\
\left({ }^{\circ} \mathrm{C}\right) \\
\end{array}$ \\
\hline Halle & 45.9 & 78.4 & -24.9 & +0.02 & 405.2 & 78.9 & -68.3 & +2.14 \\
\hline Ziegelroda & 44.5 & 86.0 & -25.4 & +0.04 & 396.6 & 78.0 & -70.2 & +2.26 \\
\hline Hakel & 43.9 & 101.0 & -19.3 & +0.18 & 390.4 & 120.0 & -55.2 & +2.12 \\
\hline Großwilsdorf & 46.6 & 93.0 & -26.7 & +0.08 & 396.5 & 93.3 & -67.4 & +2.17 \\
\hline Knutbühren & 45.2 & 144.0 & -24.4 & +0.02 & 374.7 & 82.7 & -73.0 & +2.14 \\
\hline Holzerode & 46.1 & 147.0 & -24.4 & +0.06 & 380.2 & 120.0 & -62.9 & +2.15 \\
\hline Liebenburg & 48.1 & 127.0 & -36.3 & +0.38 & 384.6 & 101.0 & -67.9 & +2.06 \\
\hline Hainleite & 40.2 & 177.0 & -16.8 & +0.17 & 374.0 & 80.0 & -73.9 & +2.08 \\
\hline Reyershausen & 44.0 & 159.0 & -25.1 & +0.04 & 372.6 & 125.0 & -62.9 & +2.13 \\
\hline
\end{tabular}

\subsubsection{Fine Root Inventories: Fine Root Biomass and Necromass}

Five mature, similarly-sized and vital trees were chosen per site and species, and two topsoil samples per tree extracted in $1.5 \mathrm{~m}$ distance from the stem base in eastern and western direction using a soil corer of $3.5 \mathrm{~cm}$ in diameter. These two samples were later combined to one, as we did not intend to study FRB variation within the same tree. For reasons of comparability, the second sampling campaign was conducted at coring locations in close vicinity of the previous campaign, but in a distance of $40 \mathrm{~cm}$ to exclude possible interference from the soil disturbance of the earlier coring.

Because the study focus was on the comparison of five species at many sites with a large number of samples, we had to restrict the sampling to the uppermost $10 \mathrm{~cm}$ of mineral soil (A-horizon), where drought effects are assumed to be largest. At all sites, the A-horizon contained by far the highest density of fine roots which decreased exponentially with soil depth. Organic layers on top of the soil were generally thin, consisted mainly of undecomposed litter and rarely contained fine roots.

The soil samples were transferred to plastic bags and stored at $4{ }^{\circ} \mathrm{C}$ in the laboratory until processing within 3 months. Prior to the root extraction procedure, the samples were soaked in tap water and carefully cleaned from attached soil residues under gently running water over a sieve of $0.25 \mathrm{~mm}$ mesh size. Only fine root fragments $(<2 \mathrm{~mm}$ in diameter, $>10 \mathrm{~mm}$ in length) of the target species were considered for analysis. In most samples, shrub and herb roots were rare or missing and the percentage of roots of non-target species was very small, because all sampling locations were situated in small monospecific forest patches of 5-10 individuals of the target species. The sorting of fine roots by species was done by morphological criteria (colour and surface structure of the root periderm, 
branching patterns of the rootlets, morphology of ectomycorrhizae in the ECM species), established in our lab during earlier work in mixed broadleaf forests in Central Germany (Jacob et al., 2014; Kubisch et al., 2015; Meinen et al., 2009). Living (biomass) and dead roots (necromass) were distinguished under the stereomicroscope by inspecting colour, root elasticity, and cohesion of the cortex, periderm, and stele (Hertel and Leuschner, 2002; Persson, 1978). The fine root biomass and necromass of every sample was dried at $70{ }^{\circ} \mathrm{C}$ for $48 \mathrm{~h}$ and weighed and expressed as $\mathrm{g} \mathrm{L}^{-1}$ soil volume.

We did not take any dead root particles $<10 \mathrm{~mm}$ length into account, although this finest fraction of decaying root particles is known to represent a considerable portion of total FRN (Bauhus and Bartsch, 1996; Leuschner et al., 2004). One reason is the sheer impossibility to assign these particles to different tree species in samples containing more than one tree species. In addition, a main study aim was the analysis of the effect of the 2018 summer drought on the N/B ratio of fine root mass. Yet, it is likely that the bulk of partly decomposed FRN fragments in the samples originate from earlier die-off events, and that the $<10 \mathrm{~mm}$ fraction is the one most influenced by the activity of decomposers in the soil. This suggested focusing on the larger, still intact necromass fragments (>10 mm length), which more likely were formed in summer 2018.

\subsubsection{Fine Root Inventories: Fine Root Morphology}

Four to five intact rootlets were picked from the living biomass fraction and further analysed for their mean root diameter, specific root surface area (SRA, in $\mathrm{cm}^{2} \mathrm{~g}^{-1}$ ), specific root length (SRL, in $\mathrm{m} \mathrm{g}^{-1}$ ), root tissue density (in $\mathrm{g} \mathrm{cm}^{-3}$ ), and the number of root tips per mass using a water bath scanner and the WinRhizo (Régent Instruments Inc., Quebec, QC, Canada) visual analysis system. All morphological parameters were calculated on a dry biomass $\left(70{ }^{\circ} \mathrm{C}\right.$ for $\left.48 \mathrm{~h}\right)$ basis.

\subsubsection{Statistical Analyses}

All calculations and tests were conducted with version 3.6.1 of R ( $\mathrm{R}$ Core Team 2019). All fine root biomass, necromass, and morphological data showed a strong right-skewed distribution and were neither within the species, nor among plots and different species normally distributed. In some cases, the necromass values were almost bi-modally distributed, as root necromass distribution within the soil was highly patchy. We therefore used non-parametric tests to detect differences between years in fine root bio- and necromass. Since it is a priori unclear, whether two soil samples taken at short distance $(40 \mathrm{~cm})$ in two subsequent years are paired or independent, we decided to conduct two 
non-parametric tests: the Wilcoxon signed-rank test and the Wilcoxon-Mann-Whitney U test. Since both tests resulted in exactly the same pattern of significant differences, we here only report the results of the signed-rank test, because pair-wise comparison seems to better fit to the repeat-sampling strategy of this study.

In order to explore the relationships between various site-specific soil characteristics, tree size attributes, climate variables and fine root data, principal components analyses (PCA) were conducted separately for site- and species-level data for the 2017 and 2018 sampling campaigns (R Packages "FactoExtra" and "FactoMineR", Kassambara and Mundt, 2017; Lê et al., 2008). The PCA included the variables mean annual precipitation (MAP), mean annual temperature (MAT), de Martonne aridity index (DMI) of the 3 months prior to sampling, soil $\mathrm{pH}, \mathrm{C} / \mathrm{N}$ ratio, resin-exchangeable $\mathrm{P}$ concentration, organic matter content, silt content and soil bulk density (0-10 $\mathrm{cm}$ depth), mean tree height, diameter at breast height (DBH), FRB, FRN, N/B ratio, specific root area (SRA), and specific root length (SRL). To account for the right-skewed distribution of fine root data, we log-transformed, centred, and scaled all biomass, necromass, and morphological data prior to the PCA analysis.

Further, linear mixed effects models were fitted for the 2017 and 2018 data sets separately for all predictors and dependent variables (R package lme4, Bates et al., 2015). The models included one of the predictors (MAP, MGSP, MAT, soil $\mathrm{pH}$, soil $\mathrm{C} / \mathrm{N}$ ratio, silt proportion, soil organic matter content, tree age, height, and DBH) and its interaction with the factor "species" as fixed effects, while the factor "site" was introduced as random effect. The random effect was introduced, because fine root data on tree level were nested within species per site. The dependent variables in the models were the log-scaled fine root mass and morphology data. Here, we only report the results of the models with MAP as predictor, as the other variables led either to very similar results (e.g., MGSP) or showed no significant effects and very small effect sizes. These minor inter-relationships among biotic, edaphic, and climatic variables in the data set are already demonstrated by the PCAs.

All models were checked for constant variance of the residuals across fitted values and between levels of the fixed effects, as well as for acceptable normality of the distribution of the residuals using Q-Q-plots. Only the model with fine root necromass as dependent variable showed slightly distorted residuals in part of the data set due to several very low necromass values, which did not apply to the model with necromass/biomass ratio. Conclusions from the N/B ratio model are thus more robust than those from the 
necromass-only model. All estimates are based on the restricted maximum likelihood (REML) criterion and $p$-values were calculated with the lmerTest package based on Satterthwaites degrees of freedom method (Kuznetsova et al., 2017).

Reported marginal "pseudo- $R^{2}$ " values were calculated per species according to Nakagawa and Schielzeth (2013) and represent a measure for explained variance of the fixed effects in mixed-effects models:

$$
R_{\text {marg }}^{2}=1-\frac{\text { variance }\left(\text { res }_{\text {marg }}\right)}{\text { variance }(\log (\text { variable }))}
$$

where resmarg are the residuals of the marginal predictions of the model.

\subsection{Results}

3.4.1 Fine Root Biomass, Necromass, and Morphology in the 2017 and 2018 Inventories

Across the nine sites, FRB density in the mineral topsoil $(0-10 \mathrm{~cm})$ was lowest in stands of $Q$. petraea and $T$. cordata (mostly in the range $0.2-0.8 \mathrm{~g} \mathrm{~L}^{-1}$ ), intermediate in A. platanoides $\left(0.3-2.0 \mathrm{~g} \mathrm{~L}^{-1}\right)$, and highest in $C$. betulus $\left(0.8-2.0 \mathrm{~g} \mathrm{~L}^{-1}\right)$ and especially $F$. excelsior (1.5-4.0 $\mathrm{g} \mathrm{L}^{-1}$; Figure 3.2a). The corresponding FRB pools in the $0-10 \mathrm{~cm}$ layer were 20-80, 30-200, 80-200, and 150-400 $\mathrm{g} \mathrm{m}^{-2}$. Thus, across all sites, F. excelsior had about fivefold larger FRB densities in the topsoil than $Q$. petraea. The FRN pools (only fragments $>10 \mathrm{~mm}$ ) were 10 to 100 times smaller than the biomass pools (Figure 3.2b), resulting in N/B ratios mostly in the range of 0.1 to 0.01 (Figure 3.2c). 

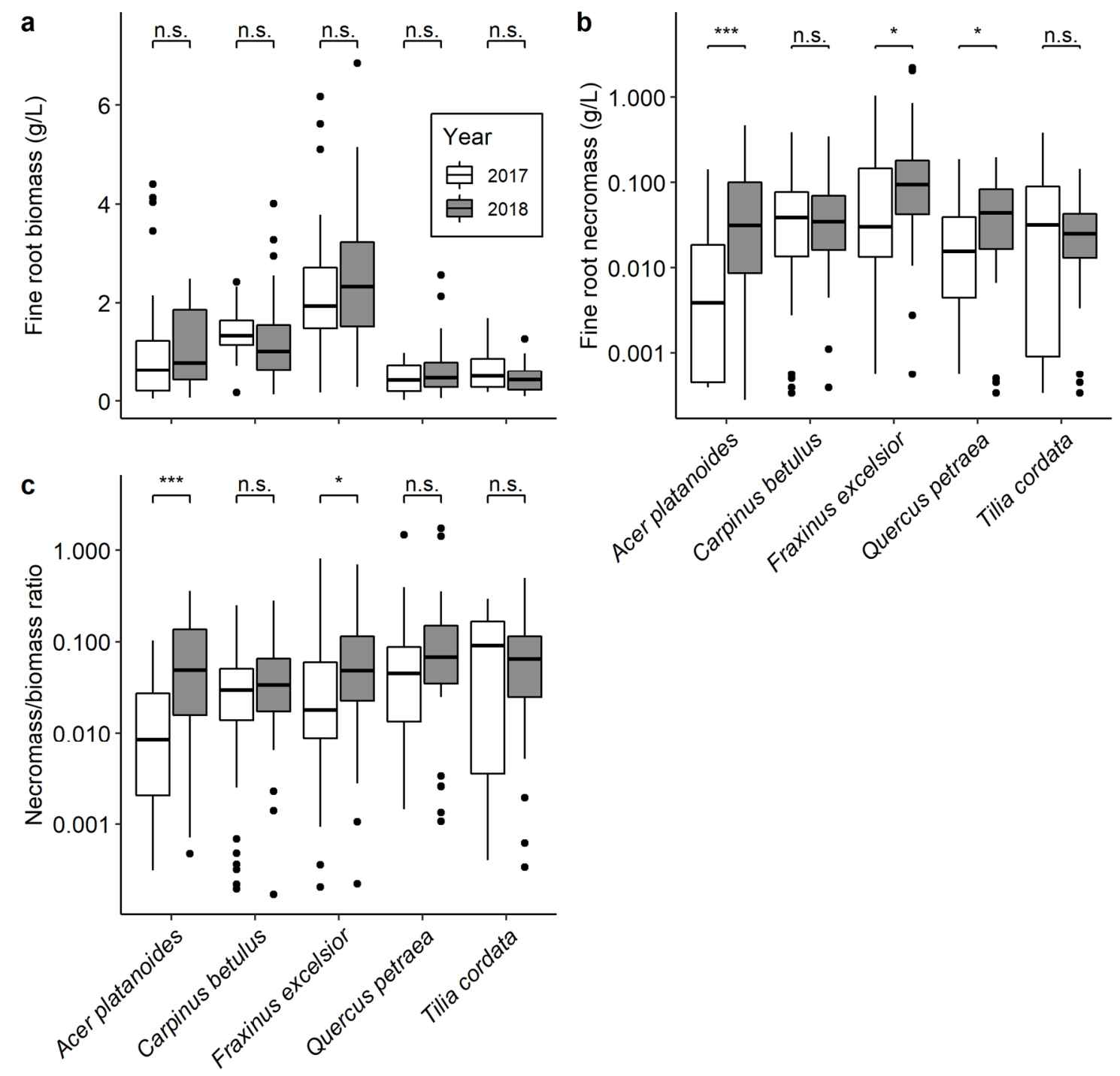

Figure 3.2: Fine root biomass (a), necromass (b), and necromass/biomass (N/B) ratio (c) of the five tree species in the topsoil $(0-10 \mathrm{~cm})$ in April 2017 and September 2018. Box-whisker plots with median and interquartile ranges $\left(\mathrm{Q}_{1}-\mathrm{Q}_{3}\right)$; whiskers extend to 1.5 times the interquartile range. Indicated significant differences between the inventories for each species are based on a non-parametric signed-rank-test; $* * *$ : $p \leq 0.001, *: p<0.05$. Note the log-scaled y-axes in (b) and (c).

Comparing the FRB recorded in the moist spring of 2017 to the biomass of the dry summer of 2018 revealed in none of the five species a significant difference, whereas necromass was significantly greater after the 2018 drought in three species ( $A$. platanoides, F. excelsior, and Q. petraea) but unchanged in the other two (Figure 3.2a,b). The N/B ratio was higher after the 2018 drought in A. platanoides and F. excelsior, but not in the other three species (Figure 3.2c). 

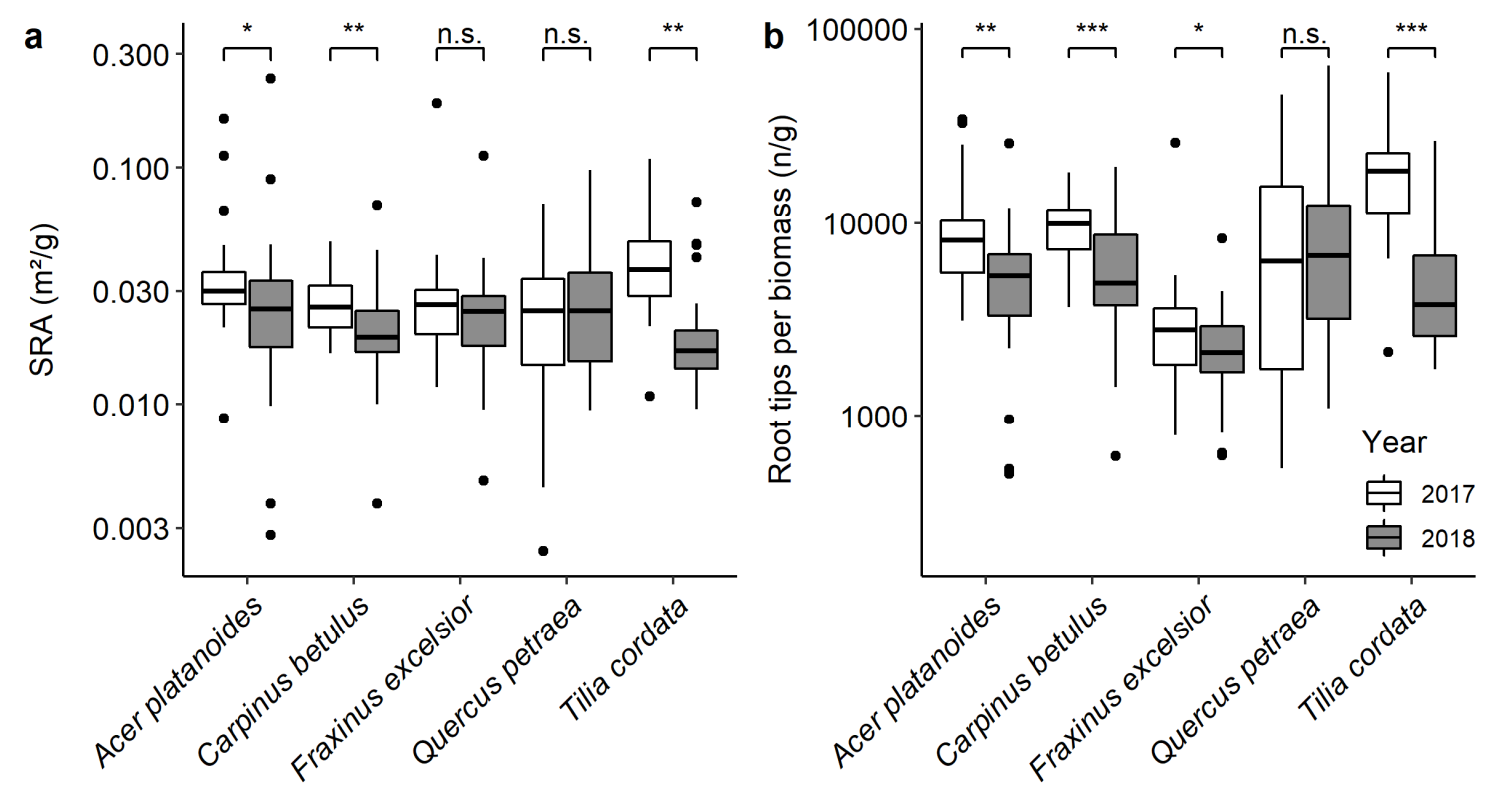

Figure 3.3: Specific root surface area (SRA) and root tips per fine root biomass of the five tree species in the topsoil $(0-10 \mathrm{~cm})$ in April 2017 and September 2018. Box-whisker plots for all species and both inventories with median and interquartile ranges $\left(\mathrm{Q}_{1}-\mathrm{Q}_{3}\right)$; whiskers extend to 1.5 times the interquartile range. Indicated significant differences between the inventories for each species are based on a nonparametric signed-rank-test; $* * *: p \leq 0.001, * *: p \leq 0.01, *: p<0.05$. Note the log-scaled y-axes.

While FRN was not different between the two inventories in C. betulus and T. cordata, SRA was significantly smaller in these species after the 2018 drought than in 2017 (Figure 3.3a). A similar morphological response was observed also in A. platanoides, while the SRA of the other two species did not respond to the drought. All species except Q. petraea showed significantly reduced root tip numbers per FRB after the 2018 drought (Figure 3.3b).

\subsubsection{Changes in Fine Root Mass and Root Traits along the Precipitation Gradient}

Under conditions of ample soil moisture in the spring of 2017, FRB density at the nine sites revealed a positive relationship with MAP in case of $Q$. petraea, a negative relation in A. platanoides, and no significant relations in the other three species (Figure 3.4, Table 3.3). FRN density increased with a decrease in MAP in all species except $Q$. petraea, and so did the N/B ratio. After the summer drought in 2018 , in contrast, we found no dependence of FRB, FRN and N/B ratio on MAP (Table 3.3) due to a marked increase in FRN at the moister end of the precipitation gradient (Figure 3.4). FRB changed relatively little between 2017 and 2018 in four species, but showed a marked increase at the moist end of the gradient in A. platanoides (Figure 3.4). 

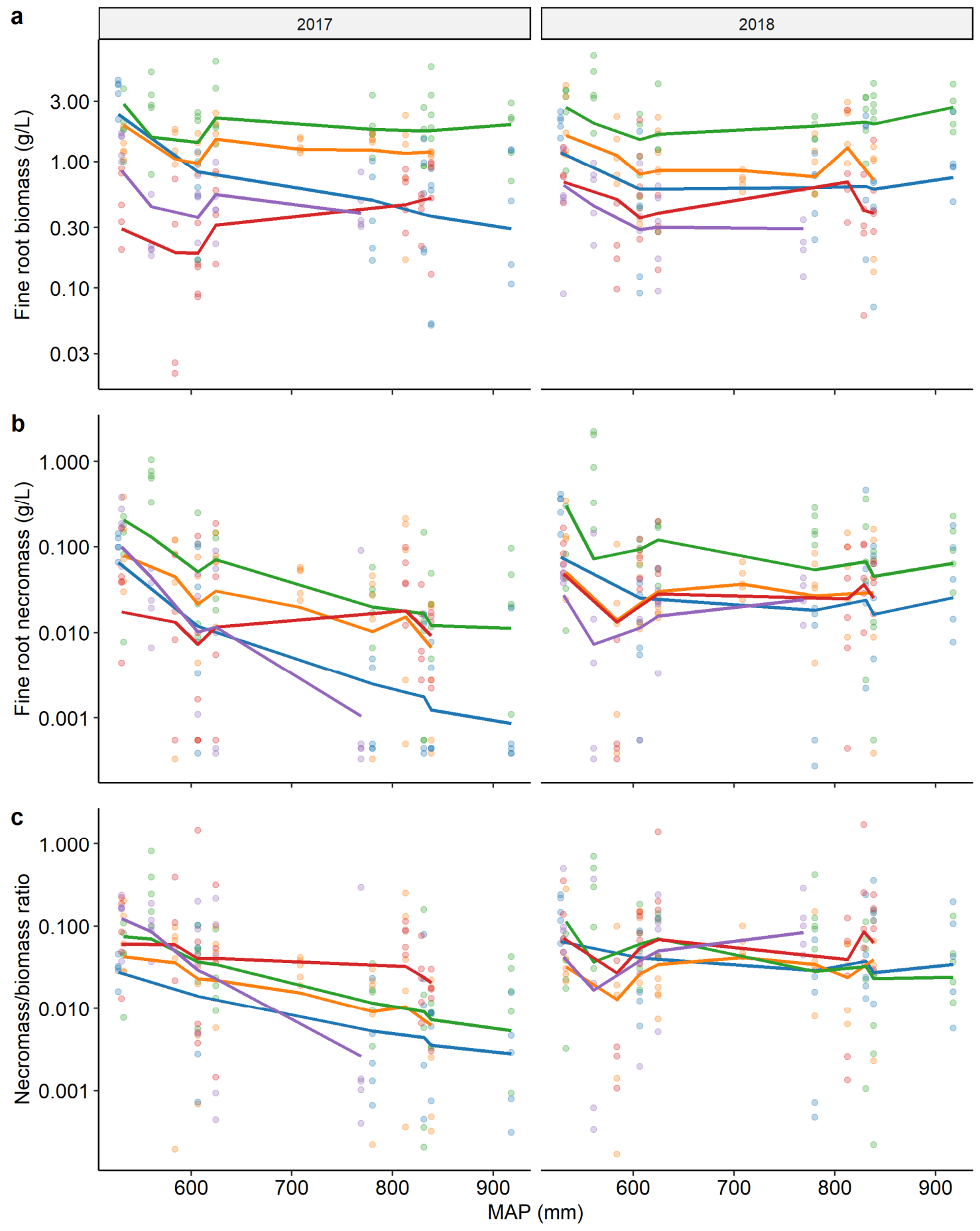

$$
\text { Species }- \text { Acer platanoides }- \text { Carpinus betulus }- \text { Fraxinus excelsior }
$$

Figure 3.4: Fine root biomass (a), necromass (b), and necromass/biomass ratio (c) in the topsoil $(0-10 \mathrm{~cm})$ of the five species in relation to mean annual precipitation (MAP) in the 2017 and 2018 inventories. Data points are tree-level values, lines represent conditional predictions of the linear mixed effects model (the predictions of the fixed effect "MAP" for each species plus an intercept for each level of the random factor "site"). Note the $\log$-scaled y-axis. The corresponding $p$ and pseudo- $R^{2}$ values are summarized in Table 3.3. Graphs for the morphology variables are given in Figure 3.6 in the Appendix B. 
Table 3.3: Results of linear mixed effects models for fine root traits in dependence of mean annual precipitation (MAP). Given are estimates of the fixed effect (fine root trait species:MAP), marginal pseudo- $R^{2}$ for the fixed effect (calculated according to Nakagawa and Schielzeth (2013)) and $p$-values. $p$ values below 0.05 are given in bold. All fine root traits were log-transformed in advance except for root diameters.

\begin{tabular}{|c|c|c|c|c|c|c|}
\hline \multirow{2}{*}{$\begin{array}{l}\text { Model } \\
\text { Species }\end{array}$} & \multicolumn{3}{|c|}{2017 (Moist) } & \multicolumn{3}{|c|}{2018 (Dry) } \\
\hline & Estimate & Pseudo $R^{2}$ & $p$-value & Estimate & Pseudo $R^{2}$ & $p$-value \\
\hline \multicolumn{7}{|c|}{ Fine root biomass $\sim$ MAP } \\
\hline Fraxinus excelsior & -0.0004 & 0 & 0.678 & 0.0007 & 0 & 0.523 \\
\hline Carpinus betulus & -0.0004 & 0.02 & 0.752 & -0.0009 & 0.03 & 0.531 \\
\hline Acer platanoides & -0.0048 & 0.31 & $<0.001$ & -0.0005 & 0.01 & 0.725 \\
\hline Quercus petraea & 0.0029 & 0.12 & 0.023 & -0.0001 & 0 & 0.933 \\
\hline Tilia cordata & -0.0024 & 0.07 & 0.264 & -0.0021 & 0.1 & 0.368 \\
\hline \multicolumn{7}{|c|}{ Fine root necromass $\sim$ MAP } \\
\hline Fraxinus excelsior & -0.0074 & 0.32 & 0.002 & -0.0034 & 0.07 & 0.147 \\
\hline Carpinus betulus & -0.0063 & 0.13 & 0.032 & 0.0011 & 0 & 0.711 \\
\hline Acer platanoides & -0.0113 & 0.47 & $<0.001$ & -0.0022 & 0.03 & 0.400 \\
\hline Quercus petraea & -0.0002 & 0 & 0.955 & 0.0005 & 0 & 0.841 \\
\hline Tilia cordata & -0.019 & 0.42 & $<0.001$ & 0.0005 & 0 & 0.923 \\
\hline \multicolumn{7}{|c|}{ Necro-/biomass-ratio MAP } \\
\hline Fraxinus excelsior & -0.007 & 0.32 & $<0.001$ & -0.004 & 0.08 & 0.081 \\
\hline Carpinus betulus & -0.0057 & 0.11 & 0.028 & 0.002 & 0.01 & 0.482 \\
\hline Acer platanoides & -0.0063 & 0.25 & 0.014 & -0.0016 & 0.02 & 0.523 \\
\hline Quercus petraea & -0.0029 & 0.05 & 0.211 & 0.0007 & 0 & 0.798 \\
\hline Tilia cordata & -0.0166 & 0.37 & $<0.001$ & 0.0028 & 0.04 & 0.533 \\
\hline \multicolumn{7}{|l|}{ SRA MAP } \\
\hline Fraxinus excelsior & -0.001 & 0.09 & 0.15 & -0.0006 & 0.03 & 0.367 \\
\hline Carpinus betulus & -0.0001 & 0 & 0.926 & -0.0022 & 0.25 & 0.011 \\
\hline Acer platanoides & -0.0008 & 0.07 & 0.266 & -0.0001 & 0 & 0.861 \\
\hline Quercus petraea & -0.002 & 0.1 & 0.013 & -0.0013 & 0.09 & 0.117 \\
\hline Tilia cordata & 0.0004 & 0 & 0.781 & 0.0001 & 0 & 0.918 \\
\hline \multicolumn{7}{|c|}{ Root tips per biomass $\sim$ MAP } \\
\hline Fraxinus excelsior & -0.0012 & 0.06 & 0.249 & -0.0008 & 0.04 & 0.421 \\
\hline Carpinus betulus & -0.0006 & 0 & 0.648 & -0.0038 & 0.35 & 0.002 \\
\hline Acer platanoides & -0.0015 & 0.11 & 0.179 & -0.0006 & 0.01 & 0.587 \\
\hline Quercus petraea & -0.0043 & 0.16 & $<0.001$ & -0.0009 & 0.01 & 0.412 \\
\hline Tilia cordata & -0.0004 & 0.01 & 0.83 & -0.0007 & 0.01 & 0.728 \\
\hline \multicolumn{7}{|c|}{ Root diameter $\sim$ MAP } \\
\hline Fraxinus excelsior & 0.1511 & 0.02 & 0.269 & 0.2416 & 0.16 & 0.014 \\
\hline Carpinus betulus & 0.1485 & 0.04 & 0.367 & 0.5943 & 0.51 & $<0.001$ \\
\hline Acer platanoides & 0.061 & 0 & 0.677 & 0.0426 & 0.01 & 0.700 \\
\hline Quercus petraea & 0.5661 & 0.18 & $<0.001$ & 0.0045 & 0 & 0.970 \\
\hline Tilia cordata & -0.0783 & 0 & 0.765 & -0.0027 & 0 & 0.989 \\
\hline
\end{tabular}

Of the root morphological traits, SRA and the number of root tips per biomass increased with decreasing MAP in the 2017 inventory in $Q$. petraea, and in 2018 in $C$. betulus, pointing at a larger absorptive capacity of the finest roots at drier sites (Table 3.3 and Figure 3.6 in the Appendix B). Accordingly, mean fine root diameter in the $<2 \mathrm{~mm}$ category increased towards the moister sites. A similar pattern was also observed in the other species in both years, but the relationships were mostly not significant (exception: root diameter in F. excelsior in 2018) and the explained variance was low; especially $T$. cordata did not show significant morphological plasticity along the gradient (Table 3.3). 


\subsubsection{Interdependencies between Climatic and Edaphic Factors and Fine Root}

\section{Variables along the Precipitation Gradient}

The principal components analysis for the inventory in spring 2017 revealed a relatively continuous distribution of the study sites along the first three axes that explained $63.4 \%$ of the total variance of the dataset (Table 3.4, a graphical representation of the PCA results is provided in the Appendix B in Figure 3.7). The first axis (27.5\% explained variance) coincided mainly with the climatic factors MAP and MAT and the weather prior to sampling (DMI). FRN and the N/B ratio were strongly correlated with the first axis as well, whereas root biomass itself and morphological attributes (SRA and SRL) coincided with the second axis (21.2\% explained variance) and soil physical and chemical properties ( $\mathrm{C} / \mathrm{N}$, silt content, bulk density, organic matter content). FRB was generally positively associated with high organic matter content in the upper mineral soil and negatively influenced by high bulk density, which itself coincided with high silt content. The third axis (14.8\% explained variance) reflects the positive association between tree height and soil $\mathrm{pH}$ and $\mathrm{P}$ availability, but did not correlate with climate or fine root variables.

Table 3.4: Results of the principal components analysis for the spring inventory in 2017 . Given are the loadings of the selected variables along the four axes with the highest explained variance in the dataset. Bold numbers mark the variables with the highest loading $(>0.4)$ on the respective axis. The values in brackets give the cumulative fraction of variance explained by the variable. MAP = mean annual precipitation, MAT = mean annual temperature, $\mathrm{DMI}=$ de Martonne aridity index of the three months prior to sampling.

\begin{tabular}{llllllllll} 
& Axis 1 & & Axis $\mathbf{2}$ & & Axis 3 & & Axis 4 \\
\multicolumn{1}{c}{ Explained Variance: } & $\mathbf{2 7 . 8 \%}$ & & $\mathbf{2 1 . 1 \%}$ & & $\mathbf{1 4 . 5 \%}$ & & $\mathbf{1 2 . 8 \%}$ \\
\hline Climate factors & & & & & & & & \\
MAP & $-\mathbf{0 . 9 3}$ & $(0.86)$ & -0.03 & $(0.86)$ & -0.10 & $(0.88)$ & 0.15 & $(0.90)$ \\
MAT & $\mathbf{0 . 8 6}$ & $(0.74)$ & -0.07 & $(0.75)$ & 0.36 & $(0.88)$ & 0.06 & $(0.88)$ \\
DMI (sampling period) & $\mathbf{- 0 . 9 2}$ & $(0.84)$ & -0.10 & $(0.85)$ & -0.24 & $(0.90)$ & -0.02 & $(0.90)$ \\
Soil properties & & & & & & & & \\
pH & -0.27 & $(0.07)$ & 0.35 & $(0.20)$ & $\mathbf{0 . 7 0}$ & $(0.69)$ & -0.06 & $(0.69)$ \\
C/N ratio & 0.23 & $(0.05)$ & $-\mathbf{0 . 7 7}$ & $(0.64)$ & -0.30 & $(0.73)$ & -0.11 & $(0.74)$ \\
Silt content & 0.01 & $(0.00)$ & $\mathbf{0 . 7 7}$ & $(0.60)$ & -0.25 & $(0.66)$ & -0.03 & $(0.66)$ \\
P concentration & -0.24 & $(0.06)$ & 0.11 & $(0.07)$ & $\mathbf{0 . 8 8}$ & $(0.85)$ & 0.19 & $(0.88)$ \\
Org. matter content & -0.25 & $(0.06)$ & $-\mathbf{0 . 7 0}$ & $(0.55)$ & $\mathbf{0 . 4 7}$ & $(0.77)$ & -0.12 & $(0.78)$ \\
Bulk density & 0.33 & $(0.11)$ & $\mathbf{0 . 7 0}$ & $(0.6)$ & -0.17 & $(0.63)$ & 0.35 & $(0.75)$ \\
Stand structural parameters & & & & & & & & \\
Tree height & -0.32 & $(0.1)$ & 0.23 & $(0.15)$ & $\mathbf{0 . 4 8}$ & $(0.39)$ & $\mathbf{0 . 5 5}$ & $(0.69)$ \\
Diameter at breast height & 0.20 & $(0.04)$ & $\mathbf{0 . 4 1}$ & $(0.21)$ & -0.06 & $(0.21)$ & $\mathbf{0 . 5 9}$ & $(0.56)$ \\
Fine root-related variables & & & & & & & & \\
Fine root biomass & 0.15 & $(0.02)$ & $-\mathbf{0 . 5 7}$ & $(0.35)$ & 0.29 & $(0.43)$ & 0.06 & $(0.44)$ \\
Fine root necromass & $\mathbf{0 . 7 7}$ & $(0.59)$ & -0.38 & $(0.73)$ & 0.12 & $(0.75)$ & 0.25 & $(0.81)$ \\
Fine root dead/live ratio & $\mathbf{0 . 8 6}$ & $(0.74)$ & -0.06 & $(0.75)$ & -0.07 & $(0.75)$ & 0.27 & $(0.82)$ \\
SRL & 0.31 & $(0.10)$ & $\mathbf{0 . 4 5}$ & $(0.30)$ & 0.13 & $(0.31)$ & $-\mathbf{0 . 7 5}$ & $(0.87)$ \\
SRA & 0.25 & $(0.06)$ & 0.39 & $(0.21)$ & 0.33 & $(0.32)$ & $-\mathbf{0 . 6 9}$ & $(0.80)$ \\
\hline
\end{tabular}


After the 2018 summer drought, the environmental and root-related variables in the data set were in general less tightly correlated to each other according to the PCA (Table 3.5, a graphical representation of the PCA results is provided in the Appendix B in Figure 3.8). The first axis (22.7\% explained variance) coincided again mostly with climatic factors but did not explain root bio- or necromass variation. Instead, root morphological parameters had a reasonable loading on this axis $(-0.67,-0.56)$. The second axis $(21.1 \%$ explained variance) reflected influences of soil properties $(\mathrm{C} / \mathrm{N}$ ratio, organic matter content, bulk density, soil texture) on FRB: The same positive effect of organic matter content and negative effect of bulk density as in 2017 was visible in this data set. Fine root bio- and necromass were strongly inter-related after the summer drought along the first two PCA axes in 2018, which relates to the relatively constant N/B ratio across plots and species in this inventory.

Table 3.5: Results of the principal components analysis for the drought inventory in 2018. Given are the loadings of the selected variables along the four axes with the highest explained variance in the dataset. Bold numbers mark the variables with the highest loading $(>0.4)$ on the respective axis. The values in brackets give the cumulative fraction of variance explained by the variable. MAP $=$ mean annual precipitation, MAT = mean annual temperature, DMI = de Martonne aridity index of the three months prior to sampling.

\begin{tabular}{|c|c|c|c|c|c|c|c|c|}
\hline Explained Variance: & $\begin{array}{l}\text { Axis 1 } \\
22.0 \%\end{array}$ & & $\begin{array}{l}\text { Axis } 2 \\
21.6 \%\end{array}$ & & $\begin{array}{l}\text { Axis } 3 \\
17.0 \%\end{array}$ & & $\begin{array}{l}\text { Axis } 4 \\
11.4 \%\end{array}$ & \\
\hline \multicolumn{9}{|l|}{ Climate factors } \\
\hline MAP & 0.65 & $(0.42)$ & 0.25 & $(0.48)$ & -0.38 & $(0.62)$ & 0.36 & $(0.75$ \\
\hline MAT & -0.54 & $(0.29)$ & 0.09 & $(0.3$ & 0.65 & 2) & -0.26 & $(0.79$ \\
\hline DMI (sampling period) & 0.85 & $(0.71)$ & -0.03 & $(0.72)$ & 0.16 & & 0.08 & $(0.75$ \\
\hline \multicolumn{9}{|l|}{ Soil properties } \\
\hline pH & 0.69 & $(0.48)$ & 0.08 & $(0.48)$ & 0.35 & $(0.61)$ & -0.37 & $(0.75$ \\
\hline $\mathrm{C} / \mathrm{N}$ ratio & $-\mathbf{0}$. & & 0.4 & & -0.24 & & 0.31 & $(0.87$ \\
\hline tent $(\%)$ & 0.26 & $(0.0$ & -0.73 & $(0$. & -0.14 & & -0.12 & $(0.64$ \\
\hline P cor & 0.5 & $(0.3)$ & 0.28 & & 0.59 & & 0.14 & $(0.81$ \\
\hline content & -0.04 & $(0.0$ & 0.84 & $(0$. & 0.14 & & 0.29 & $(0.82$ \\
\hline Bulk density & 0.15 & $(0.02)$ & -0.79 & $(0.65)$ & 0.12 & $(0.67)$ & -0.08 & $(0.67$ \\
\hline \multicolumn{9}{|l|}{ Stand structural parameters } \\
\hline Tree height & 0.51 & $(0.26)$ & 0.02 & $(0.27)$ & 0.48 & $(0.5)$ & 0.52 & $(0.77$ \\
\hline Diameter at breast height & 0.00 & $(0.00)$ & -0.48 & $(0.23)$ & 0.39 & $(0.38)$ & 0.36 & $(0.51)$ \\
\hline \multicolumn{9}{|l|}{ Fine root-related variables } \\
\hline Fine root biomass & -0.02 & $(0.00)$ & 0.56 & $(0.32)$ & 0.17 & & 0.25 & $(0.41$ \\
\hline Fine $r$ & 0.03 & $(0.00)$ & 0.65 & $(0.42)$ & 0.39 & $(0.57)$ & -0.43 & $(0.76$ \\
\hline Fine root dead/live ratio & 0.05 & $(0.00)$ & 0.33 & $(0.11)$ & 0.33 & $(0.22)$ & -0.70 & $(0.71$ \\
\hline SRL & -0.48 & $(0.23)$ & -0.32 & $(0.33)$ & 0.59 & $(0.68)$ & 0.20 & $(0.72$ \\
\hline SRA & -0.38 & $(0.15)$ & -0.21 & $(0.19)$ & 0.72 & $(0.70)$ & 0.29 & $(0.79$ \\
\hline
\end{tabular}

Stand and tree age was only weakly correlated with the studied fine root traits and we decided not to include it in the final PCAs to avoid mixing tree age/stand age data from different sources because dendrochronological determination of tree age was not possible for C. betulus. 


\subsection{Discussion}

\subsubsection{Fine Root Biomass and Belowground C Allocation in Dependence on Long-Term} Water Reduction

Our study at nine sites along the steep precipitation gradient in the rain shadow of the Harz mountains (MAP: 920-530 mm year ${ }^{-1}$ ) found only weak support for optimal partitioning theory, when applied to the FRB stocks in the topsoil. FRB in the moist sampling period 2017 did not change in a consistent manner with decreasing mean annual precipitation. A. platanoides was the only species with a significant increase in FRB from the moister to the drier sites in 2017, which could point at increased belowground $\mathrm{C}$ allocation to increase water uptake, while $Q$. petraea showed a decrease and the other three species no relation of FRB to MAP. The outcome was not different when other precipitation variables (e.g., MGSP, current-year precipitation or climatic water balance) were used instead of the long-term mean. Other studies along precipitation gradients obtained mixed results, either no consistent change in FRB and relative $\mathrm{C}$ allocation to roots (Joslin et al., 2000; Meier et al., 2018), a decrease (Leuschner et al., 2004; Meier and Leuschner, 2008a), or an increase with decreasing water availability (Hertel et al., 2013; Parker and van Lear, 1996), suggesting a large influence of species and soil moisture conditions on the drought response of carbon allocation. Clearly, our fine root inventory covers only the topsoil and we hence may have missed preferential biomass partitioning to other parts of the root system. Trees growing at drier sites could allocate more carbon to root growth in deeper soil layers to access the moister subsoil and escape surface drying (Konôpka and Lukac, 2013; Persson et al., 1995). However, a metaanalysis of root biomass data by Schenk and Jackson (2002) and a detailed study of the subsoil root system of Fagus sylvatica along a precipitation gradient by Meier et al. (2018) showed the opposite response to long-term precipitation reduction, i.e., shallower rooting of trees under water limitation. An alternative explanation for the weak support for OPT in our study could be the only moderate length of the studied precipitation gradient (MAP difference: $390 \mathrm{~mm}_{\text {year }}{ }^{-1}$ ), which apparently had only a minor effect on total tree productivity. Carbon allocations shifts in support of OPT were mostly found in studies across biomes or in experiments with very different treatments. Poorter et al. (2012) concluded from a meta-analysis that marked increases in allocation to the root system occur only, when drought reduces biomass by 50 percent or more, which is not the case here. 
The PCAs with root-related and environmental variables support the conclusion that the average soil moisture regime as indicated by the MAP gradient has only a minor influence on the FRB stocks at our study sites. In both root inventories, the association of FRB with edaphic and climatic variables suggests that topsoil FRB generally increases with organic matter content, but decreases with increasing nitrogen content, silt content and soil bulk density, while the effect of climatic factors (MAP, MAT) and also soil pH and $\mathrm{P}$ content is weak. This is in accordance with the observation that fine root density in temperate forest soils is usually highest in the carbon-rich Ah horizon and the organic layer with low bulk density (Kirfel et al., 2019; Leuschner et al., 2004).

Inherited tree species differences in FRB seem also to be more influential on FRB patterns than moisture conditions. In our study, F. excelsior had up to five times higher FRB densities in the topsoil than $Q$. petraea and $T$. cordata, with intermediate values in C. betulus and A. platanoides. While part of this variation may be due to differences in DBH and small-scale variations in stem density between species in mixed stands, comparison with earlier fine root studies in mixed forests suggests that the high FRB of $F$. excelsior and the low values of $Q$. petraea may be species-specific. This is indicated by a meta-analysis of fine root studies from temperate forests (Leuschner and Hertel, 2003) and root inventories in mixed forests (Jacob et al., 2014; Leuschner et al., 2001b). An additional explanation for low FRB values of $Q$. petraea might be a different depth distribution of fine roots, as other authors state that Central European oak species are generally deeper rooted than beech and other broadleaf tree species (Rosengren et al., 2006), but precise data on depth-distributions are lacking for our sites. The contrasting FRB patterns of $A$. platanoides and $Q$. petraea along the precipitation gradient further indicate that co-occurring tree species may differ not only in standing FRB but also in root mortality and the response of their carbon allocation modes to long-term reduction in water availability.

As predicted (hypothesis 1), all five species showed increasing amounts of FRN and an increasing N/B ratio in the topsoil with a decrease in MAP, while FRB remained unchanged (with the exception of A. platanoides). One possible explanation of this pattern is that fine root mortality increases with a permanent reduction in water availability, as has been observed in many field studies (e.g., Meier and Leuschner, 2008a) and concluded from literature reviews (e.g., Eissenstat et al., 2013; McCormack and Guo, 2014), which in turn may trigger increased carbon allocation to root growth in compensation of the FRB loss. This was observed, for example, in Norway spruce roots 
under mild drought stress (soil matrix potentials of-0.06 MPa, Gaul et al., 2008). Such a response will reduce mean fine root age and likely increase the water and nutrient uptake capacity of the tree and thus its fitness under water shortage (Brunner et al., 2015; Eissenstat and Yanai, 2002). Another possible explanation is fine root shedding with the assumed function to uncouple the rest of the hydraulic system from very low water potentials in dry soil to avoid embolism formation in more valuable organs (hydraulic fuse theory, Alder et al., 1996; Jackson et al., 2000). It could take place during more severe drought events and does not imply the immediate replacement by new fine roots. In support of this idea, McCormack and Guo (2014) predicted on the basis of a conceptual model exponential increases in root mortality at the highest drought stress intensities. This is in accordance with the results of a rainfall exclusion experiment with Picea abies trees, in which, under mild drought, root mortality increased, while fine root production was also stimulated. Under more severe drought, root mortality was high and no replacement occurred (Gaul et al., 2008).

Our data suggest that the five species differ in specific root mortality rates upon soil desiccation, as the N/B ratio showed a more than tenfold increase with the MAP reduction along the transect in $T$. cordata, intermediate N/B slopes in $C$. betulus, A. platanoides, and $F$. excelsior, and the lowest increase in $Q$. petraea. We interpret these patterns as a hint that $Q$. petraea is better able than the other species to produce fine roots capable of tolerating long-term reductions in soil moisture without suffering increased root mortality. Physiological and genetic studies have to show whether this is due to a principally different physiological constitution of the fine roots of this ring-porous species, or is caused by the specific acclimation or adaptation of different oak populations along the precipitation gradient. An alternative explanation for increasing FRN amounts and N/B ratios with a MAP reduction is that the drier and somewhat warmer climate toward the east of the transect reduces root decomposition rate and thus leads to the accumulation of FRN, independent of changes in root mortality rate. In the absence of decomposition data, this possibility cannot be ruled out, but it is not very likely. The gradients in MAT $\left(7.9-9.9^{\circ} \mathrm{C}\right)$, soil $\mathrm{pH}(4.2-6.5)$ and $\mathrm{C} / \mathrm{N}$ ratio (10.7-18.9) along the transect were only moderate and the latter factors did not covary significantly, either with MAP or FRN. Moreover, site differences in decomposition rate should mainly affect the finest root necromass particles, which were not investigated here. We assume that the analyzed larger, less fragmented necromass fractions (>10 mm length) reflect more 
directly the root mortality processes, where decomposition likely has started only very recently.

\subsubsection{Effects of the 2018 Summer Drought on Fine Root Biomass and Belowground C} Allocation

It is noteworthy that none of the species showed a decrease in mean FRB across the transect after the severe 2018 summer drought (in C. betulus, a non-significant tendency for a decrease existed). The 2018 drought with summer precipitation amounts $55-73 \%$ lower than the long-term average was extreme and resulted in the local dieback of more sensitive tree species (Picea abies, Fagus sylvatica) in the region. This indicates that all five species must be relatively tolerant of soil desiccation compared to other major timber species, and that precipitation is playing only a secondary role for the standing FRB of these species. It is possible that our FRB figures are influenced by temperature and other seasonal influences unrelated to summer drought, as fine root production and biomass stocks typically peak between April and July in central European broadleaf tree species, as is visible from studies in beech (Ladefoged, 1939; Meier and Leuschner, 2008a) and beech-oak mixed forests (Hertel and Leuschner, 2002). Thus, we cannot exclude with certainty that the biomass figures observed in September 2018 represent reduced values which are influenced by the typical seasonal FRB decrease that should have taken place later in summer. However, we did not observe a FRB reduction. Moreover, if the reduction had occurred, it should have been similar along the transect. In addition, the $A$. platanoides data from the moist transect end indicate the opposite, a FRB increase from the 2017 to the 2018 inventory.

Higher FRN amounts in three of the species (A. platanoides, F. excelsior, and $Q$. petraea) in 2018 (in comparison to 2017) indicate that drought has increased root mortality. Interestingly, the severe drought drove all N/B ratios to converge on a higher level, or, in other words, all species lost the MAP dependence of necromass and N/B ratio after the drought. This suggests that the mortality increase was greater at the moister than the drier sites in all species except for $Q$. petraea, which largely supports hypothesis 3 . We explain this pattern with a generally higher drought sensitivity of the root systems at MAP > ca. $700 \mathrm{~mm} \mathrm{year}^{-1}$, which caused higher root mortality and leveled all FRN differences that exist along the transect in normal years. In T. cordata and C. betulus, FRN and N/B ratio were also higher at the moister sites in 2018 than 2017, but this response was compensated by lower FRN amounts at the drier sites. Thus, our second hypothesis is only partly supported. 
In a meta-analysis about stand- and soil-related drivers of fine root N/B ratio across biomes, Wang et al. (2018) found elevated N/B ratios at reduced precipitation only in forests dominated by ECM tree species, but not in AM forests. This suggests an influence of mycorrhizal type on the drought response of the root system. Liese et al. (2019) confirmed these findings in a mesocosm experiment for several temperate tree species (including Acer, Fraxinus, Carpinus, Tilia, and Quercus taxa), demonstrating a much greater drought-induced root lifespan reduction in ECM than AM species (40-56\% vs. 0.5-13\%). Our data from three ECM (C. betulus, T. cordata, and Q. petraea) and two AM species (A. platanoides and F. excelsior) do not support this conclusion, as $Q$. petraea was the species with the smallest N/B response to a MAP reduction at the drier end of the gradient. The response to the 2018 summer drought even revealed the opposite response pattern to that found by Wang et al. (2018) and Liese et al. (2019), with a significant increase in the N/B ratios in the AM species A. platanoides and F. excelsior, while all ECM species did not respond. One possible explanation for the discrepancy between the results of the Wang et al. (2018) and Liese et al. (2019) studies and our investigation is that largely different spatial scales (comparison of biomes with different climates; sapling experiment; regional gradient study) are considered.

\subsubsection{Root Morphological Change in Response to Reduced Water Availability}

Trees can adapt to shortages in water or nutrients by increasing the absorptive capacity of the root system in two different ways: by enhancing root production and maintaining larger absorbing surface areas (extensive strategy), or by modifying root morphology and physiology in order to increase uptake efficiency per root mass (intensive strategy, Lõhmus et al., 2006; Ostonen et al., 2007). In contrast to the other four species, Q. petraea showed characteristics of an intensive adaptation strategy by increasing SRA and the number of root tips per root mass towards the drier sites according to the 2017 inventory, while FRB remained constant. $Q$. petraea differed further from the other species by showing no root tip shedding and no SRA reduction after the 2018 drought. A. platanoides showed the opposite response with a FRB increase towards the drier sites, while root morphology was not altered. The other three species maintained a constant FRB along the gradient, but the marked FRN increase toward the drier sites points at elevated root turnover and compensatory stimulation of fine root production under desiccation, which can be viewed as attributes of an extensive strategy.

After the 2018 drought, all species except $Q$. petraea showed a marked dieback of root tips and more distal thin rootlets. This resulted in the observed SRA reduction, which was 
particularly strong in $T$. cordata. The losses in the putatively most active finest rootlets had not been replaced until September 2018, when sampling was conducted. We interpret this response in 2018 as an indicator of belowground vulnerability to extreme drought, which must have reduced the vitality and absorptive capacity of the fine root system of F. excelsior, A. platanoides, C. betulus, and T. cordata.

\subsubsection{Species Differences in the Belowground Drought Response}

The fine root system of $Q$. petraea seems to be more resistant to both permanent moisture reduction and severe drought events than that of T. cordata, C. betulus, F. excelsior, and A. platanoides due to the following features: (1) Although fine root necromass increased after the 2018 summer drought, the N/B ratio changed only a little and it was roughly constant across the precipitation gradient. (2) Fine root morphology and the number of root tips were not affected by the drought, indicating either low sensitivity or rapid recovery in oak roots. This fits to findings from the dendrochronological analysis of climate sensitivity (e.g., Kunz et al., 2018) and more general comparative assessments of drought resistance of the species based on climate envelopes (Leuschner and Ellenberg, 2017; Walentowski et al., 2017). On the other hand, $Q$. petraea maintained the lowest fine root density in the topsoil and more generally seems to produce a relatively small fine root system. Due to still-unknown morphological and/or physiological properties, oak can also maintain its fine roots in dry periods instead of shedding and partly replacing them. This rather "conservative" strategy with lower maintenance costs and a more or less constant root biomass during wet and dry periods was also observed in other Central European oak forests by Leuschner et al. (2001b), who compared $Q$. petraea to $F$. sylvatica and concluded that this strategy comes with the drawback of inferior interspecific competitive ability.

The other four species have in common that they all show indications of a somewhat greater belowground vulnerability to severe soil drought, but they pursue different strategies. T. cordata seems to be the most vulnerable species due to large droughtinduced reductions in SRA and tip frequency, which is in line with assessments based on leaf and stem level data (Köcher et al., 2009; Leuschner et al., 2019). F. excelsior is unique due to its high fine root density, which may secure water uptake in drought periods and increase the species' competitive ability in mixed stands and on very shallow and dry soils.

Our results suggest that co-occurring tree species differ in the drought sensitivity of their fine root systems, which could play an important role with respect to the species' 
fitness and drought survival. Yet, much less is known about the belowground growth and stress tolerance strategies of trees than about aboveground responses.

This case study suffers from a number of shortcomings that are introduced with the study design and the methods used, which may bias some of the conclusions. First, the study design is not fully symmetric, as not all tree species occur at all sites, which weakens the power of statistical analysis. Second, our FRN analysis covers only the larger fragments, as the finest particles could not be identified to the species level. Consideration of the complete root necromass pool might have led to somewhat different results. Finally, edaphic inhomogeneity introduces some noise in the climatic signal retrieved from the precipitation gradient, which may weaken some of the conclusions. Fortunately, climate and soil properties did not covary systematically. While the retrieved patterns seem plausible, they need verification by additional gradient studies in other regions and with additional species.

We conclude that the comparative analysis of fine root biomass, necromass, and fine root morphology along precipitation gradients, and in moist and dry periods, has the potential to provide valuable information on the belowground drought sensitivity of tree species, thereby complementing results from canopy- and leaf-level studies. 
Author Contributions: Conceptualization, C.L., S.F., D.H., B.S.; Data curation, S.F.; Formal analysis, S.F.; Funding acquisition, C.L.; Investigation, S.F.; Methodology, S.F. and D.H.; Project administration, B.S. and C.L.; Supervision, D.H., B.S., and C.L.; Validation, S.F. and C.L.; Visualization, S.F.; Writing-original draft, S.F. and C.L.; Writing-review and editing, S.F., C.L., and D.H.

Funding: This research was funded by the Bundesministerium für Ernährung und Landwirtschaft (Germany), Bundesministerium für Umwelt, Naturschutz und nukleare Sicherheit (Germany) and the Fachagentur Nachwachsende Rohstoffe e. V. (Germany) within the frame of the "Waldklimafonds".

Acknowledgments: Many thanks go to Irmgard Gerstmann and Mechthild Stange for their skillful support with the fine root analysis. We gratefully acknowledge the financial support granted by the Bundesministerium für Ernährung und Landwirtschaft (Germany), Bundesministerium für Umwelt, Naturschutz und nukleare Sicherheit (Germany) and the Fachagentur Nachwachsende Rohstoffe e. V. (Germany) within the frame of the "Waldklimafonds" (project DIVforCLIM). Additionally, we thank the local forestry authorities of Lower Saxony and Saxony-Anhalt and the DBU-Naturerbe GmbH for permissions to conduct the study, and the Nordwestdeutsche Forstliche Versuchsanstalt for kindly providing forest inventory data for the identification of suitable study sites.

Conflicts of Interest: The authors declare no conflict of interest. The funders had no role in the design of the study; in the collection, analyses, or interpretation of data; in the writing of the manuscript, or in the decision to publish the results. 


\subsection{Appendix B}

Table 3.6: Results of linear mixed effects models for fine root bio- and necromass in dependence of actual precipitation in the year prior to sampling (act.PRCP). Given are estimates of the fixed effect (fine root trait $\sim$ species:MAP), marginal pseudo- $R^{2}$ for the fixed effect (calculated according to Nakagawa and Schielzeth (2013)), and $p$-values. $p$-values below 0.05 are given in bold. All fine root traits were log-transformed in advance.

\begin{tabular}{|c|c|c|c|c|c|c|}
\hline \multirow{2}{*}{$\begin{array}{l}\text { Model } \\
\text { Species }\end{array}$} & \multicolumn{3}{|c|}{2017 (Moist) } & \multicolumn{3}{|c|}{2018 (Dry) } \\
\hline & Estimate & Pseudo $r^{2}$ & $p$-value & Estimate & Pseudo $r^{2}$ & $p$-value \\
\hline \multicolumn{7}{|c|}{ Fine root biomass $\sim$ act.PRCP } \\
\hline Fraxinus excelsior & -0.0003 & 0.00 & 0.805 & 0.0007 & 0.00 & 0.543 \\
\hline Carpinus betulus & -0.0007 & 0.03 & 0.650 & -0.0008 & 0.02 & 0.544 \\
\hline Acer platanoides & -0.0066 & 0.33 & $<0.001$ & -0.0006 & 0.02 & 0.630 \\
\hline Quercus petraea & 0.0041 & 0.15 & 0.013 & 0.0003 & 0.00 & 0.824 \\
\hline Tilia cordata & -0.0028 & 0.04 & 0.313 & -0.0015 & 0.07 & 0.447 \\
\hline \multicolumn{7}{|c|}{ Fine root necromass $\sim$ act.PRCP } \\
\hline Fraxinus excelsior & -0.0096 & 0.30 & 0.003 & -0.0032 & 0.06 & 0.152 \\
\hline Carpinus betulus & -0.0087 & 0.14 & 0.017 & 0.0013 & 0.00 & 0.622 \\
\hline Acer platanoides & -0.0147 & 0.48 & $<0.001$ & -0.0031 & 0.06 & 0.227 \\
\hline Quercus petraea & -0.0001 & 0.00 & 0.975 & 0.0008 & 0.00 & 0.750 \\
\hline Tilia cordata & -0.0247 & 0.43 & $<0.001$ & 0.0000 & 0.00 & 0.994 \\
\hline \multicolumn{7}{|c|}{ Necro-/biomass-ratio act.PRCP } \\
\hline Fraxinus excelsior & -0.0094 & 0.32 & $<0.001$ & -0.0038 & 0.07 & 0.089 \\
\hline Carpinus betulus & -0.0077 & 0.12 & 0.014 & 0.0021 & 0.01 & 0.415 \\
\hline Acer platanoides & -0.0079 & 0.24 & 0.009 & -0.0024 & 0.04 & 0.345 \\
\hline Quercus petraea & -0.0040 & 0.06 & 0.192 & 0.0005 & 0.00 & 0.825 \\
\hline Tilia cordata & -0.0220 & 0.40 & $<0.001$ & 0.0017 & 0.03 & 0.668 \\
\hline
\end{tabular}



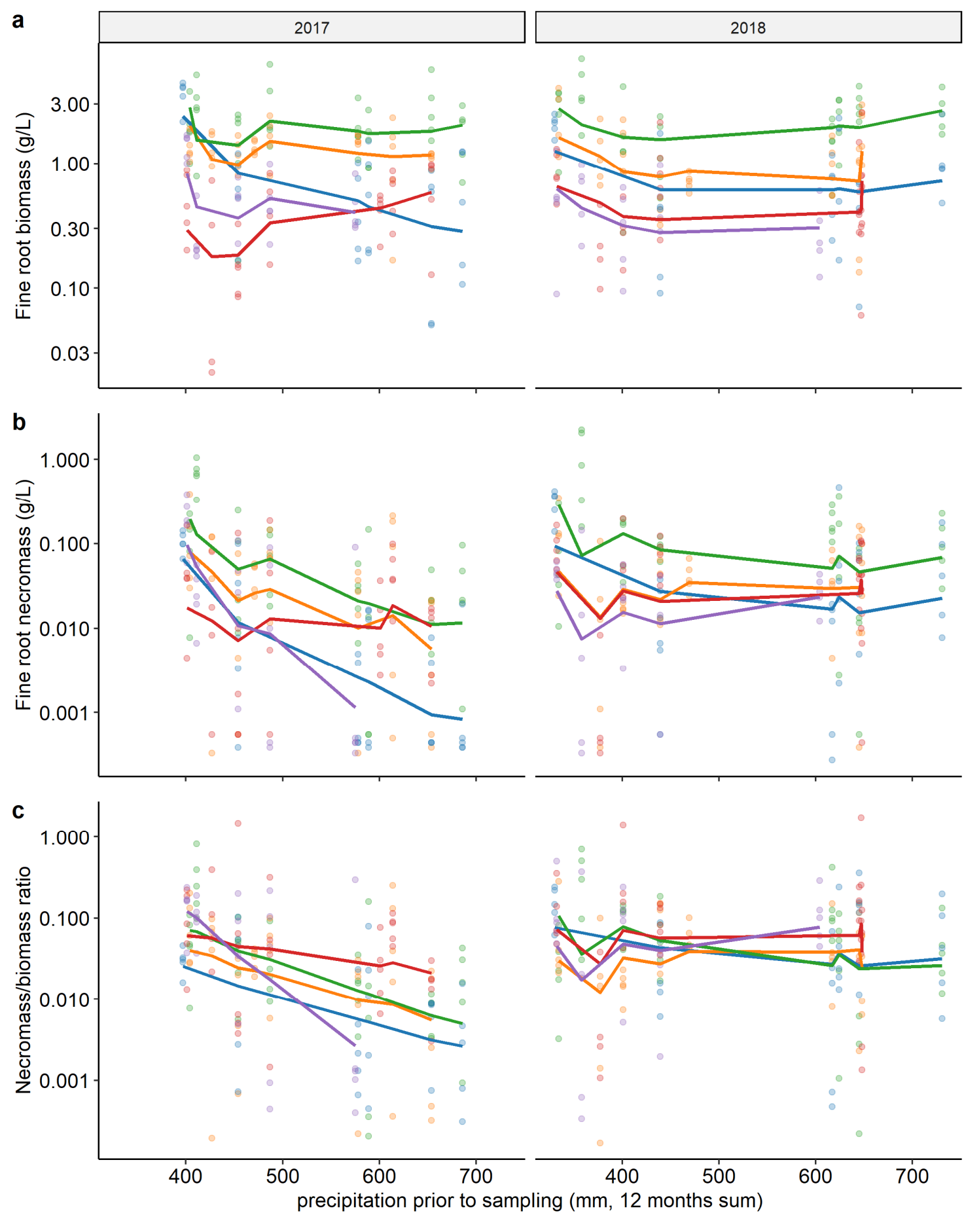

$$
\begin{aligned}
& =\text { Acer platanoides }- \text { Carpinus betulus }- \text { Fraxinus excelsior } \\
\text { Species } & =\text { Quercus petraea }=\text { Tilia cordata }
\end{aligned}
$$

Figure 3.5: Fine root biomass (a), necromass (b) and necromass/biomass ratio (c) in the topsoil $(0-10 \mathrm{~cm})$ of the five species in relation to actual precipitation in the year prior to sampling in the 2017 and 2018 inventories. Data points are tree-level values, lines represent conditional predictions of the linear mixed effects model (the predictions of the fixed effect "MAP" for each species plus an intercept for each level of the random factor "site"). Note the log-scaled $\mathrm{y}$-axis. The corresponding $\mathrm{p}$ and pseudo- $\mathrm{R}^{2}$ values are summarized in Table A1. 

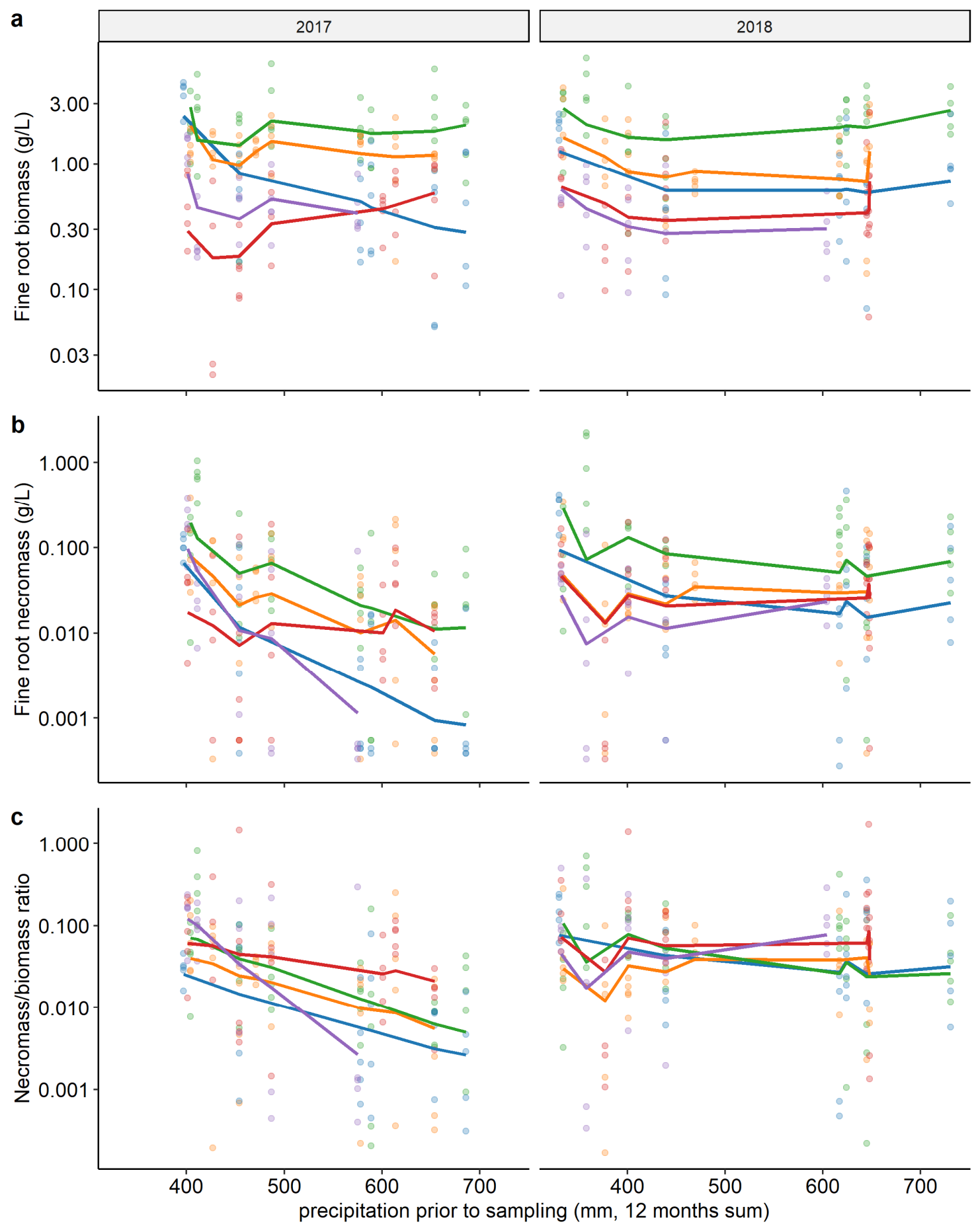

$$
\begin{aligned}
& =\text { Acer platanoides }=\text { Carpinus betulus }- \text { Fraxinus excelsior } \\
\text { Species } & =\text { Quercus petraea }=\text { Tilia cordata }
\end{aligned}
$$

Figure 3.6: Specific root area (a), fine root tips per root mass (b), and average fine root diameter (c) in the topsoil $(0-10 \mathrm{~cm})$ of the five species in relation to mean annual precipitation (MAP) in the 2017 and 2018 inventories. Data points are tree-level values, lines represent conditional predictions of the linear mixed effects model (the predictions of the fixed effect "MAP" for each species plus an intercept for each level of the random factor "site"). Note the $\log$-scaled y-axis. The corresponding $p$ and pseudo- $R^{2}$ values are summarized in Table 3.3. 


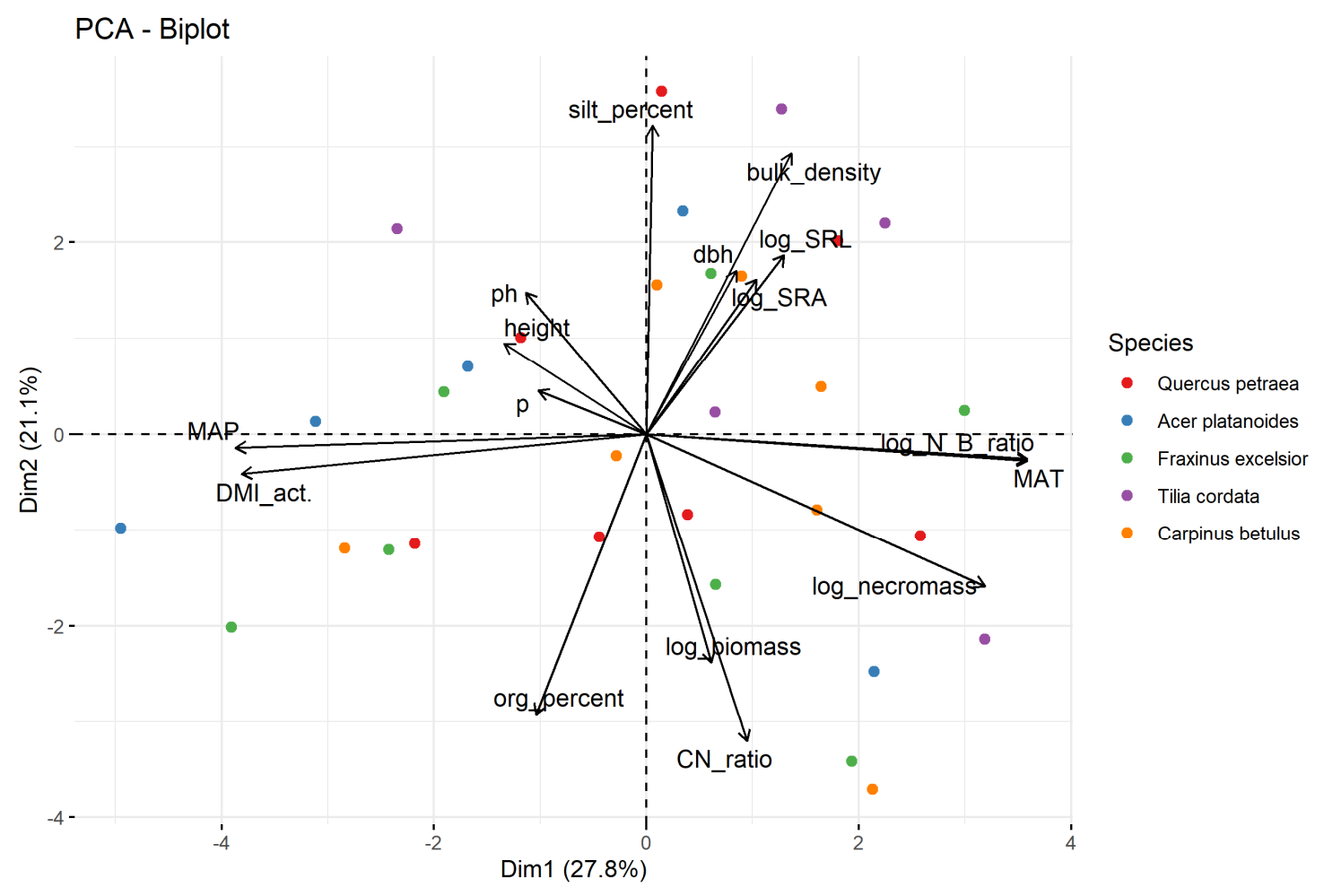

Figure 3.7: Principal components analysis (PCA) biplot of the 2017 fine root inventory. All data are aggregated on site and species level.

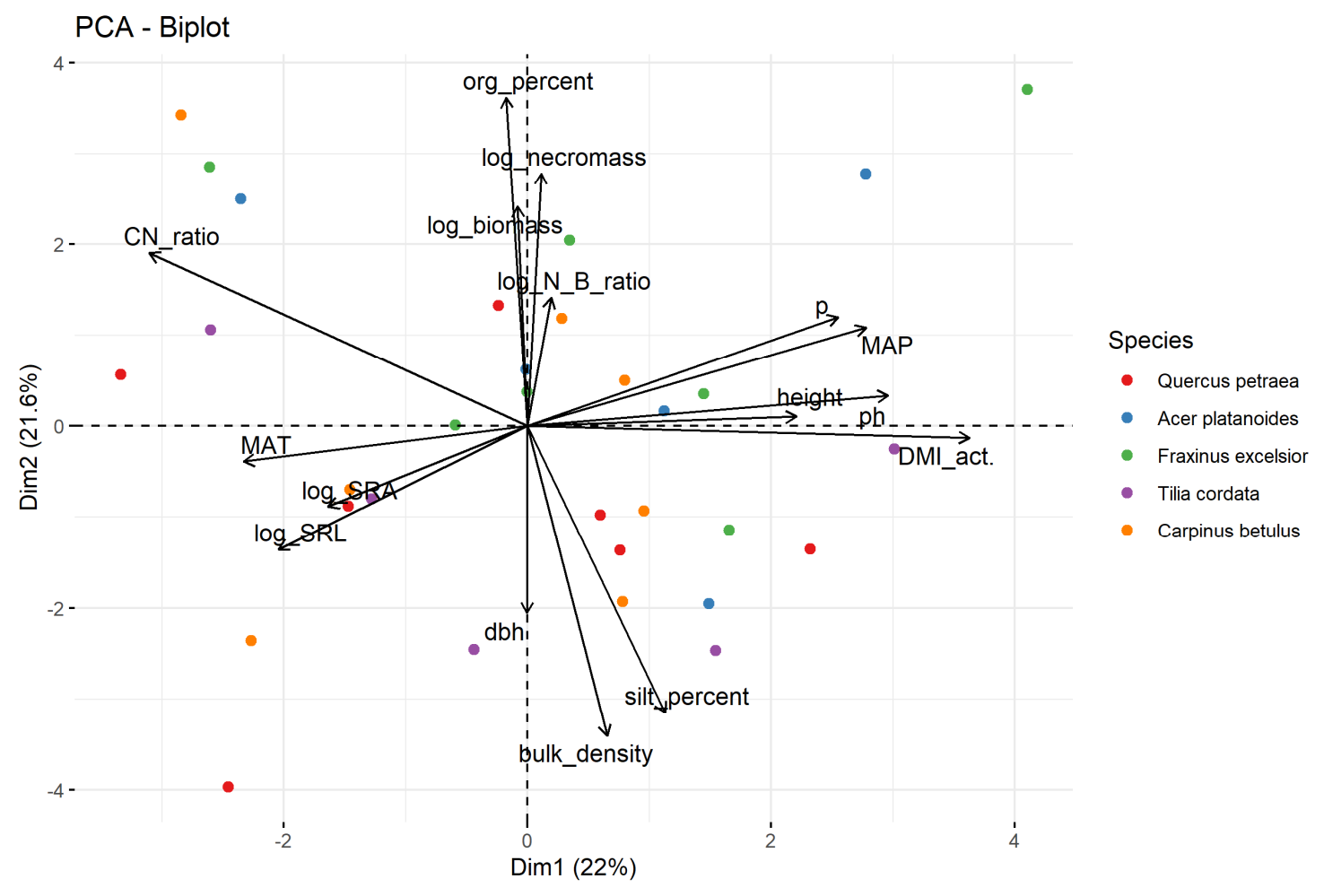

Figure 3.8: Principal components analysis (PCA) biplot of the 2018 fine root inventory. All data are aggregated on site and species level. 


\subsection{References}

Alder, N.N., Sperry, J.S., Pockman, W.T., 1996. Root and stem xylem embolism, stomatal conductance, and leaf turgor in Acer grandidentatum populations along a soil moisture gradient. Oecologia 105, 293-301. https://doi.org/10.1007/BF00328731.

Allen, C.D., Macalady, A.K., Chenchouni, H., Bachelet, D., McDowell, N., Vennetier, M. et al, 2010. A global overview of drought and heat-induced tree mortality reveals emerging climate change risks for forests. For. Ecol. Manage. 259, 660-684. https://doi.org/10.1016/j.foreco.2009.09.001.

Anderegg, W.R.L., Kane, J.M., Anderegg, L.D.L., 2013. Consequences of widespread tree mortality triggered by drought and temperature stress. Nat. Clim. Change 3, 3036. https://doi.org/10.1038/nclimate1635.

Aspelmeier, S., Leuschner, C., 2006. Genotypic variation in drought response of silver birch (Betula pendula Roth): leaf and root morphology and carbon partitioning. Trees 20, 42-52. https://doi.org/10.1007/s00468-005-0011-9.

Bakker, M.R., Augusto, L., Achat, D.L., 2006. Fine root distribution of trees and understory in mature stands of maritime pine (Pinus pinaster) on dry and humid sites. Plant Soil 286, 37-51. https://doi.org/10.1007/s11104-006-9024-4.

Bates, D., Mächler, M., Bolker, B., Walker, S., 2015. Fitting Linear Mixed-Effects Models Using lme4. J. Stat. Soft. 67. https://doi.org/10.18637/jss.v067.i01.

Bauhus, J., Bartsch, N., 1996. Fine-root growth in beech (Fagus sylvatica) forest gaps. Can. J. For. Res. 26, 2153-2159. https://doi.org/10.1139/x26-244.

Bloom, A.J., Chapin, F.S., Mooney, H.A., 1985. Resource Limitation in Plants-An Economic Analogy. Annu. Rev. Ecol. Syst. 16, 363-392. https://doi.org/10.1146/annurev.es.16.110185.002051.

Bongarten, B.C., Teskey, R.O., 1987. Dry weight partitioning and its relationship to productivity in loblolly pine seedlings from seven sources. For. Sci. 33, 255-267.

Brunner, I., Herzog, C., Dawes, M.A., Arend, M., Sperisen, C., 2015. How tree roots respond to drought. Front. Plant Sci. 6, 547. https://doi.org/10.3389/fpls.2015.00547.

Chenlemuge, T., Hertel, D., Dulamsuren, C., Khishigjargal, M., Leuschner, C., Hauck, M., 2013. Extremely low fine root biomass in Larix sibirica forests at the southern drought limit of the boreal forest. Flora 208, 488-496. https://doi.org/10.1016/j.flora.2013.08.002.

Coomes, D.A., Grubb, P.J., 2000. Impacts of root competition in forests and woodlands: A theoretical framework and review of experiments. Ecol. Monogr. 70, 171-207. https://doi.org/10.1890/0012-9615(2000)070[0171:IORCIF]2.0.CO;2.

Eissenstat, D.M., McCormack, M.L., Du, Q., 2013. Global change and root lifespan, in: Eshel A., B.T. (Ed.), Plant Roots: The Hidden Half, 4th ed. Taylor and Francis Group/CRC Press, Boca Raton, Florida, USA, 27-1 - 27-13.

Eissenstat, D.M., Wells, C.E., Yanai, R.D., Whitbeck, J.L., 2000. Building roots in a changing environment: implications for root longevity. New Phytol. 147, 33-42. https://doi.org/10.1046/j.1469-8137.2000.00686.x. 
Eissenstat, D.M., Yanai, R.D., 2002. Root life span, efficiency, and turnover, in: Kafkafi, U., Waisel, Y., Eshel, A. (Eds.), Plant Roots. CRC Press, Boca Raton, Florida, USA, pp. 221-238.

Gaul, D., Hertel, D., Borken, W., Matzner, E., Leuschner, C., 2008. Effects of experimental drought on the fine root system of mature Norway spruce. For. Ecol. Manage. 256, 1151-1159. https://doi.org/10.1016/j.foreco.2008.06.016.

Hemery, G.E., Clark, J.R., Aldinger, E., Claessens, H., Malvolti, M.E., O'connor, E. et al, 2010. Growing scattered broadleaved tree species in Europe in a changing climate: a review of risks and opportunities. Forestry 83, 65-81. https://doi.org/10.1093/FORESTRY/CPP034.

Hertel, D., Leuschner, C., 2002. A comparison of four different fine root production estimates with ecosystem carbon balance data in a Fagus-Quercus mixed forest. Plant Soil 239, 237-251. https://doi.org/10.1023/A:1015030320845.

Hertel, D., Strecker, T., Müller-Haubold, H., Leuschner, C., 2013. Fine root biomass and dynamics in beech forests across a precipitation gradient - is optimal resource partitioning theory applicable to water-limited mature trees? J. Ecol. 101, 11831200. https://doi.org/10.1111/1365-2745.12124.

Hertel, D., Therburg, A., Villalba, R., 2008. Above- and below-ground response by Nothofagus pumilio to climatic conditions at the transition from the steppe-forest boundary to the alpine treeline in southern Patagonia, Argentina. Plant Ecol. Divers. 1, 21-33. https://doi.org/10.1080/17550870802257026.

IPCC, 2014. Climate Change 2014: Impacts, Adaptation, and Vulnerability. Part A: Global and Sectoral Aspects, in: Field, C.B., Barros, V.R., Dokken, D.J., Mach, K.J., Mastrandrea, M.D. (Eds.), Contribution of Working Group II to the Fifth Assessment Report of the Intergovernmental Panel on Climate Change. Cambridge University Press, Cambridge.

Jackson, R.B., Mooney, H.A., Schulze, E.D., 1997. A global budget for fine root biomass, surface area, and nutrient contents. PNAS 94, 7362-7366. https://doi.org/10.1073/pnas.94.14.7362.

Jackson, R.B., Sperry, J.S., Dawson, T.E., 2000. Root water uptake and transport: using physiological processes in global predictions. Trends Plant Sci. 5, 482-488. https://doi.org/10.1016/S1360-1385(00)01766-0.

Jacob, A., Hertel, D., Leuschner, C., 2014. Diversity and species identity effects on fine root productivity and turnover in a species-rich temperate broad-leaved forest. Funct. Plant Biol. 41, 678. https://doi.org/10.1071/FP13195.

Joslin, J.D., Wolfe, M.H., Hanson, P.J., 2000. Effects of altered water regimes on forest root systems. New Phytol. 147, 117-129. https://doi.org/10.1046/j.14698137.2000.00692.x.

Kaspar, F., Müller-Westermeier, G., Penda, E., Mächel, H., Zimmermann, K., KaiserWeiss, A. et al, 2013. Monitoring of climate change in Germany - data, products and services of Germany's National Climate Data Centre. Adv. Sci. Res. 10, 99-106. https://doi.org/10.5194/asr-10-99-2013.

Kassambara A, Mundt F, 2017. factoextra: Extract and Visualize the Results of Multivariate Data Analyses. https://CRAN.R-project.org/package=factoextra (accessed 1 June 2019). 
Kirfel, K., Heinze, S., Hertel, D., Leuschner, C., 2019. Effects of bedrock type and soil chemistry on the fine roots of European beech - A study on the belowground plasticity of trees. For. Ecol. Manage. 444, 256-268. https://doi.org/10.1016/j.foreco.2019.04.022.

Köcher, P., Gebauer, T., Horna, V., Leuschner, C., 2009. Leaf water status and stem xylem flux in relation to soil drought in five temperate broad-leaved tree species with contrasting water use strategies. Ann. For. Sci. 66, 101. https://doi.org/10.1051/forest/2008076.

Konôpka, B., Lukac, M., 2013. Moderate drought alters biomass and depth distribution of fine roots in Norway spruce. For. Path. 43, 115-123. https://doi.org/10.1111/efp.12005.

Kozlowski, T.T., Pallardy, S.G., 2002. Acclimation and Adaptive Responses of Woody Plants to Environmental Stresses. Bot. Rev. 68, 270-334. https://doi.org/10.1663/0006-8101(2002)068[0270:AAAROW]2.0.CO;2.

Kubisch, P., Hertel, D., Leuschner, C., 2015. Do ectomycorrhizal and arbuscular mycorrhizal temperate tree species systematically differ in root order-related fine root morphology and biomass? Front. Plant Sci. 6, 64. https://doi.org/10.3389/fpls.2015.00064.

Kunz, J., Löffler, G., Bauhus, J., 2018. Minor European broadleaved tree species are more drought-tolerant than Fagus sylvatica but not more tolerant than Quercus petraea. For. Ecol. Manage. 414, 15-27. https://doi.org/10.1016/j.foreco.2018.02.016.

Kuster, T.M., Arend, M., Günthardt-Goerg, M.S., Schulin, R., 2013. Root growth of different oak provenances in two soils under drought stress and air warming conditions. Plant Soil 369, 61-71. https://doi.org/10.1007/s11104-012-1541-8.

Kuznetsova, A., Brockhoff, P., Christensen, R.H.B., 2017. lmerTest Package: Tests in Linear Mixed Effects Models. J. Stat. Soft. 82, 1-26. https://doi.org/10.18637/jss.v082.i13.

Ladefoged, K., 1939. Untersuchungen über die Periodizität im Ausbruch und Längenwachstum der Wurzeln: bei einigen unserer gewöhnlichsten Waldbäume: Dansk resume. AF Høst \& Søn, Kopenhagen, Denmark.

Lê, S., Josse, J., Husson, F., 2008. FactoMineR : An R Package for Multivariate Analysis. J. Stat. Soft. 25. https://doi.org/10.18637/jss.v025.i01.

Leuschner, C., Backes, K., Hertel, D., Schipka, F., Schmitt, U., Terborg, O. et al, 2001a. Drought responses at leaf, stem and fine root levels of competitive Fagus sylvatica L. and Quercus petraea (Matt.) Liebl. trees in dry and wet years. For. Ecol. Manage. 149, 33-46. https://doi.org/10.1016/S0378-1127(00)00543-0.

Leuschner, C., Ellenberg, H., 2017. Ecology of Central European Forests. Springer Nature, Cham.

Leuschner, C., Hertel, D., 2003. Fine Root Biomass of Temperate Forests in Relation to Soil Acidity and Fertility, Climate, Age and Species. Prog. Bot. 64, 405-438. https://doi.org/10.1007/978-3-642-55819-1_16.

Leuschner, C., Hertel, D., Coners, H., Büttner, V., 2001b. Root competition between beech and oak: a hypothesis. Oecologia 126, 276-284.

https://doi.org/10.1007/s004420000507. 
Leuschner, C., Hertel, D., Schmid, I., Koch, O., Muhs, A., Hölscher, D., 2004. Stand fine root biomass and fine root morphology in old-growth beech forests as a function of precipitation and soil fertility. Plant Soil 258, 43-56. https://doi.org/10.1023/B:PLSO.0000016508.20173.80.

Leuschner, C., Meier, I.C., 2018. The ecology of Central European tree species: Trait spectra, functional trade-offs, and ecological classification of adult trees. Perspect. Plant Ecol. Evol. Syst. 33, 89-103. https://doi.org/10.1016/j.ppees.2018.05.003.

Leuschner, C., Wedde, P., Lübbe, T., 2019. The relation between pressure-volume curve traits and stomatal regulation of water potential in five temperate broadleaf tree species. Ann. For. Sci. 76, 93. https://doi.org/10.1007/s13595-019-0838-7.

Liese, R., Leuschner, C., Meier, I.C., 2019. The effect of drought and season on root life span in temperate arbuscular mycorrhizal and ectomycorrhizal tree species. J. Ecol. 34, 187. https://doi.org/10.1111/1365-2745.13181.

Lõhmus, K., Truu, J., Truu, M., Kaar, E., Ostonen, I., Alama, S. et al, 2006. Black alder as a promising deciduous species for the reclaiming of oil shale mining areas, in: Brebbia, C.A., Mander, Ü. (Eds.), Brownfield sites III. Prevention, assessment, rehabilitation and development of brownfield sites / edited by C.A. Brebbia and U. Mander. WIT, Southampton. WIT transactions on ecology and the environment, pp. 87-97.

López, B., Sabaté, S., Gracia, C., 1998. Fine roots dynamics in a Mediterranean forest: effects of drought and stem density. Tree Physiol. 18, 601-606. https://doi.org/10.1093/treephys/18.8-9.601.

Löpmeier, 1994. Berechnung der Bodenfeuchte und Verdunstung mittels agrarmeteorologischer Modelle. Zeitschrift f. Bewässerungswirtschaft, 157-167.

Maier, U., Müller-Westermeier, G., 2010. Verifikation klimatologischer Rasterfelder. Selbstverl. des Dt. Wetterdienstes, Offenbach am Main. Berichte des Deutschen Wetterdienstes 235 .

Mainiero, R., Kazda, M., 2006. Depth-related fine root dynamics of Fagus sylvatica during exceptional drought. For. Ecol. Manage. 237, 135-142. https://doi.org/10.1016/j.foreco.2006.09.034.

Makkonen, K., Helmisaari, H.-S., 1998. Seasonal and yearly variations of fine-root biomass and necromass in a Scots pine (Pinus sylvestris L.) stand. For. Ecol. Manage. 102, 283-290. https://doi.org/10.1016/S0378-1127(97)00169-2.

Martonne, E. de, 1926. L'indice d'aridité. Bull. Assoc. Geogr. Fr. 3, 3-5. https://doi.org/10.3406/bagf.1926.6321.

McCormack, M.L., Guo, D., 2014. Impacts of environmental factors on fine root lifespan. Front. Plant Sci. 5, 205. https://doi.org/10.3389/fpls.2014.00205.

Meier, I.C., Knutzen, F., Eder, L.M., Müller-Haubold, H., Goebel, M.-O., Bachmann, J. et al, 2018. The Deep Root System of Fagus sylvatica on Sandy Soil: Structure and Variation Across a Precipitation Gradient. Ecosystems 21, 280-296. https://doi.org/10.1007/s10021-017-0148-6.

Meier, I.C., Leuschner, C., 2008a. Belowground drought response of European beech: fine root biomass and carbon partitioning in 14 mature stands across a precipitation gradient. Global Change Biol. 14, 2081-2095. https://doi.org/10.1111/j.13652486.2008.01634.x. 
Meier, I.C., Leuschner, C., 2008b. Genotypic variation and phenotypic plasticity in the drought response of fine roots of European beech. Tree Physiol. 28, 297-309. https://doi.org/10.1093/treephys/28.2.297.

Meinen, C., Hertel, D., Leuschner, C., 2009. Biomass and morphology of fine roots in temperate broad-leaved forests differing in tree species diversity: is there evidence of below-ground overyielding? Oecologia 161, 99-111. https://doi.org/10.1007/s00442009-1352-7.

Mokany, K., Raison, R.J., Prokushkin, A.S., 2006. Critical analysis of root:shoot ratios in terrestrial biomes. Global Change Biol. 12, 84-96. https://doi.org/10.1111/j.13652486.2005.001043.x.

Müller-Westermeier, G., 1995. Numerisches Verfahren zu Erstellung klimatologischer Karten. Selbstverl. des Dt. Wetterdienstes, Offenbach am Main. Berichte des Deutschen Wetterdienstes 193.

Nadelhoffer, K.J., Raich, J.W., 1992. Fine Root Production Estimates and Belowground Carbon Allocation in Forest Ecosystems. Ecology 73, 1139-1147. https://doi.org/10.2307/1940664.

Nakagawa, S., Schielzeth, H., 2013. A general and simple method for obtaining R2 from generalized linear mixed-effects models. Methods Ecol. Evol. 4, 133-142. https://doi.org/10.1111/j.2041-210x.2012.00261.x.

Ostonen, I., Lõhmus, K., Helmisaari, H.-S., Truu, J., Meel, S., 2007. Fine root morphological adaptations in Scots pine, Norway spruce and silver birch along a latitudinal gradient in boreal forests. Tree Physiol. 27, 1627-1634. https://doi.org/10.1093/treephys/27.11.1627.

Parker, M.M., van Lear, D.H., 1996. Soil Heterogeneity and Root Distribution of Mature Loblolly Pine Stands in Piedmont Soils. Soil Sci. Soc. Am. J. 60, 1920. https://doi.org/10.2136/sssaj1996.03615995006000060043x.

Persson, H.Å., 1978. Root Dynamics in a Young Scots Pine Stand in Central Sweden. Oikos 30, 508. https://doi.org/10.2307/3543346.

Persson, H.Å., Fircks, Y. von, Majdi, H., Nilsson, L.O., 1995. Root distribution in a Norway spruce (Picea abies (L.) Karst.) stand subjected to drought and ammoniumsulphate application. Plant Soil 168-169, 161-165. https://doi.org/10.1007/BF00029324.

Persson, H.Å., Stadenberg, I., 2010. Fine root dynamics in a Norway spruce forest (Picea abies (L.) Karst) in eastern Sweden. Plant Soil 330, 329-344. https://doi.org/10.1007/s11104-009-0206-8.

Poorter, H., Niklas, K.J., Reich, P.B., Oleksyn, J., Poot, P., Mommer, L., 2012. Biomass allocation to leaves, stems and roots: meta-analyses of interspecific variation and environmental control. New Phytol. 193, 30-50. https://doi.org/10.1111/j.14698137.2011.03952.x.

Puhe, J., 2003. Growth and development of the root system of Norway spruce (Picea abies) in forest stands-a review. For. Ecol. Manage. 175, 253-273. https://doi.org/10.1016/S0378-1127(02)00134-2.

Rasse, D.P., Rumpel, C., Dignac, M.-F., 2005. Is soil carbon mostly root carbon? Mechanisms for a specific stabilisation. Plant Soil 269, 341-356. https://doi.org/10.1007/s11104-004-0907-y. 
Reich, P., 2002. Root-Shoot Relations, in: Kafkafi, U., Waisel, Y., Eshel, A. (Eds.), Plant Roots. CRC Press, Boca Raton, Florida, USA, pp. 205-220.

Rewald, B., 2008. Impact of climate change-induced drought on tree root hydraulic properties and competition belowground. Dissertation, Georg-August-University Goettingen, Germany.

Rosengren, U., Göransson, H., Jönsson, U., Stjernquist, I., Thelin, G., Wallander, H., 2006. Functional Biodiversity Aspects on the Nutrient Sustainability in ForestsImportance of Root Distribution. J. Sustainable For. 21, 77-100. https://doi.org/10.1300/J091v21n02_06.

Ryan, M.G., 2011. Tree responses to drought. Tree Physiol. 31, 237-239. https://doi.org/10.1093/treephys/tpr022.

Santantonio, D., Hermann, R.K., 1985. Standing crop, production, and turnover of fine roots on dry, moderate, and wet sites of mature Douglas-fir in western Oregon. Ann. For. Sci. 42, 113-142. https://doi.org/10.1051/forest:19850201.

Schär, C., Vidale, P.L., Lüthi, D., Frei, C., Häberli, C., Liniger, M.A. et al, 2004. The role of increasing temperature variability in European summer heatwaves. Nature 427, 332-336. https://doi.org/10.1038/nature02300.

Schenk, H.J., Jackson, R.B., 2002. The global biogeography of roots. Ecol. Monogr. 72, 311-328. https://doi.org/10.1890/0012-9615(2002)072[0311:TGBOR]2.0.CO;2.

Senf, C., Pflugmacher, D., Zhiqiang, Y., Sebald, J., Knorn, J., Neumann, M. et al, 2018. Canopy mortality has doubled in Europe's temperate forests over the last three decades. Nat. Commun. 9, 4978. https://doi.org/10.1038/s41467-018-07539-6\#.

Teskey, R.O., Hinckley, T.M., 1981. Influence of temperature and water potential on root growth of white oak. Physiol. Plant. 52, 363-369. https://doi.org/10.1111/j.1399-3054.1981.tb06055.x.

Thomas, F.M., Gausling, T., 2000. Morphological and physiological responses of oak seedlings (Quercus petraea and Q. robur) to moderate drought. Ann. For. Sci. 57, 325-333. https://doi.org/10.1051/forest:2000123.

Tierney, G.L., Fahey, T.J., Groffman, P.M., Hardy, J.P., Fitzhugh, R.D., Driscoll, C.T. et al, 2003. Environmental control of fine root dynamics in a northern hardwood forest. Global Change Biol. 9, 670-679. https://doi.org/10.1046/j.13652486.2003.00622.x.

Tomlinson, P.T., Anderson, P.D., 1998. Ontogeny affects response of northern red oak seedlings to elevated $\mathrm{CO} 2$ and water stress: II. Recent photosynthate distribution and growth. New Phytol. 140, 493-504. https://doi.org/10.1046/j.14698137.1998.00291.x.

van Hees, A.F.M., 1997. Growth and morphology of pedunculate oak (Quercus robur L) and beech (Fagus sylvatica L) seedlings in relation to shading and drought. Ann. For. Sci. 54, 9-18. https://doi.org/10.1051/forest:19970102.

Walentowski, H., Falk, W., Mette, T., Kunz, J., Bräuning, A., Meinardus, C. et al, 2017. Assessing future suitability of tree species under climate change by multiple methods: a case study in southern Germany. Ann. For. Res. 60. https://doi.org/10.15287/afr.2016.789. 
Wang, C., Chen, Z., Yin, H., Guo, W., Cao, Y., Wang, G. et al, 2018. The Responses of Forest Fine Root Biomass/Necromass Ratio to Environmental Factors Depend on Mycorrhizal Type and Latitudinal Region. J. Geophys. Res. Biogeosci. 123, 17691788. https://doi.org/10.1029/2017JG004308.

Zang, U., Goisser, M., Häberle, K.-H., Matyssek, R., Matzner, E., Borken, W., 2014. Effects of drought stress on photosynthesis, rhizosphere respiration, and fine-root characteristics of beech saplings: A rhizotron field study. J. Plant Nutr. Soil Sci. 177, 168-177. https://doi.org/10.1002/jpln.201300196. 


\section{DENDROECOLOGY}

\section{IDENTIFICATION OF DROUGHT-TOLERANT TREE SPECIES THROUGH CLIMATE SENSITIVITY ANALYSIS OF RADIAL GROWTH IN CENTRAL EUROPEAN MIXED BROADLEAF FORESTS}

Published in Forest Ecology and Management:

Fuchs, S., Schuldt, B., Leuschner, C., 2021. Identification of drought-tolerant tree species through climate sensitivity analysis of radial growth in Central European mixed broadleaf forests. For. Ecol. Manage. 494, 119287. https://doi.org/10.1016/j.foreco.2021.119287.

Sebastian Fuchs ${ }^{1}$, Bernhard Schuldt ${ }^{1,2}$, Christoph Leuschner ${ }^{1}$

1 Plant Ecology, Albrecht von Haller Institute for Plant Sciences, University of Goettingen, Untere Karspüle 2, 37073 Goettingen, Germany

2 Present address: Ecophysiology and Vegetation Ecology, Julius-von-Sachs-Institute of Biological Sciences, University of Würzburg, Julius-von-Sachs-Platz, 97082 Würzburg, Germany 


\subsection{Abstract}

Climate warming and a rise in evaporative demand expose forests to increasing stress, challenging silvicultural planning in many temperate forest regions. As some major timber species are drought susceptible, the choice of native broadleaf minor timbers with assumed higher drought tolerance is a promising alternative option. However, their growth performance and vitality in a warmer and drier climate are not well known. We studied tree-ring chronologies of the Central European minor timbers Acer platanoides L., Fraxinus excelsior L., and Tilia cordata Mill. in comparison to the widely planted Quercus petraea Matt. Liebl in different mixed stands along a precipitation gradient in Central Germany and analyzed the sensitivity of radial growth to climatic drivers and severe drought events with the aim to compare the species' drought tolerance. While growth responded in all four species positively to summer (or spring) precipitation and negatively to higher summer temperature and climatic aridity, climate sensitivity of growth decreased in the period 1967-2016, proving non-stationarity. Superposed epoch analysis revealed larger growth reduction during severe drought in the diffuse-porous species (A. platanoides, T. cordata) than the ring-porous species ( $Q$. petraea, $F$. excelsior), but resilience was high in all species. Moreover, none of the species showed negative growth trends with recent climate warming, and drought sensitivity was not higher at drier sites, suggesting a considerable acclimation and adaptation potential to increasing drought stress. As all four species proved to be fairly drought tolerant, they deserve broader consideration in silvicultural concepts targeted at adapting production forests to climate warming.

Keywords: acclimation, Acer platanoides, dendroclimatology, dendroecology, Fraxinus excelsior, growth resilience, Quercus petraea, Tilia cordata, tree-rings 


\subsection{Introduction}

Accelerated climate warming since the 1980s (IPCC, 2014) and the predicted future increase in the frequency and severity of summer heat-waves (Schär et al., 2004) challenge silvicultural concepts in Central Europe. In this region, some of the main timber species seem to be relatively susceptible to drought and possibly also heat, notably Norway spruce (Picea abies (L.) H. Karst.; Spiecker, 2000), European beech (Fagus sylvatica L.; Bréda et al., 2006; Leuschner, 2020) and Scots pine (Pinus sylvestris L.; Rigling et al., 2013). This became obvious during the extreme drought and heat years 2003, 2018, and 2019 that caused widespread vitality loss and mortality increase in $P$. abies, F. sylvatica, and locally also P. sylvestris, as well as in other coniferous and broadleaf tree species (Schuldt et al., 2020; Walthert et al., 2021). F. sylvatica and $P$. abies suffered distinct growth declines over the past decades especially in regions of Central Europe with mean annual precipitation sums of less than ca. $700 \mathrm{~mm}$ and on shallow soils (Leuschner, 2020; Mäkinen et al., 2002; Scharnweber et al., 2011; Zimmermann et al., 2015).

As a response, forest ecologists and foresters have proposed to reduce stem density in drought-affected stands, to replace monocultures by mixtures, and to introduce more drought-resistant native and non-native temperate timber species (Pretzsch et al., 2013; Pretzsch et al., 2017). A favored strategy in many regions of Central Europe is to plant productive conifers in mixture with native broadleaf trees assuming that mixtures are more stable against environmental hazards, notably droughts (Steckel et al., 2020; Vannoppen et al., 2019) and pests (Brockerhoff et al., 2017; Jactel et al., 2005). However, drought exposure depends on the water consumption of the stand, and mixtures with productive species can exhaust soil water reserves to a larger extent than monocultures (Gebauer et al., 2012; Grossiord et al., 2014), which might expose one or more species of the mixture to increased drought stress. This was shown, for example, for European beech when planted in mixture with Norway spruce or Douglas fir (Pseudotsuga menziesii [Mirbel] Franco; Pretzsch et al., 2020; Thurm et al., 2016). Thus, doubts remain as to whether species mixing alone will be an effective measure to achieve a higher tolerance of temperate production forests to future drought and heat waves. It appears that the choice of suitable drought-tolerant tree species is more decisive for meeting the challenges of climate warming than the silvicultural options of species mixing and stand thinning alone. This requires information about the drought tolerance of the prospective timber species, which is available in Central Europe only for a few widely planted species 
such $F$. sylvatica, $P$. abies, and $P$. sylvestris, but is mostly lacking for putatively more drought-tolerant alternative native tree species.

In drought-prone regions in Central Europe, the promotion and establishment of alternative, more drought-tolerant species is broad consensus in silviculture, but the criteria for the choice of species are heavily debated. A widely preferred option is the introduction of non-native conifers with proven or assumed higher drought tolerance, such as Pseudotsuga menziesii and Pinus nigra J.F. Arnold (Eilmann and Rigling, 2012; Isaac-Renton et al., 2014). However, this approach raises concerns regarding the species' invasive potential and associated negative effects on native biodiversity (Felton et al., 2016), unpredictable risks regarding future susceptibility to pests (Roques et al., 2019), and soil acidification by conifers (Cremer and Prietzel, 2017; Hobbie et al., 2006). For that reason, concepts to admix and promote native, putatively drought-tolerant species that are currently only secondary timbers in Central Europe, are gaining growing interest (Brang et al., 2008; Grundmann and Roloff, 2009; Kunz et al., 2018; Vitali et al., 2017). The tree flora of Central Europe contains several tree species of the genera Acer, Carpinus, Fraxinus, Quercus, Sorbus and Tilia, which occur also in the more continental climate of eastern Central and Eastern Europe, indicating that they might be more drought tolerant than the major timbers. Scattered information from ecophysiological studies on juvenile or mature trees additionally suggest that Acer platanoides L. (Norway maple), Fraxinus excelsior L. (European ash), and Tilia cordata Mill. (Small-leaved lime) may be promising candidate species with a putatively higher drought tolerance (Hemery et al., 2010; Jaegere et al., 2016; Köcher et al., 2009; Kunz et al., 2016; Leuschner et al., 2019; Leuschner and Meier, 2018; Scherrer et al., 2011; Schumann et al., 2019).

The bulk of dendroecological studies in Central Europe have dealt with the economically most important tree genera (Picea, Pinus, Fagus, and Quercus), while the minor timber species have only rarely been studied. The dendroecology of A. platanoides has been compared to that of sessile oak (Quercus petraea Matt. Liebl) and F. sylvatica by Zimmermann et al. (2015) in Central Germany and by Kunz et al. (2018) in southwest Germany with partly diverging conclusions. In terms of radial growth patterns, $T$. cordata turned out to be more drought tolerant than F. sylvatica in Belgium (Latte et al., 2020), but the results from this moist and oceanic climate may only partly be transferable to more continental climates. Most of the published dendroecological studies on $F$. excelsior were either conducted under climates very different to that of Central Europe, or the study focus did not allow for a comparative assessment of the species' drought 
tolerance (Jalilvand, 2008; Koval and Maksymenko, 2020; Roibu et al., 2020; Weemstra et al., 2013). According to the study of Zimmermann et al. (2015) in mixed stands, $F$. excelsior is similarly drought tolerant as $Q$. petraea, and both species are more tolerant than F. sylvatica.

To fill the knowledge gap with respect to the drought tolerance of minor broadleaf timber species in Europe's temperate forests, we studied the growth patterns and climate response of $A$. platanoides, $F$. excelsior and $T$. cordata in comparison to $Q$. petraea, a major timber species in Central Europe that is dendroecologically well studied (Härdtle et al., 2013; Mette et al., 2013; Mayer et al., 2020; Scharnweber et al., 2011; Zang, 2011) and known to be drought-tolerant. The study was conducted in mixed forests along a precipitation gradient from sub-oceanic to sub-continental climate (ca. 900 to $500 \mathrm{~mm}$ annual precipitation) in Central Germany, i.e. from hydrologically optimal conditions close to the assumed drought limit of the species. The species sample consists of two ringporous (Q. petraea, F. excelsior) and two diffuse-porous species (A. platanoides, $T$. cordata), representing two tree functional types with a likely different climate sensitivity of growth (Elliott et al., 2015). In 3 to 7 stands per species, we investigated temporal changes in climate-growth relationships with a moving window approach (Biondi, 1997) for the last 50 years, testing the common assumption of stationarity in the climate dependence of growth (Wilmking et al., 2020). For selected climatically defined droughts, we conducted superposed epoch analyses (SEA) to quantify growth depressions and lag effects, and calculated growth resistance and resilience indices (Lloret et al., 2011).

Based on earlier dendroecological studies in diffuse- and ring-porous species in temperate forests (Cavin et al., 2013; Muffler et al., 2020; Zimmermann et al., 2015), we formulated the following four hypotheses that guided our research: (i) Summer drought and heat are the main climatic determinants of radial growth in all four species. (ii) The sensitivity of radial growth to low summer precipitation and summer heat decreases toward the drier sites due to local adaptation. (iii) Radial growth is more resistant to summer drought events in the ring-porous than the diffuse-porous species, while growth resilience is similar. With complementary data from earlier studies on the drought sensitivity of the hydraulic system and the fine root system (Fuchs et al., 2020, Fuchs et al., submitted), and information on crown defoliation of the same species in a severe drought, we aimed at developing a comparative assessment of the suitability of $A$. 
platanoides, F. excelsior and T. cordata for Central European silviculture in a future drier and warmer climate.

\subsection{Material and methods}

\subsubsection{Study sites and tree species}

Eight study sites were selected along a precipitation gradient in the planar to colline belt (110-440 m a.s.1.) of Central Germany. The climate is cool temperate with mean annual temperatures (MAT) ranging from 7.5 to $9.6^{\circ} \mathrm{C}$ and mean annual precipitation (MAP) from 502 to $894 \mathrm{~mm}$, with cooler and moister climate found in the west and warmer and drier climate in the east (Figure 4.1, Table 4.1).

The four investigated tree species (Acer platanoides, Fraxinus excelsior, Quercus petraea, and Tilia cordata) are widespread in Central European broadleaf mixed forests, when Fagus sylvatica, the dominant species of Central Europe's natural forest vegetation, is absent. They occur mostly in communities assigned to the phytosociological alliances Carpinion betuli (oak-hornbeam forests) and Tilio-Acerion (mixed maple slope forests, Leuschner and Ellenberg, 2017). All four species are thought to be more drought tolerant than F. sylvatica (Leuschner, 2020), which is reflected in their occurrence in the more continental east of Europe. While $Q$. petraea is a primary timber species with high economic importance in most Central European countries on drier and more acidic soils, the other three species are only rare secondary timbers.

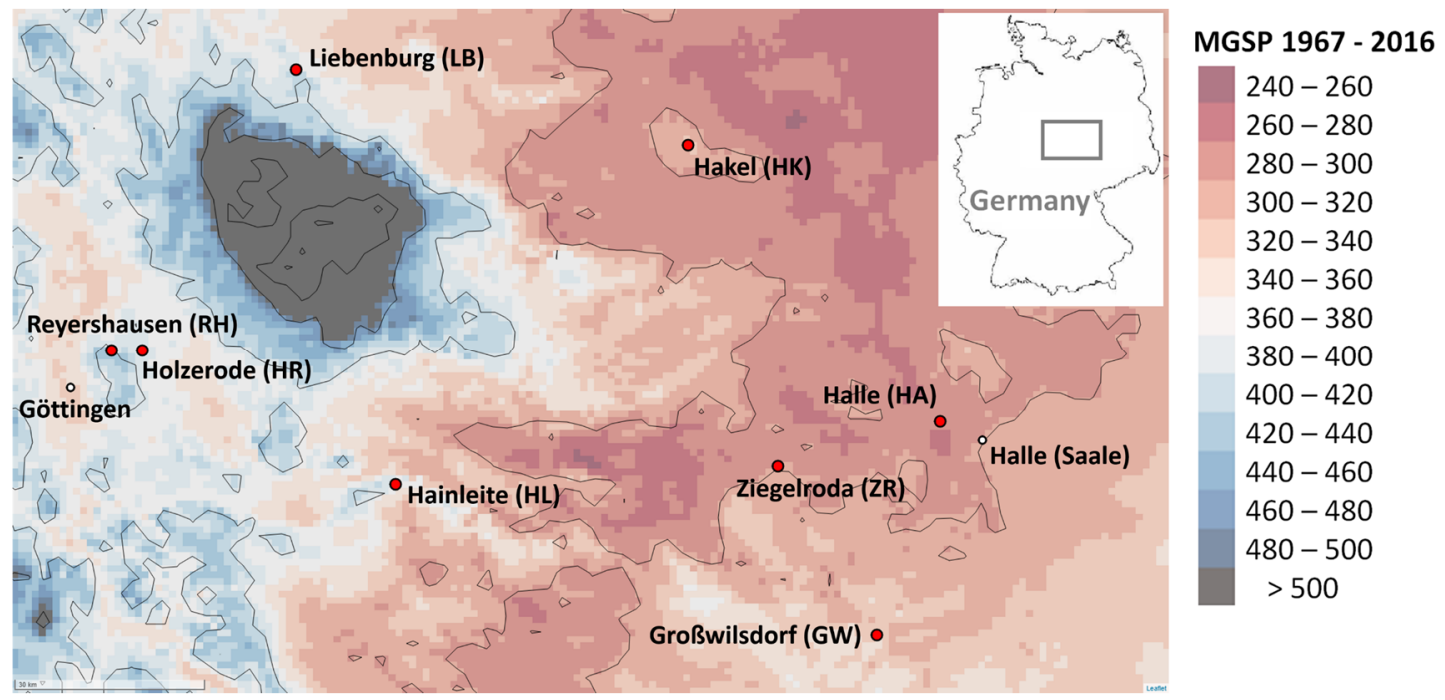

Figure 4.1: Map of the study region between the cities of Göttingen and Halle/S. in Central Germany with the precipitation gradient from west to east. The study sites are marked with red dots, the background colors indicate the long-term mean growing season precipitation (MGSP, April - September, 1967 - 2016) in mm. The area with MGSP >500 mm north-east of Göttingen is the Harz mountain range. 


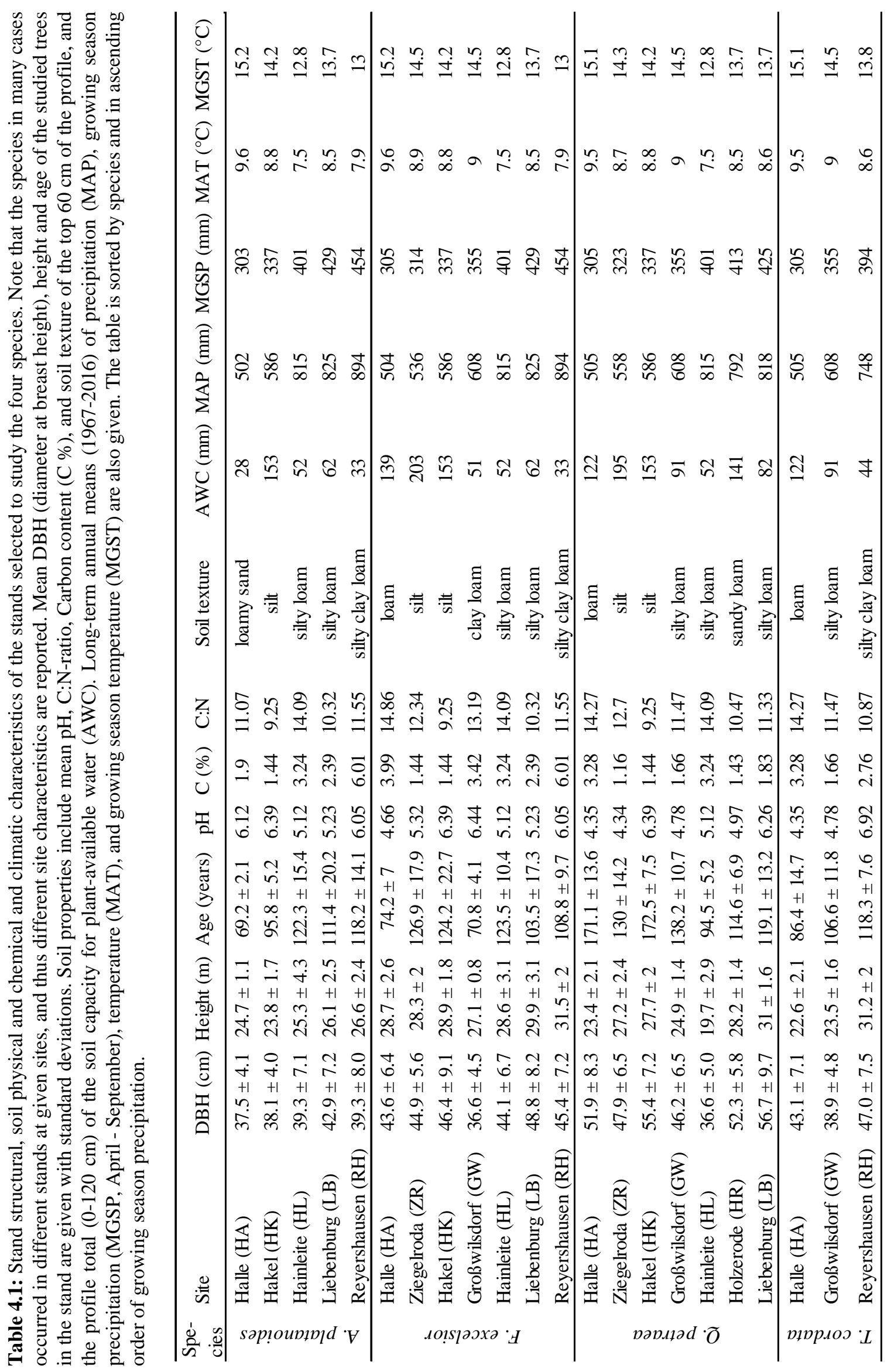


Due to their widespread but infrequent occurrence in Central Europe, not all of the four species are present at each site. F. excelcior and Q. petraea occurred at seven sites along the transect, and A. platanoides and T. cordata at only five sites. Unfortunately, we had to exclude two stands in case of $T$. cordata due to a large numbers of missing rings, and poor cross-dating results that did not match the criteria for trustworthy chronologies. All eight sites consisted of several neighboring mixed and species-rich hardwood forest stands of variable species composition, and the target species grew in a maximum distance of several hundred meters to a few kilometers within those sites. The local edaphic and climatic conditions were investigated separately for those species that did not grow in close proximity to each other in the mixed stands (Table 4.1).

Primary criteria for stand selection were the presence of at least 12 (co-)dominant individuals of a given species in the upper canopy, no groundwater influence, and the absence of steep slopes and stony or very shallow soils. We aimed at selecting mature trees of about 90-120 years in age growing on silty to loamy soil of at least $40 \mathrm{~cm}$ of soil depth, but these conditions could not always be met regarding stand age and soil texture (cf. Table 4.1). To account for differences in soil texture, we included plant-available soil water capacity (AWC) as an additional factor besides climatic variables in the analysis of tree growth responses.

\subsubsection{Climate}

We used monthly precipitation and temperature data provided by the German Meteorological Service (DWD, Deutscher Wetterdienst, Offenbach, Germany) as gridded datasets with $1 \mathrm{~km}$-mesh width, which provides precise local climatic data (Kaspar et al., 2013; Maier and Müller-Westermeier, 2010). The largest distance between any of our study sites and a weather station was $7.1 \mathrm{~km}$. All long-term means were calculated for the investigation period 1967-2016.

The non-dimensional, multi-scalar standardized precipitation-evapotranspiration index (SPEI) was calculated with the R package SPEI using monthly precipitation sums and potential evapotranspiration data based on the approach of Thornthwaite (1948). To conduct correlation analyses with monthly climate data, we calculated the SPEI for a three months-window, assuming that drought conditions in the current month mainly depend on precipitation and evapotranspiration patterns in the recent and the two preceding months. In order to identify drought years in a climatological sense, we used the SPEI score of the month August calculated with a six months-window (SPEI summer $_{\text {) }}$ to consider the drought conditions of the main vegetation period in combination with the spring and 
early summer conditions as the period with highest physiological relevance. By definition, a drought year was characterized by a SPEIsummer $<-0.84$, a threshold also used by Sohn et al. (2016) in a study in a cold-temperate climate and the SPEI Global Drought Monitor (http://sac.csic.es/spei/map/maps.htm1).

Mean growing season precipitation (April - September; MGSP) does not show a clear trend during the study period from 1967 to 2016, while mean growing season temperature (MGST) increased by roughly $1{ }^{\circ} \mathrm{C}$ (Figure 4.2). The warming was associated with a decrease in the standardized precipitation evapotranspiration index (SPEI; VicenteSerrano et al., 2010) from +0.6 to -0.4 from 1967 to 2016.

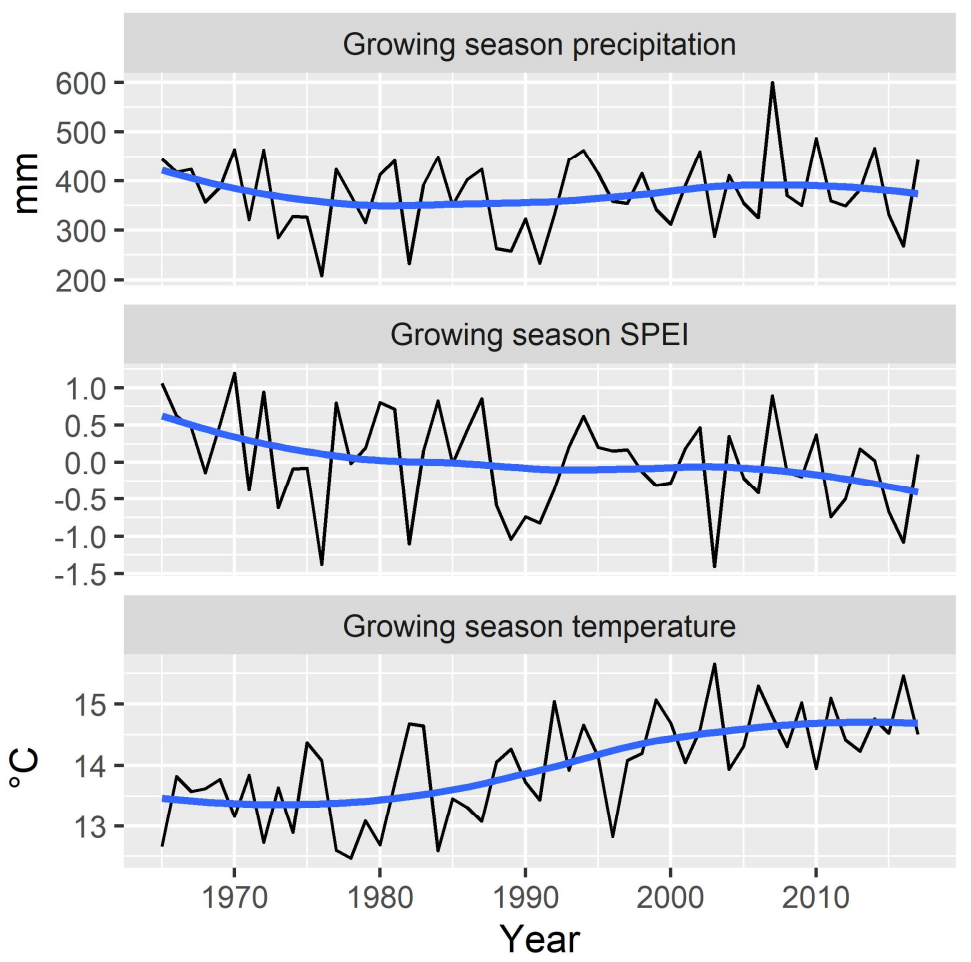

Figure 4.2: Temporal variation and long-term trend (25 year moving average) of growing season precipitation, temperature and SPEI (standardized precipitation-evapotranspiration index) in the period 1965-2016 in the study region (averaged over all study sites).

\subsubsection{Edaphic conditions}

Per site, soil samples were collected at three soil depths $(0-10 \mathrm{~cm}, 10-30 \mathrm{~cm}, 30-60$ $\mathrm{cm}$ ), analyzed for soil chemical and physical parameters and subsequently averaged. We determined soil texture, bulk density, stone content (gravel $>2 \mathrm{~mm}$ ), and soil depth (using a Pürckhauer soil corer). Soil chemical variables quantified were soil $\mathrm{pH}$ (measured in $\mathrm{H}_{2} \mathrm{O}$ ), soil carbon and soil nitrogen content (measured with gas chromatography). Values reported in Table 4.1 are weighted means of the upper $60 \mathrm{~cm}$ of the soil. To estimate soil hydrologic characteristics (van Genuchten parameters; van Genuchten, 1980) from bulk 
density and soil texture data, we employed the pedo-transfer functions proposed by Schaap et al. (2001) using the module "ROSETTA light" implemented in the software RETC (version 6.02, van Genuchten et al., 1991). Based on the van Genuchten parameters, we modelled water retention curves and estimated the soil water content at field capacity (soil matric potential of $-300 \mathrm{hPa}$ ) and at the permanent wilting point $(-1.5$ $\mathrm{MPa}$ ). Subsequently, the soil capacity for plant-available water (AWC) was calculated as the difference between these two water contents. The profile total of AWC (in mm) of a given stand was obtained by adding the AWC values of the three measured layers for the 0-60 cm profile, and extrapolating AWC to $120 \mathrm{~cm}$ depth or to bedrock depth by assuming uniform soil texture below $60 \mathrm{~cm}$ depth.

\subsubsection{Sampling and processing of wood cores, and quality assessment of chronologies}

At each study site, 12-18 dominant or co-dominant tree individuals from the upper canopy layer of each present species were cored in spring 2017. One core per tree (322 cores in total) was taken at breast height in the direction, where the influence of tension wood and other anomalies was assumed to be smallest. The cores were planed with a core microtome (WSL, Zürich, Switzerland; Gärtner and Nievergelt, 2010), colored with safranin and chalked. Tree-ring widths (TRW) were measured with a Lintab digital positioning table (Lintab 5, Rinntech, Heidelberg, Germany) using the software TSAPWin v. 4.67c (Rinntech, Heidelberg, Germany).

Cross-dating and synchronization of the tree-ring series were performed both visually and by means of statistical analysis in TSAP-Win, employing the interval-sign test ("Gleichläufigkeit", Eckstein and Bauch, 1969) and calculating $t$-values (Baillie and Pilcher, 1973). Several ring series could not be synchronized, leaving 249 cross-dated tree-ring series for further analysis (9-13 per site and species).

We applied conservative and rigorous detrending techniques, since our stands differed in age and management intensity, and we focused on single-year climate-growth interactions and short-term reactions to drought events. Flexible cubic smoothing splines with $50 \%$ frequency cut-off at 25 years were used to detrend and standardize the raw ringwidths series and we removed first-order autocorrelation by autoregressive modelling to eliminate age- and management-related trends and to accentuate year-to-year variability (Cook and Peters, 1981; Speer, 2010). Following Thurm et al. (2016), we additionally used basal area increment (BAI) time series and detrended them in the same manner as the ring-width series. All analyses were then carried out with detrended ring-width and 
BAI data, revealing very similar results for both procedures. We therefore report only the results of the detrended ring-width index series.

Chronologies were built for all sites and species with Tukey's bi-weight robust mean (Cook and Kairiukstis, 1990) and truncated to the period of 1967-2016 to exclude younger tree life stages. The quality and strength of the common signal of the chronologies was assessed by means of the inter-series correlation (Rbar) and the expressed population signal (EPS) of the 50-year time series (Table 4.2). EPS was $>0.85$ in 20 of the 22 chronologies ( 0.84 and 0.80 in the other two). Rbar was further calculated for the chronologies in a 20-year moving window to search for temporal changes in growth synchronicity.

To assess long-term trends (only for Figure 4.9, Appendix C), ring-width series were age-detrended using the regional curve standardization (RCS) method (Biondi and Qeadan, 2008; Briffa et al., 1992). The regional age trend of all investigated species was estimated by aligning all tree-ring series per species based on the cambial age and the estimated average growth curve was used to detrend single series. Subsequently, RCSchronologies were built using Tukey's bi-weight robust mean (Figure 4.9, Appendix C). All detrending procedures and the statistical analyses of chronologies were performed with the software $\mathrm{R}$ (version 4.0, $\mathrm{R}$ Core Team, Vienna) using the package “dendrochronology program library in R”, dplR (Bunn, 2008).

\subsubsection{Climate sensitivity analysis}

Climate-growth relationships were analyzed with the $\mathrm{R}$ package treeclim (Zang and Biondi, 2015) by exploring the correlation between various current-year and previous-year climate parameters and annual ring width indices in the residual chronologies. With 1000-fold bootstrapping against random climate-growth pairs of the respective chronologies, the $95 \%$-confidence intervals of the correlation coefficients were calculated and used to decide whether a coefficient was significantly different from zero or significantly different from another coefficient (when comparing the correlation coefficients of different chronology sections).

Several approaches were applied to investigate temporal and spatial variation of the climate sensitivity of growth: (1) Principal climate-growth relationships of the four species and different sites were calculated for the whole study period of 50 years between monthly precipitation, temperature and SPEI values of the previous or current season and annual radial increment to compare species and sites in terms of the general drought and 
heat sensitivity of growth, and to identify the climatic parameters with largest influence. (2) After having identified the six most influential aggregated climatic parameters (previous-summer precipitation, current-spring precipitation, current-summer precipitation, previous-summer temperature, winter temperature, current-summer temperature), we calculated correlation coefficients for these parameters using a moving window approach (window size: 20 years, window offset: 1 year) to search for temporal change over the 50 years in the sensitivity of growth to these climatic drivers. (3) Due to the finding that the influence on growth of several factors changed markedly between the first (1967-1991) and the second half of the investigation period (1992-2016), we repeated the correlation analyses separately for the first and second 25 years of the period and tested for significant differences in the correlation coefficients of the two periods. We further searched for spatial variation in the trends of growth sensitivity to climatic aridity

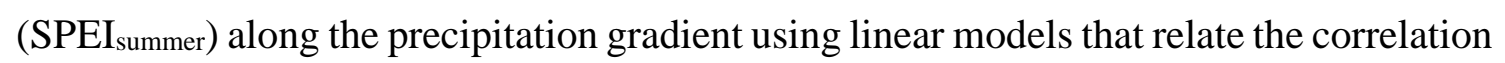
coefficients of this relation to mean growing season precipitation (MGSP) and AWC at the respective site (cf. Weigel et al., 2018; and Muffler et al., 2020).

\subsubsection{Drought response: pointer years, superposed epoch analysis, resistance and} resilience indices

For exploring whether synchronous negative growth departures increase in frequency over time or with site aridity, negative pointer years were analyzed based on Croppervalues (Cropper, 1979) with normalization in a 5-year moving window (cf. Neuwirth et al. 2007). Thresholds for weak, strong, and extreme negative pointer years were $0.8,1.2$, and 1.5 standard deviations of growth decline, respectively, for at least $60 \%$ of the population (Figure 4.13, Appendix C).

To avoid bias due to the pre-selection of pointer years according to growth performance (Schwarz et al., 2020), we based the definition of a climatic drought year on the SPEI summer threshold of $<-0.84$ only, independent of the degree of growth depression. This resulted in the identification of 9-13 drought years at the different sites.

The selected drought years were used for superposed epoch analysis (SEA) of growth depressions and for calculation of the indices of growth resistance and resilience (as defined by Lloret et al., 2011). An epoch of 11 years (five years before and after the drought year) was chosen as recommended by Kunz et al. (2018). SEA calculates the mean departure in growth performance of each year in the epoch from the mean of all analyzed epochs per chronology (Lough and Fritts, 1987). Bootstrapping (5000-times) against randomly drawn epochs from the respective chronology was used for defining 
95\% confidence intervals of the departure. SEAs were performed with the R package dplR (Bunn, 2008).

The indices of growth resistance and resilience were calculated for each tree and each drought year using detrended ring-width index data. Resistance was defined as the drought/pre-drought and resilience as the post-drought/pre-drought ratio of growth, averaging over the five pre-drought and five post-drought years (Lloret et al., 2011). The index values were averaged across the different drought years for a given tree and treewise mean values were used for further analyses. To test for significant differences in indices between the species, linear mixed effects models (R package lme4, Bates et al., 2015) were fitted, where "species" was introduced as fixed effect and the "sitexspecies" interaction as a random intercept in order to take the hierarchical variance structure of the dataset into account and correct for random site effects per species. Significant differences between species were identified using Tukey-adjusted p-values with degrees of freedom based on Satterthwaite's approximation. To test whether the indices varied across sites, we fitted sets of linear mixed effects models for every species with MGSP and AWC as fixed effects and "site" as a random intercept to account for the hierarchical variance structure of the dataset. Various other climatic and soil physical or chemical parameters were tested, but none had a significant effect on growth resistance and resilience in any of the species. $P$-values were calculated with the R package lmerTest (Kuznetsova et al., 2017) with degrees of freedom based on Satterthwaite's approximation and $R^{2}$ values calculated according to Nakagawa and Schielzeth (2013).

\subsection{Results}

\subsubsection{General characteristics of the chronologies and long-term trends in radial growth}

Mean annual tree-ring width (TRW) varied between 1.2 and $2.7 \mathrm{~mm}$ in $Q$. petraea, $A$. platanoides and T. cordata and between 1.7 and $3.0 \mathrm{~mm}$ in F. excelsior (Table 4.2) without a clear trend from the moister western to the drier eastern sites. Mean basal area increment (BAI) across all sites in the 50-year period was higher in the ring-porous species $\left(23.5\right.$ and $23.2 \mathrm{~cm}^{2}$ year $\left.{ }^{-1}\right)$ than in the diffuse-porous species $\left(16.8\right.$ and $16.8 \mathrm{~cm}^{2}$ year $\left.^{-1}\right)$. Mean sensitivity of radial growth was nearly twice as high in the two diffuseporous species (0.39-0.49) as compared to the two ring-porous species (0.20-0.27; Table 4.2). Despite marked increases in temperature and climatic aridity since the $1980 \mathrm{~s}$, none of the four species showed growth trends over time that were consistent across the sites, 
neither in the 50-year study period since 1967 nor in the more distant past, and neither in the age-detrended index nor in the raw data (Figure 4.9 and 4.10, Appendix C).

The inter-series correlation (Rbar) of the detrended chronologies, i.e. the growth synchronicity within a population, was higher for A. platanoides and Q. petraea than for F. excelsior and T. cordata (Table 4.2). In most cases, growth synchronicity either increased or decreased during the study period, but a clear pattern among species and sites with different precipitation levels did not appear (Figure 4.16, Appendix C).

Table 4.2: Statistics of ring-width series (raw data) and index-based chronologies (all truncated to the period 1967-2016) of the four species at the different sites. MRW = mean ring width of all series \pm SD, AC $(1)=$ first order autocorrelation $\pm \mathrm{SD}, \mathrm{MBAI}=$ mean basal area increment of all series $\pm \mathrm{SD}, \mathrm{Rbar}=$ interseries correlation, $\mathrm{MS}=$ mean sensitivity, $\mathrm{EPS}=$ expressed population signal. The different sites of a species are sorted in ascending order of mean growing season precipitation.

\begin{tabular}{|c|c|c|c|c|c|c|c|c|}
\hline \multirow[b]{2}{*}{ Site } & \multirow[b]{2}{*}{ Species } & \multicolumn{4}{|c|}{ Raw ring-width data } & \multicolumn{3}{|c|}{ Chronologies } \\
\hline & & $\mathrm{n}$ series & MRW (mm) & $\mathrm{AC}(1)$ & $\operatorname{MBAI}\left(\mathrm{cm}^{2}\right)$ & Rbar & MS & EPS \\
\hline HA & A. platanoides & 12 & $2.65 \pm 0.49$ & $0.56 \pm 0.20$ & $20.30 \pm 5.05$ & 0.47 & 0.49 & 0.92 \\
\hline HK & A. platanoides & 11 & $1.33 \pm 0.40$ & $0.62 \pm 0.15$ & $12.91 \pm 3.27$ & 0.45 & 0.39 & 0.90 \\
\hline HL & A. platanoides & 12 & $1.33 \pm 0.46$ & $0.48 \pm 0.19$ & $13.74 \pm 5.62$ & 0.56 & 0.48 & 0.94 \\
\hline LB & A. platanoides & 11 & $2.17 \pm 0.70$ & $0.47 \pm 0.16$ & $21.87 \pm 7.46$ & 0.61 & 0.41 & 0.95 \\
\hline RH & A. platanoides & 11 & $1.51 \pm 0.34$ & $0.52 \pm 0.15$ & $15.41 \pm 6.02$ & 0.54 & 0.4 & 0.93 \\
\hline HA & F. excelsior & 11 & $3.01 \pm 0.88$ & $0.40 \pm 0.20$ & $27.15 \pm 8.82$ & 0.33 & 0.27 & 0.84 \\
\hline ZR & F. excelsior & 12 & $1.68 \pm 0.33$ & $0.58 \pm 0.11$ & $19.32 \pm 5.15$ & 0.53 & 0.26 & 0.93 \\
\hline HK & F. excelsior & 11 & $1.95 \pm 0.48$ & $0.61 \pm 0.20$ & $21.72 \pm 6.16$ & 0.44 & 0.21 & 0.90 \\
\hline GW & F. excelsior & 13 & $2.70 \pm 0.56$ & $0.44 \pm 0.10$ & $19.66 \pm 5.24$ & 0.33 & 0.22 & 0.86 \\
\hline HL & F. excelsior & 13 & $1.93 \pm 0.38$ & $0.46 \pm 0.09$ & $21.23 \pm 6.88$ & 0.46 & 0.22 & 0.92 \\
\hline LB & F. excelsior & 12 & $3.00 \pm 1.09$ & $0.54 \pm 0.15$ & $31.60 \pm 12.07$ & 0.36 & 0.22 & 0.87 \\
\hline RH & F. excelsior & 11 & $2.29 \pm 0.54$ & $0.22 \pm 0.11$ & $23.90 \pm 6.24$ & 0.43 & 0.2 & 0.89 \\
\hline HA & Q. petraea & 11 & $1.38 \pm 0.51$ & $0.45 \pm 0.25$ & $19.83 \pm 8.71$ & 0.47 & 0.26 & 0.91 \\
\hline ZR & Q. petraea & 11 & $1.58 \pm 0.59$ & $0.63 \pm 0.16$ & $19.25 \pm 6.98$ & 0.48 & 0.26 & 0.91 \\
\hline HK & Q. petraea & 11 & $1.21 \pm 0.50$ & $0.38 \pm 0.17$ & $18.66 \pm 6.89$ & 0.45 & 0.22 & 0.90 \\
\hline GW & Q. petraea & 12 & $1.32 \pm 0.42$ & $0.36 \pm 0.15$ & $16.40 \pm 5.60$ & 0.51 & 0.21 & 0.93 \\
\hline $\mathrm{HL}$ & Q. petraea & 12 & $1.62 \pm 0.37$ & $0.53 \pm 0.16$ & $14.45 \pm 3.83$ & 0.66 & 0.32 & 0.96 \\
\hline HR & Q. petraea & 11 & $2.05 \pm 0.51$ & $0.47 \pm 0.20$ & $27.13 \pm 7.36$ & 0.47 & 0.22 & 0.91 \\
\hline LB & Q. petraea & 12 & $2.26 \pm 0.60$ & $0.52 \pm 0.16$ & $32.94 \pm 12.87$ & 0.48 & 0.25 & 0.92 \\
\hline HA & T. cordata & 9 & $1.86 \pm 0.76$ & $0.51 \pm 0.13$ & $18.72 \pm 6.21$ & 0.56 & 0.49 & 0.92 \\
\hline GW & T. cordata & 10 & $1.34 \pm 0.34$ & $0.48 \pm 0.16$ & $13.26 \pm 2.97$ & 0.28 & 0.44 & 0.80 \\
\hline $\mathrm{RH}$ & T. cordata & 10 & $1.48 \pm 0.31$ & $0.49 \pm 0.14$ & $18.50 \pm 5.48$ & 0.36 & 0.45 & 0.85 \\
\hline
\end{tabular}

\subsubsection{Climate sensitivity of growth}

The SPEI index, which combines precipitation and temperature effects, showed a significant positive influence on growth through a more humid weather (positive SPEI) in the current and previous year's summer months (May-August) in all four species and 
at nearly all sites (Figure 4.3). While T. cordata and F. excelsior were supported equally by a higher summer SPEI in the current and previous summers, A. platanoides and $Q$. petraea responded more strongly to the current than the previous season. All four species showed a positive effect of higher precipitation on radial growth, which was most pronounced for current June rainfall in all species and visible at most sites. In the ringporous species $Q$. petraea and $F$. excelsior, growth was further stimulated by the precipitation of current spring (February, March or April), while the influence of previous summer precipitation was generally not significant (Figure 4.11, Appendix C). Less clear was the influence of temperature, with all species showing a negative effect of higher temperature in single months of current and previous year's summer (Figure 4.12, Appendix C). On the other hand, $Q$. petraea responded positively to mild winter and spring temperatures at several sites, while $F$. excelsior reduced growth after warm Septembers in the previous year (Figure 4.12, Appendix C). Comparing the eight sites along the precipitation gradient revealed no trends in the growth dependence on climatic factors that could be explained by the decrease in MGSP. Q. petraea showed a weaker SPEI influence at the intermediate sites HK and GW than at the moister and drier sites (Figure 4.3). 


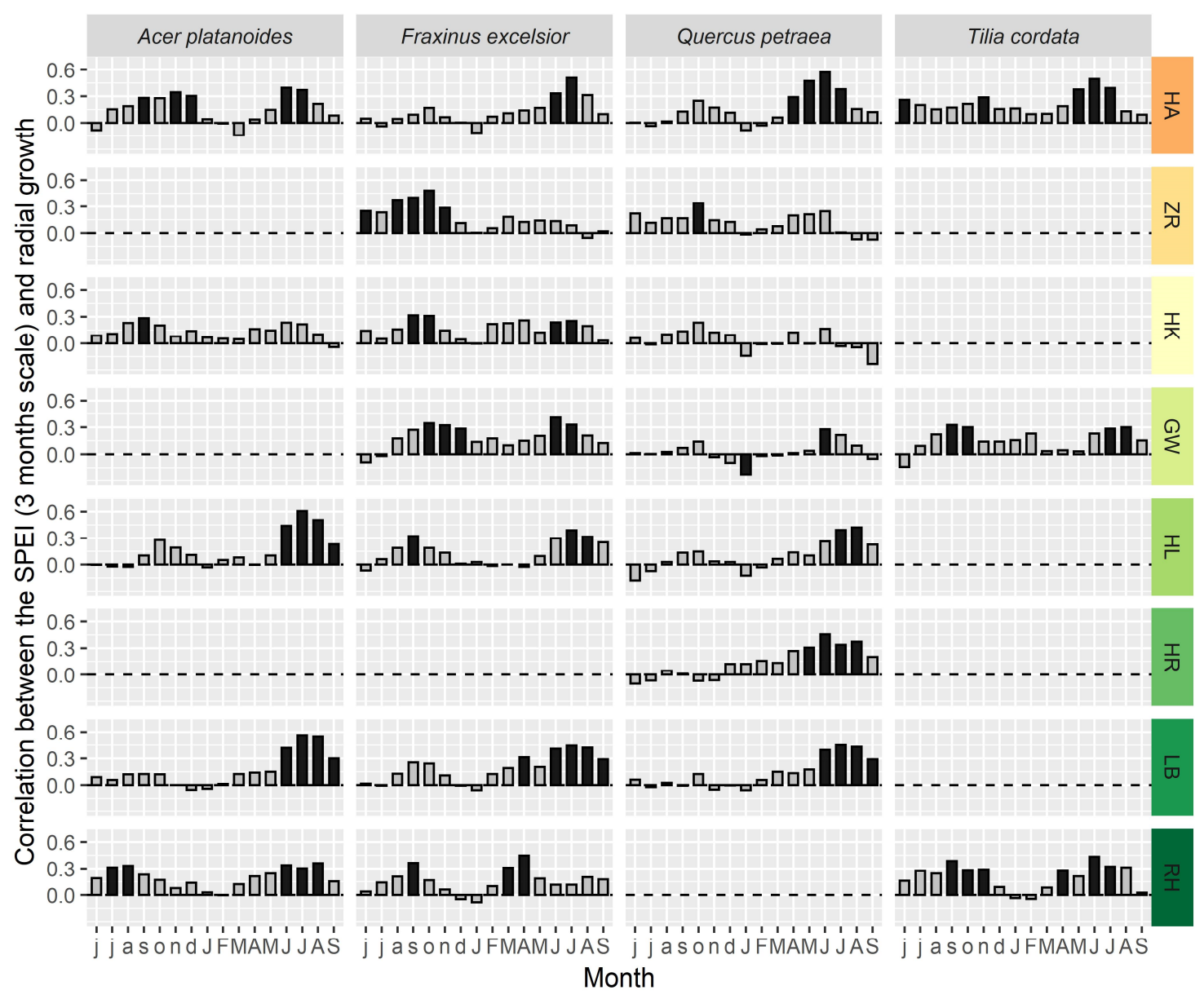

Figure 4.3: Correlation between radial growth (ring width index values) and the SPEI (standardized precipitation-evapotranspiration index) for months in the previous and current year for the four species at eight sites. The SPEI is calculated on a timescale of 3 months, because the drought conditions in the current month mainly depend on precipitation and evapotranspiration patterns in the current and the two preceding months. Months abbreviated with lower case letters refer to the previous year, months with capital letters to the current year. Given is the size of the correlation coefficient and the significance of the relation (black bars: $\mathrm{p}<0.05$; grey bars: $\mathrm{p}>0.05$ ). The color spectrum from orange to green indicates the position of the site in the gradient of mean growing season precipitation. For site abbreviations see Figure 4.1.

The moving-window analysis of climate-growth relations in the 1967-2016 period proved for all four species non-stationarity. For most of the aggregate climate variables (averaging or summing over seasons instead of months), clear differences in the direction and strength of the correlation became evident between the first and the second half of the study period. In the majority of cases, a general trend towards declining growth sensitivity to both temperature and precipitation-related variables in the last 25-year period appeared (Figure 4.4). Especially for A. platanoides and F. excelsior, the positive effect of precipitation and negative effect of temperature declined markedly in importance at almost all sites over time. The correlation coefficient for the effect of temperature (previous summer, winter and current summer) became more positive over the 50 years in almost all species-site combinations, suggesting a diminishing negative effect and/or 
increasing stimulating effect of elevated temperatures. In case of $Q$. petraea, higher winter temperatures became at nearly all sites a growth-stimulating factor over the past two decades, which was not the case in the first 30 years. In contrast to the other three species, $Q$. petraea did not show the general decline in its positive responsiveness to precipitation. Yet, the positive effect of spring precipitation on growth became significant at most sites only after 1995 (Figure 4.4).

Testing for differences between the climate-growth correlation coefficients of a species for the first (1967-1991) and the second half of the investigation period (19922016) confirmed in many cases significant changes primarily for the influence of winter and current summer temperatures (Figure 4.5). All significant changes in temperature correlation coefficients were positive, i.e. negative influences of temperature on growth weakened or turned into a positive effect. In contrast, observed changes in the correlation coefficients with previous and current summer precipitation were mostly negative, but changes were significant in only a few cases. This suggests that the positive influence of summer precipitation on radial growth tendentially decreased over time in the majority of species.

Figure 4.4 (next page): Moving window analysis of climate-growth relationships in the four species at eight sites for the period 1967-2016. Shown are the central years of the respective 20-year periods, testing for the correlation between six aggregate climate variables and annual ring width indices. Given is the size and sign of the correlation coefficient for the six relationships (red: negative relation, blue: positive relation, black frame: $\mathrm{p}<0.05$ ). Summer stands for June-August, Winter for December-February, spring for March and April. The color spectrum from orange to green indicates the position of the site in the gradient of mean growing season precipitation (orange: low, green: high). 


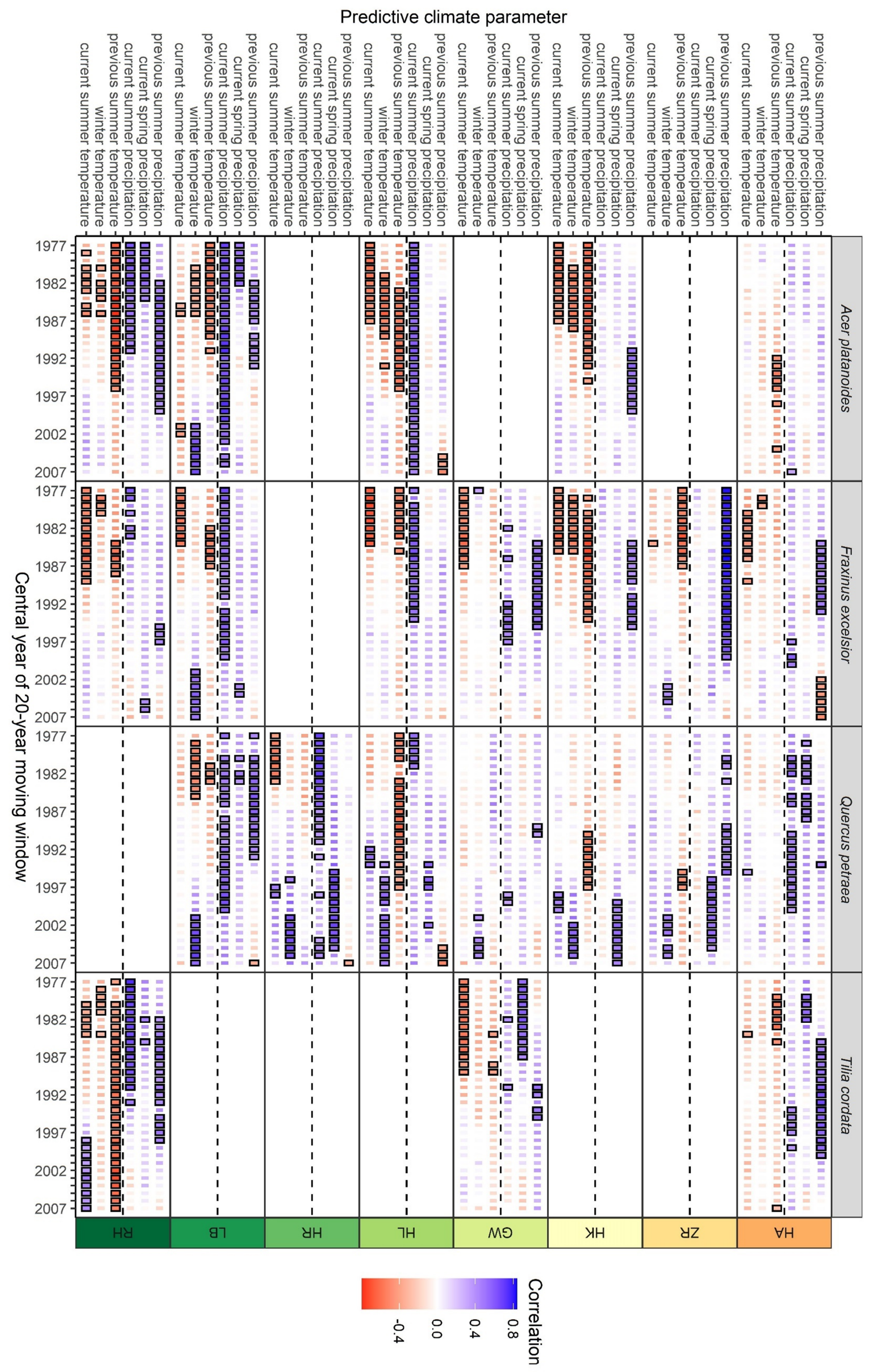




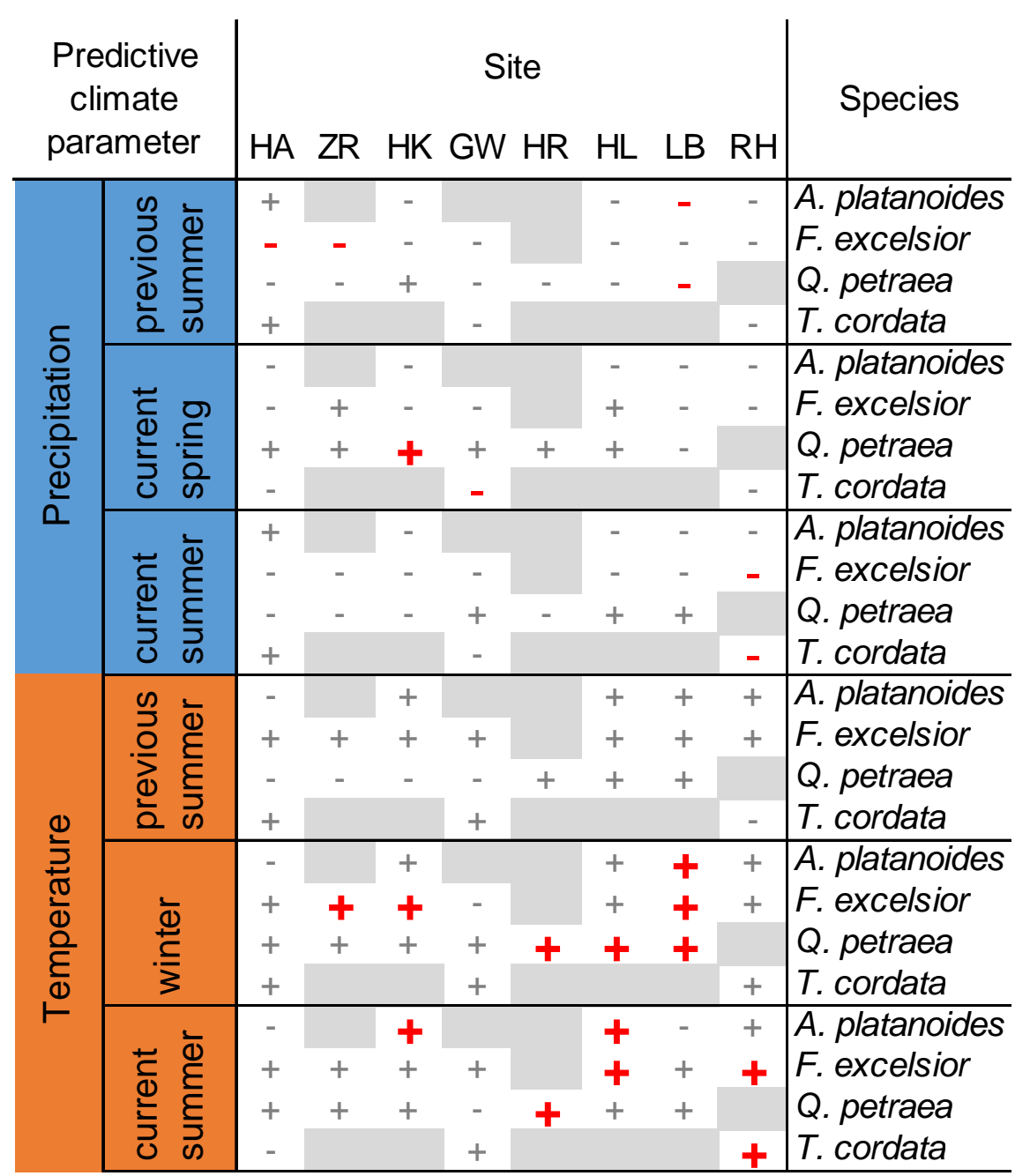

Figure 4.5: Change in the climate-growth correlation coefficients between the 1967-1991 and the 19922016 period. The "+"/“-“ signs indicate positive/negative changes in the correlation coefficients, respectively. Bold red signs represent significant changes $(\mathrm{p}<0.05)$, grey shading stands for missing data. Note: A positive change in the correlation coefficient can mean the switch from no to a positive correlation, or a switch from a negative to no correlation, a negative change means a shift in the opposite direction; see Figure 4.4 for a more detailed picture of temporal changes in the correlation coefficients.

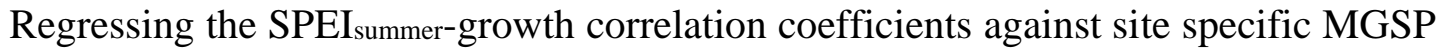
for the first and second half of the investigation period separately revealed strong spatial trends for all species except $Q$. petraea in the first half of the investigation period (Figure 4.6). Sensitivity to $\mathrm{SPEI}_{\text {summer }}$ increased significantly towards the moister sites for A. platanoides and F. excelsior ( $R^{2}$ of 0.89 and 0.55 , respectively) and the same trend was visible for $T$. cordata, which unfortunately could not be tested due to the low number of sites in this species. These trends, together with the underlying positive influence of the SPEI on growth, disappeared in the second half of the investigation period (Figure 4.6).

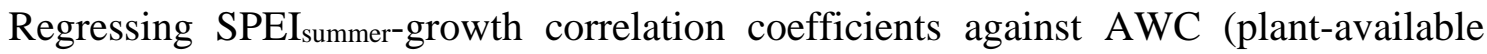
water capacity of the soil) revealed no trends at all (data not shown). 


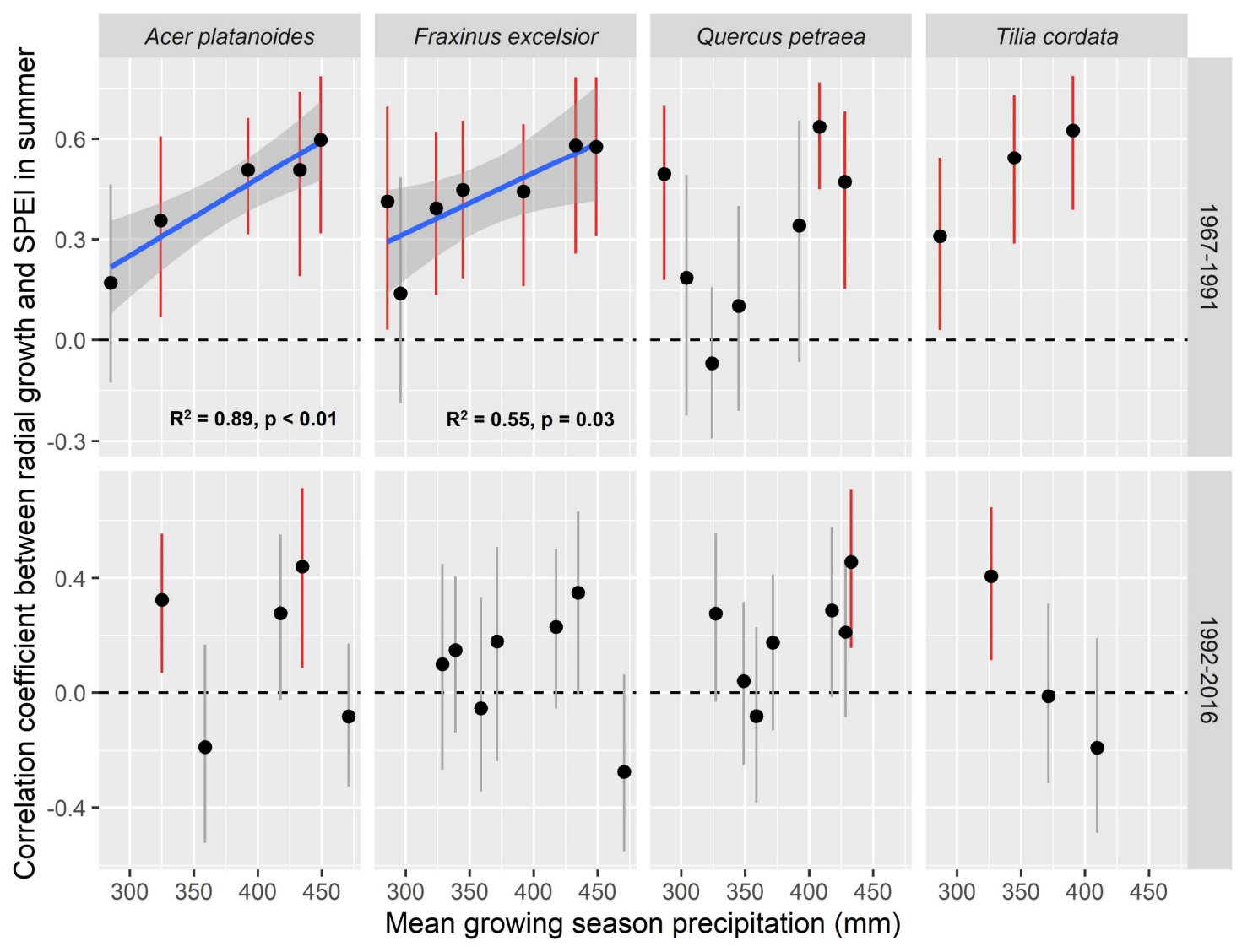

Figure 4.6: Relationship between annual ring width indices and summer SPEI (= standardized precipitation-evapotranspiration index of the month August, calculated for a 6-months window) for the four species in dependence on mean growing season precipitation (MGSP) of the stand for the 25-year periods 1967-1991 and 1992-2016. Significant correlation coefficients are marked by red 95\%-confidence interval bars. Each dot represents one site per species; MGSP refers to the corresponding 25-year periods. The blue regression lines with $95 \%$ confidence interval display significant relationships between correlation coefficient and MGSP, non-significant regression lines are not shown.

\subsubsection{Growth response to drought years}

Negative pointer years did not show a trend over time in the 50-year study period in any of the species, nor a clear pattern in dependence on MGSP (Figure 4.13, Appendix C).

Superposed epoch analysis (SEA) conducted for 9-13 climatically defined drought events revealed reduced growth in drought years for most site-species combinations, but this pattern was significant at $\mathrm{p}<0.05$ only in 5 of the 22 site-species combinations (Figure 4.7). The negative growth deviations were stronger and more often significant in the diffuse-porous than in the ring-porous species. F. excelsior did not show a single significant growth reduction in any of the drought years, but revealed a lagged negative growth departure one to three years after the drought at several sites. $T$. cordata showed the strongest and most consistent lag effect after drought years with an always significantly reduced increment in the first year after drought and at two of the three sites 
in the second year after drought as well (Figure 4.7). In three of the species, MGSP had no influence on the pattern of post-drought growth response. Only A. platanoides showed tendentially stronger and more often significant growth reductions towards the moist end of the precipitation gradient (Figure 4.7).

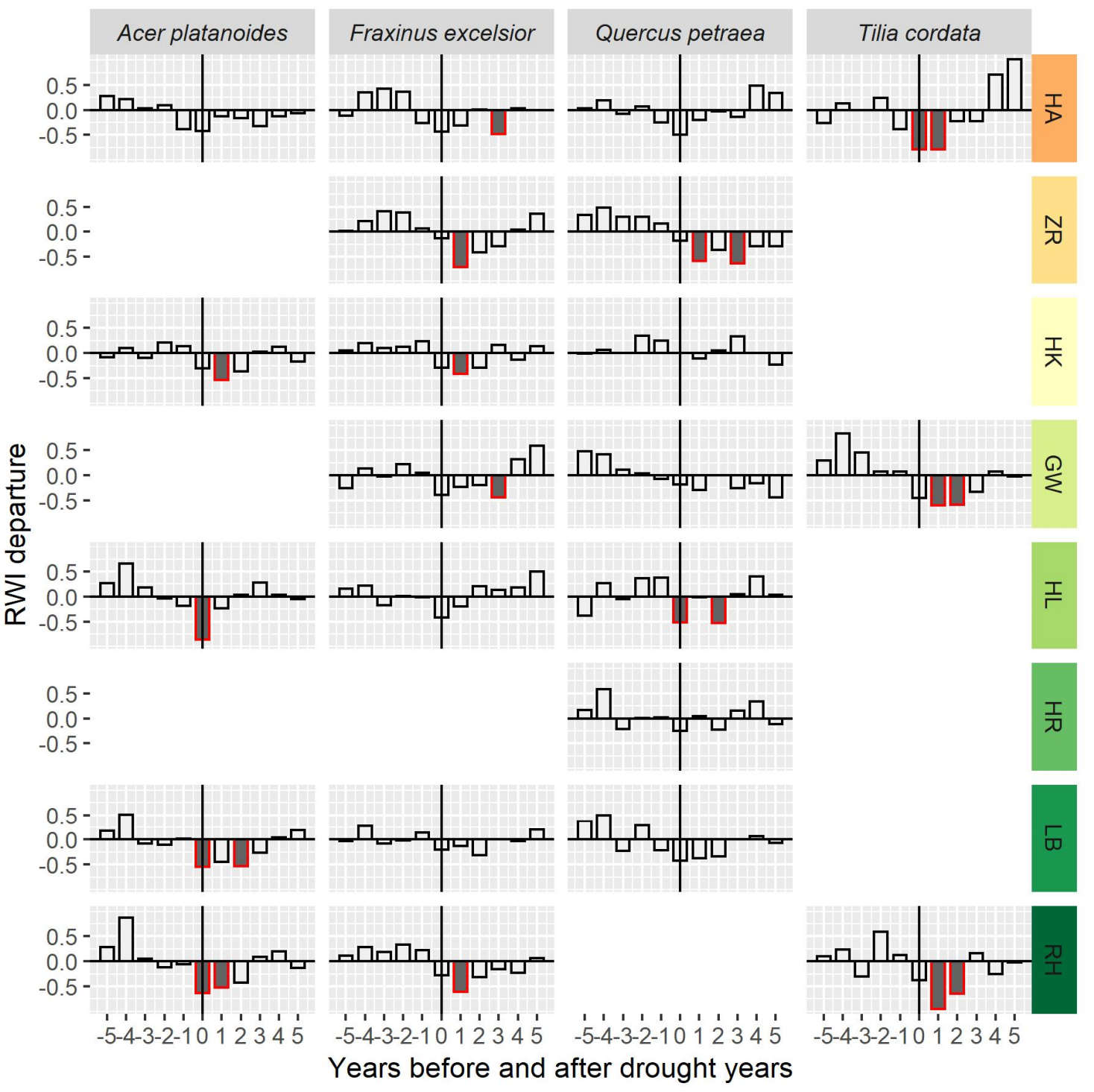

Figure 4.7: Results of superposed epoch analyses on the response of radial growth of the four species at the eight sites to drought events with a SPEI summer $<-0.84$. Shown is the deviation of mean ring width in an 11-year period with the drought years in the center from the mean ring widths in all analyzed 11-year epochs of the chronology. Significant departures $(\mathrm{p}<0.05)$ are shown in dark grey with red frame. The color spectrum from orange to green indicates the position of the site in the gradient of mean growing season precipitation (orange: low, green: high).

With respect to the two tested drought tolerance indices, A. platanoides showed the lowest drought resistance, i.e. the strongest growth depression in drought years with a median increment reduction of $21 \%$, followed by T. cordata, F. excelsior, and Q. petraea with $19 \%, 11 \%$, and $8 \%$, respectively (Figure 4.8). The differences between the species were only significant between A. platanoides and the ring-porous species. Growth 
resilience, i.e. the ratio of post-drought to pre-drought increment, was similar among the four species without significant differences and values close to 1 (Figure 4.8). This indicates that all species regained their pre-drought increment level within less than five years and were able to compensate possible lags in growth recovery in the first years after drought that were visible in the SEA (Figure 4.7) by overshooting in the $3^{\text {rd }}$ to $5^{\text {th }}$ year after drought.

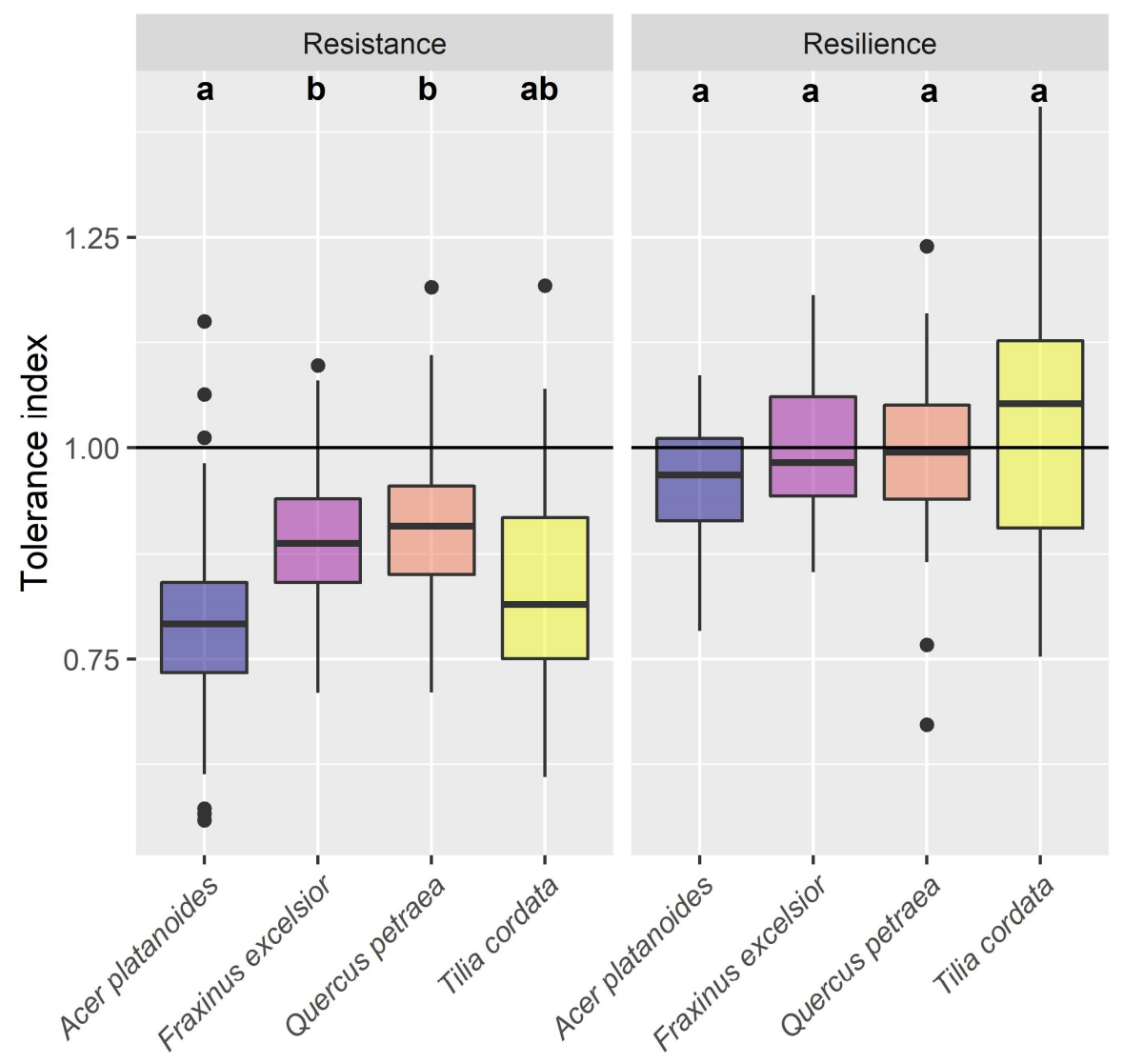

Figure 4.8: Resistance and resilience of radial growth of the four species to selected droughts in an 11-year window with the drought year in the centre of the period. All drought events with a SPEI <-0.84 (based on the SPEI of the month August with consideration of a six-months window) in the study period were considered. The indices were calculated using detrended ring width indices pooling for every species over all sites and all identified drought years. Resistance is the growth depression in a drought year compared to the 5 years prior to drought, resilience the ratio of mean radial growth in the five post-drought years relative to the growth in the five years prior to drought. Different small letters indicate significant differences between species based on Tukey-adjusted p-values from linear mixed effects models with degrees of freedom based on Satterthwaite's approximation. Number of trees was $\mathrm{n}=57$ for $A$. platanoides, $\mathrm{n}=83$ for $F$. excelsior, $\mathrm{n}=80$ for $Q$. petraea, and $\mathrm{n}=29$ for $T$. cordata; the number of studied drought events varied between 9 and 13, depending on sites.

We are aware that many studies use raw ring widths or raw BAI to calculate tolerance indices (70\% according to Schwarz et al. 2020). However, using detrended data seems to be the safe choice when dealing with all the heterogeneity and irregular management 
effects that come with minor timber species and species-rich stands. Nevertheless, the same patterns of the indices were found, when resistance and resilience were calculated with raw BAI data (Figure 4.15, Appendix C).

No relationship was observed between measures of site-specific water availability (MGSP or AWC) and growth resistance or resilience (Table 4.3). The marginal $\mathrm{R}^{2} \mathrm{~s}$ of all models were very low (0.02-0.12), indicating low explanatory power of the predictors; a considerable portion of the variance was explained by random site-effects (site SD), but most of the variance occurred between individuals (residual SD).

Table 4.3: Results of linear mixed effects models exploring the relationship between various environmental variables and the tolerance indices growth resistance and resilience. Given are the scaled estimates for the effect of MGSP (mean growing season precipitation) and AWC (soil capacity for plant-available water), as well as the standard deviation for the random effect "Site" (Site SD), the residual standard deviation (Res. $\mathrm{SD}$ ), and marginal and conditional $\mathrm{R}^{2}$ values of the models. None of the fixed effects was significant at $\mathrm{p}<$ 0.05. As data were available for T. cordata only at three sites, this species is omitted here.

\begin{tabular}{l|lrr}
\hline Species & Term & Resistance & Resilience \\
\hline Acer platanoides, & MGSP estimate & -0.042 & 0.204 \\
$\mathrm{n}=57$ & AWC estimate & -0.157 & 0.080 \\
& Site SD & 0.681 & 0.234 \\
& Res. SD & 0.894 & 0.884 \\
& Marg. Rsq. & 0.026 & 0.064 \\
& Cond. Rsq. & 0.384 & 0.164 \\
\hline Fraxinus excelsior & MGSP estimate & 0.065 & -0.082 \\
$\mathrm{n}=83$ & AWC estimate & -0.205 & -0.380 \\
& Site SD & 0.461 & 0.431 \\
& Res. SD & 0.918 & 0.881 \\
& Marg. Rsq. & 0.048 & 0.124 \\
& Cond. Rsq. & 0.239 & 0.293 \\
\hline Quercus petraea & MGSP estimate & -0.051 & 0.335 \\
& AWC estimate & 0.193 & -0.264 \\
& Site SD & 0.578 & 0.777 \\
& Res. SD & 0.893 & 0.742 \\
& Marg. Rsq. & 0.028 & 0.094 \\
& Cond. Rsq. & 0.316 & 0.567 \\
\hline
\end{tabular}

\subsection{Discussion}

\subsubsection{Higher drought tolerance of the ring-porous species}

We found a nearly twice as high mean sensitivity of radial growth for the diffuseporous species (A. platanoides, $T$. cordata) as compared to the ring-porous species $(F$. excelsior, $Q$. petraea). This was linked to the ring-porous species' lower growth sensitivity to severe drought events, as revealed in the superposed epoch analysis (SEA), 
supporting our third hypothesis. A relatively low growth sensitivity to drought of temperate ring-porous tree species is a well-recognized phenomenon (Kunz et al., 2018; Meyer et al., 2020; Scharnweber et al., 2011; Zimmermann et al., 2015). While the high drought tolerance of $Q$. petraea has been reported in many dendrochronological studies (Cavin et al., 2013; Elliott et al., 2015; Kunz et al., 2018; Zang, 2011; Zimmermann et al., 2015), much less is known about the drought response of F. excelsior. Our results confirm the judgement of Zimmermann et al. (2015) that the drought tolerance of growth of $F$. excelsior is comparable to that of $Q$. petraea.

A plausible explanation of the higher drought sensitivity of growth of diffuse-porous species is provided by the different seasonality of cambial activity and the contrasting hydraulic importance of early-wood formation in ring- and diffuse-porous species. Earlywood formation in ring-porous species usually occurs before and during bud burst (Barbaroux and Bréda, 2002), and the hydraulic capacity of ring-porous species is highly dependent on these newly formed early-wood vessels. In fact, the bulk of the hydraulic conductance in the stem xylem is provided by the current-year ring, while older vessels typically suffer from drought- or frost-induced embolism formation (Cochard and Tyree, 1990; Michelot et al., 2012b).

Temporal avoidance of drought effects on cambial activity may be a main cause of the reduced inter-annual variation in tree-ring widths (TRW) in ring-porous species. In agreement with this interpretation, we did not find a single missing ring in any of the ringporous cores. Drought stress during spring has been identified as the single most important climatic factor controlling radial increment in oak (Tardif and Conciatori, 2006). This is supported by the growth response to the 1976 drought with water deficits already in spring, when negative growth departures were similarly strong in $Q$. petraea and F. excelsior as in A. platanoides and T. cordata (Figure 4.14, Appendix C). However, when the drought occurs later in the season, as usually does in Central Germany, ringporous species may show smaller growth reductions than diffuse-porous species.

\subsubsection{Climatic drivers of radial growth}

The SPEI index as a proxy of the climatic water balance had in all species a larger influence on radial growth than precipitation or temperature alone, which suggests that water availability acts together with the atmospheric evaporative demand in the control of foliar, stem and root water status and thus cambial growth activity. Many dendrochronological studies in Central European lowland forests have shown that the growth of beech, oak and other broadleaf trees is primarily limited by moisture 
availability (Knutzen et al., 2017; Latte et al., 2016; Scharnweber et al., 2011). A reduced TRW in dry summers might be caused by processes that impair the growth potential of the stem cambium, among others reduced carbon gain due to partial stomatal closure, turgor loss in cambial cells due to a reduction in the tree's hydraulic capacity, and reduced allocation of carbohydrates to radial growth due to enhanced investment in roots (Allen et al., 2010; Bréda et al., 2006; Müller-Haubold et al., 2013). However, smaller annual rings can also mirror an acclimation response of the tree to increase drought hardiness through the production of thicker pit membranes and narrower and/or a smaller number of conduits that accompany smaller tree rings (Fonti et al., 2013). This reduces hydraulic efficiency, but increases hydraulic safety (Hacke and Sperry, 2001). Reduced radial growth could then increase fitness in the longer term, and the growth reduction may represent a strength rather than a weakness in the face of drought (Bréda et al., 2006; Gessler et al., 2020, Lloret et al., 2011). In the absence of long-term mortality records of the stands, it remains questionable whether the ring-porous species of our sample with their lower responsiveness to summer droughts are more successful than the diffuseporous species.

The consistent influence of previous-year's summer SPEI on the growth of $F$. excelsior and $T$. cordata indicates that radial growth relies strongly on stored carbohydrates of the past summer in these species (Kozlowski and Pallardy, 1997). In accordance, earlier studies on $F$. excelsior also observed that the previous years' summer climate explains most of the current-year growth (Jalilvand, 2008; Koval and Maksymenko, 2020; Roibu et al., 2020). Important carry-over effects on radial growth have also been found in other temperate broadleaf species such as F. sylvatica (Di Filippo et al., 2007; Dittmar et al., 2003; Lebourgeois et al., 2005; Müller-Haubold et al., 2015). In our study, A. platanoides showed a significant and consistent influence of the previous summer only for the negative temperature effect, but a much weaker influence of previous year's precipitation. For the radial growth of $Q$. petraea, in contrast, previous summer's weather was relatively unimportant, matching the generally lower susceptibility of oak growth to variation in precipitation and temperature (Friedrichs et al., 2009b; Mérian et al., 2011; Michelot et al., 2012a; Meyer et al., 2020). One possible explanation of species differences in the importance of carry-over effects on radial growth is the extent of carbohydrate allocation to the fine root system. $Q$. petraea seems to maintain a smaller fine root system than the other species and its fine roots are less drought-sensitive than in the other species (Fuchs 
et al., 2020). Temporal shifts in the carbohydrate allocation to the root system might therefore be less important in oak than in the other species.

\subsubsection{Climate sensitivity of growth and drought acclimation}

Our data demonstrate non-stationarity in the relationship between climate factors and TRW during the last 50 years for all species with a major change in the correlation patterns occurring in the 1980s/90s. All four species showed distinct and similar temporal trends of the climate sensitivity of growth, notably a loss of temperature and summer precipitation sensitivity from the 1970s and 1980s towards the 1990s and 2000s. This unexpected trend was particularly strong in A. platanoides and F. excelsior and less clear in $Q$. petraea. While age- and size-related processes often affect the climate-growth relationships of trees (Carrer and Urbinati, 2004; Rozas, 2005; Trouillier et al., 2019), this influence can be excluded as the predominant driver in our study, as the sensitivity decline was observed across all age classes and in stands of different height and stem diameter. For the same reason, an increase in competition intensity, which has been shown to cause a gradual loss of climate sensitivity (Piutti and Cescatti, 1997; Rozas, 2001), can be excluded as a driver as well. The stands have been subject to repeated selective cutting in the past, yet at different intervals and intensities. Since the climategrowth response was similar, but the management regime different in the stands, lowintensity timber extraction cannot be the underlying cause either. Thus, the ongoing temperature increase and decrease in the SPEI in the growing season must be the principal driver of the declining climate sensitivity of growth.

Our finding relates to the 'divergence problem' (D'Arrigo et al., 2008) and the 'loss of track' phenomenon (Wilmking et al., 2020) that have been reported mostly in forests at colder sites, where radial growth failed to capture the climate warming trend of the past decades and concomitantly lost its temperature sensitivity. However, most of the observations refer to tree line or high-latitude forests, where the temperature influence on growth is positive (D'Arrigo et al., 2008). In lowland forests, in contrast, summer temperature is usually negatively correlated with growth. Here, edaphic and atmospheric drought and heat exposure are usually the main climatic drivers of growth (Knutzen et al., 2017; Scharnweber et al., 2011). Increases in temperature and climatic aridity should increase the drought sensitivity of tree growth in such environments, which has been observed for various species including Q. petraea (Friedrichs et al., 2009b; Kolár̆ et al., 2017; Roibu et al., 2020). In contrast, other authors reported decreases in growth sensitivity to summer temperature or summer SPEI during the last decades (Mérian et al., 
2011; Dobrovolný et al., 2016) and during the warm decade in the 1940s for Q. petraea (Friedrichs et al., 2009a), which is in line with our results.

One possible explanation for such a phenomenon may be offered by the analysis of theoretical environment-growth response curves (Wilmking et al., 2020). Applying this concept to our observations suggests that episodically increased drought intensities in an already drought-limited environment should reduce the drought sensitivity of the species, because water shortage is limiting growth in every year. However, this concept does not provide a plausible explanation for the climate sensitivity decrease in our study, because a general growth reduction over time was absent.

We observed in none of the species a clear decrease in mean radial growth rate towards the drier end of the transect, which might indicate acclimation or adaptation of the local populations to reduced water availability either genetically or within the frame of phenotypic plasticity. This is supported by the decreasing sensitivity to summer SPEI towards the dry end of the climatic gradient in all species except $Q$. petraea, which was found for the period 1967-1991 (but not in the 1992-2016 period; Figure 4.6). Corresponding patterns of apparent adaptation to drier habitats were reported for $F$. sylvatica in pan-European studies (Cavin and Jump, 2017; Muffler et al., 2020), but lacked in $Q$. petraea in our study. Whatever the cause, constant growth rates in a period of increasing climatic aridity, in association with reduced climatic sensitivity of growth, must be interpreted as a sign of a considerable drought tolerance of all four tree species. In conclusion, the decreasing drought sensitivity towards drier conditions in the three minor timber species, both on a spatial and a temporal scale, indicates adaptation and acclimation processes to drier conditions.

\subsubsection{Growth resistance and resilience to severe drought events}

The results of the SEA study on the species' growth response to climatically defined droughts revealed species differences. The growth depression in the drought year was generally greater in the two diffuse-porous species (smaller resistance), suggesting that diffuse-porous species may be more flexible in their carbon allocation by reducing radial growth more strongly in drought years. This could be a result of higher investment in fine root production, which seems to be rather low in ring-porous Q. petraea (Fuchs et al., 2020; Hertel and Leuschner, 2002). Yet, all species showed high growth resilience in the five post-drought years with partial overshoot in some cases. This suggests that the four species may pursue different growth and allocation strategies in response to severe droughts, while fitness maintenance after drought is similar. This is indicated by the 50- 
year TRW chronologies (Figure 4.9 and 4.10, Appendix C), which show for none of the species a lasting growth depression after the severe 1976 drought.

To which extent radial growth reductions after drought and mortality are interlinked in the four species is largely unknown. However, many temperate tree species exhibit decades of reduced growth before they die (Cailleret et al., 2017). This suggests that the studied populations of the four species are unlikely to suffer increased drought-induced dieback in the near future, as none of the TRW chronologies showed marked declines. The survey of crown conditions conducted on all study sites in late summer 2019 after two consecutive drought years with the most extreme heatwaves in Central Europe since the beginning of climate records supports this assumption, as no severe defoliation or partial canopy dieback was observed (Figure 4.17, Appendix C).

Growth resistance and resilience did not vary systematically with the local climate and soil water capacity of the sites. The high residual variance of the models indicates that most of the variation found in the resistance and resilience indices occurs between individuals and not sites. This is plausible, as small-scale heterogeneity in stand microclimatic and soil physical properties at the position of the tree individuals is large in mixed stands with bigger distance between the sampled individuals.

Climate and soil are not the only factors influencing the growth response to drought, tree age may also be important. We tested for tree age effects on growth resistance and resilience but did not find any effect (but see Kunz et al., 2018). We attribute this to the fact that most trees of our study were of mature age (90-130 years).

\subsubsection{Other sources of growth reductions}

Negative pointer years may not only be caused by exceptional droughts, but can result from other abiotic and biotic factors as well. The two most important biotic factors are masting years (Pearse et al., 2016) and infestations with insects, fungi or other pests (Schweingruber, 1996). Within our species sample, Q. petraea is by far most affected by these biotic stress factors with a large number of periodically upcoming pests and insect infestations (Gibbs and Greig, 1997; Roloff et al., 2010). Oak is also a distinct mastfruiting species with a large seed mass amplitude between years and related high carbon costs (Nussbaumer et al., 2018). F. excelsior is a mast-fruiting species as well (Tapper, 1996), whereas fluctuations in seed production of A. platanoides and T. cordata are rather low (Roloff et al., 2010; Wesołowski et al., 2015). The species-specific masting behavior offers a possible explanation of the high frequency of negative pointer years in $Q$. petraea 
that mostly did not coincide with drought years, in contrast to the small number of negative pointer years in $T$. cordata.

Mast years in F. excelsior are, in a similar manner as in F. sylvatica, typically cued by a warm and sunny previous summer with a long foliation period (Piovesan and Adams, 2001; Tapper, 1996; Vacchiano et al., 2017). In contrast, mast-fruiting in Q. petraea is triggered by a warm spring of the current year (Bogdziewicz et al., 2019). These species differences between $F$. excelsior and $Q$. petraea can explain the different lag effects of warm and dry previous years on radial growth (Figure 4.3), because low SPEI values over the previous vegetation period may have induced masting years with reduced TRW in $F$. excelsior but not in $Q$. petraea. The consistent negative growth reaction of $F$. excelsior to a higher previous year's September temperature, which is associated with a longer foliation period, supports this explanation.

Due to large differences in pest-induced vitality fluctuation and in inter-annual variability of masting intensity and related carbon costs among the four species, we rate pointer year frequency as a weak tool for drought-sensitivity assessments in species comparisons. Conventional pointer year definitions (e.g after Cropper, 1979) depend on growth synchronicity in the stand, with higher growth synchronicity increasing the probability of pointer year identification. Yet, low synchronicity is not necessarily an indicator of high drought tolerance. In our study, pointer year frequency was not consistently related to the frequency and severity of drought events during the past 50 years. The strongest and regionally most consistent negative pointer year in $Q$. petraea was 1996, a cold and moist year, in which negative growth deviations of $Q$. petraea were most likely caused by a relatively short vegetation period due to cold spring temperatures. Further, the species with the lowest growth synchronicity (T. cordata) exhibited the lowest frequency of pointer years, but showed stronger growth reductions in drought years than $Q$. petraea and $F$. excelsior. Considering the influence of these droughtunrelated factors suggests that the calculation of growth resistance and resilience to droughts may in part be biased and the drought tolerance of highly pest-susceptible and mast-fruiting species such as $Q$. petraea and partly $F$. excelsior might be overestimated.

\subsubsection{Conclusions}

Assessing the drought tolerance of tree species through the analysis of radial growth resistance to drought events and its responsiveness to climatic factors can provide valuable information on abiotic drivers of tree vitality. However, a concise drought tolerance assessment requires additional information on background and drought-induced 
mortality in unmanaged stands, which is difficult to obtain in the managed forests of Central Europe. A causal analysis of drought-induced mortality events that includes physiological measurements would help to identify lethal stress levels and critical elements in the species' drought response strategy, as it remains questionable whether growth reductions are always an expression of vitality loss, or are part of a plastic drought response that leads to morphological, anatomical and physiological acclimation.

All three minor timber species showed decreasing summer drought sensitivities towards the dry end of the gradient in the 1970s and 1980s and a general loss in climate sensitivity over time, which may point at considerable potential to acclimate to a warmer and drier climate. $Q$. petraea exhibits only minor inter-annual variation in TRW and thus a low growth sensitivity to climate and the highest resistance to drought years of all studied species. However, the apparent climate-insensitivity of growth in Q. petraea is partly caused by the large number of other growth-reducing events, notably pests and mast-fruiting, which may weaken the climatic signal and lead to overestimation of the species' drought tolerance. The dendrochronological data for $F$. excelsior suggest that the species is almost as drought tolerant as $Q$. petraea and thus equally suited for a warmer and drier climate. However, the species is severely threatened by the pan-European ash dieback caused by the fungus Hymenoscyphus fraxineus. A. platanoides and T. cordata showed distinct growth reductions in drought years and a high growth sensitivity to the SPEI, but both were highly resilient and fully regained their pre-drought growth levels, which is reflected in only low defoliation and no recorded dieback on the study sites after the exceptional 2018/19 drought. We conclude that all four studied broadleaf species are in terms of their radial growth performance relatively drought tolerant. This qualifies the three minor timbers for further assessment of their suitability for the establishment of drought-tolerant forests in Central Europe. 
Acknowledgements: We gratefully acknowledge the financial support granted by the Bundesministerium für Ernährung und Landwirtschaft (Germany), Bundesministerium für Umwelt, Naturschutz und nukleare Sicherheit (Germany) and the Fachagentur Nachwachsende Rohstoffe e. V. (Germany) within the frame of the "Waldklimafonds" (project DIVforCLIM). Additionally, we thank the local forestry authorities of Lower Saxony and Saxony-Anhalt and the DBU-Naturerbe $\mathrm{GmbH}$ for permissions to conduct the study, and the Nordwestdeutsche Forstliche Versuchsanstalt for kindly providing forest inventory data for the identification of suitable study sites. Special thanks go to Annegret Kellner, Jutta Czernitzki, Irmgard Gerstmann and Leonhard Klinck for their skillful support in the lab and field work. 


\subsection{Appendix C}

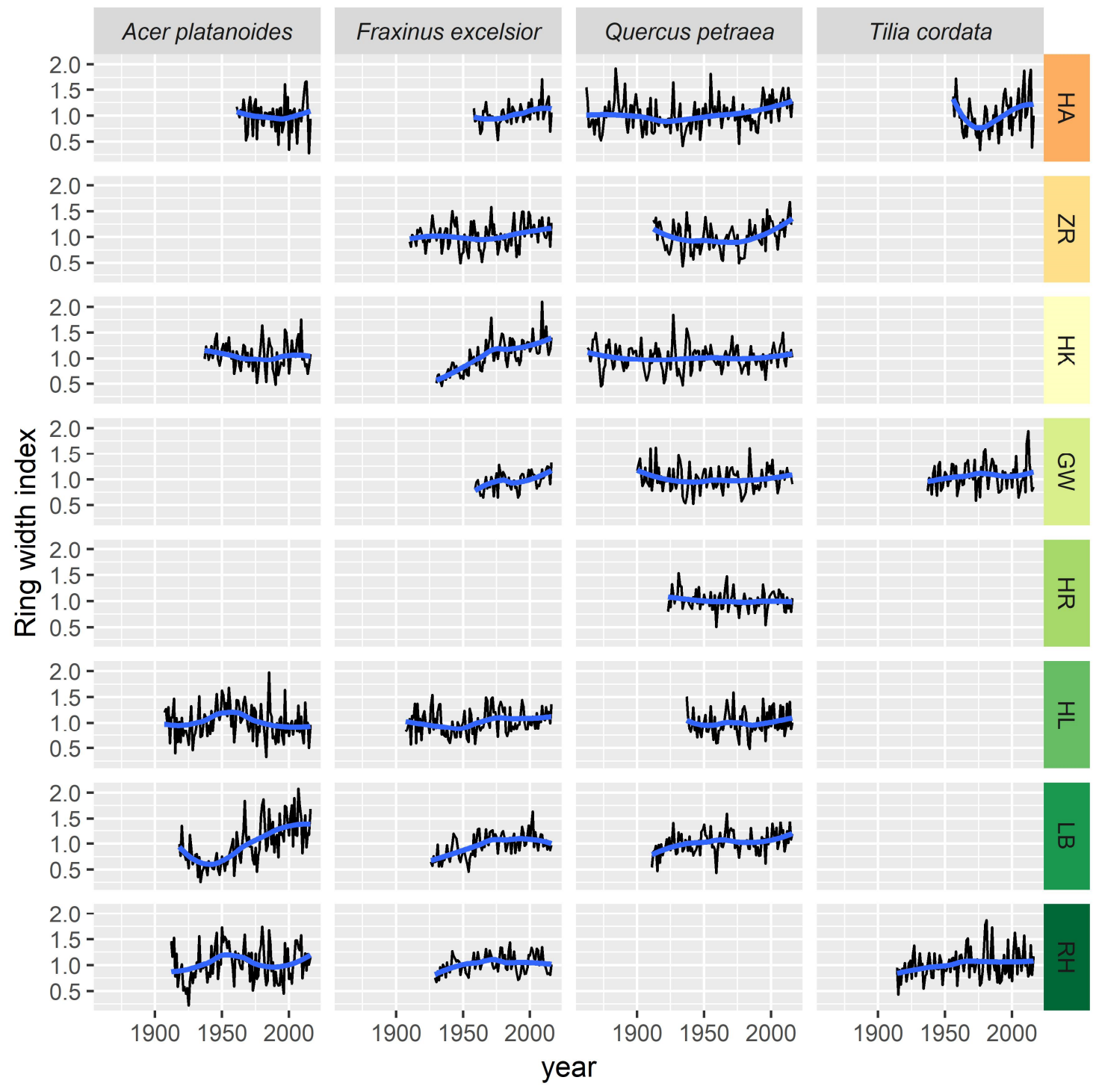

Figure 4.9: Ring width index chronologies for the four species at the eight sites, age-detrended with regional curve standardization (RCS). The blue line is a 25-year smoothing spline. The color spectrum from orange to green indicates the position of the site in the gradient of mean growing season precipitation (orange: low, green: high). 


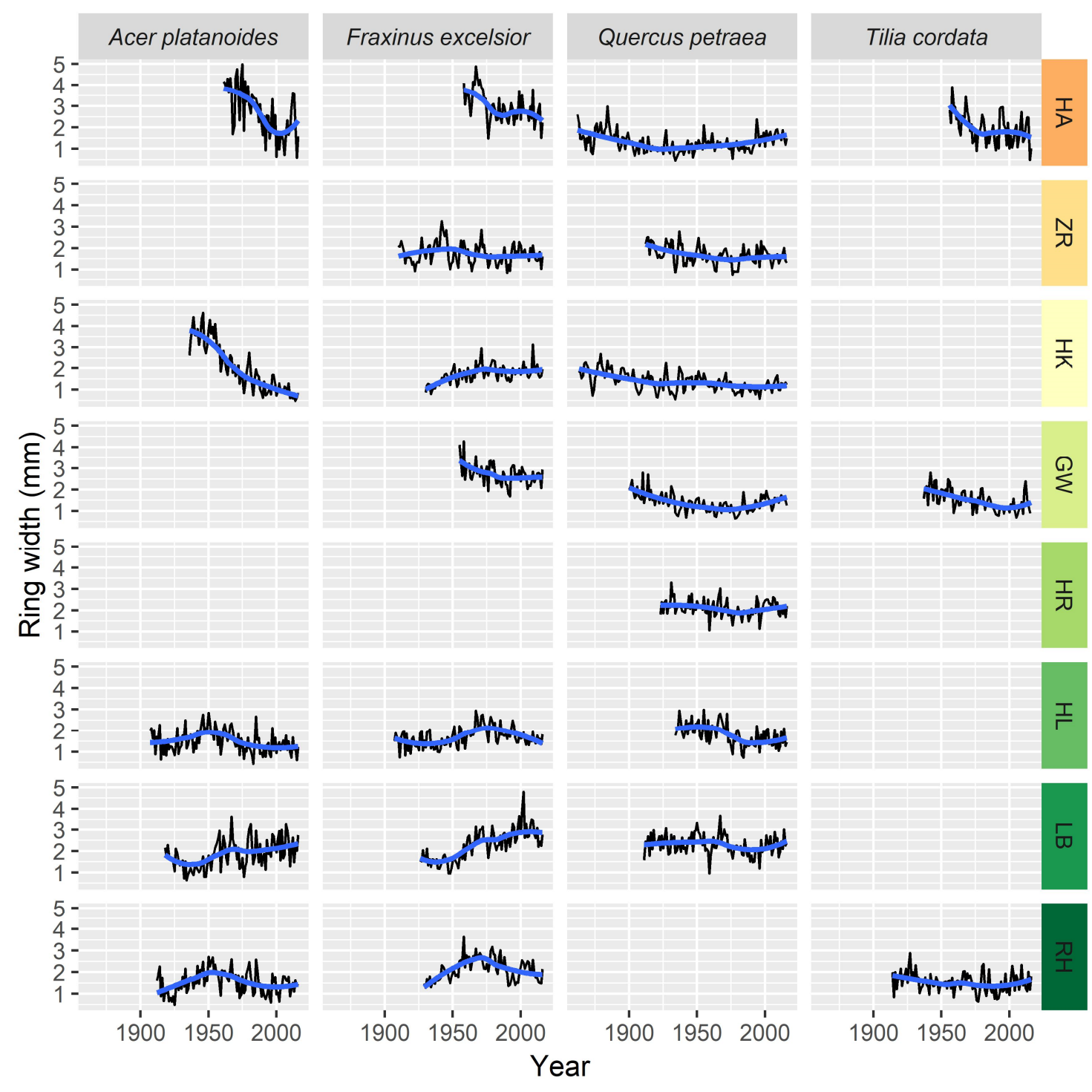

Figure 4.10: Ring-width chronologies for the four species at the eight sites using the raw data from 9-13 tree individuals per stand which were averaged using Tukey's bi-weight robust mean. The color spectrum from orange to green indicates the position of the site in the gradient of mean growing season precipitation (orange: low, green: high). 


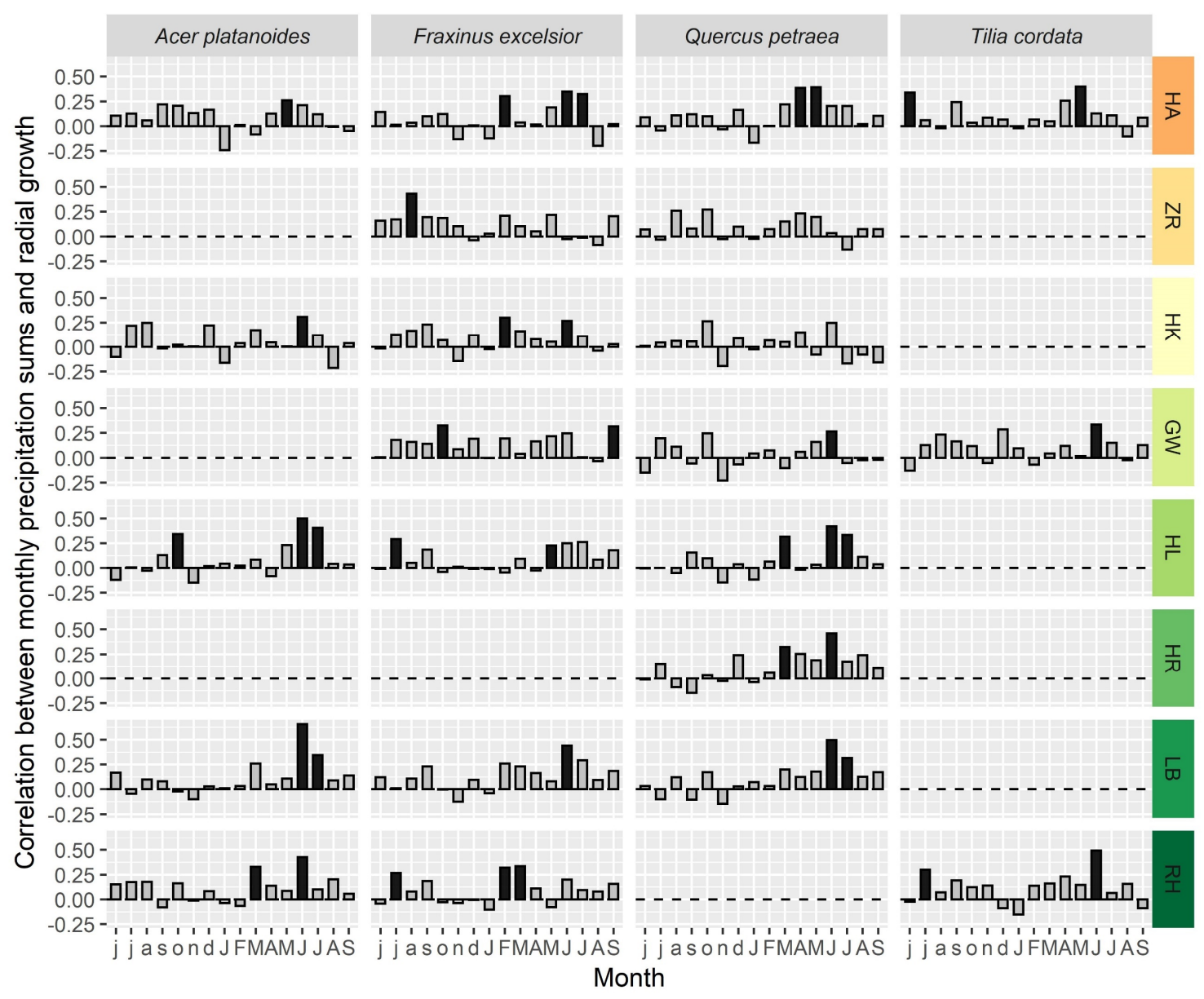

Figure 4.11: Correlation between radial growth (ring width index values) and the precipitation totals of months in the previous and current year for the four species at eight sites. Months abbreviated with lower case letters refer to the previous year, months with capital letters to the current year. Given is the size of the correlation coefficient and the significance of the relation (black bars: $p<0.05$; grey bars: $p>0.05$ ) based on 1000x bootstrapping against randomly chosen precipitation-growth pairs. The color spectrum from orange to green indicates the position of the site in the gradient of mean growing season precipitation (orange: low, green: high). 


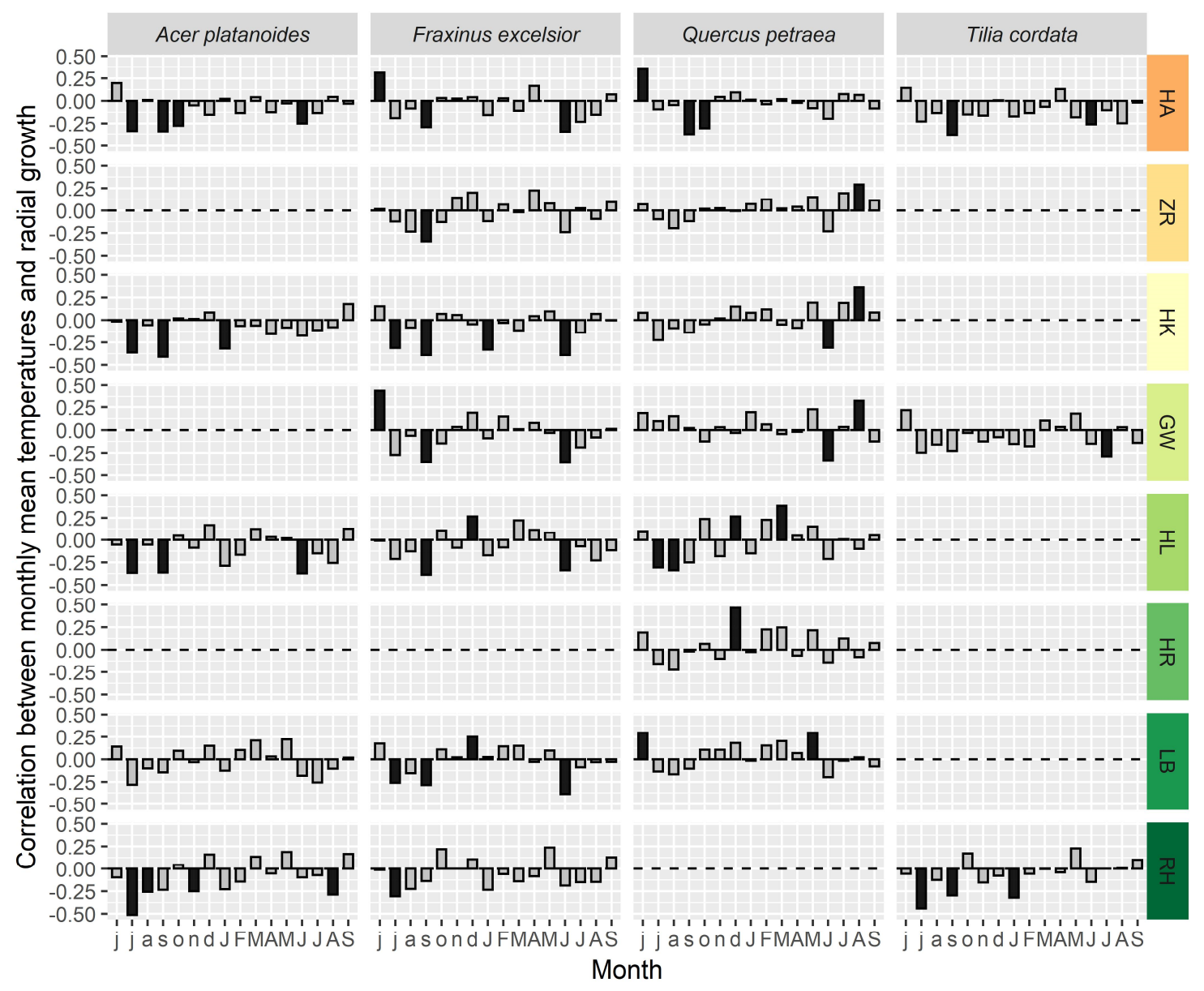

Figure 4.12: Correlation between radial growth (ring width index values) and mean temperature of the months in the previous and current year for the four species at eight sites. Months abbreviated with lower case letters refer to the previous year, months with capital letters to the current year. Given is the size of the correlation coefficient and the significance of the relation (black bars: $p<0.05$; grey bars: $p>0.05$ ) based on 1000x bootstrapping against randomly chosen temperature-growth pairs. The color spectrum from orange to green indicates the position of the site in the gradient of mean growing season precipitation (orange: low, green: high). 


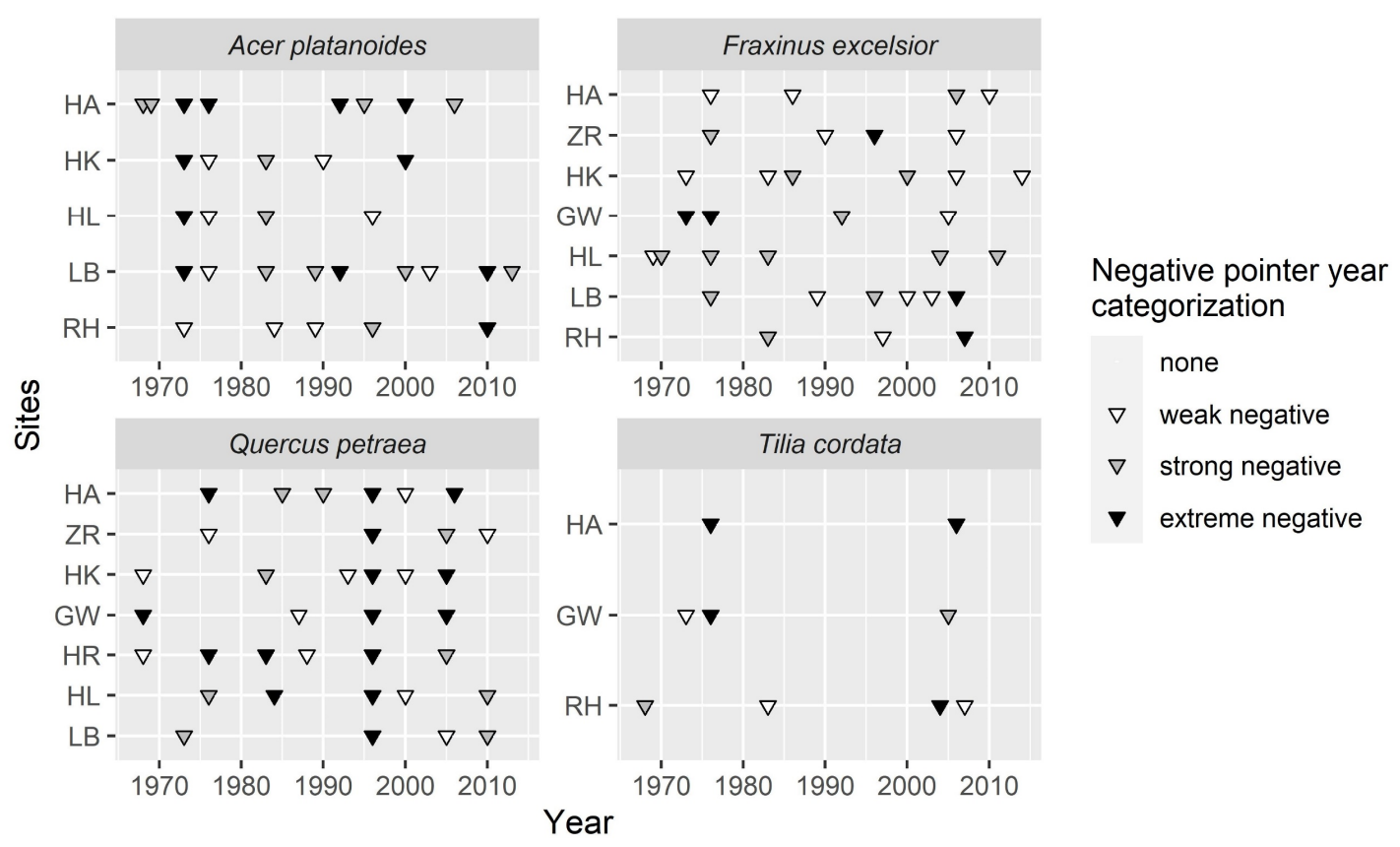

Figure 4.13: Negative pointer years of the four species on the eight sites in the period 1967-2016 according to Cropper-values following the approach of Neuwirth et al. (2007) with normalization in a 5-year moving window. Thresholds for weak, strong, and extreme negative pointer years were $0.8,1.2$, and 1.5 standard deviations of growth decline, respectively, for at least $60 \%$ of the population. Site are arranged according to mean growing season precipitation from drier to moister. 


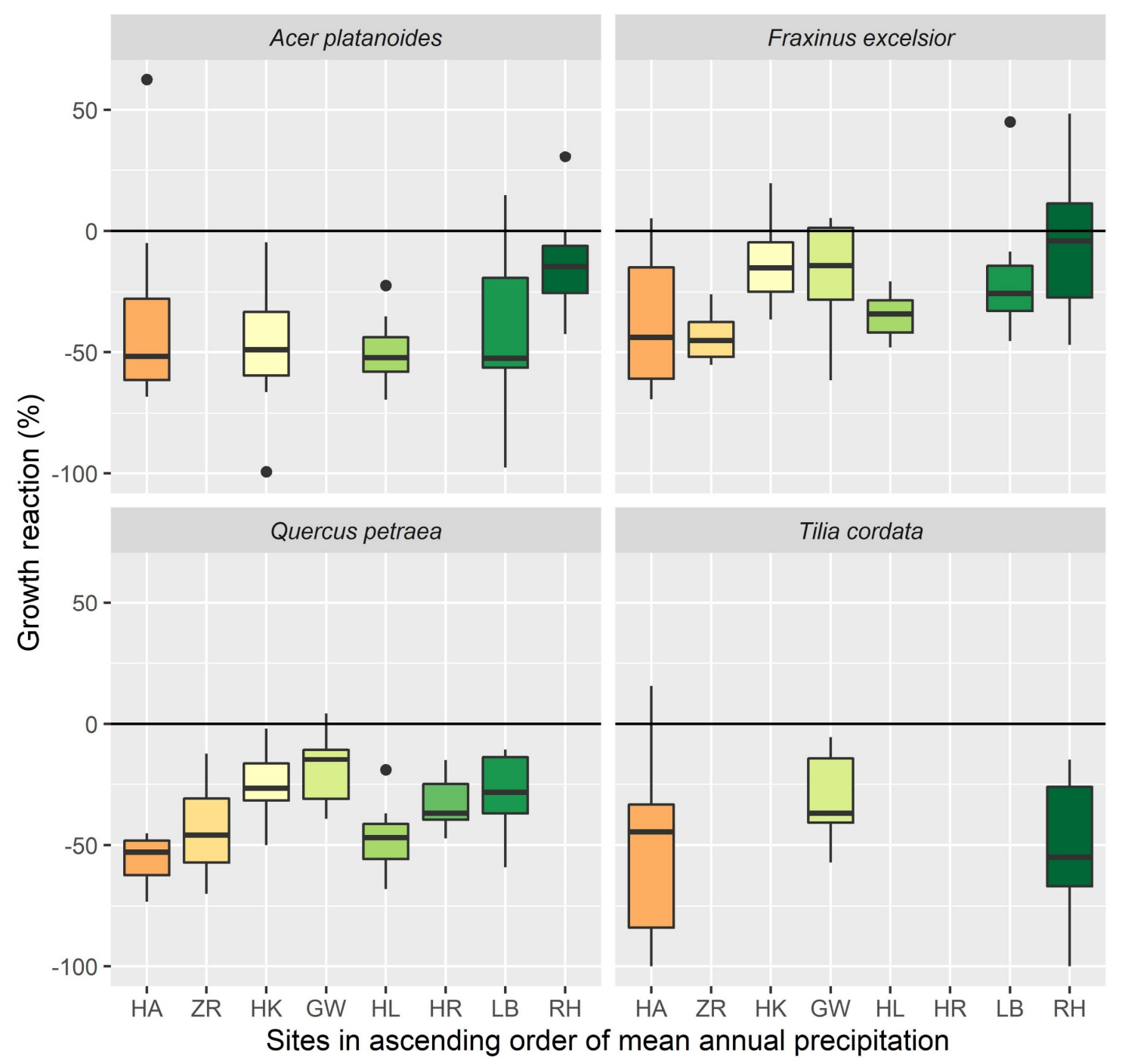

Figure 4.14: Percental reduction in BAI in the drought year 1976 relative to the average BAI of the five preceding years for the four species at the eight sites. The color spectrum from orange to green indicates the position of the site in the gradient of mean growing season precipitation (orange: low, green: high). 


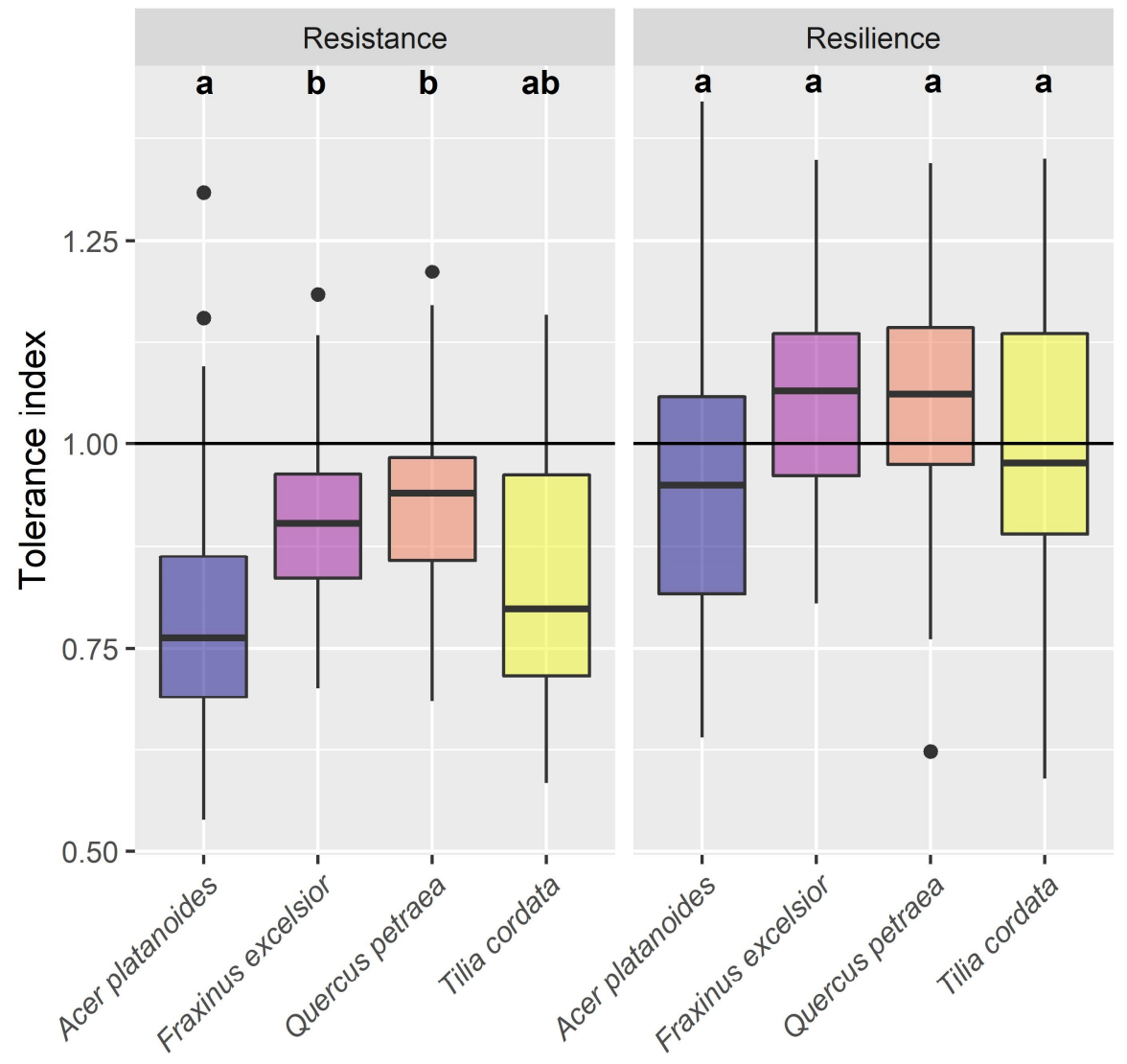

Figure 4.15: Resistance and resilience of basal increment of the four species to selected droughts in an 11year window with the drought year in the centre of the period. All drought events with a SPEI $<-0.84$ (based on the SPEI of the month August with consideration of a six-months window) in the study period were considered. The indices were calculated using raw BAI data pooling for every species over all sites and all identified drought years. Resistance is the growth depression in a drought year compared to the 5 years prior to drought, resilience the ratio of mean radial growth in the five post-drought years relative to the growth in the five years prior to drought. Different small letters indicate significant differences between species based on Tukey-adjusted p-values from linear mixed effects models with degrees of freedom based on Satterthwaite's approximation. Number of trees was $\mathrm{n}=57$ for A. platanoides, $\mathrm{n}=83$ for F. excelsior, $\mathrm{n}=80$ for $Q$. petraea, and $\mathrm{n}=29$ for $T$. cordata; the number of studied drought events varied between 9 and 13 , depending on sites. 


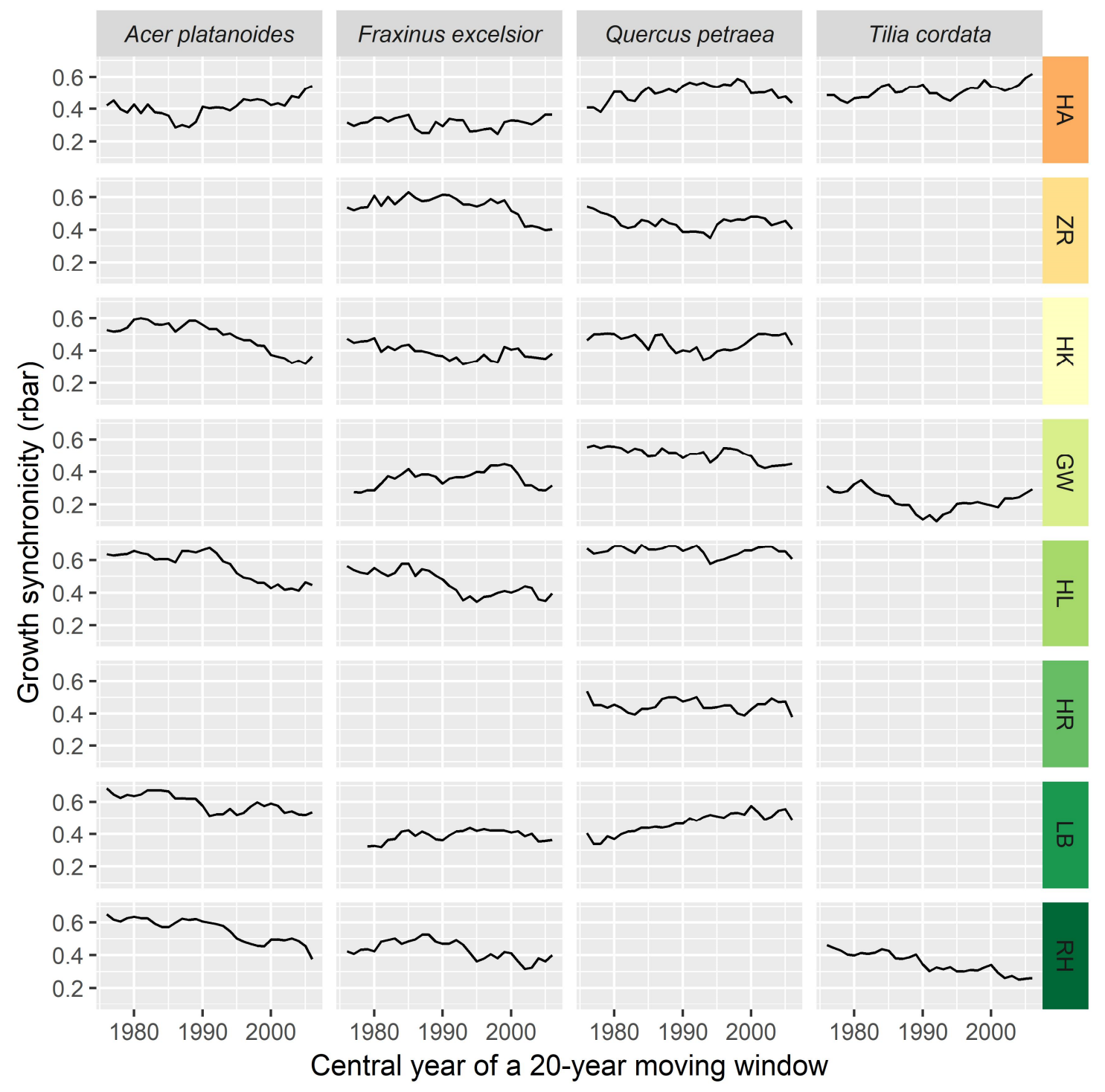

Figure 4.16: Within-population growth synchronicity of the four species at the eight sites in the period 1967-2016. Given is the interseries correlation (Rbar) as derived from a moving 20-year window analysis of ring width index series. The color spectrum from orange to green indicates the position of the site in the gradient of mean growing season precipitation (orange: low, green: high). 


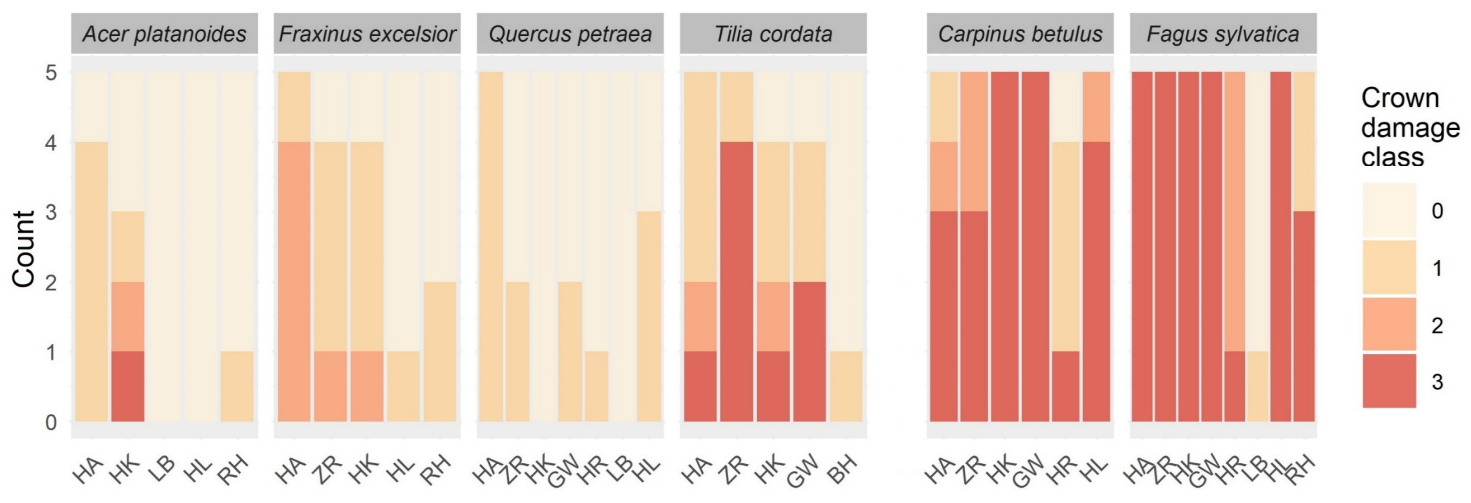

Figure 4.17: Frequency of crown damage classes in late summer of 2019 (September) in the stands of the four species at eight sites after the extreme 2018/19 drought as derived from the inspection of each five individuals. Site acronyms are explained in Figure 1. The crown damage classes 0 to 3 base on a groundbased visual assessment of the canopy's defoliation and discoloration (damage is defined as the sum of discolored and fallen leaves in percent of full foliation; $0=0 \%-10 \%$ damage; $1=10 \%-25 \%$ damage, 2 $=25 \%-60 \%$ damage, $3=>60 \%$ damage). Carpinus betulus and Fagus sylvatica trees that occurred in the same stands are reported for comparison. 


\subsection{References}

Allen, C.D., Macalady, A.K., Chenchouni, H., Bachelet, D., McDowell, N., Vennetier, M. et al, 2010. A global overview of drought and heat-induced tree mortality reveals emerging climate change risks for forests. For. Ecol. Manage. 259, 660-684. https://doi.org/10.1016/j.foreco.2009.09.001.

Baillie, M.G., Pilcher, J.R., 1973. A Simple Crossdating Program for Tree-Ring Research. Tree-ring Bull. 33, 7-14.

Barbaroux, C., Bréda, N., 2002. Contrasting distribution and seasonal dynamics of carbohydrate reserves in stem wood of adult ring-porous sessile oak and diffuseporous beech trees. Tree Physiol. 22, 1201-1210. https://doi.org/10.1093/treephys/22.17.1201.

Bates, D., Mächler, M., Bolker, B., Walker, S., 2015. Fitting Linear Mixed-Effects Models Using lme4. J. Stat. Soft. 67. https://doi.org/10.18637/jss.v067.i01.

Biondi, F., 1997. Evolutionary and moving response functions in dendroclimatology. Dendrochronologia 15, 139-150.

Biondi, F., Qeadan, F., 2008. A Theory-Driven Approach to Tree-Ring Standardization: Defining the Biological Trend from Expected Basal Area Increment. Tree-Ring Res. 64, 81-96. https://doi.org/10.3959/2008-6.1.

Bogdziewicz, M., Szymkowiak, J., Fernández-Martínez, M., Peñuelas, J., Espelta, J.M., 2019. The effects of local climate on the correlation between weather and seed production differ in two species with contrasting masting habit. Agric. For. Meteorol. 268, 109-115. https://doi.org/10.1016/J.AGRFORMET.2019.01.016.

Brang, P., Bugmann, H., Bürgi, A., Mühlethaler, U., Rigling, A., Schwitter, R., 2008. Klimawandel als waldbauliche Herausforderung | Climate change as a challenge for silviculture. Schweiz. Z. Forstwes. 159, 362-373. https://doi.org/10.3188/szf.2008.0362.

Bréda, N., Huc, R., Granier, A., Dreyer, E., 2006. Temperate forest trees and stands under severe drought: a review of ecophysiological responses, adaptation processes and long-term consequences. Ann. For. Sci. 63, 625-644. https://doi.org/10.1051/forest:2006042.

Briffa, K.R., Jones, P.D., Bartholin, T.S., Eckstein, D., Schweingruber, F.H., Karlen, W. et al, 1992. Fennoscandian summers from AD 500: temperature changes on short and long timescales. Clim. Dyn. 7, 111-119.

Brockerhoff, E.G., Barbaro, L., Castagneyrol, B., Forrester, D.I., Gardiner, B., González-Olabarria, J.R. et al, 2017. Forest biodiversity, ecosystem functioning and the provision of ecosystem services. Biodivers. Conserv. 26, 3005-3035. https://doi.org/10.1007/s10531-017-1453-2.

Bunn, A.G., 2008. A dendrochronology program library in R (dplR). Dendrochronologia 26, 115-124. https://doi.org/10.1016/J.DENDRO.2008.01.002.

Cailleret, M., Jansen, S., Robert, E.M.R., Desoto, L., Aakala, T., Antos, J.A. et al, 2017. A synthesis of radial growth patterns preceding tree mortality. Global Change Biol. 23, 1675-1690. https://doi.org/10.1111/gcb.13535. 
Carrer, M., Urbinati, C., 2004. Age-dependent tree-ring growth responses to climate in Larix decidua and Pinus cembra. Ecology 85, 730-740. https://doi.org/10.1890/020478 .

Cavin, L., Jump, A.S., 2017. Highest drought sensitivity and lowest resistance to growth suppression are found in the range core of the tree Fagus sylvatica L. not the equatorial range edge. Global Change Biol. 23, 362-379. https://doi.org/10.1111/gcb.13366.

Cavin, L., Mountford, E.P., Peterken, G.F., Jump, A.S., 2013. Extreme drought alters competitive dominance within and between tree species in a mixed forest stand. Functional Ecology, 27(6), 1424-1435. Funct. Ecol. 27, 1424-1435. https://doi.org/10.1111/1365-2435.12126.

Cochard, H., Tyree, M.T., 1990. Xylem dysfunction in Quercus: vessel sizes, tyloses, cavitation and seasonal changes in embolism. Tree Physiol. 6, 393-407. https://doi.org/10.1093/treephys/6.4.393.

Cook, E.R., Kairiukstis, L.A. (Eds.), 1990. Methods of Dendrochronology: Applications in the Environmental Sciences. Springer Netherlands, Dordrecht, s.l.

Cook, E.R., Peters, K., 1981. The smoothing spline: a new approach to standardizing forest interior tree-ring width series for dendroclimatic studies. Tree-ring Bull. 41, $45-53$.

Cremer, M., Prietzel, J., 2017. Soil acidity and exchangeable base cation stocks under pure and mixed stands of European beech, Douglas fir and Norway spruce. Plant Soil 415, 393-405. https://doi.org/10.1007/s11104-017-3177-1.

Cropper, J., 1979. Tree-Ring Skeleton Plotting by Computer. Tree-ring Bull. 39, 47-59.

D'Arrigo, R., Wilson, R., Liepert, B., Cherubini, P., 2008. On the 'Divergence Problem' in Northern Forests: A review of the tree-ring evidence and possible causes. Global Planet. Change 60, 289-305. https://doi.org/10.1016/J.GLOPLACHA.2007.03.004.

Di Filippo, A., Biondi, F., Čufar, K., Luis, M. de, Grabner, M., Maugeri, M. et al, 2007. Bioclimatology of beech (Fagus sylvatica L.) in the Eastern Alps: spatial and altitudinal climatic signals identified through a tree-ring network. J. Biogeogr. 34, 1873-1892. https://doi.org/10.1111/J.1365-2699.2007.01747.X.

Dittmar, C., Zech, W., Elling, W., 2003. Growth variations of Common beech (Fagus sylvatica L.) under different climatic and environmental conditions in Europe-a dendroecological study. For. Ecol. Manage. 173, 63-78. https://doi.org/10.1016/S0378-1127(01)00816-7.

Dobrovolný, P., Rybníček, M., Büntgen, U., Trnka, M., Brázdil, R., Stachoň, Z. et al, 2016. Recent growth coherence in long-term oak (Quercus spp.) ring width chronologies in the Czech Republic. Clim. Res. 70, 133-141. https://doi.org/10.3354/cr01402.

Eckstein, D., Bauch, J., 1969. Beitrag zur Rationalisierung eines dendrochronologischen Verfahrens und zur Analyse seiner Aussagesicherheit. Forstw. Cbl. 88, 230-250. https://doi.org/10.1007/BF02741777.

Eilmann, B., Rigling, A., 2012. Tree-growth analyses to estimate tree species' drought tolerance. Tree Physiol. 32, 178-187. https://doi.org/10.1093/treephys/tps004. 
Elliott, K.J., Miniat, C.F., Pederson, N., Laseter, S.H., 2015. Forest tree growth response to hydroclimate variability in the southern Appalachians. Global Change Biol. 21, 4627-4641. https://doi.org/10.1111/gcb.13045.

Essiamah, S., Eschrich, W., 1986. Water Uptake in Deciduous Trees During Winter and the Role of Conducting Tissues in Spring Reactivation. IAWA J. 7, 31-38. https://doi.org/10.1163/22941932-90000435.

Felton, A., Gustafsson, L., Roberge, J.-M., Ranius, T., Hjältén, J., Rudolphi, J. et al, 2016. How climate change adaptation and mitigation strategies can threaten or enhance the biodiversity of production forests: Insights from Sweden. Biol. Conserv. 194, 11-20. https://doi.org/10.1016/J.BIOCON.2015.11.030.

Fonti, P., Heller, O., Cherubini, P., Rigling, A., Arend, M., 2013. Wood anatomical responses of oak saplings exposed to air warming and soil drought. Plant. Biol. 15 Suppl 1, 210-219. https://doi.org/10.1111/j.1438-8677.2012.00599.x.

Friedrichs, D.A., Büntgen, U., Frank, D.C., Esper, J., Neuwirth, B., Löffler, J., 2009a. Complex climate controls on $20^{\text {th }}$ century oak growth in Central-West Germany. Tree Physiol. 29, 39-51. https://doi.org/10.1093/treephys/tpn003.

Friedrichs, D.A., Trouet, V., Büntgen, U., Frank, D.C., Esper, J., Neuwirth, B. et al, 2009b. Species-specific climate sensitivity of tree growth in Central-West Germany. Trees 23, 729-739. https://doi.org/10.1007/S00468-009-0315-2.

Fuchs, S., Hertel, D., Schuldt, B., Leuschner, C., 2020. Effects of Summer Drought on the Fine Root System of Five Broadleaf Tree Species along a Precipitation Gradient. Forests 11, 289. https://doi.org/10.3390/F11030289.

Gärtner, H., Nievergelt, D., 2010. The core-microtome: A new tool for surface preparation on cores and time series analysis of varying cell parameters. Dendrochronologia 28, 85-92. https://doi.org/10.1016/J.DENDRO.2009.09.002.

Gebauer, T., Horna, V., Leuschner, C., 2012. Canopy transpiration of pure and mixed forest stands with variable abundance of European beech. J. Hydrol. 442-443, 2-14. https://doi.org/10.1016/j.jhydrol.2012.03.009.

Gessler, A., Bottero, A., Marshall, J., Arend, M., 2020. The way back: recovery of trees from drought and its implication for acclimation. New Phytol. https://doi.org/10.1111/nph.16703.

Gibbs, J.N., Greig, B.W., 1997. Biotic and abiotic factors affecting the dying back of pedunculate oak Quercus robur L. Forestry 70, 399-406. https://doi.org/10.1093/forestry/70.4.399.

Grossiord, C., Granier, A., Ratcliffe, S., Bouriaud, O., Bruelheide, H., Chećko, E. et al, 2014. Tree diversity does not always improve resistance of forest ecosystems to drought. PNAS 111, 14812-14815. https://doi.org/10.1073/pnas.1411970111.

Grundmann, B.M., Roloff, A., 2009. Use of Forest Tree Species Under Climate Change, in: Feldmann, F. (Ed.), Crop plant resistance to biotic and abiotic factors. Current potential and future demands. DPG, Braunschweig. Spectrum Phytomedizin.

Hacke, U.G., Sperry, J.S., 2001. Functional and ecological xylem anatomy. Perspect. Plant Ecol. Evol. Syst. 4, 97-115. https://doi.org/10.1078/1433-8319-00017. 
Härdtle, W., Niemeyer, T., Assmann, T., Aulinger, A., Fichtner, A., Lang, A. et al, 2013. Climatic responses of tree-ring width and $\delta 13 \mathrm{C}$ signatures of sessile oak (Quercus petraea Liebl.) on soils with contrasting water supply. Plant Ecol 214, 1147-1156. https://doi.org/10.1007/s11258-013-0239-1.

Hemery, G.E., Clark, J.R., Aldinger, E., Claessens, H., Malvolti, M.E., O'connor, E. et al, 2010. Growing scattered broadleaved tree species in Europe in a changing climate: a review of risks and opportunities. Forestry 83, 65-81. https://doi.org/10.1093/FORESTRY/CPP034.

Hertel, D., Leuschner, C., 2002. A comparison of four different fine root production estimates with ecosystem carbon balance data in a Fagus-Quercus mixed forest. Plant Soil 239, 237-251. https://doi.org/10.1023/A:1015030320845.

Hobbie, S.E., Reich, P.B., Oleksyn, J., Ogdahl, M., Zytkowiak, R., Hale, C. et al, 2006. Tree species effects on decomposition and forest floor dynamics in a common garden. Ecology 87, 2288-2297. https://doi.org/10.1890/00129658(2006)87[2288:TSEODA]2.0.CO;2.

IPCC, 2014. Climate Change 2014: Impacts, Adaptation, and Vulnerability. Part A: Global and Sectoral Aspects, in: Field, C.B., Barros, V.R., Dokken, D.J., Mach, K.J., Mastrandrea, M.D. (Eds.), Contribution of Working Group II to the Fifth Assessment Report of the Intergovernmental Panel on Climate Change. Cambridge University Press, Cambridge.

Isaac-Renton, M.G., Roberts, D.R., Hamann, A., Spiecker, H., 2014. Douglas-fir plantations in Europe: a retrospective test of assisted migration to address climate change. Global Change Biol. 20, 2607-2617. https://doi.org/10.1111/gcb.12604.

Jactel, H., Brockerhoff, E., Duelli, P., 2005. A Test of the Biodiversity-Stability Theory: Meta-analysis of Tree Species Diversity Effects on Insect Pest Infestations, and Reexamination of Responsible Factors, in: Scherer-Lorenzen, M. (Ed.), Forest diversity and function. Temperate and boreal systems. Springer, Berlin. Ecological Studies 176, pp. 235-262.

Jaegere, T. de, Hein, S., Claessens, H., 2016. A Review of the Characteristics of SmallLeaved Lime (Tilia cordata Mill.) and Their Implications for Silviculture in a Changing Climate. Forests 7, 56. https://doi.org/10.3390/f7030056.

Jalilvand, H., 2008. Tree-Ring Growth Response of Common Ash (Fraxinus excelsior L.) to Climatic Variables Using Multiple Regressions. J. Water Soil Sci. 11.

Kaspar, F., Müller-Westermeier, G., Penda, E., Mächel, H., Zimmermann, K., KaiserWeiss, A. et al, 2013. Monitoring of climate change in Germany - data, products and services of Germany's National Climate Data Centre. Adv. Sci. Res. 10, 99-106. https://doi.org/10.5194/asr-10-99-2013.

Knutzen, F., Dulamsuren, C., Meier, I.C., Leuschner, C., 2017. Recent Climate Warming-Related Growth Decline Impairs European Beech in the Center of Its Distribution Range. Ecosystems 20, 1494-1511. https://doi.org/10.1007/s10021-0170128-X.

Köcher, P., Gebauer, T., Horna, V., Leuschner, C., 2009. Leaf water status and stem xylem flux in relation to soil drought in five temperate broad-leaved tree species with contrasting water use strategies. Ann. For. Sci. 66, 101.

https://doi.org/10.1051/forest/2008076. 
Kolář, T., Čermák, P., Trnka, M., Žid, T., Rybníček, M., 2017. Temporal changes in the climate sensitivity of Norway spruce and European beech along an elevation gradient in Central Europe. Agric. For. Meteorol. 239, 24-33. https://doi.org/10.1016/J.AGRFORMET.2017.02.028.

Koval, I., Maksymenko, N., 2020. The radial increment of European ash (Fraxinus excelsior L.) under climate change, Ukraine. J. For. Sci. 66, 288-298. https://doi.org/10.17221/37/2020-JFS.

Kozlowski, T.T., Pallardy, S.G., 1997. Growth control in woody plants. Acad. Press, San Diego, California, US. Physiological ecology series.

Kunz, J., Löffler, G., Bauhus, J., 2018. Minor European broadleaved tree species are more drought-tolerant than Fagus sylvatica but not more tolerant than Quercus petraea. For. Ecol. Manage. 414, 15-27. https://doi.org/10.1016/j.foreco.2018.02.016.

Kunz, J., Räder, A., Bauhus, J., 2016. Effects of Drought and Rewetting on Growth and Gas Exchange of Minor European Broadleaved Tree Species. Forests 7, 239. https://doi.org/10.3390/F7100239.

Kuznetsova, A., Brockhoff, P., Christensen, R.H.B., 2017. lmerTest Package: Tests in Linear Mixed Effects Models. J. Stat. Soft. 82, 1-26. https://doi.org/10.18637/jss.v082.i13.

Latte, N., Perin, J., Kint, V., Lebourgeois, F., Claessens, H., 2016. Major Changes in Growth Rate and Growth Variability of Beech (Fagus sylvatica L.) Related to Soil Alteration and Climate Change in Belgium. Forests 7, 174. https://doi.org/10.3390/f7080174.

Latte, N., Taverniers, P., Jaegere, T. de, Claessens, H., 2020. Dendroecological assessment of climate resilience of the rare and scattered forest tree species Tilia cordata Mill. in northwestern Europe. Forestry 93, 675-684. https://doi.org/10.1093/forestry/cpaa011.

Lebourgeois, F., Bréda, N., Ulrich, E., Granier, A., 2005. Climate-tree-growth relationships of European beech (Fagus sylvatica L.) in the French Permanent Plot Network (RENECOFOR). Trees 19, 385-401. https://doi.org/10.1007/S00468-0040397-9.

Leuschner, C., 2020. Drought response of European beech (Fagus sylvatica L.) - a review. Perspect. Plant Ecol. Evol. Syst. 47, 125576 (in press). https://doi.org/10.1016/j.ppees.2020.125576.

Leuschner, C., Ellenberg, H., 2017. Ecology of Central European Forests. Springer Nature, Cham.

Leuschner, C., Meier, I.C., 2018. The ecology of Central European tree species: Trait spectra, functional trade-offs, and ecological classification of adult trees. Perspect. Plant Ecol. Evol. Syst. 33, 89-103. https://doi.org/10.1016/j.ppees.2018.05.003.

Leuschner, C., Wedde, P., Lübbe, T., 2019. The relation between pressure-volume curve traits and stomatal regulation of water potential in five temperate broadleaf tree species. Ann. For. Sci. 76, 93. https://doi.org/10.1007/s13595-019-0838-7.

Lloret, F., Keeling, E.G., Sala, A., 2011. Components of tree resilience: effects of successive low-growth episodes in old ponderosa pine forests. Oikos 120, 19091920. https://doi.org/10.1111/J.1600-0706.2011.19372.X. 
Lough, J.M., Fritts, H.C., 1987. An assessment of the possible effects of volcanic eruptions on North American climate using tree-ring data, 1602 to 1900 A.D. Clim. Change 10, 219-239. https://doi.org/10.1007/BF00143903.

Maier, U., Müller-Westermeier, G., 2010. Verifikation klimatologischer Rasterfelder. Selbstverl. des Dt. Wetterdienstes, Offenbach am Main. Berichte des Deutschen Wetterdienstes 235.

Mäkinen, H., Nöjd, P., Kahle, H.-P., Neumann, U., Tveite, B., Mielikäinen, K. et al, 2002. Radial growth variation of Norway spruce (Picea abies (L.) Karst.) across latitudinal and altitudinal gradients in central and northern Europe. For. Ecol. Manage. 171, 243-259. https://doi.org/10.1016/S0378-1127(01)00786-1.

Mérian, P., Bontemps, J.-D., Bergès, L., Lebourgeois, F., 2011. Spatial variation and temporal instability in climate-growth relationships of sessile oak (Quercus petraea [Matt.] Liebl.) under temperate conditions. Plant Ecol 212, 1855-1871. https://doi.org/10.1007/S11258-011-9959-2.

Mérian, P., Pierrat, J.-C., Lebourgeois, F., 2013. Effect of sampling effort on the regional chronology statistics and climate-growth relationships estimation. Dendrochronologia 31, 58-67. https://doi.org/10.1016/J.DENDRO.2012.07.001.

Mette, T., Dolos, K., Meinardus, C., Bräuning, A., Reineking, B., Blaschke, M. et al, 2013. Climatic turning point for beech and oak under climate change in Central Europe. Ecosphere 4, art145. https://doi.org/10.1890/ES13-00115.1.

Meyer, B.F., Buras, A., Rammig, A., Zang, C.S., 2020. Higher susceptibility of beech to drought in comparison to oak. Dendrochronologia 64, 125780. https://doi.org/10.1016/j.dendro.2020.125780.

Michelot, A., Bréda, N., Damesin, C., Dufrêne, E., 2012a. Differing growth responses to climatic variations and soil water deficits of Fagus sylvatica, Quercus petraea and Pinus sylvestris in a temperate forest. For. Ecol. Manage. 265, 161-171. https://doi.org/10.1016/J.FORECO.2011.10.024.

Michelot, A., Simard, S., Rathgeber, C., Dufrêne, E., Damesin, C., 2012b. Comparing the intra-annual wood formation of three European species (Fagus sylvatica, Quercus petraea and Pinus sylvestris) as related to leaf phenology and non-structural carbohydrate dynamics. Tree Physiol. 32, 1033-1045. https://doi.org/10.1093/treephys/tps052.

Muffler, L., Weigel, R., Hacket-Pain, A.J., Klisz, M., Maaten, E., Wilmking, M. et al, 2020. Lowest drought sensitivity and decreasing growth synchrony towards the dry distribution margin of European beech. J. Biogeogr. 47, 1910-1921. https://doi.org/10.1111/jbi.13884.

Müller-Haubold, H., Hertel, D., Leuschner, C., 2015. Climatic Drivers of Mast Fruiting in European Beech and Resulting C and N Allocation Shifts. Ecosystems 18, 10831100. https://doi.org/10.1007/s10021-015-9885-6.

Müller-Haubold, H., Hertel, D., Seidel, D., Knutzen, F., Leuschner, C., 2013. Climate Responses of Aboveground Productivity and Allocation in Fagus sylvatica: A Transect Study in Mature Forests. Ecosystems 16, 1498-1516. https://doi.org/10.1007/s10021-013-9698-4. 
Nakagawa, S., Schielzeth, H., 2013. A general and simple method for obtaining R2 from generalized linear mixed-effects models. Methods Ecol. Evol. 4, 133-142. https://doi.org/10.1111/j.2041-210x.2012.00261.x.

Neuwirth, B., Schweingruber, F.H., Winiger, M., 2007. Spatial patterns of central European pointer years from 1901 to 1971. Dendrochronologia 24, 79-89. https://doi.org/10.1016/J.DENDRO.2006.05.004.

Nussbaumer, A., Waldner, P., Apuhtin, V., Aytar, F., Benham, S., Bussotti, F. et al, 2018. Impact of weather cues and resource dynamics on mast occurrence in the main forest tree species in Europe. For. Ecol. Manage. 429, 336-350. https://doi.org/10.1016/J.FORECO.2018.07.011.

Pearse, I.S., Koenig, W.D., Kelly, D., 2016. Mechanisms of mast seeding: resources, weather, cues, and selection. New Phytol. 212, 546-562. https://doi.org/10.1111/nph.14114.

Piovesan, G., Adams, J.M., 2001. Masting behaviour in beech: linking reproduction and climatic variation. Can. J. Bot. 79, 1039-1047. https://doi.org/10.1139/cjb-79-91039.

Piutti, E., Cescatti, A., 1997. A quantitative analysis of the interactions between climatic response and intraspecific competition in European beech. Can. J. For. Res. 27, 277284. https://doi.org/10.1139/x96-176.

Pretzsch, H., Forrester, D.I., Bauhus, J. (Eds.), 2017. Mixed-species forests: Ecology and management. Springer, Berlin.

Pretzsch, H., Grams, T., Häberle, K.H., Pritsch, K., Bauerle, T., Rötzer, T., 2020. Growth and mortality of Norway spruce and European beech in monospecific and mixed-species stands under natural episodic and experimentally extended drought. Results of the KROOF throughfall exclusion experiment. Trees 34, 957-970. https://doi.org/10.1007/s00468-020-01973-0.

Pretzsch, H., Schütze, G., Uhl, E., 2013. Resistance of European tree species to drought stress in mixed versus pure forests: evidence of stress release by inter-specific facilitation. Plant. Biol. 15, 483-495. https://doi.org/10.1111/j.14388677.2012.00670.x.

Rigling, A., Bigler, C., Eilmann, B., Feldmeyer-Christe, E., Gimmi, U., Ginzler, C. et al, 2013. Driving factors of a vegetation shift from Scots pine to pubescent oak in dry Alpine forests. Global Change Biol. 19, 229-240. https://doi.org/10.1111/gcb.12038.

Roibu, C.-C., Sfeclă, V., Mursa, A., Ionita, M., Nagavciuc, V., Chiriloaei, F. et al, 2020. The Climatic Response of Tree Ring Width Components of Ash (Fraxinus excelsior L.) and Common Oak (Quercus robur L.) from Eastern Europe. Forests 11, 600. https://doi.org/10.3390/F11050600.

Roloff, A., Weisgerber, H., Lang, U.M., Stimm, B. (Eds.), 2010. Bäume Mitteleuropas: Von Aspe bis Zirbel-Kiefer, 1. Aufl. Wiley-VCH, Weinheim. Sachbuch.

Roques, A., Auger-Rozenberg, M.-A., Capretti, P., Sauvard, D., La Porta, N., Santini, A., 2019. Pests and diseases in the native and European range of Douglas-fir., in: Spiecker, H., Lindner, M., Schuler, J.K. (Eds.), Douglas-fir. An option for Europe. European Forest Institute, Joensuu. 
Rozas, V., 2001. Detecting the impact of climate and disturbances on tree-rings of Fagus sylvatica L. and Quercus robur L. in a lowland forest in Cantabria, Northern Spain. Ann. For. Sci. 58, 237-251. https://doi.org/10.1051/forest:2001123.

Rozas, V., 2005. Dendrochronology of pedunculate oak (Quercus robur L.) in an oldgrowth pollarded woodland in northern Spain: tree-ring growth responses to climate. Ann. For. Sci. 62, 209-218. https://doi.org/10.1051/forest:2005012.

Schaap, M.G., Leij, F.J., van Genuchten, M.T., 2001. Rosetta: a computer program for estimating soil hydraulic parameters with hierarchical pedotransfer functions. J. Hydrol. 251, 163-176. https://doi.org/10.1016/S0022-1694(01)00466-8.

Schär, C., Vidale, P.L., Lüthi, D., Frei, C., Häberli, C., Liniger, M.A. et al, 2004. The role of increasing temperature variability in European summer heatwaves. Nature 427, 332-336. https://doi.org/10.1038/nature02300.

Scharnweber, T., Manthey, M., Criegee, C., Bauwe, A., Schröder, C., Wilmking, M., 2011. Drought matters - Declining precipitation influences growth of Fagus sylvatica L. and Quercus robur L. in north-eastern Germany. For. Ecol. Manage. 262, 947-961. https://doi.org/10.1016/j.foreco.2011.05.026.

Scherrer, D., Bader, M.K.-F., Körner, C., 2011. Drought-sensitivity ranking of deciduous tree species based on thermal imaging of forest canopies. Agric. For. Meteorol. 151, 1632-1640. https://doi.org/10.1016/j.agrformet.2011.06.019.

Schuldt, B., Buras, A., Arend, M., Vitasse, Y., Beierkuhnlein, C., Damm, A. et al, 2020. A first assessment of the impact of the extreme 2018 summer drought on Central European forests. Basic Appl. Ecol. 45, 86-103. https://doi.org/10.1016/j.baae.2020.04.003.

Schumann, K., Leuschner, C., Schuldt, B., 2019. Xylem hydraulic safety and efficiency in relation to leaf and wood traits in three temperate Acer species differing in habitat preferences. Trees 33, 1475-1490. https://doi.org/10.1007/s00468-019-01874-X.

Schwarz, J., Skiadaresis, G., Kohler, M., Kunz, J., Schnabel, F., Vitali, V. et al, 2020. Quantifying Growth Responses of Trees to Drought—a Critique of Commonly Used Resilience Indices and Recommendations for Future Studies. Curr. Forestry Rep. 6, 185-200. https://doi.org/10.1007/S40725-020-00119-2.

Schweingruber, F.H., 1996. Tree rings and environment - Dendroecology. Haupt, Berne, Stuttgart, Vienna.

Sohn, J.A., Hartig, F., Kohler, M., Huss, J., Bauhus, J., 2016. Heavy and frequent thinning promotes drought adaptation in Pinus sylvestris forests. Ecol. Appl. 26, 2190-2205. https://doi.org/10.1002/eap.1373.

Speer, J.H., 2010. Fundamentals of tree-ring research. Univ. of Arizona Press, Tucson, Arizona.

Spiecker, H., 2000. Growth of Norway spruce (Picea abies [L.] Karst.) under changing environmental conditions in Europe, in: Klimo, E., Hager, H., Kulhavy, J. (Eds.), EFI Proceedings. Spruce Monocultures in Central Europe - Problems and Prospects 33, pp. 11-26. 
Steckel, M., del Río, M., Heym, M., Aldea, J., Bielak, K., Brazaitis, G. et al, 2020. Species mixing reduces drought susceptibility of Scots pine (Pinus sylvestris L.) and oak (Quercus robur L., Quercus petraea (Matt.) Liebl.) - Site water supply and fertility modify the mixing effect. For. Ecol. Manage. 461, 117908. https://doi.org/10.1016/j.foreco.2020.117908.

Tapper, P.-G., 1996. Long-Term Patterns of Mast Fruiting in Fraxinus Excelsior. Ecology 77, 2567-2572. https://doi.org/10.2307/2265756.

Tardif, J.C., Conciatori, F., 2006. Influence of climate on tree rings and vessel features in red oak and white oak growing near their northern distribution limit, southwestern Quebec, Canada. Can. J. For. Res. 36, 2317-2330. https://doi.org/10.1139/x06-133.

Thornthwaite, C.W., 1948. An Approach toward a Rational Classification of Climate. Geogr. Rev. 38, 55. https://doi.org/10.2307/210739.

Thurm, E.A., Uhl, E., Pretzsch, H., 2016. Mixture reduces climate sensitivity of Douglas-fir stem growth. For. Ecol. Manage. 376, 205-220. https://doi.org/10.1016/j.foreco.2016.06.020.

Trouillier, M., van der Maaten-Theunissen, M., Scharnweber, T., Würth, D., Burger, A., Schnittler, M. et al, 2019. Size matters - a comparison of three methods to assess age- and size-dependent climate sensitivity of trees. Trees 33, 183-192. https://doi.org/10.1007/s00468-018-1767-z.

Vacchiano, G., Hacket-Pain, A., Turco, M., Motta, R., Maringer, J., Conedera, M. et al, 2017. Spatial patterns and broad-scale weather cues of beech mast seeding in Europe. New Phytol. 215, 595-608. https://doi.org/10.1111/nph.14600.

van Genuchten, M.T., 1980. A Closed-form Equation for Predicting the Hydraulic Conductivity of Unsaturated Soils. Soil Sci. Soc. Am. J. 44, 892-898. https://doi.org/10.2136/sssaj1980.03615995004400050002x.

van Genuchten, M.T., Leij, F.J., Yates, S., Williams, J., 1991. The RETC Code for Quantifying Hydraulic Functions of Unsaturated Soils. Environmental Protection Agency EPA/600/2-91/065, Washington, D.C. 83.

Vannoppen, A., Kint, V., Ponette, Q., Verheyen, K., Muys, B., 2019. Tree species diversity impacts average radial growth of beech and oak trees in Belgium, not their long-term growth trend. For. Ecosyst. 6. https://doi.org/10.1186/s40663-019-0169-z.

Vicente-Serrano, S.M., Beguería, S., López-Moreno, J.I., 2010. A Multiscalar Drought Index Sensitive to Global Warming: The Standardized Precipitation Evapotranspiration Index. J. Clim. 23, 1696-1718. https://doi.org/10.1175/2009JCLI2909.1.

Vitali, V., Büntgen, U., Bauhus, J., 2017. Silver fir and Douglas fir are more tolerant to extreme droughts than Norway spruce in south-western Germany. Global Change Biol. 23, 5108-5119. https://doi.org/10.1111/gcb.13774.

Walthert, L., Ganthaler, A., Mayr, S., Saurer, M., Waldner, P., Walser, M. et al, 2021. From the comfort zone to crown dieback: Sequence of physiological stress thresholds in mature European beech trees across progressive drought. Sci. Total Environ. 753, 141792, in press. https://doi.org/10.1016/j.scitotenv.2020.141792.

Weemstra, M., Eilmann, B., Sass-Klaassen, U.G.W., Sterck, F.J., 2013. Summer droughts limit tree growth across 10 temperate species on a productive forest site. For. Ecol. Manage. 306, 142-149. https://doi.org/10.1016/J.FORECO.2013.06.007. 
Weigel, R., Muffler, L., Klisz, M., Kreyling, J., van der Maaten-Theunissen, M., Wilmking, M. et al, 2018. Winter matters: Sensitivity to winter climate and cold events increases towards the cold distribution margin of European beech (Fagus sylvatica L.). J. Biogeogr. 45, 2779-2790. https://doi.org/10.1111/jbi.13444.

Wesołowski, T., Rowiński, P., Maziarz, M., 2015. Interannual variation in tree seed production in a primeval temperate forest: does masting prevail? Eur. J. Forest Res. 134, 99-112. https://doi.org/10.1007/s10342-014-0836-0.

Wilmking, M., van der Maaten-Theunissen, M., van der Maaten, E., Scharnweber, T., Buras, A., Biermann, C. et al, 2020. Global assessment of relationships between climate and tree growth. Global Change Biol. 26, 3212-3220. https://doi.org/10.1111/gcb.15057.

Zang, C.S., 2011. Growth reaction of temperate forest trees to summer drought. Dissertation, Technische Universität München, Germany.

Zang, C.S., Biondi, F., 2015. treeclim: an R package for the numerical calibration of proxy-climate relationships. Ecography 38, 431-436. https://doi.org/10.1111/ecog.01335.

Zimmermann, J., Hauck, M., Dulamsuren, C., Leuschner, C., 2015. Climate WarmingRelated Growth Decline Affects Fagus sylvatica, But Not Other Broad-Leaved Tree Species in Central European Mixed Forests. Ecosystems 18, 560-572. https://doi.org/10.1007/s10021-015-9849-x. 


\section{SYNOPSIS}

In the following, I start with a general overview of drought response strategies and their implications for the ability of a species to withstand drought in the light of existing knowledge from literature. Thereafter, I summarize and integrate the main findings of the three manuscripts presented in my dissertation, incorporating them into a profound evaluation of the species' strategies to cope with drought. In doing so, I deduce a drought stress resistance ranking of the studied species to rate the suitability to grow under increasingly dry and hot conditions in sub-continental regions in Central Europe.

\subsection{Drought response strategies}

Drought resistance in a broad sense describes adaptive features of plants to enable them to either escape, avoid, or tolerate drought stress (Basu et al., 2016; Levitt, 1980). Applied to trees, escape strategies (e.g. by completion of life cycles before the onset of drought) are not an option. Thus, trees either tolerate or avoid drought stress.

This dualism is mirrored in the spectrum of anisohydric (tolerating drought stress) and isohydric strategies (avoiding drought stress; McDowell et al., 2008). Sensu stricto, the terms iso- and anisohydry originate from a clear distinction between two stomatal control strategies (Tardieu and Simonneau, 1998), but lately, they have rather been found to represent the extremes of a continuum (Klein, 2014) and to be interrelated with many other functional traits (Leuschner et al., 2019; McDowell et al., 2008). Isohydry involves a stringent stomatal control during drought, keeping the xylem water potential in a range that protects the rather vulnerable xylem from excessive embolism. This implies restricted carbon assimilation during drought and therefore large capacities to store assimilates and water within the plant. Otherwise, isohydric plants are prone to carbon starvation (i.e. the vitality loss and/or mortality due to a negative carbon balance as a consequence of reduced assimilation; McDowell et al., 2008). In contrast, anisohydric plants close their stomata less strictly during drought, allowing for lower xylem water potentials to extract water from drier soils, maintaining carbohydrate assimilation, and relying on high resistances against xylem embolism and leaf turgor loss (McDowell et al., 2008). This strategy allows for a better carbon balance during drought, but low values of minimum leaf water potentials also imply narrow safety margins.

Stomatal closure, closely correlated with leaf turgor loss (Brodribb et al., 2003) and controlled by a complex interplay of physiological mechanisms and chemical signaling 
(Guyot et al., 2012; Tardieu and Davies, 1993), is the predominant mechanism to cope with non-extreme drought conditions (Choat et al., 2018; Meinzer et al., 2009). During prolonged drought conditions, however, stomatal closure cannot prevent further tissue desiccation due to residual water loss through bark and cuticle (Choat et al., 2012; Duursma et al., 2019). At this point, the width of the hydraulic safety margin is critical, as it represents the safety buffer between stomatal closure and hydraulic failure (irreversible xylem damage due to embolism). Hydraulic safety margins can therefore be considered as highly informative for comparing the resistance of given species to prolonged drought (Choat et al., 2018).

Summing up the above, hydraulic safety-related traits (like xylem embolism resistance, leaf turgor loss and hydraulic safety margins) in combination with stomatal control strategies give insights in the physiological drought responses of a species. Nevertheless, responses to drought stress also occur on other levels across all organs of a tree. Many species shed their leaves in order to reduce transpiration (Blackman et al., 2019) and adjust carbon partitioning to root growth (McDowell et al., 2008; Ryan, 2011). The prominent role of fine roots in plant-water-relations is well accepted (Brunner et al., 2015), but the role of soil-root-interactions is still underestimated and often neglected in modelling approaches of drought-related mortality (Carminati and Javaux, 2020).

A higher investment to root growth could find expression in deeper rooting to better access remaining soil water reserves, a denser fine root system to extract residual soil water, and higher fine root turn-over. While deeper and denser root systems seem intuitively the most obvious responses to reduced water availability, field studies are inconsistent on this matter (Bakker et al., 2006; Blanck et al., 1995; Chenlemuge et al., 2013; Hertel et al., 2008; Hertel et al., 2013; Kuster et al., 2013; Leuschner et al., 2004; Meier and Leuschner, 2008; Parker and van Lear, 1996; Santantonio and Hermann, 1985). In contrast, increased fine root mortality has been concordantly reported (Brunner et al., 2015; Wang et al., 2018), although a reduction of the absorbing surface in the face of reduced water availability seems counterintuitive. Explanations are either the quick replacement by new, physiologically more active roots to increase the absorptive capacity or the active shedding of fine roots to uncouple more expensive organs from low water potentials in the dry soil ('hydraulic fuse theory'; Alder et al., 1996; Jackson et al., 2000; Kotowska et al., 2015). Alternatively, fine roots may just die due to dehydration and need to be replaced. Being the most distal organs belowground, fine roots are quickly replaceable and relatively cheap in terms of carbon costs (only representing a few percent 
of the tree's total biomass; Jackson et al., 1997) and can be shed or sacrificed in a similar manner as leaves upon drought. In any case, increased fine root necromass/biomass ratios indicate an elevated stress level, low drought resistance of the fine roots, and/or a deficient or slow replacement by new fine roots.

The interplay of stomatal control strategies and associated constraints on carbon assimilation, leaf shedding, investments in hydraulic safety, and fine root replacement results in shifts in carbon allocation within the whole tree. In consequence of reduced carbon assimilation, the allocation to replacement of distal organs, reproduction and even carbon storage is often prioritized over radial stem growth (Wiley et al., 2017). In addition, a greater proportion of the fixed carbon is lost through photorespiration during drought stress (Wingler et al., 1999). Therefore, a higher level of drought exposure in the growing season is directly affecting a tree's radial stem growth, which is - in return - a good proxy of a species ability to tolerate stress and maintain assimilation rates. However, narrower annual rings are also associated with acclimation and/or adaptation responses in the stem xylem of the tree to increase drought resistance through the production of thicker pit membranes and less and smaller conduits (Fonti et al., 2013). This reduces hydraulic efficiency but increases hydraulic safety (Hacke and Sperry, 2001). Reduced radial growth could then increase fitness in the longer term, and the growth reduction may represent a strength rather than a weakness in the face of increasing drought exposure (Bréda et al., 2006; Gessler et al., 2020; Lloret et al., 2011).

\subsection{Species-specific ability to cope with drought and their suitability for future silviculture}

\subsubsection{Quercus petraea}

In agreement with various reports in literature, $Q$. petraea turned out to be the most drought-tolerant of the five species (e.g. Cavin et al., 2013; Kunz et al., 2018; Leuschner et al., 2001; Scharnweber et al., 2011; Zimmermann et al., 2015). Its radial increment is highly resistant to dry conditions (Chapter 4) and it did not suffer crown defoliation or discoloration after severe drought (Chapter 4). The latter relates to its relatively xeromorphic and heat resistant leaves (Epron and Dreyer, 1993; Thomas, 2000). $Q$. petraea is strictly anisohydric (Aranda et al., 2000; Bréda et al., 1993; Epron and Dreyer, 1993), maintaining high transpiration and assimilation rates under moderate drought conditions. This is facilitated by an embolism-resistant xylem (Dietrich et al., 2018; Lobo 
et al., 2018), by the capability of xylem anatomical adaptation (Martínez-Sancho et al., 2017) and leaf osmotic adjustments to drier conditions (Leuschner et al., 2001), and by drought-resistant fine roots (Chapter 3) and a deep rooting system (Rosengren et al., 2006), allowing for sustained water uptake. Leaf osmotic adjustments are reflected by the decreasing turgor loss point $\left(P_{\mathrm{TLP}}\right)$ with increasing climatic aridity (Figure 5.1). This anisohydric strategy has also been described in literature (e.g. Renninger et al., 2015) and enables $Q$. petraea to maintain fairly constant annual stem increment also in drought years (Chapter 4). In addition, the physiological responses to drought in juvenile stages indicate a high drought resistance of saplings in comparison to other broadleaves (Kunz et al., 2016; Thomas, 2000).

Although deep-rooting, $Q$. petraea seems to produce a less dense fine root system in comparison to the other species (Chapter 3; Hertel and Leuschner, 2002) and its fine root mortality under drought is low (Chapter 3). Shifts in carbon allocation to the root system might therefore be less important in $Q$. petraea than in other species.

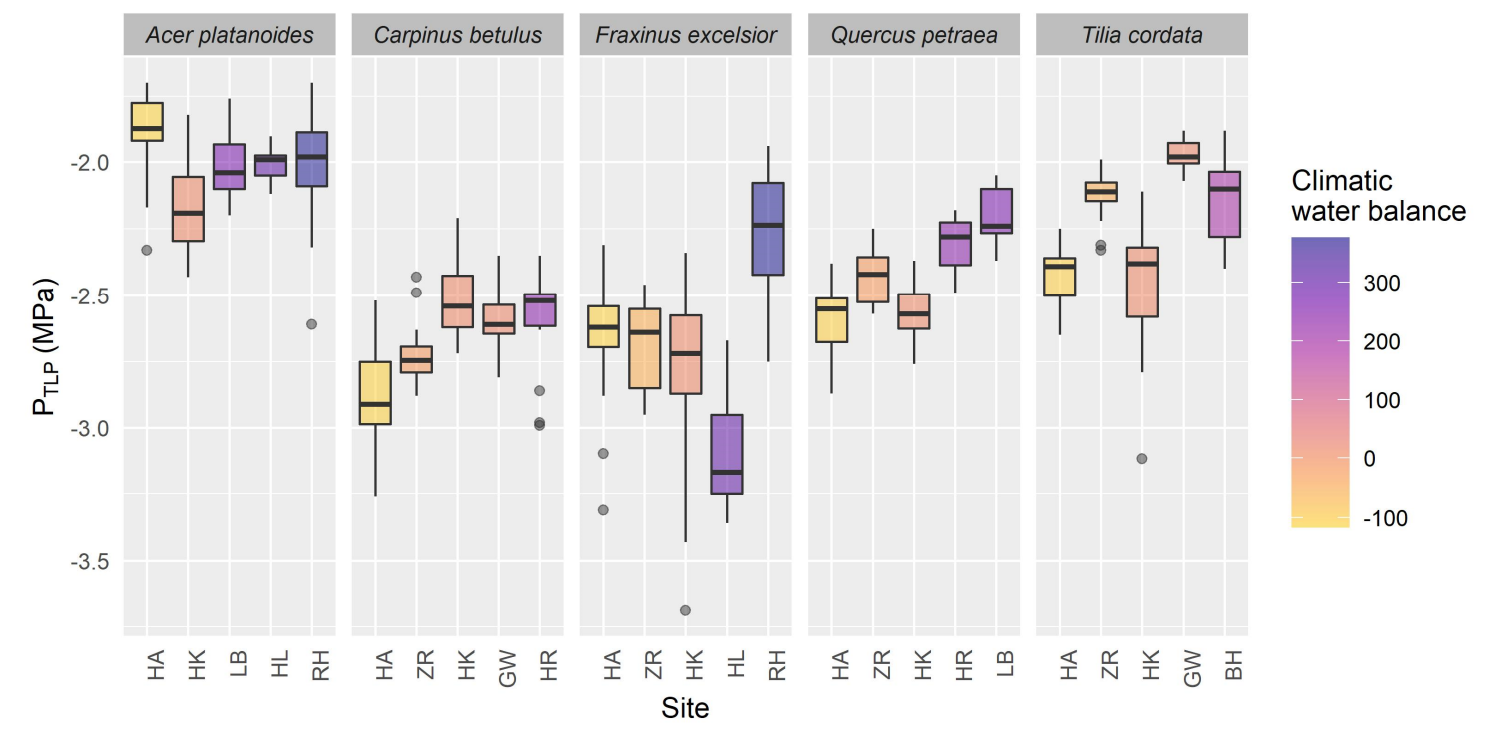

Figure 5.1: Leaf water potential at turgor loss point $\left(P_{\mathrm{TLP}}\right)$ of all five species. Sites are sorted in ascending order according to the climatic water balance. The methodology is described in chapter 2, where Q. petraea and F. excelsior were not included in the figures.

However, the apparent climate-insensitivity of growth in $Q$. petraea is partly caused by the large number of other growth-reducing events, notably pests and mast-fruiting, which may weaken the climatic signal and lead to overestimation of the species' drought tolerance (Chapter 4). Nevertheless, $Q$. petraea is a demanded high-quality timber for construction and furniture and must be seen as an important component of future droughttolerant production forests in sub-continental Central Europe. 


\subsubsection{Acer platanoides}

A. platanoides is an isohydric species that pursues a drought-avoidance strategy. With a strict stomatal control and a very wide hydraulic safety margin (HSM), it sacrifices carbon assimilation for the sake of a safe and intact hydraulic system (Leuschner et al., 2019). This is confirmed by the hydraulic characterization in Chapter 2 , and in agreement with results from a study in Central Germany on mature trees, where minimum xylem water potential $\left(P_{\min }\right)$ and stomatal conductance were repeatedly measured over several months during summer, confirming a strictly isohydric stomatal control strategy (Messinger, 2017, unpublished). In combination with the highly embolism resistant xylem (Chapter 2), A. platanoides must be suited to survive even prolonged drought conditions, as isohydric species are less prone to hydraulic failure under severe drought (Choat et al., 2012; McDowell et al., 2008).

Although A. platanoides suffered the strongest radial growth depressions in drought years, it was also highly resilient, recovered quickly (Chapter 4), and showed almost no noticeable crown damage after the droughts of 2018/19 (Chapter 4). This relates to the isohydric behavior, as this "safe" strategy reduces the likeliness of damage to leaf and stem xylem tissue and prevents legacy effects of droughts. The fine root system of $A$. platanoides proved to be highly plastic, it was the only species adjusting (increasing) its fine root density towards the drier sites. However, the vulnerability of fine roots and finest root tips to drought was higher than in the other species (Chapter 3).

In conclusion, A. platanoides emerged as the "safe choice" among the studied species. Drought-related mortality seems very unlikely, and a high resilience makes up for the growth sensitivity to drought events. Additionally, a complementary study on saplings (Kunz et al., 2016) attested a high drought resistance in juvenile stages. Its wood properties partly resemble $F$. sylvatica (Roloff et al., 2010), thus, it can be a replacement species on dry sites, where F. sylvatica is declining (cf. Zimmermann et al., 2015).

\subsubsection{Fraxinus excelsior}

F. excelsior is known for its exceptionally wide ecological amplitude regarding water availability (Leuschner and Ellenberg, 2017). This is based on its high ecophysiological plasticity regarding leaf and xylem-related functional traits. Its xylem embolism resistance varies in dependence of the site water availability (Lemoine et al., 2001) and it is capable of significant osmotic adjustments in its leaves by accumulating malate and mannitol (Guicherd et al., 1997, Lübbe et al., 2017). These strong adjustments are 
reflected in the highly variable turgor loss point (Figure 5.1). Like Q. petraea, F. excelsior is highly anisohydric with large leaf water potential reductions during drought periods, which enable the species to maintain water extraction in drying soil (Köcher et al., 2009; Leuschner et al., 2019), keeping stomata open even at predawn water potentials near -5 MPa (Carlier et al., 1992; Guicherd et al., 1997). With that said, the low defoliation rate after the two consecutive drought years of 2018/19 is surprising and another indication of a high drought-hardening potential of the leaves via osmotic adjustments. The anisohydric behavior relates to its low drought sensitivity of radial growth that is comparable to $Q$. petraea (Chapter 4; Zimmermann et al., 2015).

F. excelsior has a uniquely high fine root density (Chapter 3 ), which may secure water uptake in drought periods and increase the species' competitive ability in mixed stands and on very shallow and dry soils.

Its drought-tolerance and the versatile wood for furniture and tool production could qualify $F$. excelsior as a promising candidate for future forestry. However, the species is severely threatened by the fungus Hymenoscyphus fraxineus, affecting crown, stem base, and rootstock vitality, causing a pan-European ash dieback. Although the selection of resistant genotypes might be possible (McKinney et al., 2014), and the virulence of the fungus seems to be lower in dry and hot years (Goberville et al., 2016; Grosdidier et al., 2018), the current epidemiologic projections render any recommendations for silvicultural planning impossible in the near future (Enderle, 2019).

\subsubsection{Tilia cordata}

Distinct growth reductions in drought years, clearly visible legacy effects in 1-2 years after drought, and a high growth sensitivity to the SPEI (Chapter 4) indicate a low drought tolerance. This is in line with the increasing fine root necromass/biomass ratio toward drier sites and the marked loss of fine root tips after drought (Chapter 3). In addition, its xylem showed to be highly vulnerable to embolism formation (Chapter 2). However, $T$. cordata was very resilient and fully regained its pre-drought growth levels (Chapter 4, in agreement with Latte et al., 2020) in contrast to co-occurring F. sylvatica (Latte et al., 2020; Zimmermann et al., 2015).

Characterizations of $T$. cordata within the isohydry-anisohydry syndrome are inconsistent in literature. Stomatal control is not stringent under drought, relatively high stomatal conductance and water losses classify as rather anisohydric (Moser et al., 2016). This implies a low water use efficiency and is in line with relatively low foliar $\delta^{13} \mathrm{C}$ signatures (Figure 5.2) in comparison to the other species, because higher levels of gas 
exchange accentuate the discrimination in the assimilation of the heavier ${ }^{13} \mathrm{C}$-isotope. However, T. cordata keeps the leaf water potentials in a mediocre range by buffering the water loss with high leaf and stem water capacitance (Köcher et al., 2009; Köcher et al., 2013; Leuschner et al., 2019). This buffer might as well enable this species to operate with a very narrow hydraulic safety margin (Chapter 2 ). Thus, T. cordata is rather a waterspending, semi-isohydric species, avoiding drought stress by improved water storage (instead of strict stomatal control; Leuschner et al., 2019) and deep rooting (Pigott, 1991). In contrast to the other species, $T$. cordata has highly elastic leaf cell walls and is capable of reversible wilting (Leuschner et al., 2019).

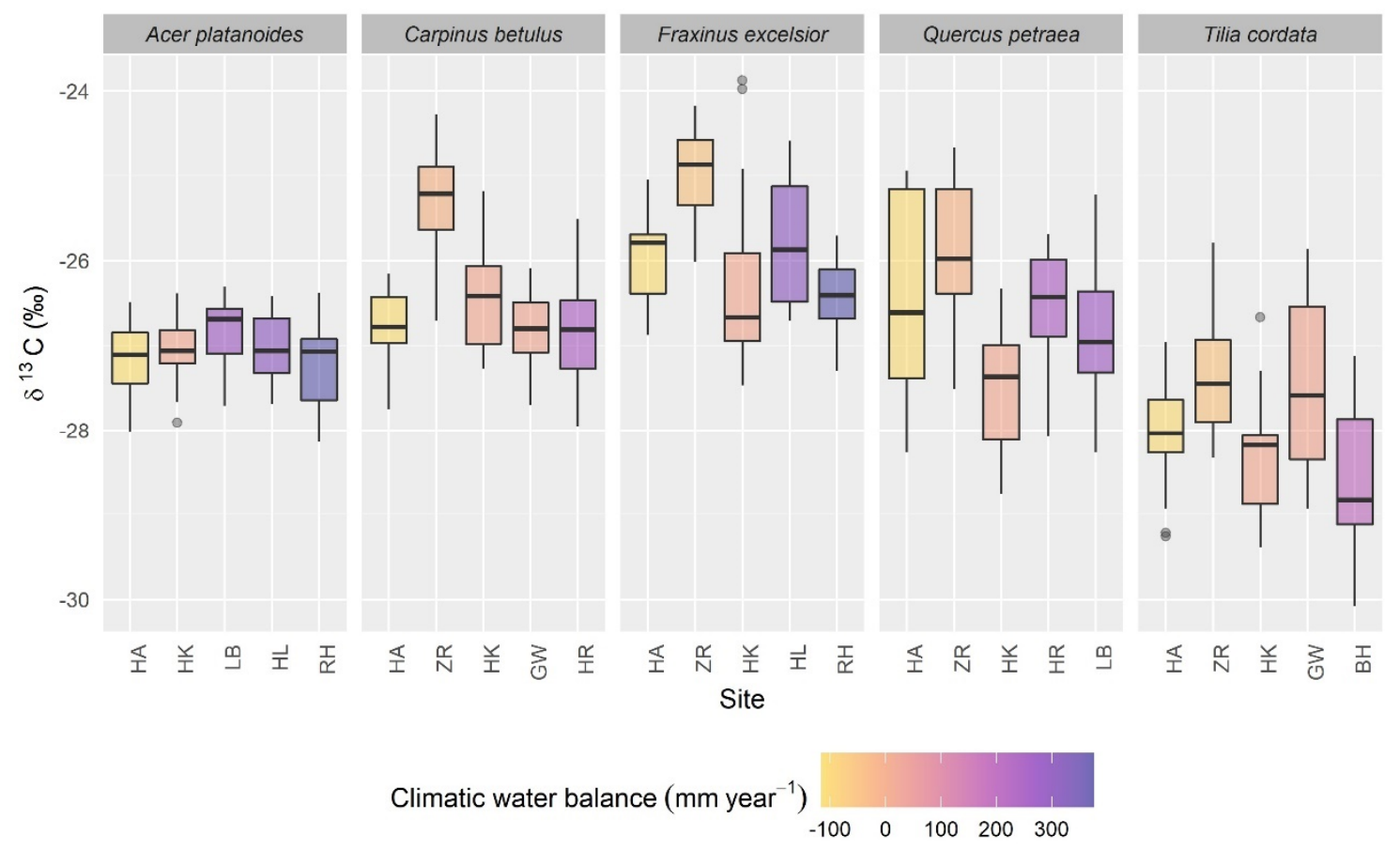

Figure 5.2: Foliar $\delta^{13} \mathrm{C}$-signatures of the leaf bulk tissue of sun leaves of all five species, given in standard $\delta$ notion: $\delta(\% o)=\left(\mathrm{R}_{\text {sample }} / \mathrm{R}_{\text {standard }}-1\right) \times 1000$. Measurements were conducted in the laboratory for stable isotope measurements (KOSI) at the University of Göttingen with a Delta plus isotope mass spectrometer (Finnigan MAT, Bremen, Germany), a Conflo III interface (Thermo Electron Cooperation, Bremen, Germany) and a NA2500 elemental analyzer (CE-Instruments, Rodano, Milano, Italy). Sites are sorted in ascending order according to the climatic water balance.

Several reviews on the ecology of $T$. cordata attest a considerable drought tolerance in comparison to several major timber species (Hemery et al., 2010; Jaegere et al., 2016; Pigott, 1991), but this tolerance seems to be restricted to short and moderate drought periods (Jaegere et al., 2016). This is in line with its water-spending, semi-isohydric strategy, relying on internal water storage and the reversibility of leaf-wilting. Due to its thermophilic properties and high resistance to heat (Hemery et al., 2010; Jaegere et al., 2016), as well as its resilience to drought (Latte et al., 2020), it may gain competitive 
advantages over F. sylvatica in Central Europe. However, its drought resistance seems to be inferior in comparison to A. platanoides, Q. petraea and F. excelsior.

\subsubsection{Carpinus betulus}

In terms of hydraulic properties, $C$. betulus has a relatively resistant xylem, a wide safety margin, and remarkable plasticity (Chapter 2). Especially the $P_{88}$, (water potential at $88 \%$ loss of conductivity), which is assumed to be the threshold for catastrophic hydraulic failure for angiosperms (Choat, 2013; Urli et al., 2013), was very low in this species (Chapter 2). The $P_{88}$ has also been linked to the drought-induced mortality risk of angiosperm trees (Li et al., 2016; Li et al., 2018), thus, C. betulus might be resistant to drought-driven mortality. Its stomatal control strategy is intermediate on the iso-/ anisohydry spectrum (Leuschner et al., 2019), tending towards an anisohydric behavior (Li et al., 2016), keeping the stomata open during moderate drought conditions. This is in line with a low turgor loss point found in Chapter 2. However, C. betulus tends to shed its leaves earlier in severe droughts in comparison to the other species to keep branch and stem xylem safe. This behavior has been observed in reaction to the 2003 drought (Leuzinger et al., 2005) and as well to the 2018/2019 drought (Chapter 4, Figure 4.17), where $C$. betulus showed high rates of defoliation and prematurely discolored leaves in August and September, but reached full foliation in the following spring again.

In agreement with Leuzinger et al. (2005) who found $C$. betulus to be able to efficiently take up water in the uppermost soil horizon after minor rain events, the fine root density in the topsoil was high (Chapter 3). Although no increase in its fine root necromass/biomass ratio after drought was observed, specific root area and fine root tips were distinctly reduced (Chapter 3 ). This behavior was similar to T. cordata. In combination with a medium to shallow rooting system (Köstler et al., 1968), C. betulus shows no outstanding belowground adaptations to prolonged droughts.

Due to the missing dendroecological results of this species, we cannot pass a conclusive judgement on the productivity of $C$. betulus under a drier and warmer climate. Leuzinger et al. (2005), however, found this species to show rapid radial growth during moist periods in the early vegetation period, but it ceased radial growth almost completely in late summer in three consecutive years in Central Europe, demonstrating a high reliance of its increment on ample water supply. Because of its curvy and irregular stem shape, spiral growth and mediocre qualities for woodworking, the utilization of this timber is fairly limited anyway, but its high wood density and caloric value make it useful for the production of certain tools and for energy generation. 
However, its hydraulic properties and its known shade-tolerance indicate a low mortality risk and a certain tenacity to cope with unfavorable conditions as admixture in a resilient future broadleaf forest.

\subsubsection{Drought stress resistance ranking}

In comparison to $Q$. petraea, none of the minor timber species proved to be more drought resistant. However, F. excelsior pursues a very similar drought tolerance strategy and seems to be almost on the same level in most aspects. The diffuse-porous species differ clearly from the ring-porous species in their strategies. Especially A. platanoides with a strict drought-avoidance behavior, a high embolism resistance, a plastic fine root system, and high resilience to drought events turned out to be a safe choice for a drier and warmer climate. Table 5.1 shows a synoptic ranking of the five species including most of the mentioned drought resistance related aspects and traits and ranks the species in the following order: $Q$. petraea $>$ A. platanoides $>F$. excelsior $>C$. betulus $>$ T. cordata .

Table 5.1: Overview of drought stress resistance-related traits of the five species. The rates range from very good (++) over good (+) and mediocre (o) to subpar (-) and the reasoning behind the assessments is explained in Chapter 5.1 and 5.2. Grey panels are based on knowledge from literature, black panels represent missing information.

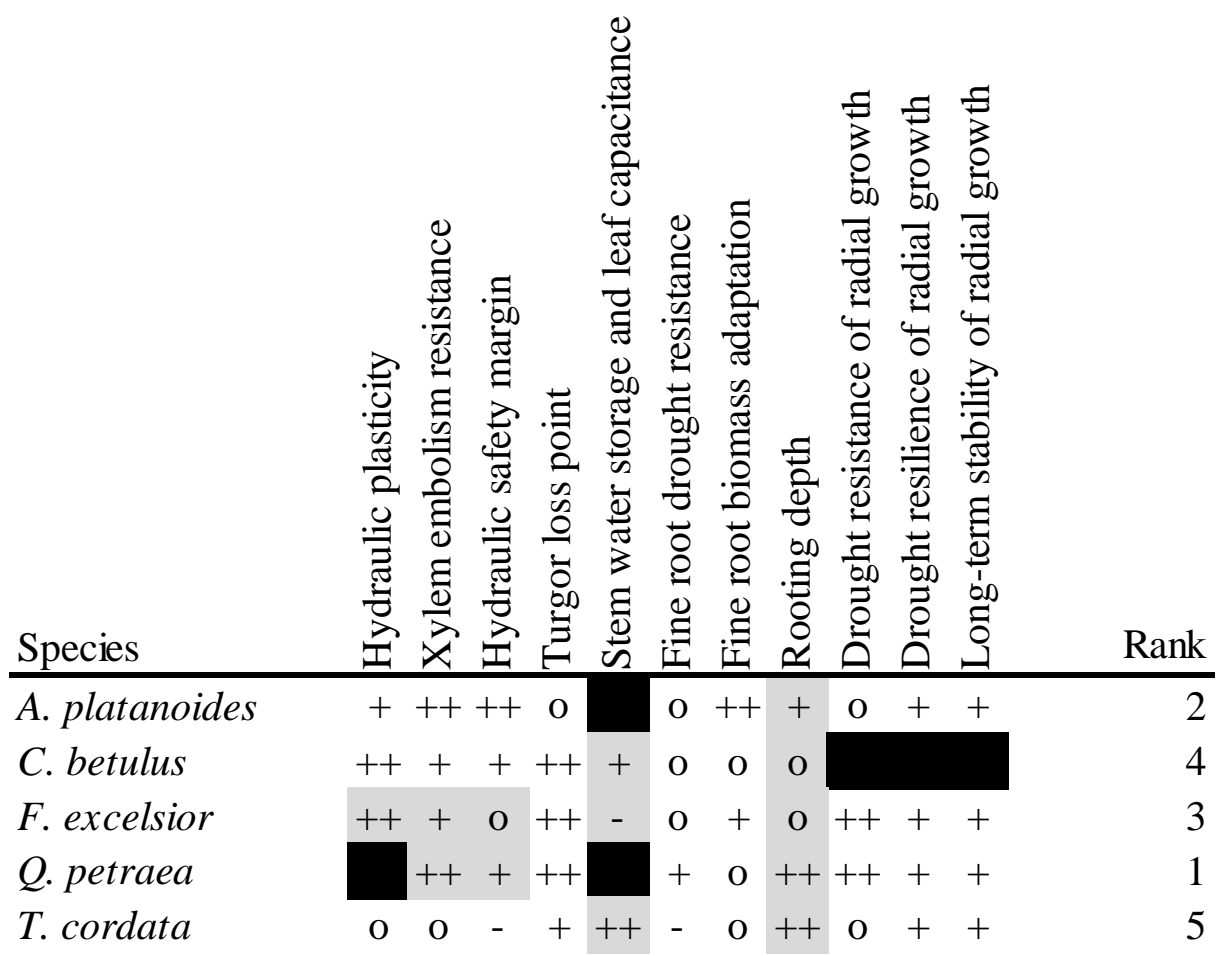




\subsection{Future directions}

Generally, transect field studies across climatic gradients as "space-for-time substitutions" are a valid and established tool in plant ecology to derive climatic limits of changes in increment, physiological responses, and stress indicators in the face of climate change. In the present case, however, the predictive power of climatic aridity on stand water availability was weakened by inhomogeneous soil types. Including plant available water capacity of the soil as explanatory variable is a way to cope with this problem, but simultaneously necessitate a higher number of study sites, which is always limited in field studies with a focus on the comparison of several species. Additionally, differences in nutrient availability across the gradient might have obscured some relationships. The mentioned compromises in the homogeneity of the study sites are primarily a consequence of the infrequent co-occurrence of the targeted minor timbers, rendering the number of suitable study sites very small. Future transect field studies addressing minor timbers could reduce the number of compared species in order to increase the number of stands and facilitate the detection of suitable sites.

The present dissertation provides valuable insights into drought response strategies of the five species and the plasticity of functional traits along a climatic gradient, closing several knowledge gaps with respect to rarely studied minor timbers. However, future studies must consider that resisting drought by either tolerance or avoidance strategies has different implications on growth performance and mortality risks. Clearly, retrospective analyses of radial growth, as in Chapter 4, are limited to living trees and the results therefore might be biased, as they only represent the surviving part of the populations and do not capture mortality rates. To fully capture the impact of increasing drought exposure on a species, both, growth reactions and mortality rates, have to be addressed. To record drought-driven mortality, information on natural (background) mortality of unmanaged stands is required, which is difficult to obtain in regions as Central Europe, where most forests are managed. A causal analysis of drought-induced mortality events which includes physiological measurements would help to identify lethal stress levels and critical elements in the species' drought response strategy.

Additionally, short term growth reductions in response to drought should be complemented with wood anatomical and physiological investigations in the postdrought phase to assess, whether they are primarily an expression of vitality loss, or are part of a plastic drought response, which leads to morphological, anatomical and physiological acclimation and increases future drought tolerance. 


\subsection{References}

Alder, N.N., Sperry, J.S., Pockman, W.T., 1996. Root and stem xylem embolism, stomatal conductance, and leaf turgor in Acer grandidentatum populations along a soil moisture gradient. Oecologia 105, 293-301. https://doi.org/10.1007/BF00328731.

Aranda, I., Gil, L., Pardos, J.A., 2000. Water relations and gas exchange in Fagus sylvatica L. and Quercus petraea (Mattuschka) Liebl. in a mixed stand at their southern limit of distribution in Europe. Trees 14, 344-352. https://doi.org/10.1007/s004680050229.

Bakker, M.R., Augusto, L., Achat, D.L., 2006. Fine root distribution of trees and understory in mature stands of maritime pine (Pinus pinaster) on dry and humid sites. Plant Soil 286, 37-51. https://doi.org/10.1007/s11104-006-9024-4.

Basu, S., Ramegowda, V., Kumar, A., Pereira, A., 2016. Plant adaptation to drought stress. F1000Research 5. https://doi.org/10.12688/f1000research.7678.1.

Blackman, C.J., Li, X., Choat, B., Rymer, P.D., Kauwe, M.G. de, Duursma, R.A. et al, 2019. Desiccation time during drought is highly predictable across species of Eucalyptus from contrasting climates. New Phytol. 224, 632-643. https://doi.org/10.1111/nph.16042.

Blanck, K., Lamersdorf, N., Dohrenbusch, A., Murach, D., 1995. Response of a Norway spruce forest ecosystem to drought/rewetting experiments at Solling, Germany. Water Air Soil Pollut. 85, 1251-1256. https://doi.org/10.1007/BF00477153.

Bréda, N., Cochard, H., Dreyer, E., Granier, A., 1993. Water transfer in a mature oak stand (Quercus petraea): seasonal evolution and effects of a severe drought. Can. J. For. Res. 23, 1136-1143. https://doi.org/10.1139/x93-144.

Bréda, N., Huc, R., Granier, A., Dreyer, E., 2006. Temperate forest trees and stands under severe drought: a review of ecophysiological responses, adaptation processes and long-term consequences. Ann. For. Sci. 63, 625-644. https://doi.org/10.1051/forest:2006042.

Brodribb, T.J., Holbrook, N.M., Edwards, E.J., Gutierrez, M.V., 2003. Relations between stomatal closure, leaf turgor and xylem vulnerability in eight tropical dry forest trees. Plant Cell Environ. 26, 443-450. https://doi.org/10.1046/j.13653040.2003.00975.x.

Brunner, I., Herzog, C., Dawes, M.A., Arend, M., Sperisen, C., 2015. How tree roots respond to drought. Front. Plant Sci. 6, 547. https://doi.org/10.3389/fpls.2015.00547.

Carlier, G., Peltier, J.P., Gielly, L., 1992. Comportement hydrique du frêne (Fraxinus excelsior L) dans une formation montagnarde mésoxérophile. Ann. For. Sci. 49, 207-223. https://doi.org/10.1051/forest:19920301.

Carminati, A., Javaux, M., 2020. Soil Rather Than Xylem Vulnerability Controls Stomatal Response to Drought. Trends Plant Sci. 25, 868-880. https://doi.org/10.1016/j.tplants.2020.04.003.

Cavin, L., Mountford, E.P., Peterken, G.F., Jump, A.S., 2013. Extreme drought alters competitive dominance within and between tree species in a mixed forest stand. Functional Ecology, 27(6), 1424-1435. Funct. Ecol. 27, 1424-1435. https://doi.org/10.1111/1365-2435.12126. 
Chenlemuge, T., Hertel, D., Dulamsuren, C., Khishigjargal, M., Leuschner, C., Hauck, M., 2013. Extremely low fine root biomass in Larix sibirica forests at the southern drought limit of the boreal forest. Flora 208, 488-496. https://doi.org/10.1016/j.flora.2013.08.002.

Choat, B., 2013. Predicting thresholds of drought-induced mortality in woody plant species. Tree Physiol. 33, 669-671. https://doi.org/10.1093/treephys/tpt046.

Choat, B., Brodribb, T.J., Brodersen, C.R., Duursma, R.A., López, R., Medlyn, B.E., 2018. Triggers of tree mortality under drought. Nature 558, 531-539. https://doi.org/10.1038/s41586-018-0240-x.

Choat, B., Jansen, S., Brodribb, T.J., Cochard, H., Delzon, S., Bhaskar, R. et al, 2012. Global convergence in the vulnerability of forests to drought. Nature 491, 752-755. https://doi.org/10.1038/nature11688.

Dietrich, L., Delzon, S., Hoch, G., Kahmen, A., 2018. No role for xylem embolism or carbohydrate shortage in temperate trees during the severe 2015 drought. J. Ecol. 107, 334-349. https://doi.org/10.1111/1365-2745.13051.

Duursma, R.A., Blackman, C.J., Lopéz, R., Martin-Stpaul, N.K., Cochard, H., Medlyn, B.E., 2019. On the minimum leaf conductance: its role in models of plant water use, and ecological and environmental controls. New Phytol. 221, 693-705. https://doi.org/10.1111/nph.15395.

Enderle, R., 2019. An overview of ash (Fraxinus spp.) and the ash dieback disease in Europe. CAB Reviews 14. https://doi.org/10.1079/PAVSNNR201914025.

Epron, D., Dreyer, E., 1993. Long-term effects of drought on photosynthesis of adult oak trees [Quercus petraea (Matt.) Liebl. and Quercus robur L.] in a natural stand. New Phytol. 125, 381-389. https://doi.org/10.1111/j.1469-8137.1993.tb03890.x.

Fonti, P., Heller, O., Cherubini, P., Rigling, A., Arend, M., 2013. Wood anatomical responses of oak saplings exposed to air warming and soil drought. Plant. Biol. 15 Suppl 1, 210-219. https://doi.org/10.1111/j.1438-8677.2012.00599.x.

Gessler, A., Bottero, A., Marshall, J., Arend, M., 2020. The way back: recovery of trees from drought and its implication for acclimation. New Phytol. https://doi.org/10.1111/nph.16703.

Goberville, E., Hautekèete, N.-C., Kirby, R.R., Piquot, Y., Luczak, C., Beaugrand, G., 2016. Climate change and the ash dieback crisis. Sci. Rep. 6, 35303. https://doi.org/10.1038/srep35303.

Grosdidier, M., Ioos, R., Marçais, B., 2018. Do higher summer temperatures restrict the dissemination of Hymenoscyphus fraxineus in France? For. Path. 48, e12426. https://doi.org/10.1111/EFP.12426.

Guicherd, P., Peltier, J.P., Gout, E., Bligny, R., Marigo, G., 1997. Osmotic adjustment in Fraxinus excelsior L . : malate and mannitol accumulation in leaves under drought conditions. Trees 11, 155-161. https://doi.org/10.1007/PL00009664.

Guyot, G., Scoffoni, C., Sack, L., 2012. Combined impacts of irradiance and dehydration on leaf hydraulic conductance: insights into vulnerability and stomatal control. Plant Cell Environ. 35, 857-871. https://doi.org/10.1111/j.13653040.2011.02458.x.

Hacke, U.G., Sperry, J.S., 2001. Functional and ecological xylem anatomy. Perspect. Plant Ecol. Evol. Syst. 4, 97-115. https://doi.org/10.1078/1433-8319-00017. 
Hemery, G.E., Clark, J.R., Aldinger, E., Claessens, H., Malvolti, M.E., O'connor, E. et al, 2010. Growing scattered broadleaved tree species in Europe in a changing climate: a review of risks and opportunities. Forestry 83, 65-81. https://doi.org/10.1093/FORESTRY/CPP034.

Hertel, D., Leuschner, C., 2002. A comparison of four different fine root production estimates with ecosystem carbon balance data in a Fagus-Quercus mixed forest. Plant Soil 239, 237-251. https://doi.org/10.1023/A:1015030320845.

Hertel, D., Strecker, T., Müller-Haubold, H., Leuschner, C., 2013. Fine root biomass and dynamics in beech forests across a precipitation gradient - is optimal resource partitioning theory applicable to water-limited mature trees? J. Ecol. 101, 11831200. https://doi.org/10.1111/1365-2745.12124.

Hertel, D., Therburg, A., Villalba, R., 2008. Above- and below-ground response by Nothofagus pumilio to climatic conditions at the transition from the steppe-forest boundary to the alpine treeline in southern Patagonia, Argentina. Plant Ecol. Divers. 1, 21-33. https://doi.org/10.1080/17550870802257026.

Jackson, R.B., Mooney, H.A., Schulze, E.D., 1997. A global budget for fine root biomass, surface area, and nutrient contents. PNAS 94, 7362-7366. https://doi.org/10.1073/pnas.94.14.7362.

Jackson, R.B., Sperry, J.S., Dawson, T.E., 2000. Root water uptake and transport: using physiological processes in global predictions. Trends Plant Sci. 5, 482-488. https://doi.org/10.1016/S1360-1385(00)01766-0.

Jaegere, T. de, Hein, S., Claessens, H., 2016. A Review of the Characteristics of SmallLeaved Lime (Tilia cordata Mill.) and Their Implications for Silviculture in a Changing Climate. Forests 7, 56. https://doi.org/10.3390/f7030056.

Klein, T., 2014. The variability of stomatal sensitivity to leaf water potential across tree species indicates a continuum between isohydric and anisohydric behaviours. Funct. Ecol. 28, 1313-1320. https://doi.org/10.1111/1365-2435.12289.

Köcher, P., Gebauer, T., Horna, V., Leuschner, C., 2009. Leaf water status and stem xylem flux in relation to soil drought in five temperate broad-leaved tree species with contrasting water use strategies. Ann. For. Sci. 66, 101. https://doi.org/10.1051/forest/2008076.

Köcher, P., Horna, V., Leuschner, C., 2013. Stem water storage in five coexisting temperate broad-leaved tree species: significance, temporal dynamics and dependence on tree functional traits. Tree Physiol. 33, 817-832. https://doi.org/10.1093/treephys/tpt055.

Köstler, J.N., Brückner, E., Bibelriether, H., 1968. Die Wurzeln der Waldbäume. Verlag Paul Parey, Hamburg und Berlin.

Kotowska, M.M., Hertel, D., Rajab, Y.A., Barus, H., Schuldt, B., 2015. Patterns in hydraulic architecture from roots to branches in six tropical tree species from cacao agroforestry and their relation to wood density and stem growth. Front. Plant Sci. 6, 191. https://doi.org/10.3389/fpls.2015.00191.

Kunz, J., Löffler, G., Bauhus, J., 2018. Minor European broadleaved tree species are more drought-tolerant than Fagus sylvatica but not more tolerant than Quercus petraea. For. Ecol. Manage. 414, 15-27. https://doi.org/10.1016/j.foreco.2018.02.016. 
Kunz, J., Räder, A., Bauhus, J., 2016. Effects of Drought and Rewetting on Growth and Gas Exchange of Minor European Broadleaved Tree Species. Forests 7, 239. https://doi.org/10.3390/F7100239.

Kuster, T.M., Arend, M., Günthardt-Goerg, M.S., Schulin, R., 2013. Root growth of different oak provenances in two soils under drought stress and air warming conditions. Plant Soil 369, 61-71. https://doi.org/10.1007/s11104-012-1541-8.

Latte, N., Taverniers, P., Jaegere, T. de, Claessens, H., 2020. Dendroecological assessment of climate resilience of the rare and scattered forest tree species Tilia cordata Mill. in northwestern Europe. Forestry 93, 675-684. https://doi.org/10.1093/forestry/cpaa011.

Lemoine, D., Peltier, J.-P., Marigo, G., 2001. Comparative studies of the water relations and the hydraulic characteristics in Fraxinus excelsior, Acer pseudoplatanus and A. opalus trees under soil water contrasted conditions. Ann. For. Sci. 58, 723-731. https://doi.org/10.1051/forest:2001159.

Leuschner, C., Backes, K., Hertel, D., Schipka, F., Schmitt, U., Terborg, O. et al, 2001. Drought responses at leaf, stem and fine root levels of competitive Fagus sylvatica L. and Quercus petraea (Matt.) Liebl. trees in dry and wet years. For. Ecol. Manage. 149, 33-46. https://doi.org/10.1016/S0378-1127(00)00543-0.

Leuschner, C., Ellenberg, H., 2017. Ecology of Central European Forests. Springer Nature, Cham.

Leuschner, C., Hertel, D., Schmid, I., Koch, O., Muhs, A., Hölscher, D., 2004. Stand fine root biomass and fine root morphology in old-growth beech forests as a function of precipitation and soil fertility. Plant Soil 258, 43-56. https://doi.org/10.1023/B:PLSO.0000016508.20173.80.

Leuschner, C., Wedde, P., Lübbe, T., 2019. The relation between pressure-volume curve traits and stomatal regulation of water potential in five temperate broadleaf tree species. Ann. For. Sci. 76, 93. https://doi.org/10.1007/s13595-019-0838-7.

Leuzinger, S., Zotz, G., Asshoff, R., Körner, C., 2005. Responses of deciduous forest trees to severe drought in Central Europe. Tree Physiol. 25, 641-650. https://doi.org/10.1093/treephys/25.6.641.

Levitt, J., 1980. Responses of plants to environmental stresses: Volume II. Water, radiation, salt, and other stresses, 2. ed. Academic Press, New York, US. Series: Physiological ecology.

Li, S., Feifel, M., Karimi, Z., Schuldt, B., Choat, B., Jansen, S., 2016. Leaf gas exchange performance and the lethal water potential of five European species during drought. Tree Physiol. 36, 179-192. https://doi.org/10.1093/treephys/tpv117.

Li, X., Blackman, C.J., Choat, B., Duursma, R.A., Rymer, P.D., Medlyn, B.E. et al, 2018. Tree hydraulic traits are coordinated and strongly linked to climate-of-origin across a rainfall gradient. Plant Cell Environ. 41, 646-660. https://doi.org/10.1111/pce.13129.

Lloret, F., Keeling, E.G., Sala, A., 2011. Components of tree resilience: effects of successive low-growth episodes in old ponderosa pine forests. Oikos 120, 19091920. https://doi.org/10.1111/J.1600-0706.2011.19372.X. 
Lobo, A., Torres-Ruiz, J.M., Burlett, R., Lemaire, C., Parise, C., Francioni, C. et al, 2018. Assessing inter- and intraspecific variability of xylem vulnerability to embolism in oaks. For. Ecol. Manage. 424, 53-61. https://doi.org/10.1016/j.foreco.2018.04.031.

Lübbe, T., Schuldt, B., Leuschner, C., 2017. Acclimation of leaf water status and stem hydraulics to drought and tree neighbourhood: alternative strategies among the saplings of five temperate deciduous tree species. Tree Physiol. 37, 456-468. https://doi.org/10.1093/treephys/tpw095.

Martínez-Sancho, E., Dorado-Liñán, I., Hacke, U.G., Seidel, H., Menzel, A., 2017. Contrasting Hydraulic Architectures of Scots Pine and Sessile Oak at Their Southernmost Distribution Limits. Front. Plant Sci. 8, 598. https://doi.org/10.3389/fpls.2017.00598.

McDowell, N., Pockman, W.T., Allen, C.D., Breshears, D.D., Cobb, N., Kolb, T. et al, 2008. Mechanisms of plant survival and mortality during drought: why do some plants survive while others succumb to drought? New Phytol. 178, 719-739. https://doi.org/10.1111/j.1469-8137.2008.02436.x.

McKinney, L.V., Nielsen, L.R., Collinge, D.B., Thomsen, I.M., Hansen, J.K., Kjaer, E.D., 2014. The ash dieback crisis: genetic variation in resistance can prove a longterm solution. Plant Pathol. 63, 485-499. https://doi.org/10.1111/ppa.12196.

Meier, I.C., Leuschner, C., 2008. Belowground drought response of European beech: fine root biomass and carbon partitioning in 14 mature stands across a precipitation gradient. Global Change Biol. 14, 2081-2095. https://doi.org/10.1111/j.13652486.2008.01634.x.

Meinzer, F.C., Johnson, D.M., Lachenbruch, B., McCulloh, K.A., Woodruff, D.R., 2009. Xylem hydraulic safety margins in woody plants: coordination of stomatal control of xylem tension with hydraulic capacitance. Funct. Ecol. 23, 922-930. https://doi.org/10.1111/j.1365-2435.2009.01577.x.

Messinger, E., 2017. Hydraulic safety margins and stomatal control strategies of five ring- and diffuse-porous temperate tree species. Masters thesis, Göttingen, Germany.

Moser, A., Rötzer, T., Pauleit, S., Pretzsch, H., 2016. The Urban Environment Can Modify Drought Stress of Small-Leaved Lime (Tilia cordata Mill.) and Black Locust (Robinia pseudoacacia L.). Forests 7, 71. https://doi.org/10.3390/f7030071.

Parker, M.M., van Lear, D.H., 1996. Soil Heterogeneity and Root Distribution of Mature Loblolly Pine Stands in Piedmont Soils. Soil Sci. Soc. Am. J. 60, 1920. https://doi.org/10.2136/sssaj1996.03615995006000060043x.

Pigott, C.D., 1991. Biological Flora of the British Isles: Tilia Cordata Miller. J. Ecol. 79, 1147. https://doi.org/10.2307/2261105.

Renninger, H.J., Carlo, N.J., Clark, K.L., Schäfer, K.V.R., 2015. Resource use and efficiency, and stomatal responses to environmental drivers of oak and pine species in an Atlantic Coastal Plain forest. Front. Plant Sci. 6, 297. https://doi.org/10.3389/fpls.2015.00297.

Roloff, A., Weisgerber, H., Lang, U.M., Stimm, B. (Eds.), 2010. Bäume Mitteleuropas: Von Aspe bis Zirbel-Kiefer, 1. Aufl. Wiley-VCH, Weinheim. Sachbuch. 
Rosengren, U., Göransson, H., Jönsson, U., Stjernquist, I., Thelin, G., Wallander, H., 2006. Functional Biodiversity Aspects on the Nutrient Sustainability in ForestsImportance of Root Distribution. J. Sustainable For. 21, 77-100. https://doi.org/10.1300/J091v21n02_06.

Ryan, M.G., 2011. Tree responses to drought. Tree Physiol. 31, 237-239. https://doi.org/10.1093/treephys/tpr022.

Santantonio, D., Hermann, R.K., 1985. Standing crop, production, and turnover of fine roots on dry, moderate, and wet sites of mature Douglas-fir in western Oregon. Ann. For. Sci. 42, 113-142. https://doi.org/10.1051/forest:19850201.

Scharnweber, T., Manthey, M., Criegee, C., Bauwe, A., Schröder, C., Wilmking, M., 2011. Drought matters - Declining precipitation influences growth of Fagus sylvatica L. and Quercus robur L. in north-eastern Germany. For. Ecol. Manage. 262, 947-961. https://doi.org/10.1016/j.foreco.2011.05.026.

Tardieu, F., Davies, W.J., 1993. Integration of hydraulic and chemical signalling in the control of stomatal conductance and water status of droughted plants. Plant Cell Environ. 16, 341-349. https://doi.org/10.1111/j.1365-3040.1993.tb00880.x.

Tardieu, F., Simonneau, T., 1998. Variability among species of stomatal control under fluctuating soil water status and evaporative demand: modelling isohydric and anisohydric behaviours. J. Exp. Bot. 49, 419-432. https://doi.org/10.1093/jxb/49.Special_Issue.419.

Thomas, F.M., 2000. Growth and water relations of four deciduous tree species (Fagus sylvatica L., Quercus petraea [Matt.] Liebl., Q. pubescens Willd., Sorbus aria [L.] Cr.) occurring at Central-European tree-line sites on shallow calcareous soils: physiological reactions of seedlings to severe drought. Flora 195, 104-115. https://doi.org/10.1016/S0367-2530(17)30958-1.

Urli, M., Porté, A.J., Cochard, H., Guengant, Y., Burlett, R., Delzon, S., 2013. Xylem embolism threshold for catastrophic hydraulic failure in angiosperm trees. Tree Physiol. 33, 672-683. https://doi.org/10.1093/treephys/tpt030.

Wang, C., Chen, Z., Yin, H., Guo, W., Cao, Y., Wang, G. et al, 2018. The Responses of Forest Fine Root Biomass/Necromass Ratio to Environmental Factors Depend on Mycorrhizal Type and Latitudinal Region. J. Geophys. Res. Biogeosci. 123, 17691788. https://doi.org/10.1029/2017JG004308.

Wiley, E., Casper, B.B., Helliker, B.R., 2017. Recovery following defoliation involves shifts in allocation that favour storage and reproduction over radial growth in black oak. J. Ecol. 105, 412-424. https://doi.org/10.1111/1365-2745.12672.

Wingler, A., Quick, W.P., Bungard, R.A., Bailey, K.J., Lea, P.J., Leegood, R.C., 1999. The role of photorespiration during drought stress: an analysis utilizing barley mutants with reduced activities of photorespiratory enzymes. Plant Cell Environ. 22, 361-373. https://doi.org/10.1046/j.1365-3040.1999.00410.x.

Zimmermann, J., Hauck, M., Dulamsuren, C., Leuschner, C., 2015. Climate WarmingRelated Growth Decline Affects Fagus sylvatica, But Not Other Broad-Leaved Tree Species in Central European Mixed Forests. Ecosystems 18, 560-572. https://doi.org/10.1007/s10021-015-9849-x. 


\section{GENERAL APPENDiX}

\subsection{Index of Figures}

Figure 1.1: Distribution ranges of the four minor timber species (A. platanoides, C. betulus, $F$. excelsior, and T. cordata) and two major timbers ( $Q$. petraea and $F$. sylvatica) based on the synthetic chorology database of Caudullo (2017)......

Figure 1.2: Map of the study area between Göttingen and Halle/S. in central Germany with the precipitation gradient from the west to the east. The nine study sites are marked with red dots. The background colors and isohyets indicate the mean annual precipitation (MAP 1991-2017). The area with MAP over $1000 \mathrm{~mm}$ north-east of Göttingen is the Harz mountain range. For further information on the study sites, refer to the detailed tables 2.1,3.1, and 4.1 in the following chapters.

Figure 2.1: Map of the study area between Göttingen and Halle/S. in central Germany with the precipitation gradient from west to east. The study sites are marked with red dots, the background colours indicate the mean annual precipitation (MAP 1991-2017). The area with MAP over $1000 \mathrm{~mm}$ northeast of Göttingen is the Harz mountain range

Figure 2.2: Hydraulic safety-related traits: (A) Xylem water potential at $50 \%$ loss of conductivity $\left(P_{50}\right),(\mathrm{B})$ xylem water potential at $12 / 88 \%$ loss of conductivity $\left(P_{12 / 88}\right),(\mathrm{C})$ leaf water potential at turgor loss point $\left(P_{\mathrm{TLP}}\right)$, and (D) hydraulic safety margins of the three tree species at all study sites. Sites are sorted in ascending order according to the climatic water balance. Box-whisker plots include median and interquartile ranges (Q1-Q3); whiskers extend to max. 1.5 times the interquartile range. Different letters denote significantly different means between sites within a species based on Tukey-adjusted p-values with degrees of freedom based on Satterthwaite's approximation from linear mixed effects models with post-hoc tests for pairwise differences

Figure 2.3: Hydraulic efficiency-related traits: (A) $A_{\text {Xylem }} / A_{\text {Leaves }}$-ratio of branches (Huber value), and (B) xylem area-specific hydraulic conductivity of branches $\left(K_{\mathrm{S}}\right)$ of the three tree species at all study sites. Sites are sorted in ascending order according to the climatic water balance. Boxwhisker plots include median and interquartile ranges (Q1-Q3); whiskers extend to max. 1.5 times the interquartile range. Different letters denote significantly different means between sites within a species based on Tukey-adjusted p-values with degrees of freedom based on Satterthwaite's approximation from linear mixed effects models with post-hoc tests for pairwise differences.

Figure 2.4: (A) Coefficient of quartile variation of the studied traits across all species and measurements; (B) variance decomposition between different levels of organization (between species, between populations, and between individuals; see Appendix A, Table 2.4 for full model output). Given are the xylem water potential at $50 \%$ loss of conductivity $\left(P_{50}\right)$, the leaf water potential at turgor loss point $\left(P_{\mathrm{TLP}}\right), A_{\text {xylem }} / A_{\text {leaf }}-$ ratio of branches (Huber value, $\mathrm{HV}$ ) and xylem area-specific hydraulic conductivity $\left(K_{\mathrm{S}}\right)$. 'Residual' denotes the unexplained variance of the models (i.e. variability between branches + estimation and measurement uncertainty). 
Figure 2.5: Distribution ranges of the three minor timber species (Acer platanoides, Carpinus betulus, and Tilia cordata) based on the synthetic chorology database of Caudullo et al. (2017).

Figure 2.6: Xylem vulnerability curves illustrating percent loss of conductivity vs. xylem water potential. Plotted lines represent conditional predictions for single branches (colored, dotted), single trees (colored), and sites (black) based on species-wise non-linear mixed-effects models (pointsymmetrically, sigmoidal)....

Figure 2.7: (A) Xylem water potential at $50 \%$ loss of conductivity $\left(P_{50}\right)$, (B) leaf water potential at turgor loss point ( $\left.P_{\mathrm{TLP}}\right),(\mathrm{C}) A_{\text {Xylem }} / A_{\text {Leaves }}$-ratio of branches (Huber value), and (D) xylem areaspecific hydraulic conductivity of branches $\left(K_{\mathrm{S}}\right)$ of the three tree species on all study sites. Sites are given in ascending order of plant-available water capacity of the soil. Box-whisker plots include median and interquartile ranges (Q1-Q3); whiskers extend to 1.5 times the interquartile range.

Figure 2.8: Pearson correlation matrix of environmental and tree-specific predictors and functional traits. Given are Pearson correlation coefficients per species in the top right triangle and the corresponding data in the lower left triangle. MAP = mean annual precipitation (period 19912017); CWB = climatic water balance; $\mathrm{MAT}=$ mean annual temperature; $\mathrm{AWC}=$ plant-available water storage capacity of the soil; $\mathrm{DBH}=$ Stem diameter at breast height; $P_{50} / P_{12} / P_{88}=$ xylem water potential at 50/12/88 \% loss of conductivity; Slope $_{\mathrm{vc}}=$ slope of the vulnerability curve at the inflexion point; $P_{\mathrm{TLP}}=$ leaf water potential at turgor loss point; $K_{\mathrm{S}}=$ xylem area specific hydraulic conductivity of branches; $\mathrm{HV}=$ Huber value $\left(\mathrm{A}_{\mathrm{Xylem}} / \mathrm{A}_{\text {Leaves }}\right.$-ratio of branches $) . K_{\mathrm{S}}$ and $\mathrm{HV}$ are natural log-transformed, traits measured on branch/leaf-level are means per tree. All variables are scaled by their standard deviation and centered around zero.

Figure 2.9: Tendency of a hydraulic safety-efficiency trade-off across species between $K_{\mathrm{S}}$ (xylem area-specific hydraulic conductivity) and $P_{50}$ (xylem water potential at $50 \%$ loss of conductivity). Shown are mean values per site and species with standard errors and p-value and $R^{2}$ of a linear regression across all species and sites

Figure 3.1: Map of the study area between Göttingen and Halle/S. in central Germany with the precipitation gradient from the west to the east. The nine study sites are marked with red dots. The colors indicate the mean annual precipitation (MAP 1991-2017). The area with MAP over $1000 \mathrm{~mm}$ NE of Göttingen is the Harz mountain range.

Figure 3.2: Fine root biomass (a), necromass (b), and necromass/biomass (N/B) ratio (c) of the five tree species in the topsoil $(0-10 \mathrm{~cm})$ in April 2017 and September 2018. Box-whisker plots with median and interquartile ranges $\left(\mathrm{Q}_{1}-\mathrm{Q}_{3}\right)$; whiskers extend to 1.5 times the interquartile range. Indicated significant differences between the inventories for each species are based on a nonparametric signed-rank-test; ***: $p \leq 0.001, *: p<0.05$. Note the log-scaled y-axes in (b) and (c).

Figure 3.3: Specific root surface area (SRA) and root tips per fine root biomass of the five tree species in the topsoil (0-10 cm) in April 2017 and September 2018. Box-whisker plots for all species and both inventories with median and interquartile ranges $\left(\mathrm{Q}_{1}-\mathrm{Q}_{3}\right)$; whiskers extend to 1.5 times the interquartile range. Indicated significant differences between the inventories for each species 
are based on a non-parametric signed-rank-test; ***: $p \leq 0.001, * *: p \leq 0.01, *: p<0.05$. Note the log-scaled y-axes.

Figure 3.4: Fine root biomass (a), necromass (b), and necromass/biomass ratio (c) in the topsoil (0$10 \mathrm{~cm}$ ) of the five species in relation to mean annual precipitation (MAP) in the 2017 and 2018 inventories. Data points are tree-level values, lines represent conditional predictions of the linear mixed effects model (the predictions of the fixed effect "MAP" for each species plus an intercept for each level of the random factor "site"). Note the log-scaled y-axis. The corresponding $p$ and pseudo- $R^{2}$ values are summarized in Table 3.3. Graphs for the morphology variables are given in Figure 3.6 in the Appendix B.

Figure 3.5: Fine root biomass (a), necromass (b) and necromass/biomass ratio (c) in the topsoil (0$10 \mathrm{~cm}$ ) of the five species in relation to actual precipitation in the year prior to sampling in the 2017 and 2018 inventories. Data points are tree-level values, lines represent conditional predictions of the linear mixed effects model (the predictions of the fixed effect "MAP" for each species plus an intercept for each level of the random factor "site"). Note the log-scaled y-axis. The corresponding $\mathrm{p}$ and pseudo- $\mathrm{R}^{2}$ values are summarized in Table A1.

Figure 3.6: Specific root area (a), fine root tips per root mass (b), and average fine root diameter (c) in the topsoil $(0-10 \mathrm{~cm})$ of the five species in relation to mean annual precipitation (MAP) in the 2017 and 2018 inventories. Data points are tree-level values, lines represent conditional predictions of the linear mixed effects model (the predictions of the fixed effect "MAP" for each species plus an intercept for each level of the random factor "site"). Note the log-scaled y-axis. The corresponding $p$ and pseudo- $R^{2}$ values are summarized in Table 3.3.

Figure 3.7: Principal components analysis (PCA) biplot of the 2017 fine root inventory. All data are aggregated on site and species level.

Figure 3.8: Principal components analysis (PCA) biplot of the 2018 fine root inventory. All data are aggregated on site and species level..

Figure 4.1: Map of the study region between the cities of Göttingen and Halle/S. in Central Germany with the precipitation gradient from west to east. The study sites are marked with red dots, the background colors indicate the long-term mean growing season precipitation (MGSP, April September, 1967 - 2016) in mm. The area with MGSP >500 mm north-east of Göttingen is the Harz mountain range.

Figure 4.2: Temporal variation and long-term trend ( 25 year moving average) of growing season precipitation, temperature and SPEI (standardized precipitation-evapotranspiration index) in the period 1965-2016 in the study region (averaged over all study sites).

Figure 4.3: Correlation between radial growth (ring width index values) and the SPEI (standardized precipitation-evapotranspiration index) for months in the previous and current year for the four species at eight sites. The SPEI is calculated on a timescale of 3 months, because the drought conditions in the current month mainly depend on precipitation and evapotranspiration patterns in the current and the two preceding months. Months abbreviated with lower case letters refer to the previous year, months with capital letters to the current year. Given is the size of the correlation coefficient and the significance of the relation (black bars: $p<0.05$; grey bars: 
$\mathrm{p}>0.05)$. The color spectrum from orange to green indicates the position of the site in the gradient of mean growing season precipitation. For site abbreviations see Figure 4.1.

Figure 4.4 (next page): Moving window analysis of climate-growth relationships in the four species at eight sites for the period 1967-2016. Shown are the central years of the respective 20-year periods, testing for the correlation between six aggregate climate variables and annual ring width indices. Given is the size and sign of the correlation coefficient for the six relationships (red: negative relation, blue: positive relation, black frame: $\mathrm{p}<0.05)$. Summer stands for June-August, Winter for December-February, spring for March and April. The color spectrum from orange to green indicates the position of the site in the gradient of mean growing season precipitation (orange: low, green: high).

Figure 4.5: Change in the climate-growth correlation coefficients between the 1967-1991 and the 1992-2016 period. The “+”/“_“" signs indicate positive/negative changes in the correlation coefficients, respectively. Bold red signs represent significant changes $(\mathrm{p}<0.05)$, grey shading stands for missing data. Note: A positive change in the correlation coefficient can mean the switch from no to a positive correlation, or a switch from a negative to no correlation, a negative change means a shift in the opposite direction; see Figure 4.4 for a more detailed picture of temporal changes in the correlation coefficients.

Figure 4.6: Relationship between annual ring width indices and summer SPEI (= standardized precipitation-evapotranspiration index of the month August, calculated for a 6-months window) for the four species in dependence on mean growing season precipitation (MGSP) of the stand for the 25-year periods 1967-1991 and 1992-2016. Significant correlation coefficients are marked by red 95\%-confidence interval bars. Each dot represents one site per species; MGSP refers to the corresponding 25-year periods. The blue regression lines with $95 \%$ confidence interval display significant relationships between correlation coefficient and MGSP, nonsignificant regression lines are not shown.

Figure 4.7: Results of superposed epoch analyses on the response of radial growth of the four species at the eight sites to drought events with a $\mathrm{SPEI}_{\text {summer }}<-0.84$. Shown is the deviation of mean ring width in an 11-year period with the drought years in the center from the mean ring widths in all analyzed 11-year epochs of the chronology. Significant departures $(p<0.05)$ are shown in dark grey with red frame. The color spectrum from orange to green indicates the position of the site in the gradient of mean growing season precipitation (orange: low, green: high).

Figure 4.8: Resistance and resilience of radial growth of the four species to selected droughts in an 11-year window with the drought year in the centre of the period. All drought events with a SPEI $<-0.84$ (based on the SPEI of the month August with consideration of a six-months window) in the study period were considered. The indices were calculated using detrended ring width indices pooling for every species over all sites and all identified drought years. Resistance is the growth depression in a drought year compared to the 5 years prior to drought, resilience the ratio of mean radial growth in the five post-drought years relative to the growth in the five years prior to drought. Different small letters indicate significant differences between species based on Tukeyadjusted p-values from linear mixed effects models with degrees of freedom based on Satterthwaite's approximation. Number of trees was $\mathrm{n}=57$ for A. platanoides, $\mathrm{n}=83$ for $F$. 
excelsior, $\mathrm{n}=80$ for $Q$. petraea, and $\mathrm{n}=29$ for $T$. cordata; the number of studied drought events varied between 9 and 13, depending on sites.

Figure 4.9: Ring width index chronologies for the four species at the eight sites, age-detrended with regional curve standardization (RCS). The blue line is a 25 -year smoothing spline. The color spectrum from orange to green indicates the position of the site in the gradient of mean growing season precipitation (orange: low, green: high).

Figure 4.10: Ring-width chronologies for the four species at the eight sites using the raw data from 9-13 tree individuals per stand which were averaged using Tukey's bi-weight robust mean. The color spectrum from orange to green indicates the position of the site in the gradient of mean growing season precipitation (orange: low, green: high).

Figure 4.11: Correlation between radial growth (ring width index values) and the precipitation totals of months in the previous and current year for the four species at eight sites. Months abbreviated with lower case letters refer to the previous year, months with capital letters to the current year. Given is the size of the correlation coefficient and the significance of the relation (black bars: $\mathrm{p}<0.05$; grey bars: $\mathrm{p}>0.05$ ) based on $1000 \mathrm{x}$ bootstrapping against randomly chosen precipitationgrowth pairs. The color spectrum from orange to green indicates the position of the site in the gradient of mean growing season precipitation (orange: low, green: high).

Figure 4.12: Correlation between radial growth (ring width index values) and mean temperature of the months in the previous and current year for the four species at eight sites. Months abbreviated with lower case letters refer to the previous year, months with capital letters to the current year. Given is the size of the correlation coefficient and the significance of the relation (black bars: $\mathrm{p}<0.05$; grey bars: $\mathrm{p}>0.05$ ) based on $1000 \mathrm{x}$ bootstrapping against randomly chosen temperaturegrowth pairs. The color spectrum from orange to green indicates the position of the site in the gradient of mean growing season precipitation (orange: low, green: high).

Figure 4.13: Negative pointer years of the four species on the eight sites in the period 1967-2016 according to Cropper-values following the approach of Neuwirth et al. (2007) with normalization in a 5-year moving window. Thresholds for weak, strong, and extreme negative pointer years were $0.8,1.2$, and 1.5 standard deviations of growth decline, respectively, for at least $60 \%$ of the population. Site are arranged according to mean growing season precipitation from drier to moister.

Figure 4.14: Percental reduction in BAI in the drought year 1976 relative to the average BAI of the five preceding years for the four species at the eight sites. The color spectrum from orange to green indicates the position of the site in the gradient of mean growing season precipitation (orange: low, green: high).

Figure 4.15: Resistance and resilience of basal increment of the four species to selected droughts in an 11-year window with the drought year in the centre of the period. All drought events with a SPEI $<-0.84$ (based on the SPEI of the month August with consideration of a six-months window) in the study period were considered. The indices were calculated using raw BAI data pooling for every species over all sites and all identified drought years. Resistance is the growth depression in a drought year compared to the 5 years prior to drought, resilience the ratio of mean radial growth in the five post-drought years relative to the growth in the five years prior to 
drought. Different small letters indicate significant differences between species based on Tukeyadjusted p-values from linear mixed effects models with degrees of freedom based on Satterthwaite's approximation. Number of trees was $\mathrm{n}=57$ for A. platanoides, $\mathrm{n}=83$ for $F$. excelsior, $\mathrm{n}=80$ for $Q$. petraea, and $\mathrm{n}=29$ for $T$. cordata; the number of studied drought events varied between 9 and 13, depending on sites.

Figure 4.16: Within-population growth synchronicity of the four species at the eight sites in the period 1967-2016. Given is the interseries correlation (Rbar) as derived from a moving 20-year window analysis of ring width index series. The color spectrum from orange to green indicates the position of the site in the gradient of mean growing season precipitation (orange: low, green: high).

Figure 4.17: Frequency of crown damage classes in late summer of 2019 (September) in the stands of the four species at eight sites after the extreme 2018/19 drought as derived from the inspection of each five individuals. Site acronyms are explained in Figure 1. The crown damage classes 0 to 3 base on a ground-based visual assessment of the canopy's defoliation and discoloration (damage is defined as the sum of discolored and fallen leaves in percent of full foliation; $0=$ $0 \%-10 \%$ damage; $1=10 \%-25 \%$ damage, $2=25 \%-60 \%$ damage, $3=>60 \%$ damage). Carpinus betulus and Fagus sylvatica trees that occurred in the same stands are reported for comparison.

Figure 5.1: Leaf water potential at turgor loss point $\left(P_{\mathrm{TLP}}\right)$ of all five species. Sites are sorted in ascending order according to the climatic water balance. The methodology is described in chapter 2, where $Q$. petraea and $F$. excelsior were not included in the figures.

Figure 5.2: Foliar $\delta^{13} \mathrm{C}$-signatures of the leaf bulk tissue of sun leaves of all five species, given in standard $\delta$ notion: $\delta(\% o)=\left(\mathrm{R}_{\text {sample }} / \mathrm{R}_{\text {standard }}-1\right) \times 1000$. Measurements were conducted in the laboratory for stable isotope measurements (KOSI) at the University of Göttingen with a Delta plus isotope mass spectrometer (Finnigan MAT, Bremen, Germany), a Conflo III interface (Thermo Electron Cooperation, Bremen, Germany) and a NA2500 elemental analyzer (CEInstruments, Rodano, Milano, Italy). Sites are sorted in ascending order according to the climatic water balance. 


\subsection{Index of Tables}

Table 2.1: Site and tree characteristics of the studied stands sorted by species and in ascending order of the local climatic water balance (CWB). MAP = mean annual precipitation (period 19912017); MAT = mean annual temperature; MGSP = mean growing season precipitation (AprilSeptember); CWB = climatic water balance; soil texture is defined according to the nomenclature of the FAO (Food and Agriculture Organization of the United Nations); AWC = plant-available water storage capacity of the soil; $\mathrm{DBH}=$ Stem diameter at breast height. Tree age, $\mathrm{DBH}$, and tree height are given as means with standard deviation. Tree age of all sampled individuals was determined with dendrochronological analyses for increment cores with the exception of $C$. betulus, which was not part of the dendrochronological study; age information was here derived from forestry inventory data of the local forestry offices ..................................

Table 2.2: Means \pm SE of measured traits per species pooled over all study sites. Different letters denote significantly different means based on Tukey-adjusted p-values from linear mixed effects models with post-hoc tests for pairwise species differences with degrees of freedom based on Satterthwaite's approximation. $P_{50 / 12 / 88}=$ xylem water potential at 50/12/88 \% loss of conductivity; $P_{\mathrm{TLP}}=$ leaf water potential at turgor loss point; HSM = hydraulic safety margin; Huber value $(\mathrm{HV})=A_{\text {Xylem }} / A_{\text {Leaves }}$-ratio of branches; $K_{\mathrm{S}}=$ xylem area specific hydraulic conductivity of branches.

Table 2.3: Results of the linear mixed effects models examining the relationships between environmental variables and functional traits. $P_{50}=$ xylem water potential at $50 \%$ loss of conductivity; $P_{\mathrm{TLP}}=$ leaf water potential at turgor loss point; HSM = hydraulic safety margin; Huber value $(\mathrm{HV})=A_{\text {xylem }} / A_{\text {leaf }}-$ ratio of branches; $K_{\mathrm{S}}=$ xylem area specific hydraulic conductivity of branches. Given are the scaled estimates for CWB (climatic water balance) and AWC (plant-available water storage capacity of the soil), as well as the standard deviation for the tree-wise random intercept (Tree SD), the residual standard deviation (Res. SD), and marginal and conditional $R^{2}$ of the models (Marg. $R^{2}$ and Cond. $R^{2}$ ). Bold estimates represent significant effects $(*, P<0.05$; **, $P<0.01)$, (a) denotes marginally significant effects $(P<0.1)$. The full output of the models is given in Appendix A, Table 2.5.

Table 2.4: Full output table of the linear mixed effects models for the variance decomposition (Fig.

4b). Given are the fixed effect estimates for the intercept (i.e. the Carpinus average), the differences of Acer and Tilia to Carpinus, with their standard errors, estimated degrees of freedom (edf) based on Sattherthwaite's approximation and $P$-values, as well as the estimates of the three variance components (tree level, population level and residual SD) ............................ 6

Table 2.5 (next page): Full output table of the linear mixed effects models examining the relationships between environmental variables and functional traits (corresponds to Table 2.3). Given are the scaled estimates for CWB (climatic water balance) and AWC (plant-available water storage capacity of the soil), the standard errors of the estimates (SE), the estimated degrees of freedom (DF) based on Sattherthwaite's approximation, $P$-values, and lower and upper border of likelihood-profile-based confidence intervals (CI low and CI high). 
Table 3.1: Site and tree characteristics of the nine study sites with the each 2-5 species occurring in the stands, sorted in ascending order of mean annual precipitation (MAP) . ............................... 83

Table 3.2: PET, precipitation, and temperature in the three months prior to the sampling dates in 2017 and 2018. Given are the totals of potential evapotranspiration (PET) and precipitation (P), the deviation of $\mathrm{P}$ from the long-term mean (1991-2017) in percent, and the absolute deviation of the average temperature of the three-month period from the long-term mean (1991-2017) in that period in ${ }^{\circ} \mathrm{C}$.

Table 3.3: Results of linear mixed effects models for fine root traits in dependence of mean annual precipitation (MAP). Given are estimates of the fixed effect (fine root trait species:MAP), marginal pseudo- $R^{2}$ for the fixed effect (calculated according to Nakagawa and Schielzeth 2013)) and $p$-values. $p$-values below 0.05 are given in bold. All fine root traits were $\log$ ransformed in advance except for root diameters......................................................... 93

Table 3.4: Results of the principal components analysis for the spring inventory in 2017. Given are the loadings of the selected variables along the four axes with the highest explained variance in he dataset. Bold numbers mark the variables with the highest loading (>0.4) on the respective axis. The values in brackets give the cumulative fraction of variance explained by the variable. MAP = mean annual precipitation, MAT = mean annual temperature, DMI = de Martonne aridity Index of the three months prior to sampling .............................................................. 94

Table 3.5: Results of the principal components analysis for the drought inventory in 2018. Given are the loadings of the selected variables along the four axes with the highest explained variance in the dataset. Bold numbers mark the variables with the highest loading ( $>0.4)$ on the respective axis. The values in brackets give the cumulative fraction of variance explained by the variable. $\mathrm{MAP}=$ mean annual precipitation, $\mathrm{MAT}=$ mean annual temperature, $\mathrm{DMI}=$ de Martonne aridity ndex of the three months prior to sampling.......................................................................... 95

Table 3.6: Results of linear mixed effects models for fine root bio- and necromass in dependence of actual precipitation in the year prior to sampling (act.PRCP). Given are estimates of the fixed effect (fine root trait $\sim$ species:MAP), marginal pseudo- $R^{2}$ for the fixed effect (calculated according to Nakagawa and Schielzeth (2013)), and $p$-values. $p$-values below 0.05 are given in pold. All fine root traits were log-transformed in advance........................................................ 104

Table 4.1: Stand structural, soil physical and chemical and climatic characteristics of the stands selected to study the four species. Note that the species in many cases occurred in different stands at given sites, and thus different site characteristics are reported. Mean DBH (diameter at breast height), height and age of the studied trees in the stand are given with standard deviations. Soil properties include mean $\mathrm{pH}, \mathrm{C}: \mathrm{N}$-ratio, Carbon content $(\mathrm{C} \%)$, and soil texture of the top $60 \mathrm{~cm}$ of the profile, and the profile total $(0-120 \mathrm{~cm})$ of the soil capacity for plant-available water (AWC). Long-term annual means (1967-2016) of precipitation (MAP), growing season precipitation (MGSP, April - September), temperature (MAT), and growing season temperature (MGST) are also given. The table is sorted by species and in ascending order of growing season precipitation.......................................................................................................

Table 4.2: Statistics of ring-width series (raw data) and index-based chronologies (all truncated to the period 1967-2016) of the four species at the different sites. MRW = mean ring width of all series 
$\pm \mathrm{SD}, \mathrm{AC}(1)=$ first order autocorrelation $\pm \mathrm{SD}, \mathrm{MBAI}=$ mean basal area increment of all series E SD, Rbar = inter-series correlation, MS = mean sensitivity, EPS = expressed population signal. The different sites of a species are sorted in ascending order of mean growing season

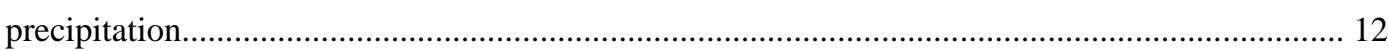

Table 4.3: Results of linear mixed effects models exploring the relationship between various environmental variables and the tolerance indices growth resistance and resilience. Given are the scaled estimates for the effect of MGSP (mean growing season precipitation) and AWC (soil capacity for plant-available water), as well as the standard deviation for the random effect "Site" (Site SD), the residual standard deviation (Res. SD), and marginal and conditional $\mathrm{R}^{2}$ values of the models. None of the fixed effects was significant at $\mathrm{p}<0.05$. As data were available for $T$. cordata only at three sites, this species is omitted here.

Table 5.1: Overview of drought stress resistance-related traits of the five species. The rates range from very good (++) over good (+) and mediocre (o) to subpar (-) and the reasoning behind the assessments is explained in Chapter 5.1 and 5.2. Grey panels are based on knowledge from literature, black panels represent missing information. 


\subsection{Danksagung}

Finishing this project would have been impossible without the invaluable help of colleagues, friends and my family. I am grateful for having you around!

First of all, I'd like to thank Prof. Dr. Christoph Leuschner and Prof. Dr. Bernhard Schuldt for offering me the opportunity of this challenging $\mathrm{PhD}$ project and for all the competent support, patience, advice, optimism and trust over the years.

I further wish to thank Prof. Dr. Dirk Hölscher for his support as part of my thesis advisory committee and Prof. Dr. Holger Kreft, Prof. Dr. Hermann Behling and Prof. Dr. Erwin Bergmeier for their willingness to be part of my examination board.

Special thanks go to Roman Link for endless support in any statistics-related troubles and for all the provided help, to Heinz Coners for all the technical support, to Dietrich Hertel for competently answering all my "belowground" questions, and to Robert Weigel for all his "dendro-ideas".

I am incredibly thankful for all the help in field- and labwork by Ana Sapoznikowa, Leonhard Klinck, Hannah Korp, Greta Weithmann, Amauta Halvorsen, Natalia Sierra Cornejo, Kyra Zembold, Jutta Czernitzki, Irmgard Gerstmann, Annegret Kellner and Mechthild Stange.

Credits go to all my colleagues in Göttingen for fruitful discussions and, similarly important, trash- and small-talk in coffee and lunch breaks.

Finally and most importantly, my greatest thank goes to my parents for their everlasting support and encouragement and to Tina for all the patience, for the countless hours of support in the final sprint, and for being the most amazing person in the world. 


\subsection{Curriculum Vitae}

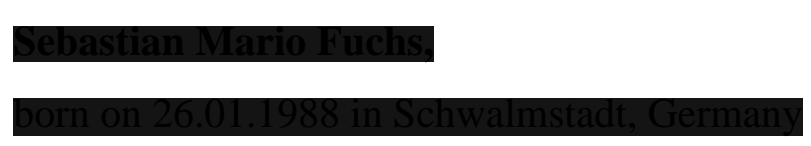

Education
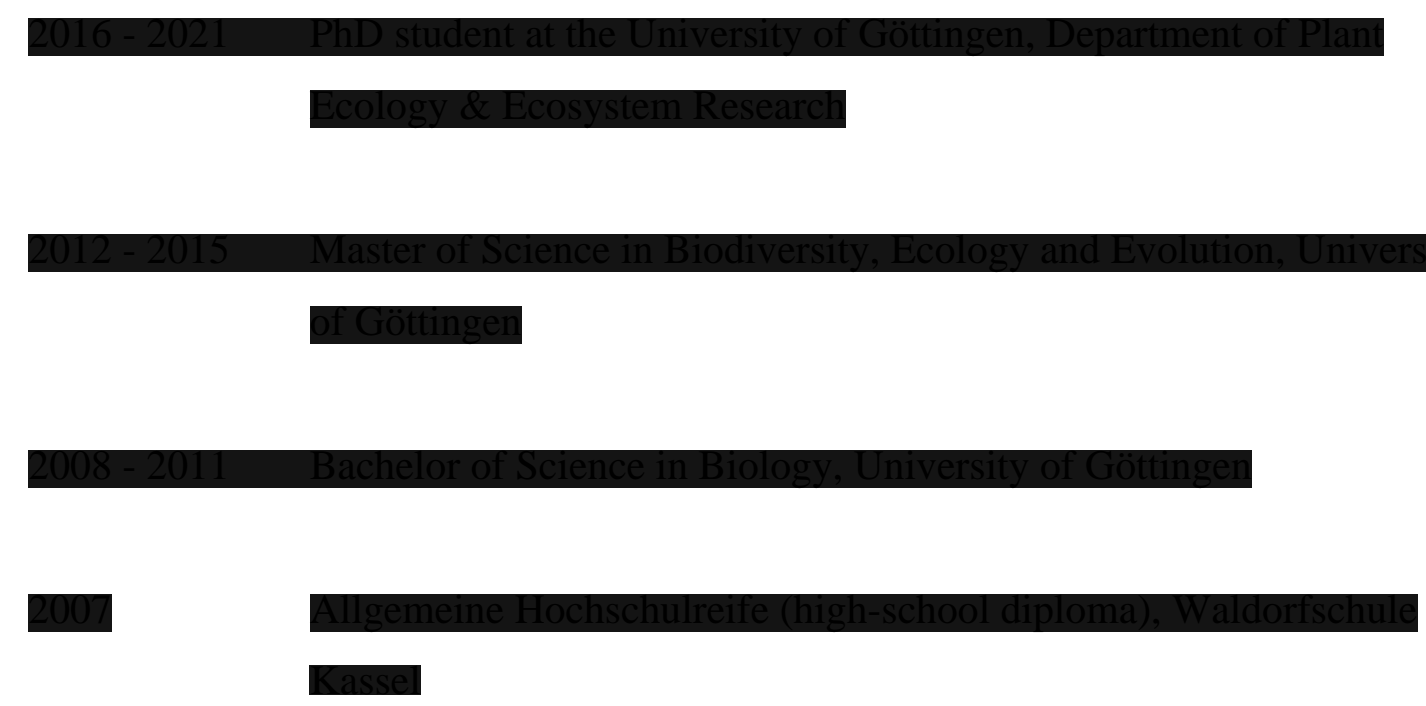

Work experience

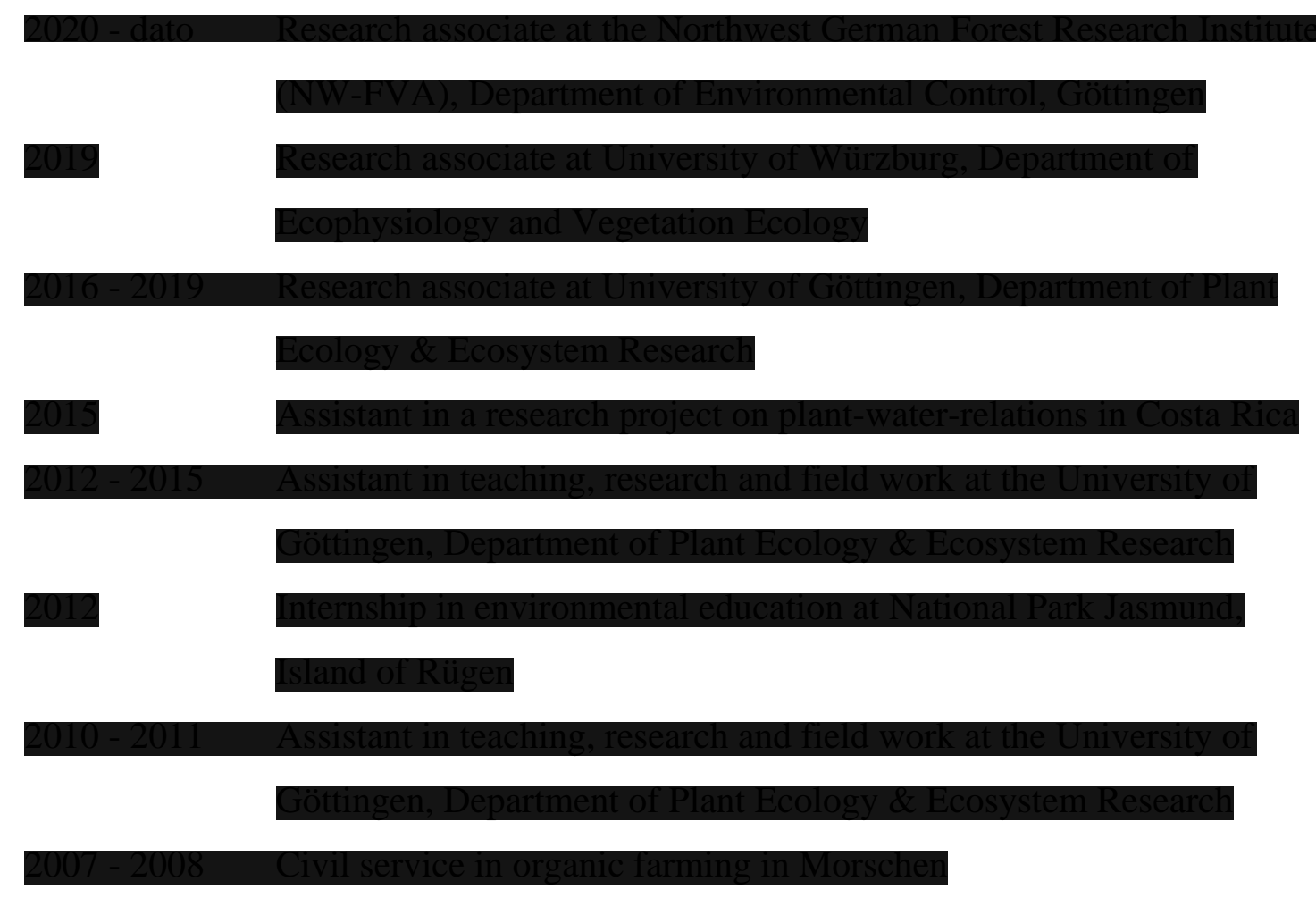




\section{Publications}

2021

Fuchs, S., Schuldt, B., Leuschner, C., 2021. Identification of droughttolerant tree species through climate sensitivity analysis of radial growth in Central European mixed broadleaf forests. For. Ecol. Manage. 494, 119287. https://doi.org/10.1016/j.foreco.2021.119287.

Fuchs, S., Leuschner, C., Link, R.M., Schuldt, B., 2021. Hydraulic variability of three temperate broadleaf tree species along a water availability gradient in central Europe. New Phytol. 231, 1387-1400. https://doi.org/10.1111/nph.17448.

Fuchs, S., Hertel, D., Schuldt, B., Leuschner, C., 2020. Effects of Summer Drought on the Fine Root System of Five Broadleaf Tree Species along a Precipitation Gradient. Forests 11, 289. https://doi.org/10.3390/F11030289.

2020 Link, R.M., Fuchs, S., Arias Aguilar, D., Leuschner, C., Castillo Ugalde, M., Valverde Otarola, J.C. et al, 2020. Tree height predicts the shape of radial sap flow profiles of Costa-Rican tropical dry forest tree species. Agric. For. Meteorol. 287, 107913. https://doi.org/10.1016/j.agrformet.2020.107913.

Calibration and comparison of thermal dissipation, heat ratio and heat field deformation sap flow probes for diffuse-porous trees. Agric. For. Meteorol. 244-245, 151-161.

https://doi.org/10.1016/j.agrformet.2017.04.003. 


\subsection{Declaration of originality and certificate of ownership}

I, Sebastian Fuchs, hereby declare that I am the sole author of this dissertation entitled 'DIVERSE FORESTS FOR CLIMATE CHANGE: DROUGHT STRESS TOLERANCE OF SECONDARY TIMBER SPECIES'. All references and data sources that were used in the dissertation have been appropriately acknowledged. I furthermore declare that this work has not been submitted elsewhere in any form as part of another dissertation procedure.

Göttingen, July 2021

(Sebastian Fuchs) 